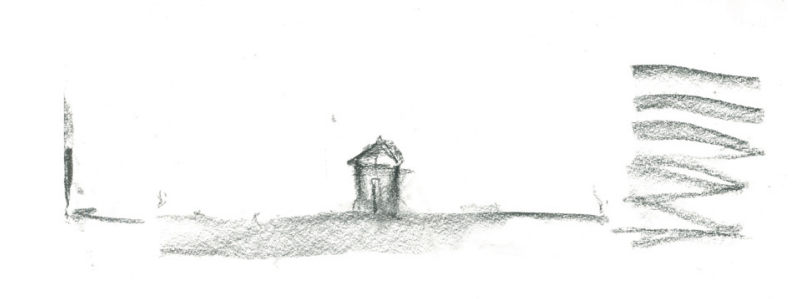


fig. 1. Initial sketch of the site. Compressed charcoal, March 2015 


\section{Tangible Remains}

SOLANGE MARIE LOCHORE THORP

A 120--point thesis submitted to the Victoria University of Wellington in partial fulfilment of the requirements for the degree of Master of Architecture (Professional) Victoria University of Wellington School of Architecture 


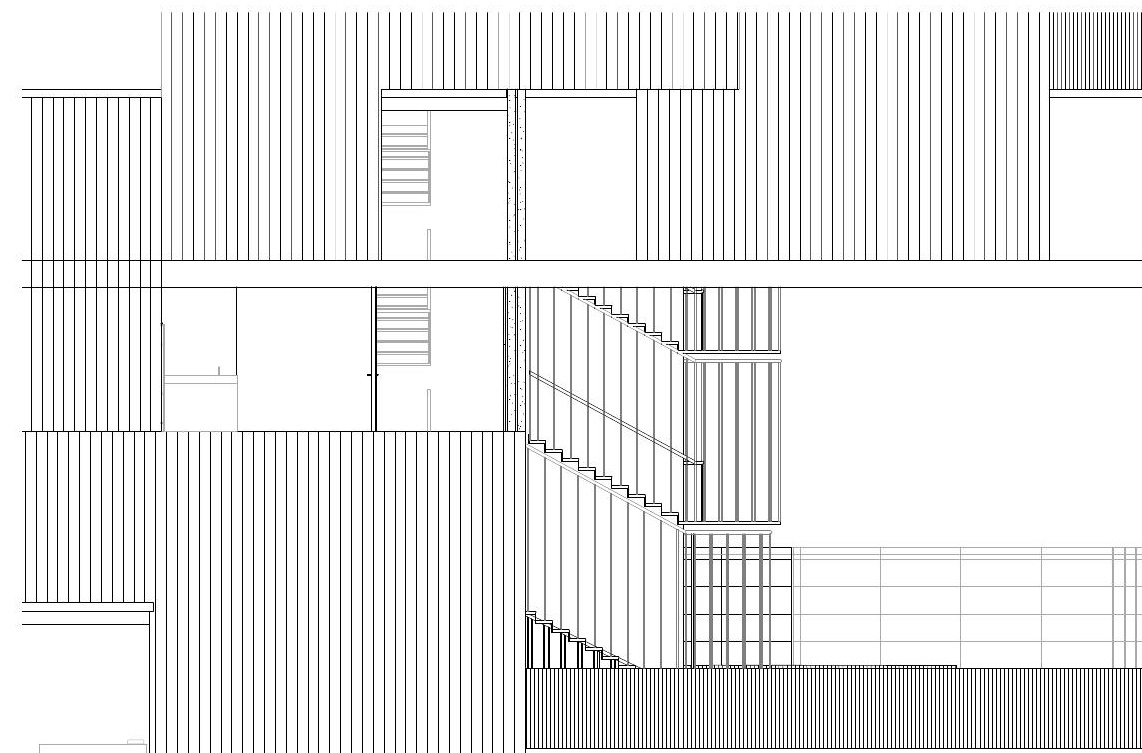




\section{Abstract}

This design led research advocates for an architecture indicative of the preceding history; that engages in an active dialogue with the site. Developed through shifting scales and media, the thesis investigates how architecture can give expression to the singularities of site.

The milieu of erasures and the enduring traces are drawn to the surface and manifested across three design phases: 1 Chinese Garden, present condition; 2 Art School, past reflection; 3 Artist Colony, future projection. Through a process of editing, fragments are extended and retracted between the phases as more intense programs are introduced. The final design outcome is the result of an additive design methodology, developed across the course of the thesis. The design methodology is a model for combining sites in contemporary urban development; a model for co-existence of past and present into the future. 

For Mum and Dad 

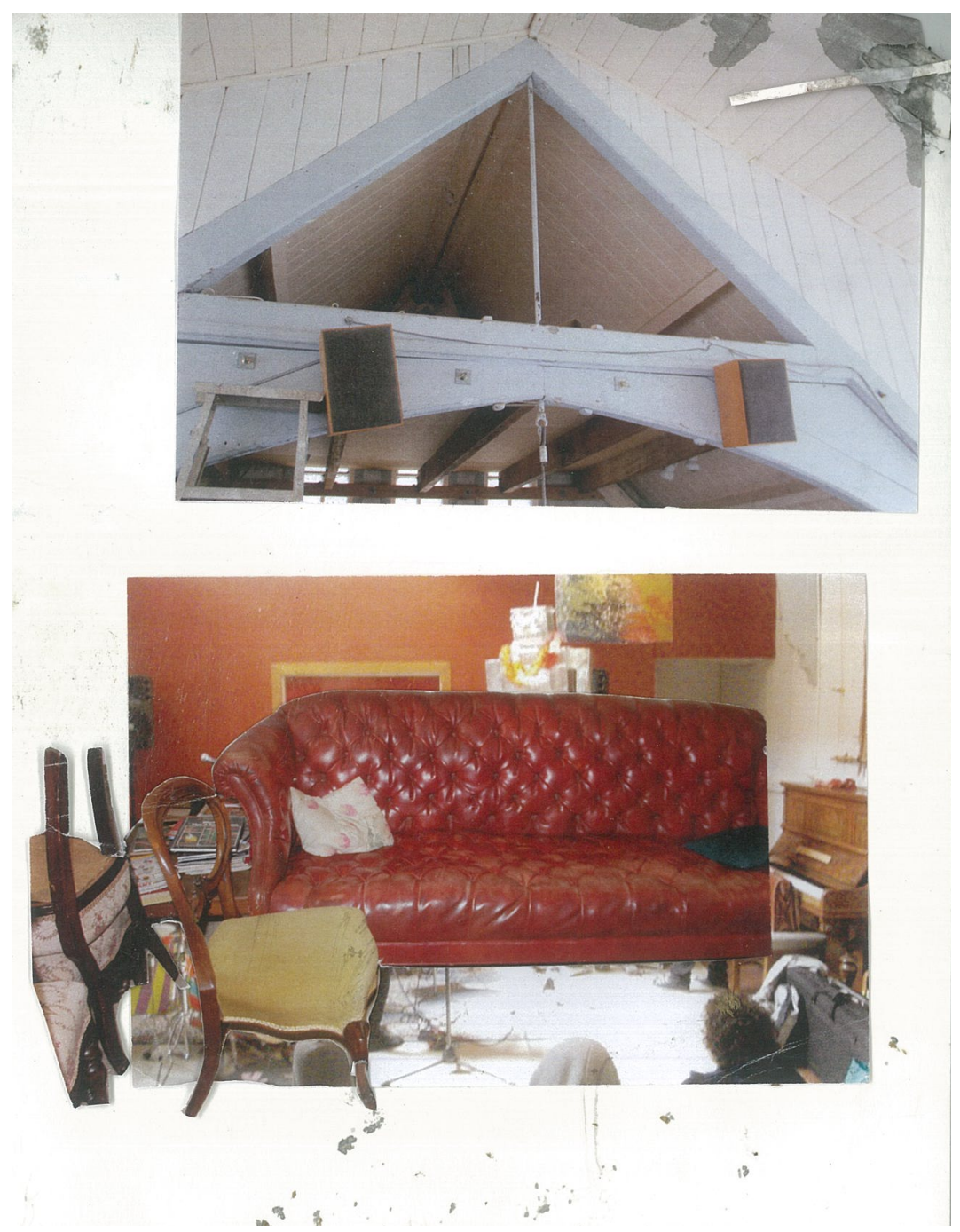

fig. 3. Collage. Spatial study of the Chinese Mission Hall 


\section{Acknowledgements}

Firstly, I need to thank my parents. Be it from afar, your support has been unyielding and I couldn't be prouder to hold your interest. Thank you for opening my mind and inspiring me constantly.

I am grateful for the support of The Ecologies Lab, notably Peter Connolly. I have enjoyed our discussions and collective energy. My wider family, friends and peers; thank you for the laughter and valued distractions.

To all the technicians, librarians, artists and experts who have donated their time and generous support. In particular, my thanks goes to the gentlemen of the City MenzShed for inviting me into their home and to the previous residents and admirers of the Chinese Mission Hall thank you for your memories.

Mark Southcombe, it has been a pleasure. Thank you for the utmost support and provocation. Your insights and enthusiasm for your students and our discipline are above and beyond and I thank you for sharing your time. 


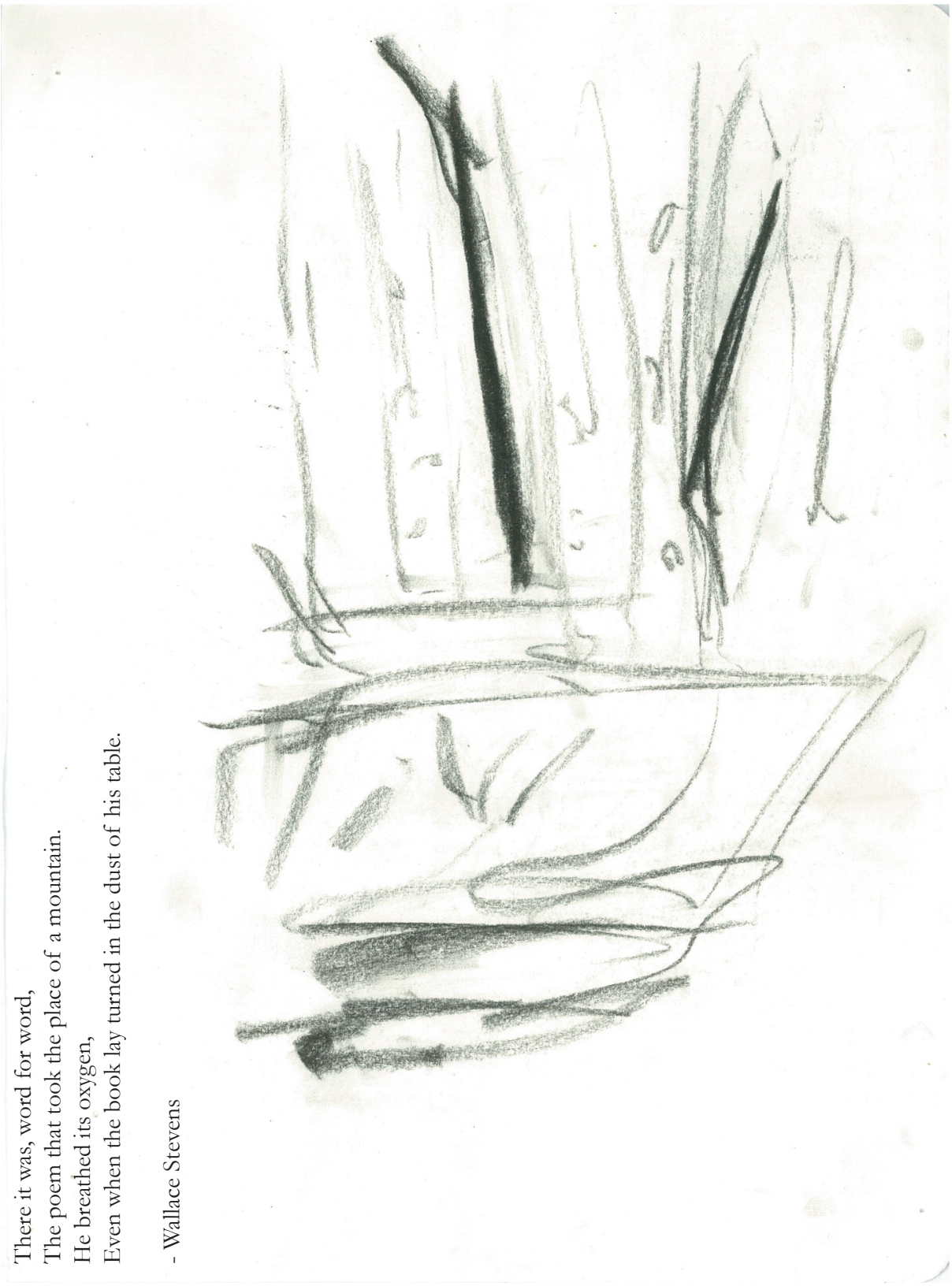

fig. 4. Corymbia-maculata trees. Compressed charcoal 


\section{Preface}

The conception of this thesis grew from an affinity for the immaterial and the ruin. Accumulating layers of history, the ruin stalls between the old and the new. How can these ruins retain their silent potency yet evolve with contemporary development? How can a landscape [re]define its future?

The thesis year began in a cathedral of Corymbia-maculata trees in Kur-ing-gai National Park under the tutelage of Richard Leplastrier and Peter Stutchbury. They taught through storytelling and linguistics the primacy of the landscape and of an architecture sensitive to culture and place. Through drawing, modelling, poetry and listening we discovered the physical and immaterial forces of the land; the rhythm of the landscape. The potentials of articulating such idiosyncrasies confirmed an urge to read my urban site and decode the patterns. 


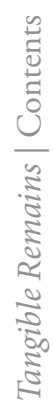




\section{Contents}

Abstract vii

Acknowledgements $\quad$ ix

Preface xi

Introduction $\mid$ the conscious act 1

I | Beginnings; research context and methods 9

One | Palimpsest and the involuntary 11

Two | Immediate Answers $\quad 17$

Three | Excavation of site $\quad 31$

II | 3 Test Buildings 67

Four| the ground plane 69

Five | Introducing volume; an Art School 109

Six | Future projections; scale and the domestic 155

\begin{tabular}{ll} 
Seven & Conclusion \\
\hline
\end{tabular} 
Architectural Heritage starts with good design today - Sir Ian Athfield 


\section{Introduction $\mid$ the conscious act}

The development of knowledge over history is accelerating at an exponential rate. Man-made and natural moments of inflection present at more frequent intervals only to become buried within a historical stratification. In the midst of this trajectory, societies are at risk of losing connectivity to such events embedded in their narratives. Societies are at risk of embracing an automated architecture dissociated to place.

The prospect of this erasure of context is acute in New Zealand cities as significant quantities of historic architecture have been lost. As these tangible remains, tangible reminders of the past are cleared; vacant plots are quickly in-filled by new developments, irrespective of the preceding history. This thesis deals with architecture's relationship to site and the potentials of historically informed site-specific design. The design-research investigation explores the disconnection between the built form and site history in a critique of standardisation and loss of memory in architecture. 
This thesis addresses the increasing autonomy in the built environment in an investigation of site specific design. It advocates for an architecture indicative of the preceding history; that engages in an active dialogue with the site. Instigated by a rigorous archaeological dig, the thesis investigates how architecture can give expression to the singularities of site. It will aim to manifest the unique characteristics specific to the identified site.

\section{"[s]ingularities are turning points and points of inflection; bottlenecks, knots, foyers, and centers; points of fusion and condensation, and boiling; points of tears and joy, sickness and health, hope and anxiety, 'sensitive' points"}

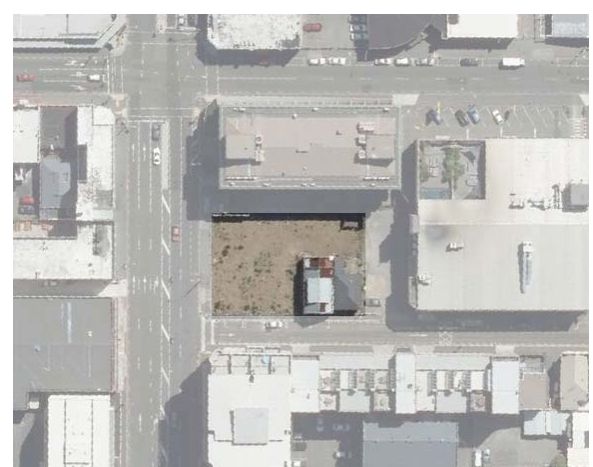

fig. 5. Aerial of Site. Te Aro, Wellington

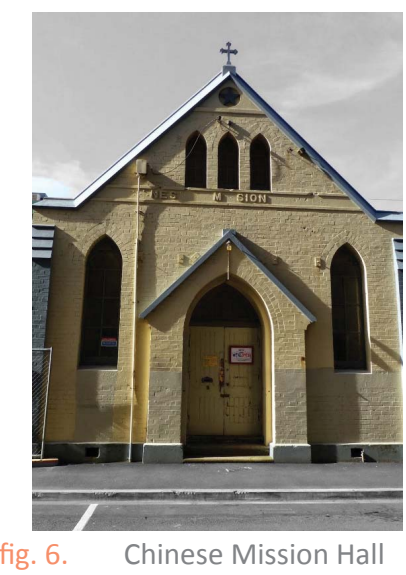

The scope of the thesis will focus on a place-case study of an urban Wellington, site on the corner of Taranaki Street and Frederick Street ${ }^{\text {fig. }}$. The site shows visible indications of its built history. The majority of the site is rubble with one remaining historic ${ }^{2}$ building; Chinese Mission Hall, $1905^{\text {fig. } 6}$. The site will be explored at various scales to unpack its past, existing and potential future conditions of cultural, ecological, physical identity. A tangible scale will be embraced in the process to engage inputs and ecological trajectories.

Key terms:

\section{Singularity}

Influential French philosopher Giles Deleuze and his collaborations with Félix Guattari provide the theoretical framework for the thesis through the notion of singularity. First appearing in the text Difference and Repetition, Deleuze adapted the term from its meaning in differential calculus to render a synonym of haeecity; the property of being a unique and individual thing ${ }^{3}$

$\begin{array}{ll}\text { 1. } & \text { (The Logic of Sense 64) } \\ \text { 2. } & \text { Recognised in the District Plan as a heritage building by Wellington } \\ \text { 3. City Council but not registered by Heritage New Zealand. } \\ \text { (Oxford Dictionaries) }\end{array}$


Influential texts by preceding philosophers will be examined to take a critical review of the Deleuzean discourse. Alfred Whitehead's Process and Reality, articulates a shift in philosophical discourse from "materialism to Organic Realism" -substance to process. ${ }^{4}$ Whitehead's interest in event was praised by Deleuze in his text, The Fold ${ }^{5}$ and was evident in descriptions of his work:

Deleuze's position presents an alternative to traditional philosophies of substance, challenging the notion that reality ought to be understood in terms of the determinate states of things. ${ }^{6}$

\section{Palimpsest}

The notion of palimpsest will be employed as a methodology as well as support an understanding of historical layers of the site and the process of erasure. Literature surrounding palimpsest will be explored to unpack the preconceptions of the method within architecture as well as landscape. In landscape architecture it is considered as a field, a territory; the natural environment is in itself a palimpsest. In particular, the work and surrounding discourse of Carlo Scarpa, Bernard Tschumi and Peter Eisenman will help generate an evaluative criteria based on the success results.

\section{Heritage}

A taxonomy presented by Andrew Charleson and Mark Southcombe in [Re] Cuba: Renegotiating seismic resilience in Cuba Street, Wellington provides a theoretical framework for structural retrofitting with a particularly relevant emphasis on seismic considerations. ${ }^{7}$ It outlines approaches for the binary conditions, developed by Prof. Michael Oswald ${ }^{8}$, of: Invisibility, Separation and Dialogue, extended to include Indifference. For the purpose of this thesis, the strategies are considered beyond the scope of structure to include all new interventions.

\begin{tabular}{ll}
\hline 4. & (Whitehead 471) \\
5. & (Deleuze The Fold: Leibniz and the Baroque) \\
6. & (Stagoll 90) \\
7. & (Southcombe and Charleson 14-17) \\
8. & (Ostwald 23-40)
\end{tabular}


The thesis will employ a design-through-research methodology whereby the design process is integral to the research. The initial unpacking of the site will see methods weighted in an analytical mode before entering an investigative design process with generative methods. The notion of palimpsest will be engaged in both the analytical and generative stages with the support of supplementary methods. The methods each have a degree to which an element of chance can be applied, to be developed as the project unfolds.

\section{Chance}

The role of chance will be explored through a surrealist notion of managed chance and an event inspired view from Nassim Nicholas Taleb. Marc Angélil and Mark Lee's essay, Informe ${ }^{9}$, will help to unpack Jean Bataille's understanding of formlessness. Bataille's formlessness was also a response to materialism and substance yet the avoidance of rationalisation will support the speculative drive in the design-research. The essay presents a series of strategies to employ to defer the hand of the architect; horizontality: inverting the field, base materialism: embracing raw material (without celebration), pulse: exploring temporality and dynamic structure, and entropy: challenging order to embrace circumstantiality. Angélil and Lee expand on these to include event situations and against classifications. These strategies offer the thesis a kit of tools to disrupt the intuition at play within the design-research.

Event inspired chance will be examined from a statistical stand point of Black Swan Theory ${ }^{10}$. Taleb coined the term 'black swan' to articulate surprising events with major historical consequences, often overlooked. It will prompt consideration of inflections of history as highly improbable events that in cases are post rationalised.

\footnotetext{
9. (Angélil and Lee)

10. (Taleb)
} 
The notion of thinking-through-doing underpins the methodology and the experimental design process. Combinations of methods will be explored and adjusted over the course of the thesis in a dynamic progression of shifts in pace, media and scale. A rigorous investigation through design.

\section{Palimpsest as methodology}

By origin, palimpsest refers to a manuscript or piece of writing material on which later writing has been superimposed on effaced or partially erased writing. As a design-research method it entails an understanding of site as a physical palimpsest as well as the site of several completely erased layers that are potentially fruitful; an analytical and generative tool for understanding, design and representation.

This thesis will engage the notion of palimpsest in the initial stages of the research to "deconstruct what exists by critically analysing the historical layers that preceded it". ${ }^{11}$ The design research will begin with an archaeological dig to uncover these layers, inherently discovering singularities of site. This will involve archival searches and an analysis of the existing through behavioural studies, interviews, landscape mapping, diagram and photography.

Composite images will be constructed influenced by the processes of Perry Kulper ${ }^{\text {fig. }}$. The reference to Kulper helps situate the process within the scope of the thesis by understanding a need to "resist the banal and simplistic reductionism so typical of architectural representation" ${ }^{12}$. Herein architectural representation gives expression to the singularity of site.

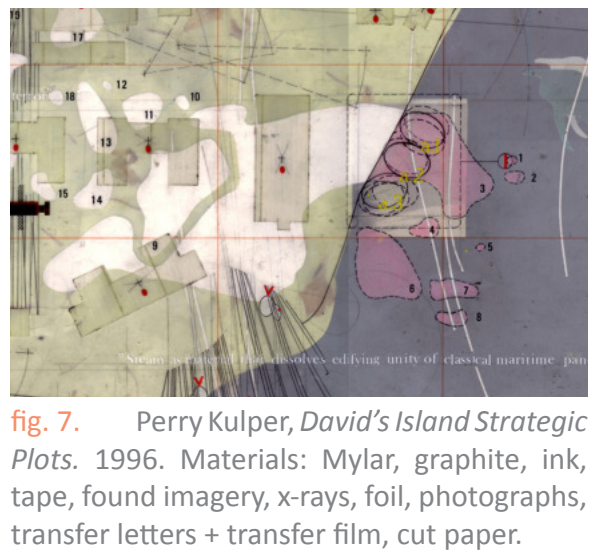

transfer letters + transfer film, cut paper.

\footnotetext{
11. (Tschumi 193)

12. (Kulper 86)
} 
Analogue shifts

Drawing and physical modelling will be a fundamental component of the method involving a performance between the architect and the representation. It presents opportunities for intuitive and analytical processes to develop in the generative process to be conducted alongside precise digital conclusions. This return to the manual process of craft, analysis and representation the architecture will seek to engage notions of risk in an inherent expression of the singular.

\section{- Maquette modelling ${ }^{13}$}

The method will play a key role in the formative stages of the design process to realise extractions from the palimpsest process (and potential relationships between) in three dimensions. The method allows opportunity for the notion of superimposition to be continued in the process in the recycling of materials across iterations or the use of a continuous material — the method thus presents opportunity to give agency to the materials.

\section{- Series Working}

Serial iterations will be used throughout the design process as a key tool of research through design. The method encourages multiple variants and conscious refinement that will complement the investigation of standardisation and chance. Sandra Kaji-O'Grady positions the serial attitude well within the scope of this thesis through the work of Deleuze and Peter Eisenman:

In light of the argument made by Jacques Derrida and Gilles Deleuze that repetition is not a reiteration of the same but a dynamic process of affirming difference, the lateral repetitions made by Eisenman and Hejduk can be seen to dissolve the distinction between origin and copy, form and idea. ${ }^{14}$

13. Maquette modelling entails dispensable sketch modelling at small scale; mode of manifesting preliminary ideas.

14. (Kaji-O'Grady 17) 
This thesis is structured into 2 sections followed by a brief concluding chapter to underpin the findings of the research.

Section I presents the research contexts and methods before entering a theoretical excavation of the site. The aim of the section is to establish a position on the relationship between the old and the new for the subsequent design tests. Chapter One investigates the extent of palimpsest in an incremental design methodology and the understanding of assemblage across disciplines. Chapter Two analyses various strategies of heritage projects in the local setting of Te Aro, Wellington before casting abroad. Chapter Three establishes the historical layers of the thesis site; extracting a set of orders.

Section II involves 3 design phases, testing the methodology across different conditions in each chapter ${ }^{\text {fig. }}{ }^{8}$. Chapter Four, a Chinese Garden, retains the existing scale of the site in a minimal intervention $^{(a)}$. Chapter Five, an Art School, respects the scale of the previous buildings ${ }^{(b)}$. Chapter Six, an Artist Colony, considers the future potential of the site by introducing apartments and approaching the height restriction ${ }^{(c)}$.

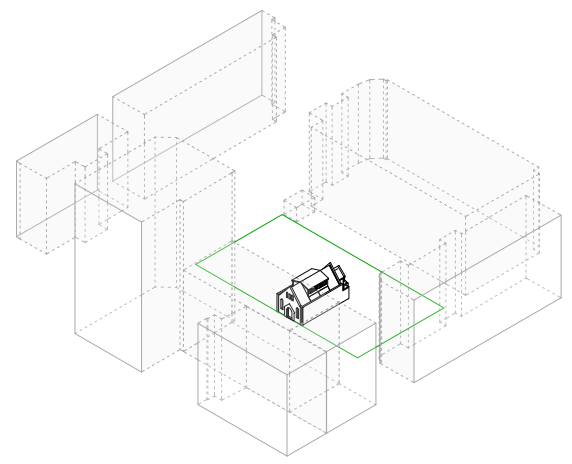

a Design Phase 1; Preserving Existing Scale

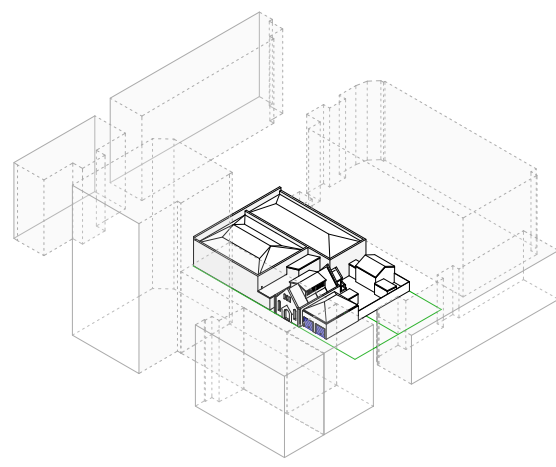

b Design Phase 2; Restoring Previous Scale

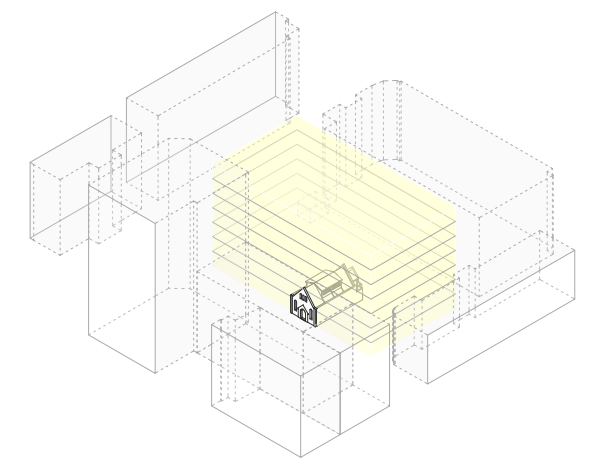

c Design Phase 3; Responding to Maximum Scale

fig. 8. Diagram illustrating the focus of the separate Design Phases 



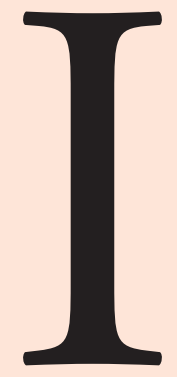

Beginnings:

Research Context and Methods 
"Singularization is a self-organizing process that at its most basic level concerns bringing together ensembles of diverse components (material/semiotic; individual/collective), that is, assemblages ("straddling", in interaction, between radically heterogeneous domains' [CS 29]) that deploy their own intrinsic references (inventing relations with the outside as well), and the analysis of their effects (especially transformations) on the formation of subjectivity beyond the individuated subject and prefabricated versions of him/her; for Guattari, 'the assemblage of enunciation "exceeds" the problematic of the individuated subject, the consciously delimited thinking monad, faculties of the soul (apprehension, will) in their classical sense' (CS 28).... An assemblage ... capable of singularized becomings, indeed, involve articulations of any number of components" 14

Gary Genosko in Felix Guattari: An Aberrant Introduction

14. (Genosko 135-136) Chapter 3 Japanese Singularity discusses singularity and architecture with reference to Guattari's text , "CS" Cartographies schizoanalytiques (1989) 


\section{One | Palimpsest and the involuntary}

The design-led nature of the thesis is fundamental in the investigation of singularity. The accumulation of design phases creates concrete things to reflect on and extract meaning through; what is singular?

The structure of the three design phases was initially conceived as discrete experiments to focus on a particular condition. Once this process began, the potentials of composition and layering in the design process became increasingly apparent. In the same way I argue we read sites, the design outcome will be perceived without origin or end point but in a continual state of becoming; an assemblage. Full of erasures and overwritten tales, the design will have a contingent, non-finality nature to engage the involuntary.

\section{The hand of the architect}

The design process does not shy from individual subjection, but embraces preconception and impulse. Instantaneous responses were captured after various shifts with analogous methods under time and medium constraints. These captured the essence of impulsive thought and action to feed into the contingent design. Projecting forward helped to flush preconceptions of the research, inviting reflection and critique. 


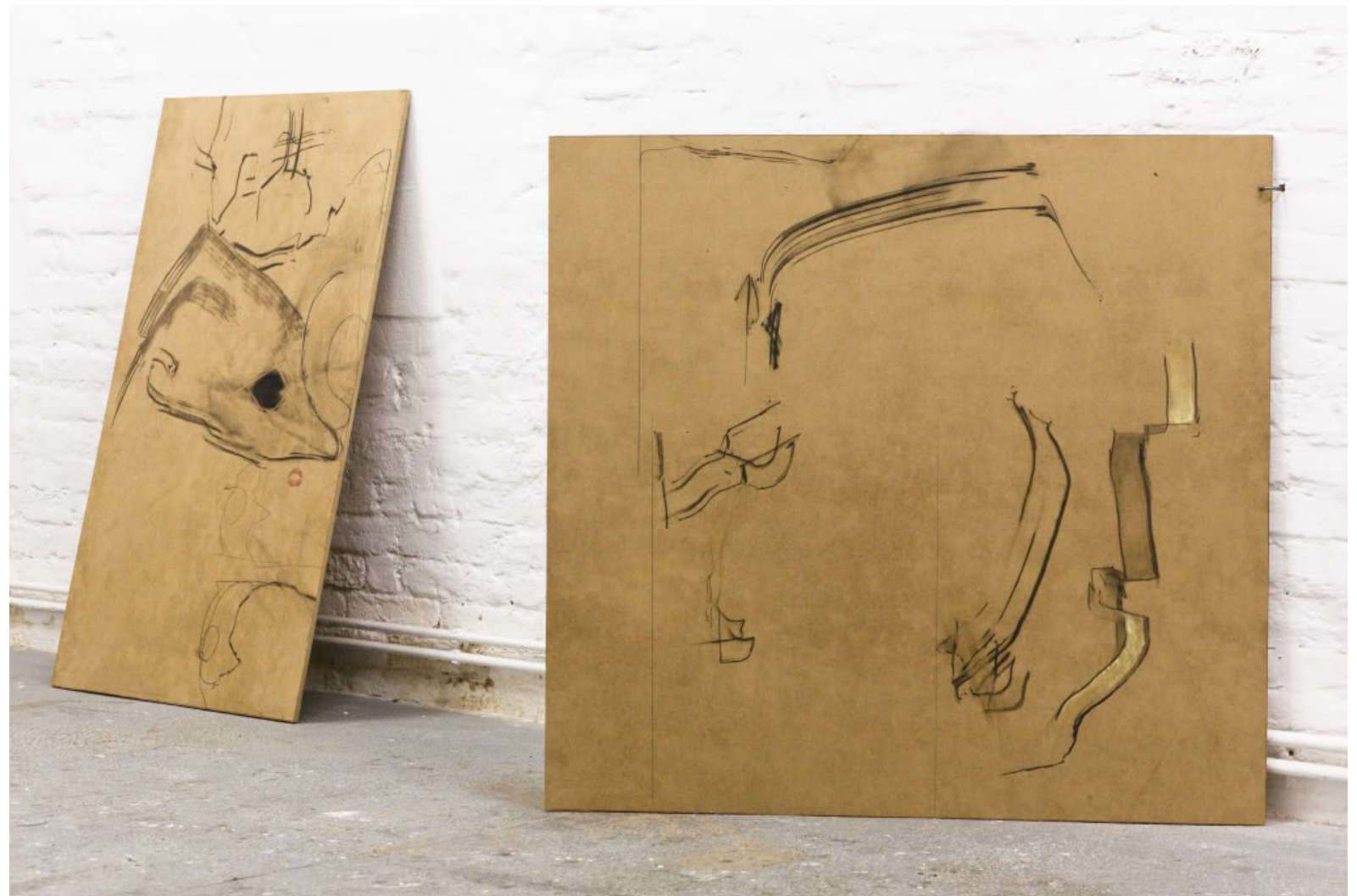

fig. 1.1. Jessica Parker Valentine Untitled, 2010, metal, graphite, chalk, MDF 
In the same way that frames are edited out of a flm, some of my drawings are hidden. The difference is-you can see that I am hiding something from you-this is a sculptural property that creates a performative relationship between us. In the same way that I use erasure in my drawings to create an image, the blatant covering of an image with another creates yet another image. There is a recurrent push and pull of additive and subtractive processes.

The end product is often a palimpsest that reveals the evidence of time and action. Everything is improvised because the structure is based on discovery. ${ }^{15}$

- Jessica Parker Valentine

15. (Valentine) 
"Whitehead himself notes that individuals are not monads nor independent worlds, but modes that are interconnected by the same substance. Deleuze picks up on this to insist that all monads 'prehend' a series of elements outside of them through the unconscious power of contraction; this is how events make the individual, but also how the individual is part of an objective world of singularities which it traverses or connects" 16

$\overline{16 . \quad \text { (Young 337) }}$ 

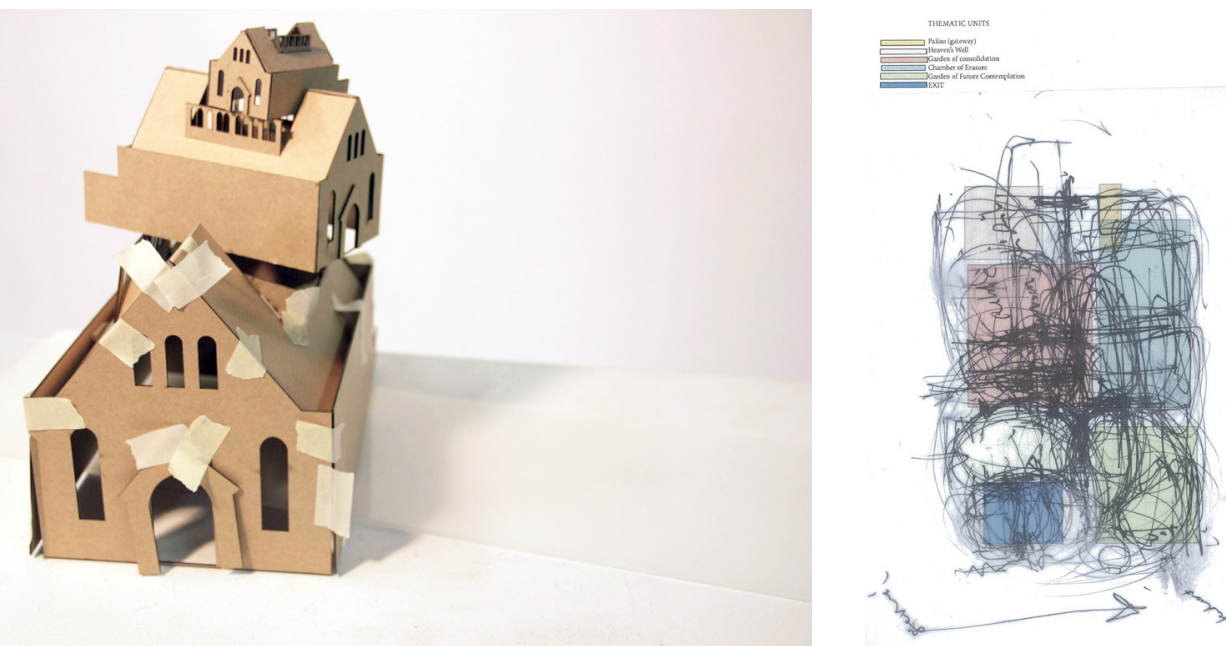

fig. 1.2. Chinese Mission Hall Models

fig. 1.3. Overlay of Chinese Garden Plan.

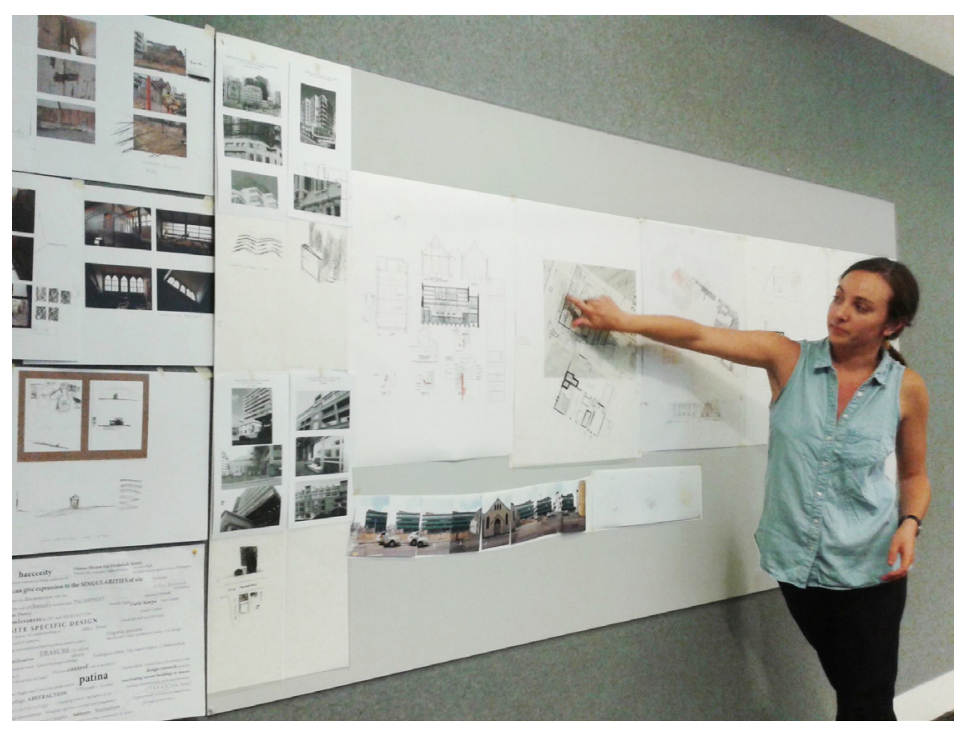

fig. 1.4. Presentation of Fast Track Panels, March 2015 
"Without getting too theoretical, the most important thing in architecture is the feeling of the continuous present. Old and new things shouldn't look like they don't know one another. It's like a bookshelf: you put things beside each other, and there they stand. Your new thing should feel like it was already there, and has come into itself out of what was around it. Every single building was new, once, and it's not a crisis." 17

John Tuomey

$\overline{\text { 17. } \quad \text { (Tuomey) }}$ 


\section{Two | immediate answers}

This chapter analyses architectural precedents that have a relationship to heritage buildings to explore potential approaches. ${ }^{\text {fig. }} .1 .1$ The analysis begins in Te Aro before extending abroad to understand the impact of cultural context. A range of scales and degree of interventions are selected to inspire the range of scale shifts projected for the thesis. The potential approaches are framed within the categories of Invisibility, Indifference, Separation and Dialogue.

Invisibility; concealed seismic solution
a) Return to original
b) Distil present condition

Returning heritage buildings to their former glory is commonly advocated in New Zealand/Western society driven by nostalgia. The restoration of the, Category 2 Listed Heritage Building, Chevening Apartments is a prime example. Seismic strengthening was integrated into the internal fit out, carefully upgrading with original materials. This method of invisibility distils a particular period in the architecture but I extend the approach to include the idea of distilling the present condition - preserving the ruin. Both of the angles on the approach, however, reduce the historic narrative of the site to a particular moment in history - disconnecting the site from a live understanding of time.
Chevening Flats 1929_Studio Pacific, 2011 90 Salamanca Road, Kelburn, Wellington invisibility
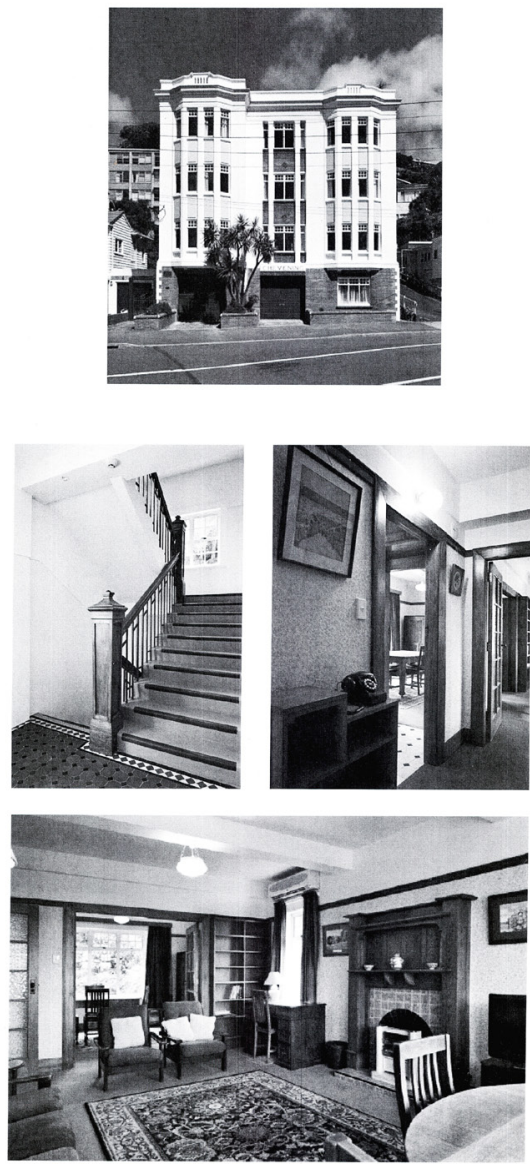

a

fig. 2.1. Photographs and sketch analysis of 9 local heritage projects in Te Aro, Wellington. Above: Chevening Apartments; (From left) p18-19: Qual IT Building, Majestic Centre, Appartmento II Casino, Cubana Apartments, Coffee Cart, St Andrew's Church; p20-21: Croxley Mills Apartments, Te Puni Kōkiri House 
Historic House, 1866_Qual IT Building separation
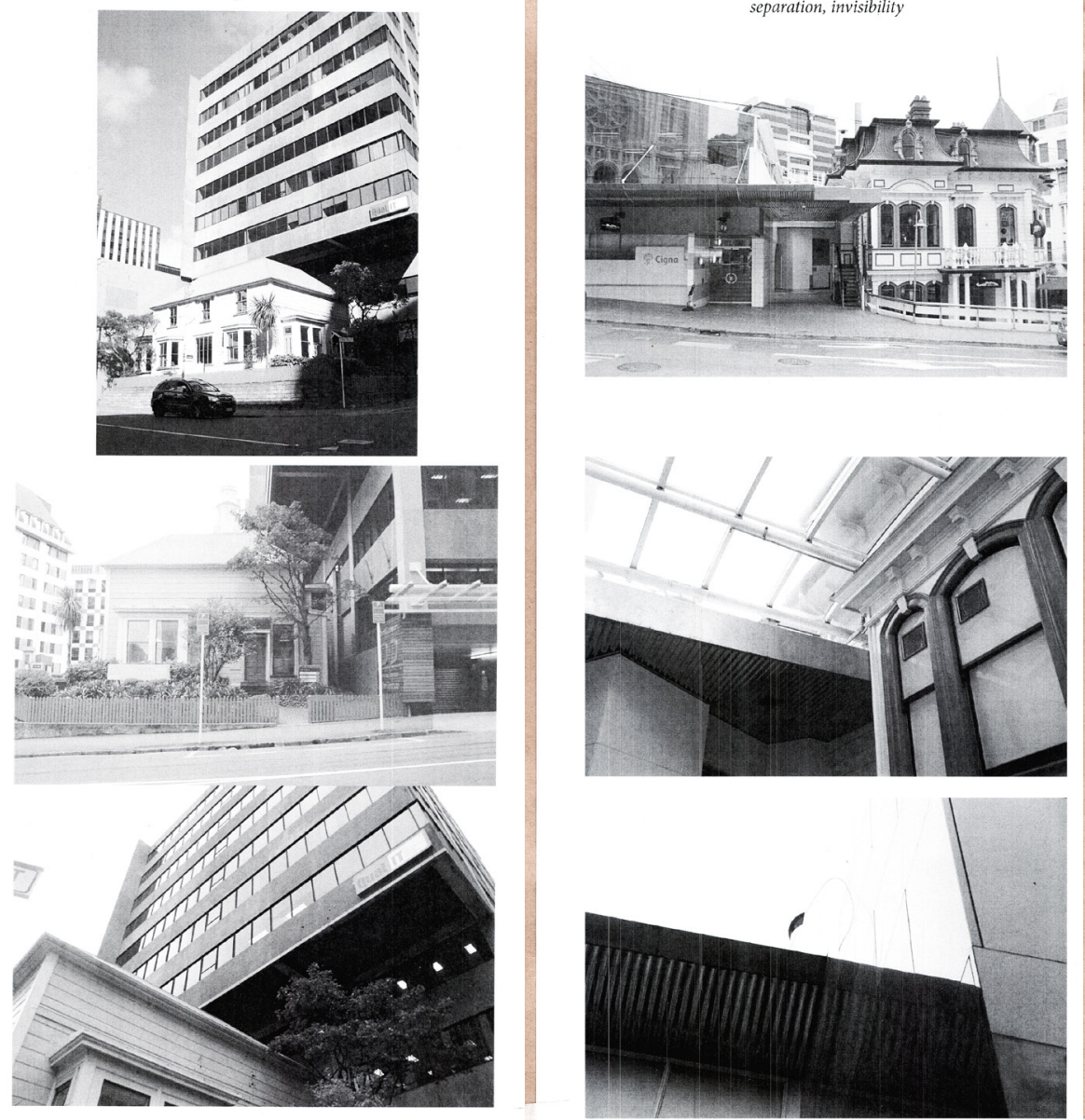
Willis Strect, Wellingto separation, invisibility
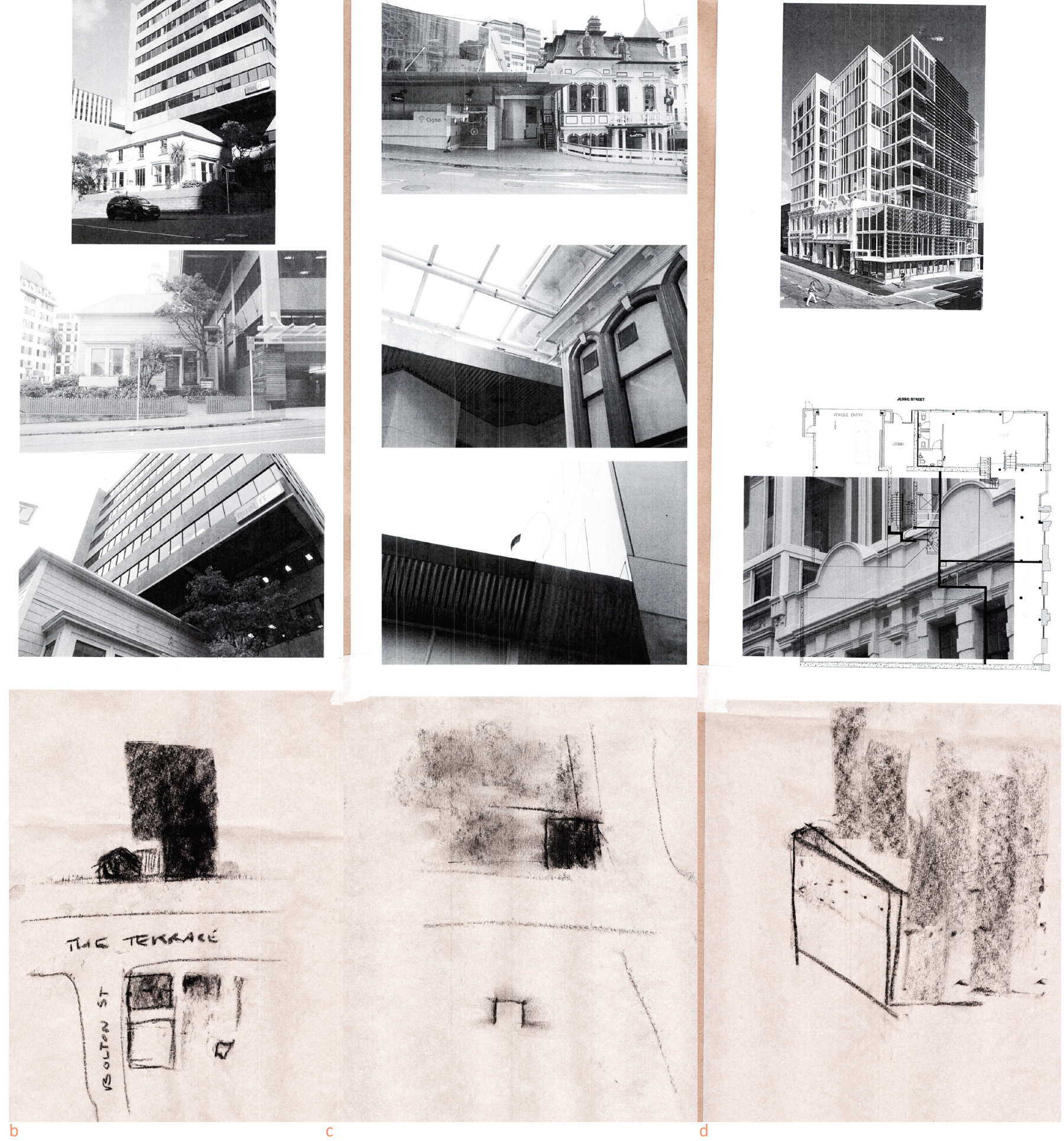

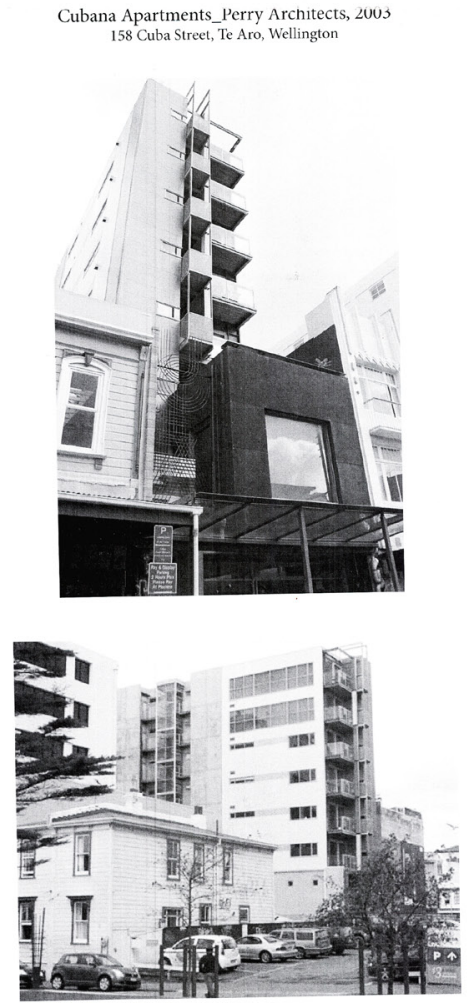

st Andrews (hurch, 1923

Vacant building with Coffee Cart
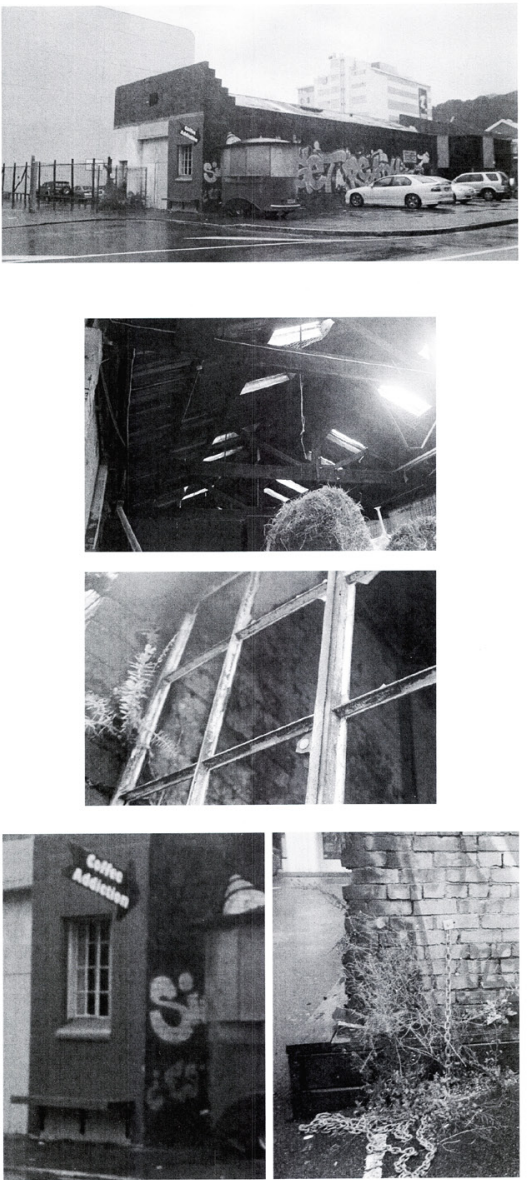

28-30 The Terrace, Wellington
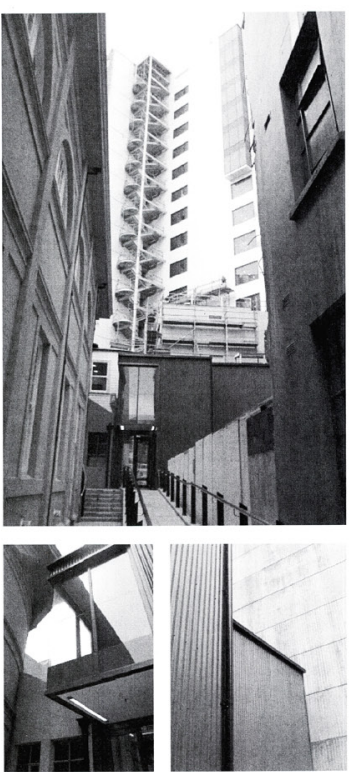

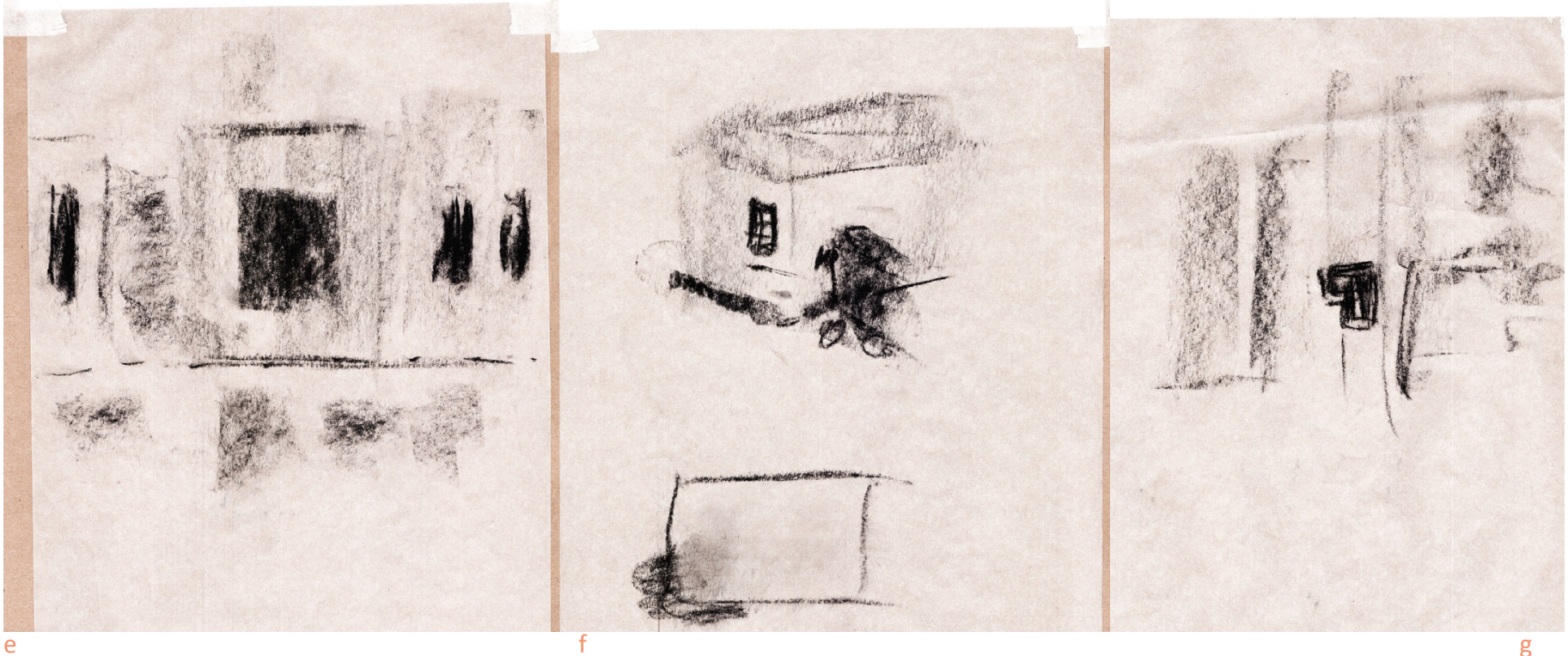


Croxley Mills Apartments_Custance, 2003 33 Frederick Street, Te Aro, Wellington dialogue
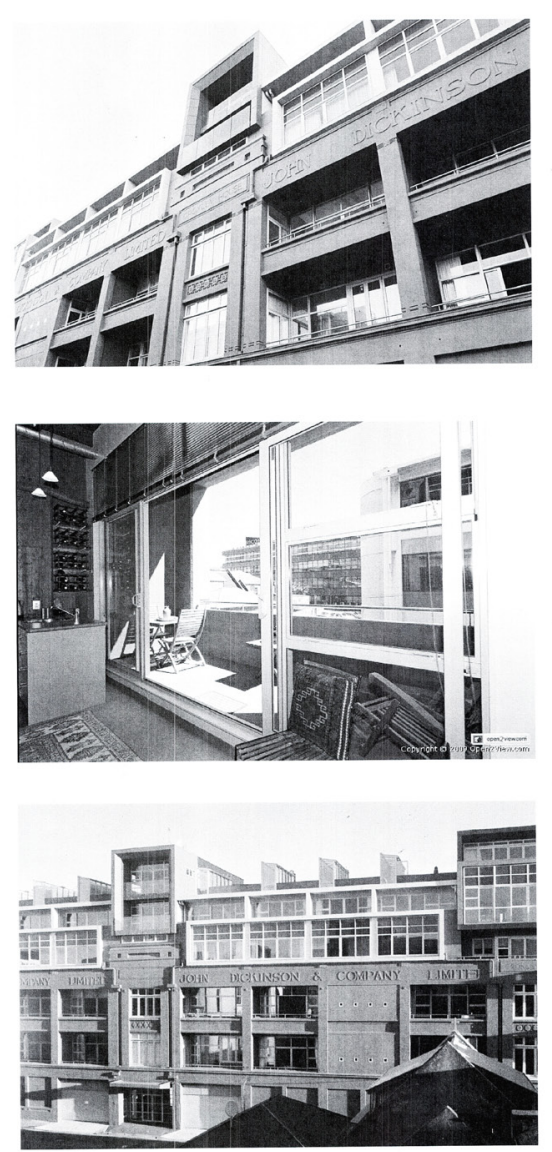

h

\section{Indifference}

The approach entails the new intervention dominating the old irrespective of its latent qualities. This strategy presents an opportunity to clearly express the programmatic and structural requirements of the intervention. The intervention would thus distil the cultural climate of the present day; the present condition. An opportunity however is lost to capitalise on the latent qualities and potentials of the existing built remains.

Separation; distinct and autonomous intervention

The third approach enters the ring of architectural dialogue by visually articulating the separate conditions; past and present. Thresholds between the new and old zones of a building present rich opportunities to emphasise the layers of coexistence. A space gap or the introduction of a third material is often used to define the inbetween spaces to visually (and even structurally) separate the two surfaces.

\section{Dialogue; hybrid exchange}

The final approach opens up the design to a conversation; the new intervention and the old feed off one another in a hybrid exchange. The new becomes a whole, a continual language where each phase is articulated yet in harmony. Here, the opportunity presents to critique the existing and previous history. Latent and active qualities can be extracted and manifested with the new design whilst deficient areas can be buried in the palimpsest. The threshold again is significant with potential to articulate the give-and-take occurring across a divide or blurring the boundary. Negative detailing is beneficial again to give an ephemerality to the transition. Particularly with competing materials, the approach helps to obscure the tectonic pragmatics of the exchange. 
Former State Insurance Building, 1940 Te Puni Kōkiri House 143-149 Lambton Quay, Wellington separation, dialogue

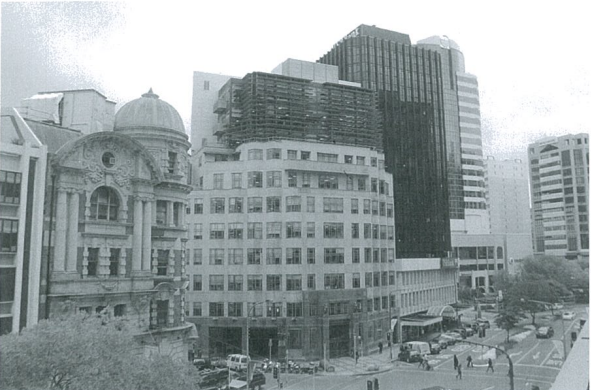

This taxonomy poses questions for the research inquiry as to where present day interventions should be positioned in the palimpsest. Is the use of dialogue critical of all layers, of built and immaterial conditions, over time or is it reserved for a particular layer, e.g., present day. The iterative test designs that follow will be framed against present, previous and future conditions towards an architecture interacting with all - achieving continuity in time and space.
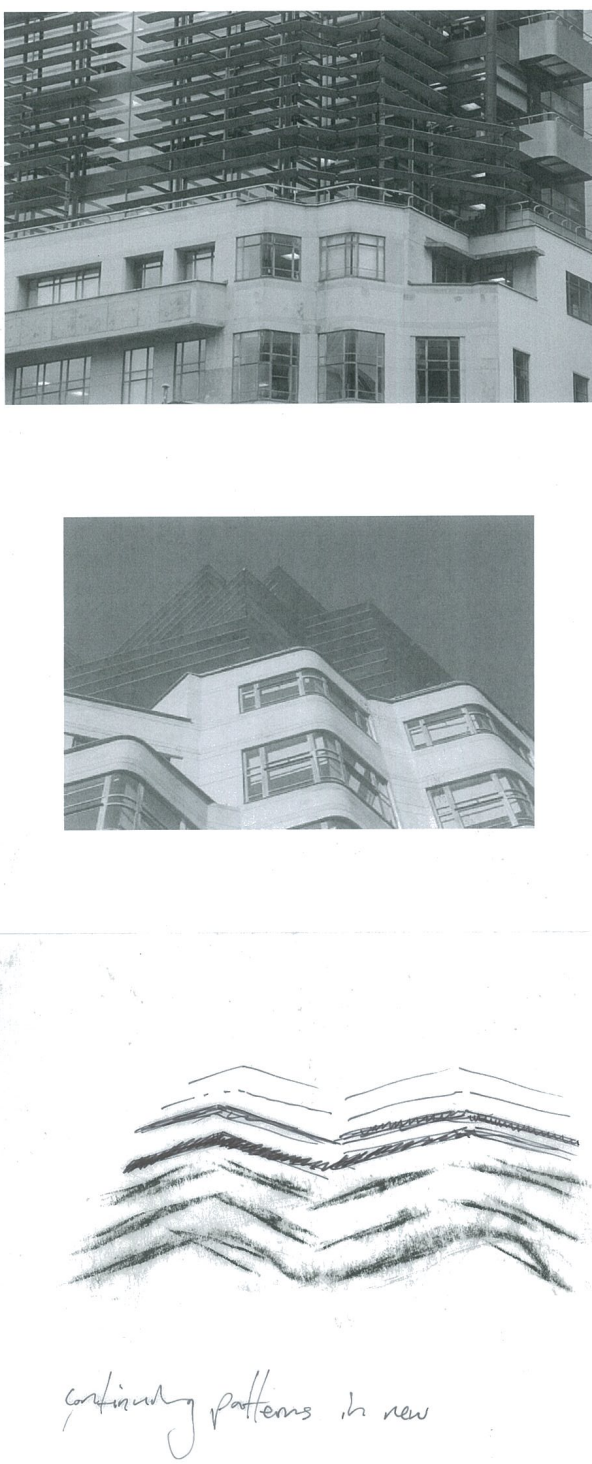
Fondazione Querini Stampalia

Venice, Italy 1950-1963
Carlo Scarpa

$\underline{\text { Museo Civico di Castelvecchio }}$

Verona, Italy 1959-1973

Originally Constructed 1354- 1376

The work and methodology of Carlo Scarpa exhibits a deep sensitivity for historical layers and how things transform over time. Described as a 'spatial stratification', Scarpa was interested in how palimpsests could communicate with newly added interventions ${ }^{18}$. The Foundazione Querini Stampalia and the Museo Civico di Castelvecchio demonstrate a critical review of the existing before selectively erasing, grafting or introducing elements. This is evident in his working drawings where the final design emerges through layers of overwritten iterations or thoughts. The Foundazione is particularly relevant for Design Phase 1 where subtle shifts in the ground plane are used to disorient the individual from the fluctuating tide of the canal. ${ }^{19}$

\footnotetext{
18. (Schultz 16)

19. (Cadwell 3-46)
} 

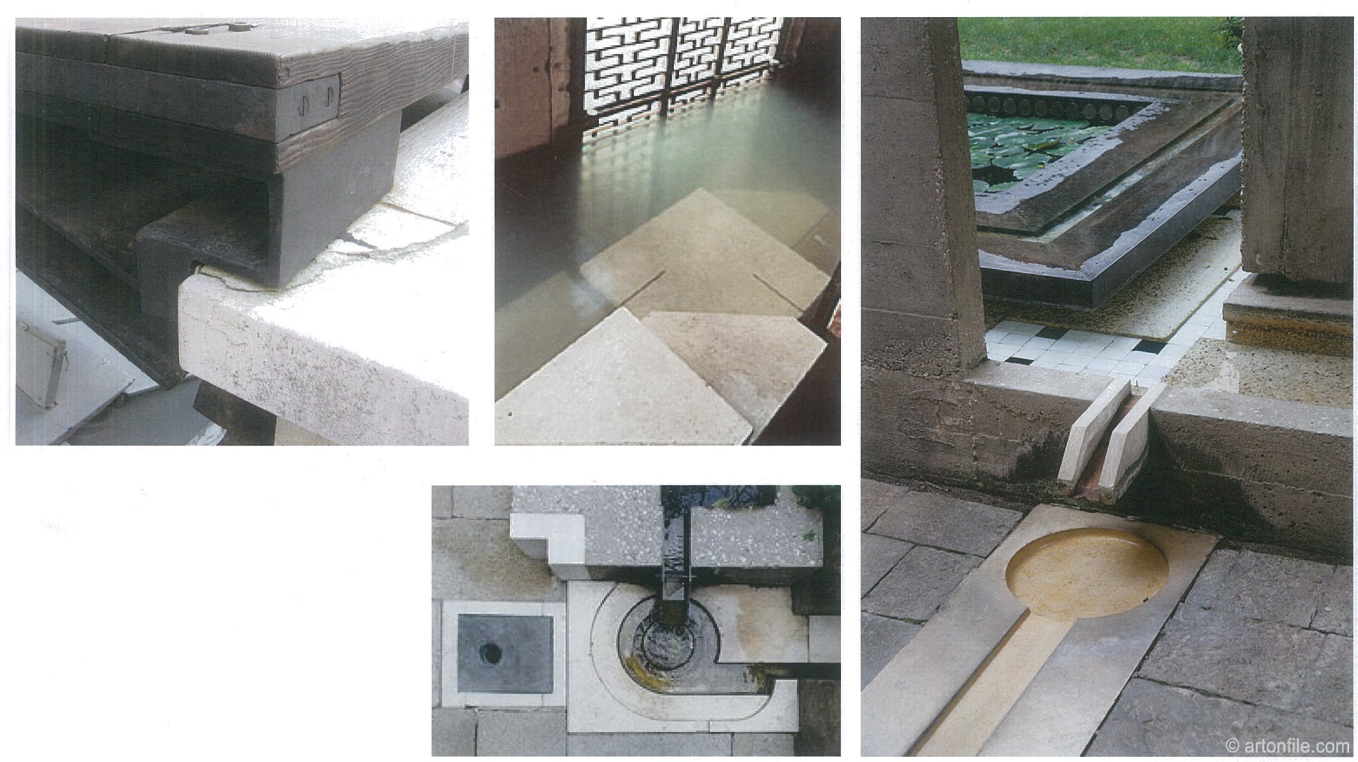

FOUDAZIONE QUERINI STAMPALIA, CARLO SLRAPA, VENICE

$1961-1963$

fig. 2.2. Fondazione Querini Stampalia
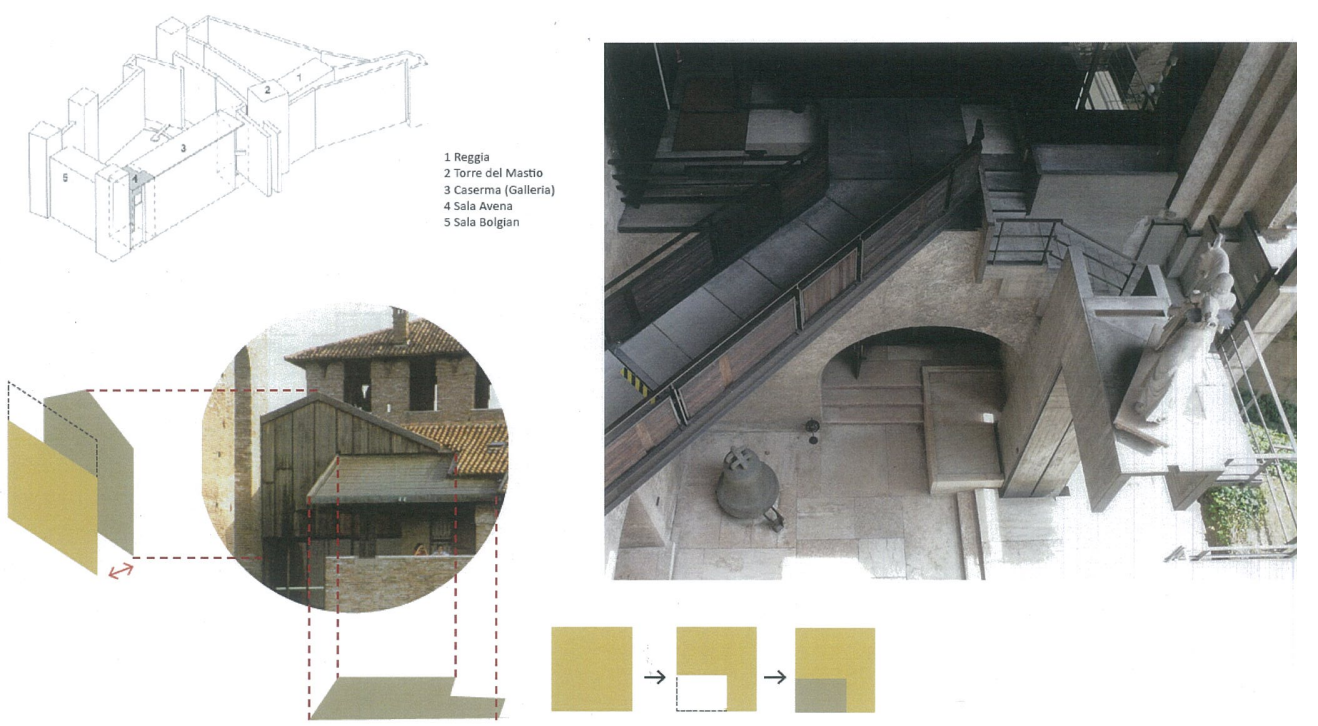

MUSEO CIVICO DICASTELVECCHIO, CARLO SCARPA, VERONA

$1959-1973$

fig. 2.3. Analysis of spatial stratification at Museo Civico di Castelvecchio 


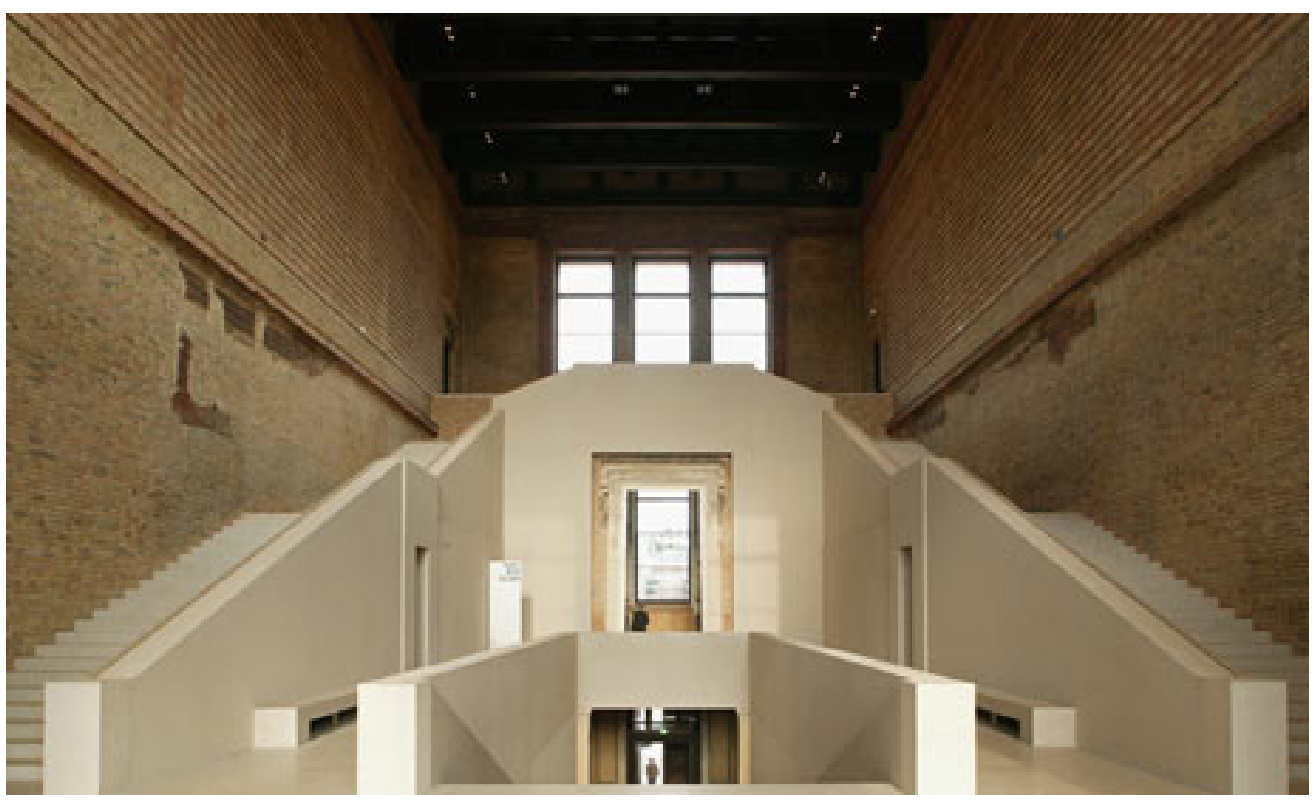

fig. 2.4. Neues Museum Central Stairway restored

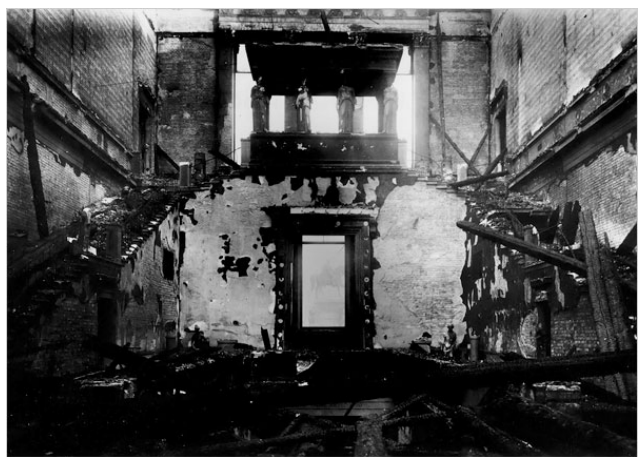

fig. 2.5. Neues Museum Central Stairway after the 1943 bombings

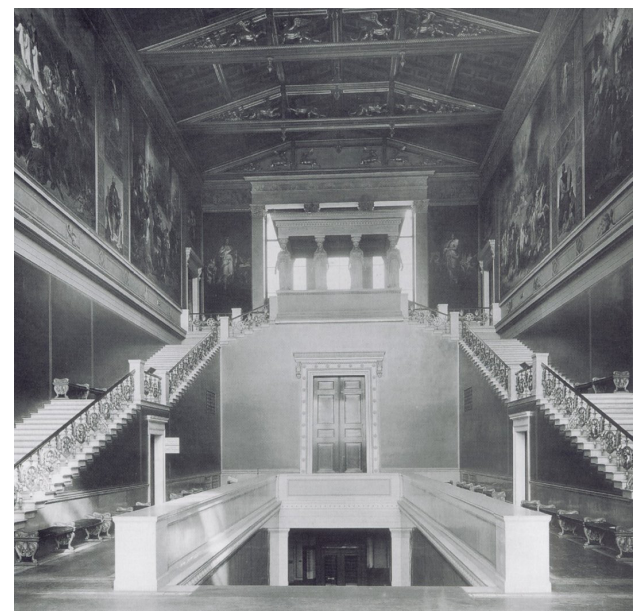

fig. 2.6. Central Stairway designed by Friedrich August Stüler constructed 1841-1859 
Neues Museum

David Chipperfield Architects

Berlin, Germany 1997-2009

Originally Constructed by Friedrich August Stüler 1841-1859

The 'augmented rebuild' of the Neues Museum distils a notable debate in the restoration of post-war Germany over how best to approach the ruin. Suffering severe bomb damage, the partially dissembled building sat dormant whilst restoration groups lobbied for various treatments. The central stairway is a pivot of coexistence of new and ruinous construction. It captures the grandeur essence of the space but without the ornamental decoration of the period. The project surfs a line between theories of meticulous conservation, postulated by John Ruskin, and visible ruin, by Hans Döllgast to align with the editing work of Scarpa. ${ }^{20}$

20. (von Buttlar 32-33) 


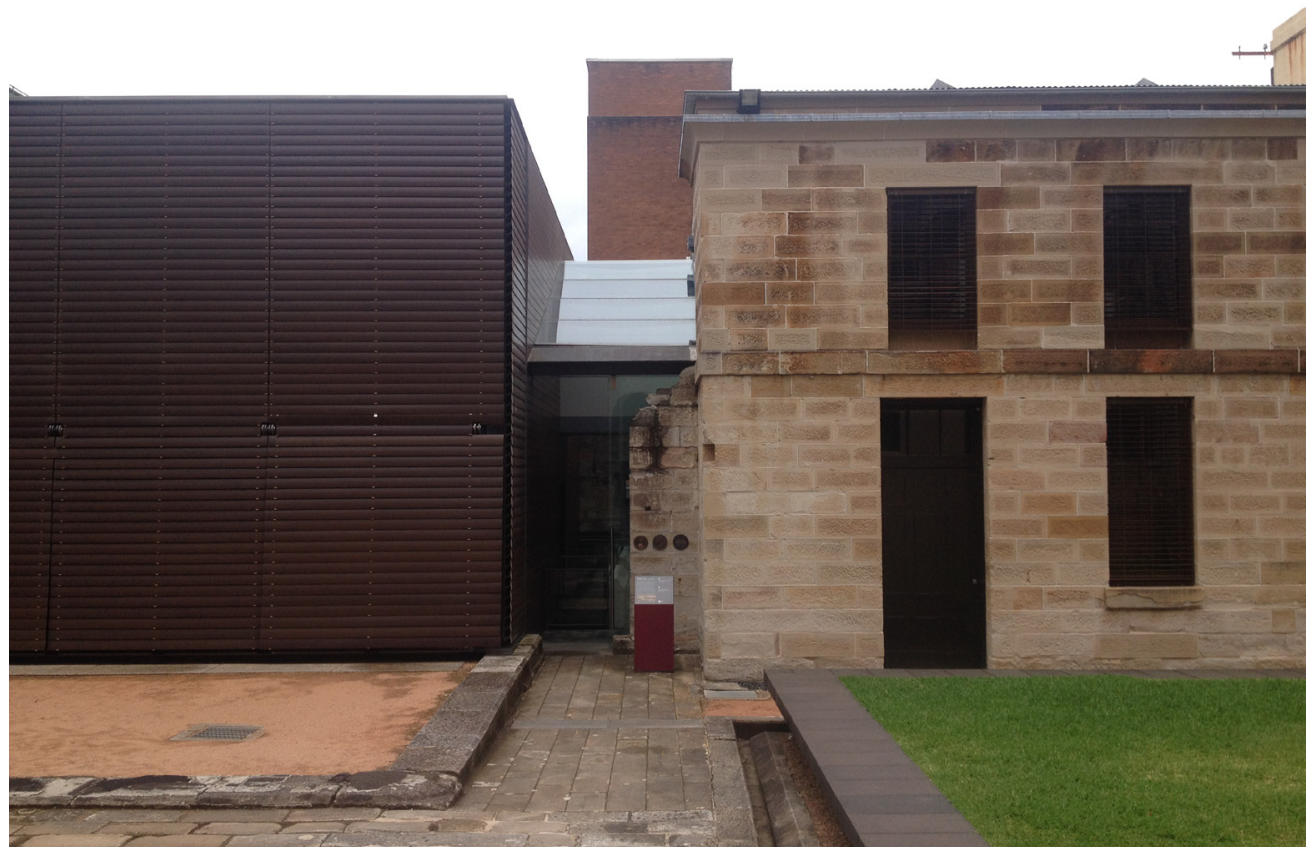

fig. 2.7. Photo. The scale of the new addition,left, shares similar proportions to the former factory

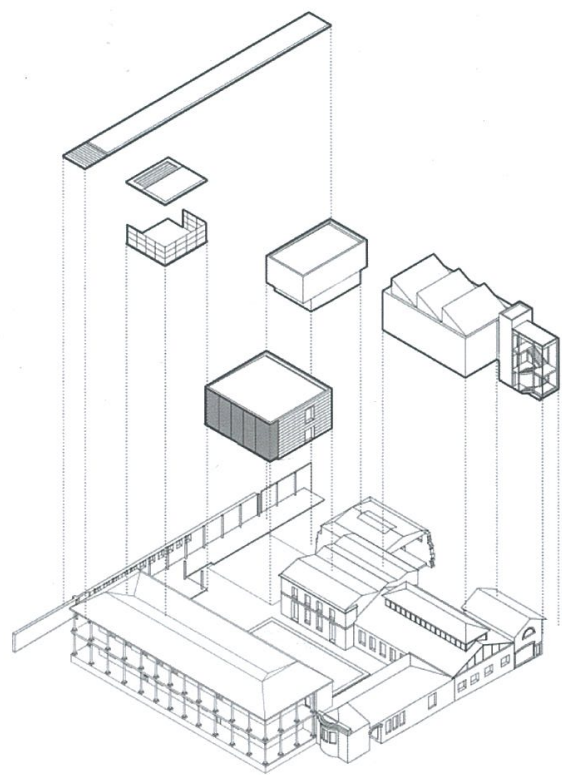

fig. 2.8. Exploded diagram of new additions at The Mint 

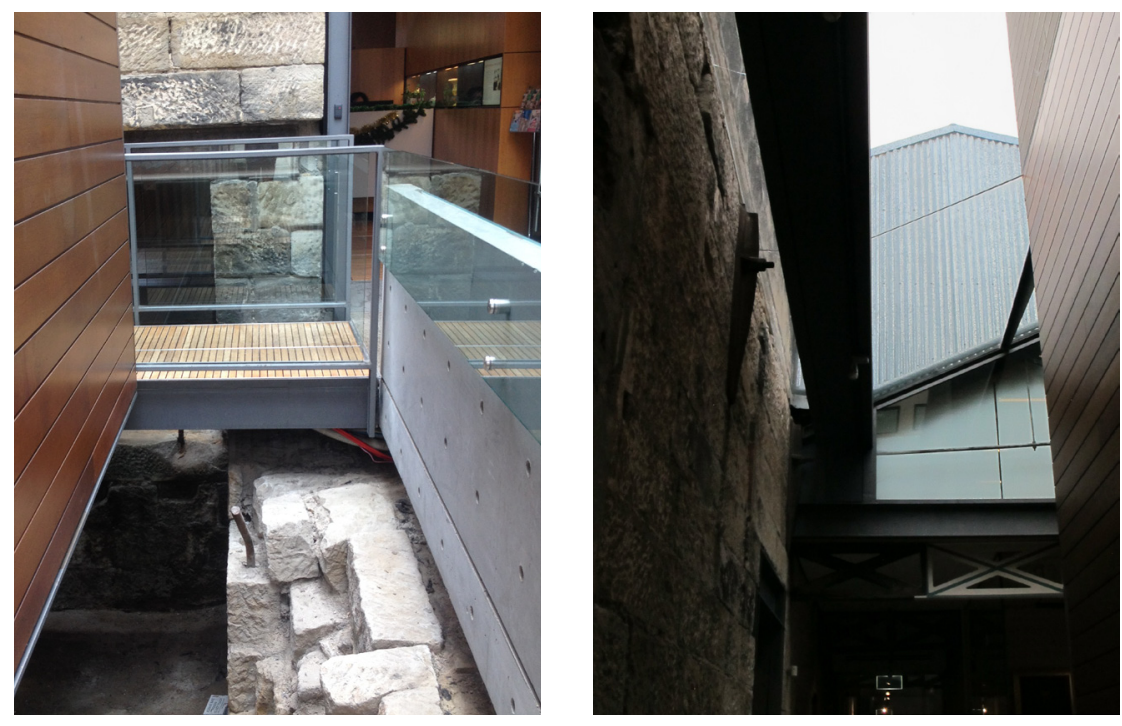

fig. 2.9. Photos of the dialogue between old and new at The Mint

\section{The Mint}

Francis-Jones Morehen Thorp

Sydney, Australia 2005

Originally Constructed 1816 and extended 1855

The transformation of the 1850's Coin Factory at The Mint presents the same editing method as Scarpa and Chipperfield, yet with a "cluster of ruinous and neglected shells" 21 . The project shares a similar scale to the previous factories of the thesis site. The fragments of history are interlaced with the new interventions in an assemblage nurturing a public realm.

21. (RAIA jury) The Mint was awarded Sir John Sulman Medallion for Outstanding Public Architecture 

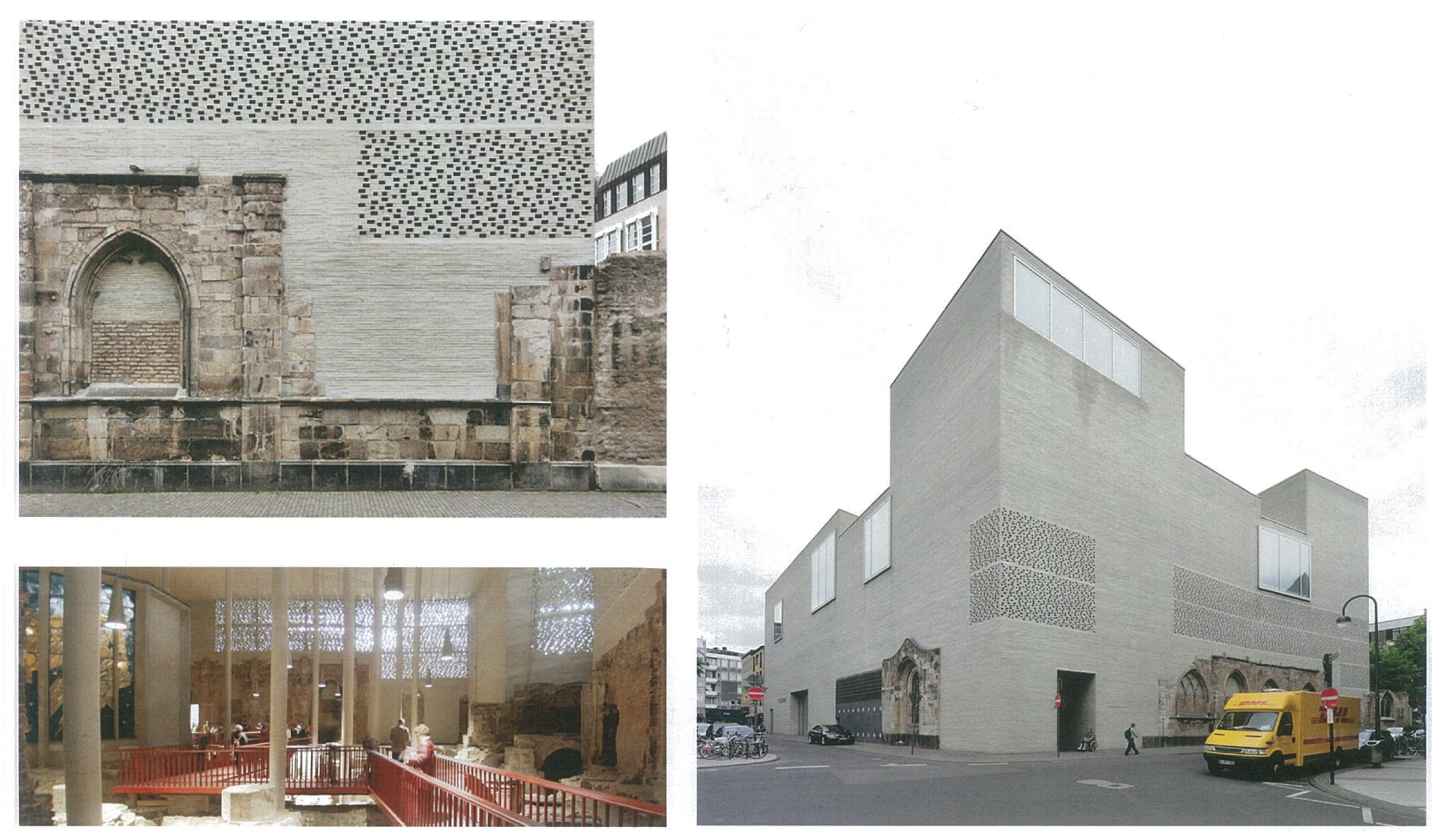

$$
\begin{gathered}
\text { KOLUMBA MUSEUM, ZUMTHOR, COLOGNE } \\
2003-2007
\end{gathered}
$$

fig. 2.10. Photos of Kolumba Museum

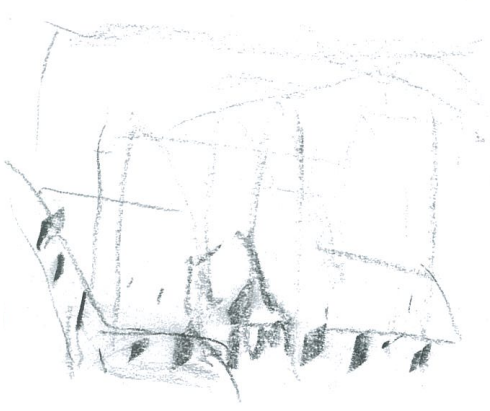

fig. 2.11. Sketch tests Zumthor's approach; elevating the building above the thesis site
Kolumba Museum

Peter Zumthor

Cologne, Germany 2002- 2007

The Museum revitalises the ruins of a late-gothic church into a new building, evocative of the previous form. Restoring the volume with a blank addition is a contemporary trend, often resulting in a stark contrast to the existing. ${ }^{22}$ Zumthor masters the approach with the sensitive use of colour and proportion in the brickwork. fig. 2.10 The project also presents an approach to preserve the physical traces of the past by elevating above the existing or excavated site.

22. (Wainwright) 


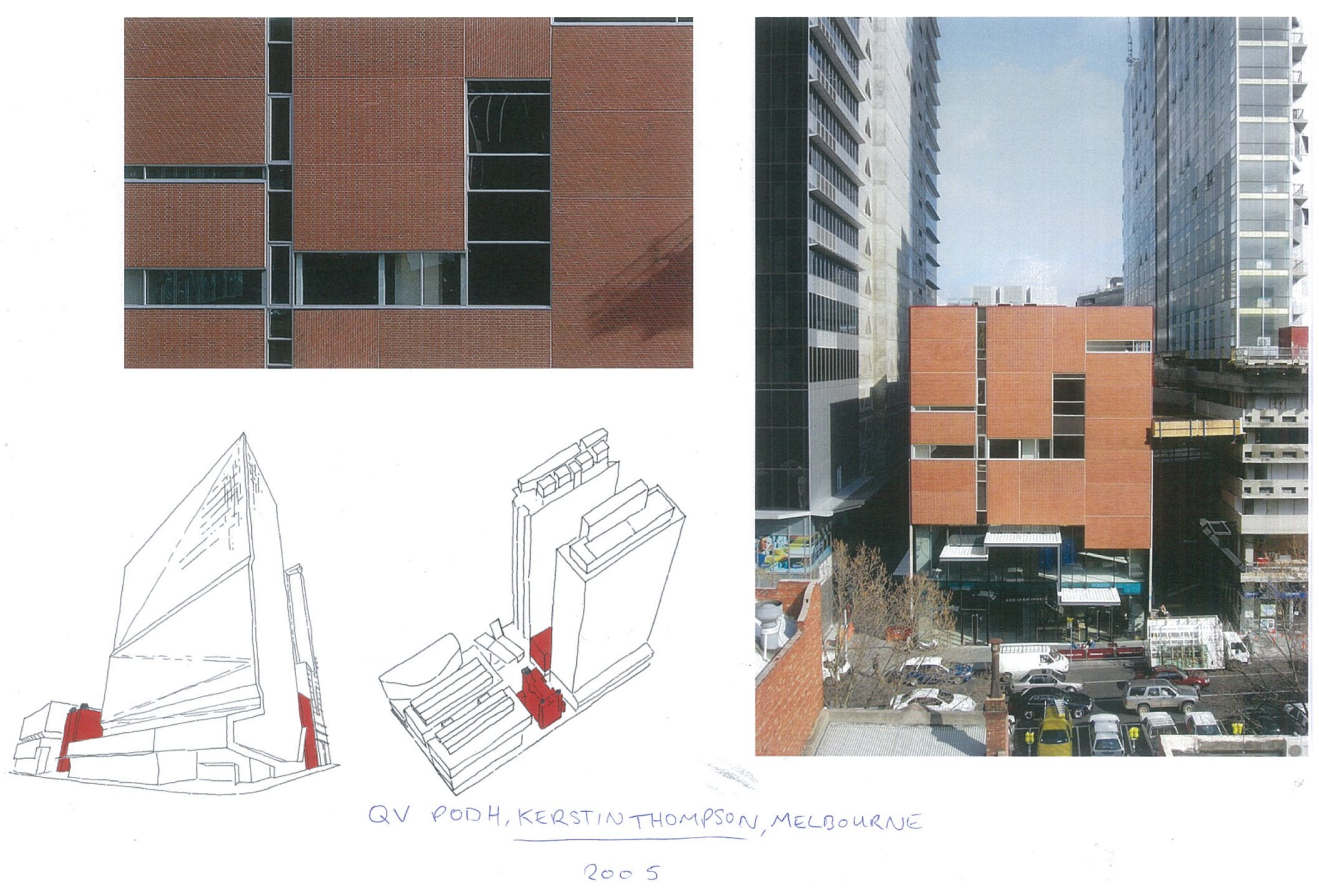

fig. 2.12. Clockwise from top; a, Brick details; b, Street elevation; c, Diagrams of relationship between the existing building and the $Q V$ Pod $H$

\section{QV Pod H}

Kerstin Thompson Architects (KTA)

Melbourne, Australia 2005

The QV Pod $\mathrm{H}$ is one of several buildings built as part of the development of an entire city block. It presents an alternative to the amalgamation of urban lots by introducing laneways and shifts in scale. Cornered by four towers the QV Pod $\mathrm{H}$ has a significant role within the block; to cement a human scale and, through materiality and form, retain a dialogue with the last remaining wing of the former hospital.

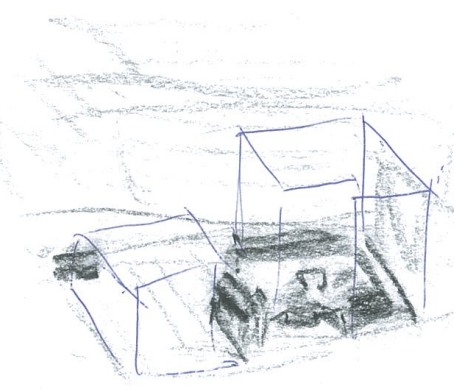

fig. 2.13. Sketch tests KTA's approach; dividing the site 


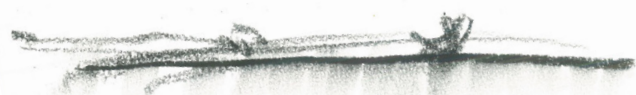

fig. 3.14. Site Visit One. Compressed Charcoal

Upon the tracks overlaid by the march of time, site interpretation detects potentialities to be nurtured and passed on.

The reading is thus that of an inheritance and eventual project a bequest. ${ }^{22}$

- Sebastian Marot

$\overline{22 . \quad \text { (Marot 50) }}$ 


\section{Three | Excavation of site}

This section presents the process of unpacking the historic narrative of the site, its future and the present condition. My first impressions of the site were recorded with care, to distil my initial glance. Then the site was subject to an in-depth study to record and expose the latent layers of history, like a theoretical excavation. A diligent timeline conveys a dissection of the site's palimpsest which is then re-collapsed through layered compositions. These compositions see the reengagement of my individual subjection, working to extract a set of orders from the site.

\section{The singular and the first impression}

The initial visits to the site in February 2015 sought to capture my first impression and distil the present condition of the site. Although my preconceptions and prior knowledge of the site are key influences on both studies, it was crucial to conduct the first impression at the dawn of the thesis project with limited instruments: a $2 \mathrm{H}$ pencil, compressed charcoal stick, $150 \mathrm{G}$ paper. The process sought to capture the energy of the site with immediacy to establish the singularities. After entering the Chinese Mission Hall with a camera, I lifted the constraints; diving into all modes of research resources and returned persistently over the course of the year, I was intimate with each gravel stone of the vacant plots. 

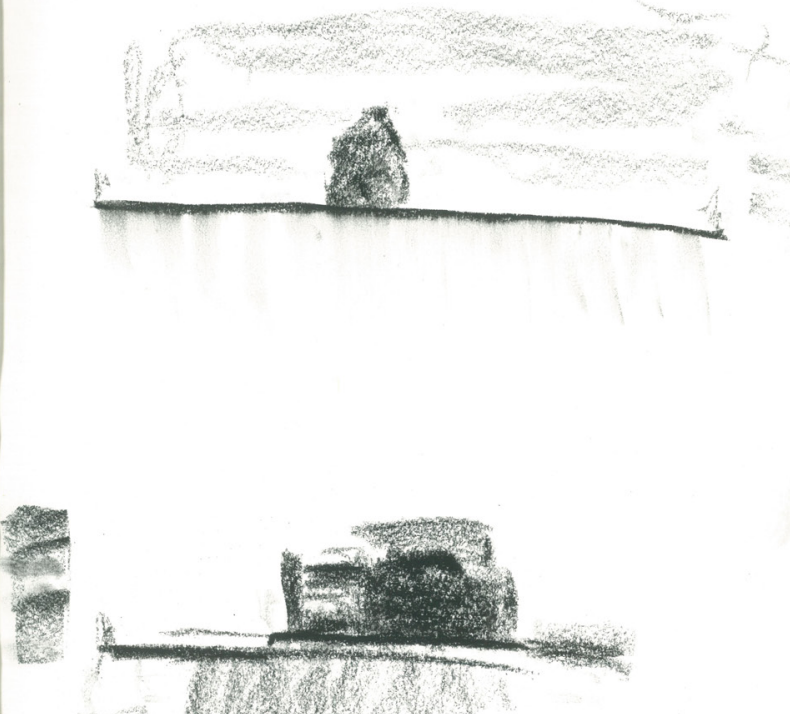

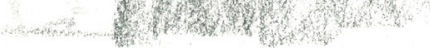

fig. 3.15. Site Visit One. Vast plane. Compressed charcoal 


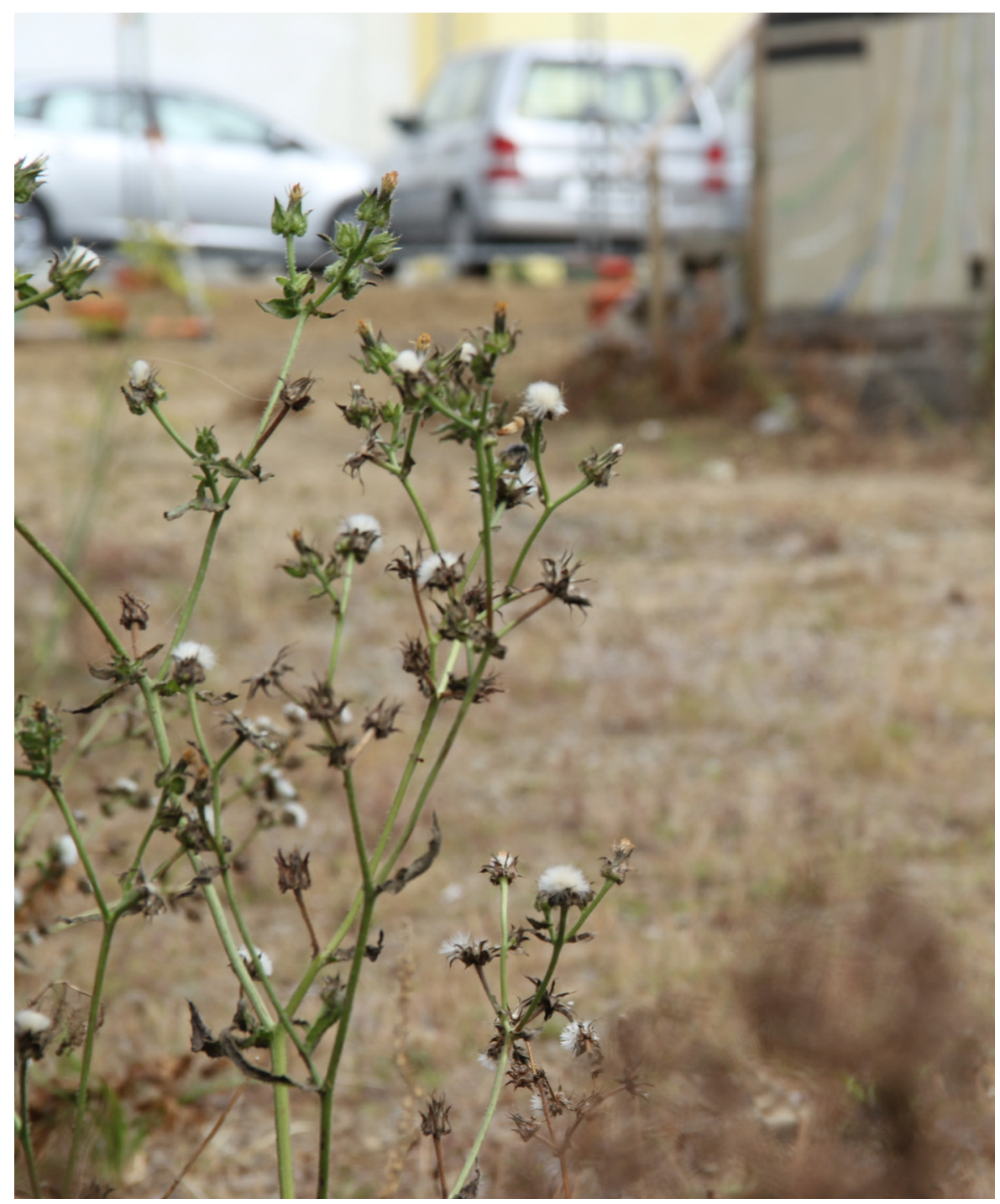

fig. 3.16. Site Visit One. Vast plane. Photo

The close proximity to my workplace at the university deformalized the 'site visit' quickly and I began to enjoy checking in on the corner site at various hours, from various angles and among various routines. The affinity with the qualities intricacies of my first impression became apparent early on. On Day 17, the weeds were flattened by clay cover soil and my blood ran cold. Day 120, the weeds saw resilience and had resurfaced through the gravel. A fond whisper of the site I remembered. 


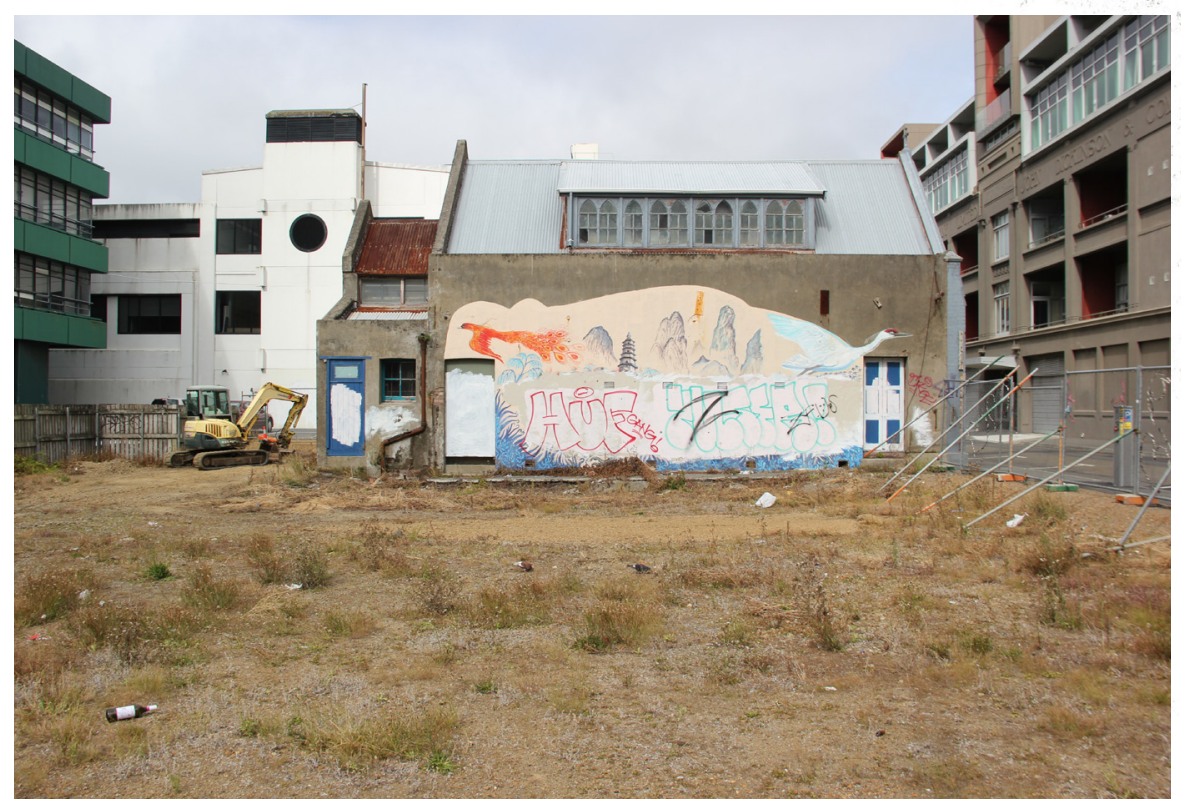

fig. 3.17. Site Visit One. View from Taranaki Street

A gem in these vast planes.

A distinctive remnant from a forgotten time, the Chinese Mission Hall stands alone. A notion of the minuscule is amplified by the empty space surrounding the building and the comparatively large scale of its neighbours. A world inside awaits. 


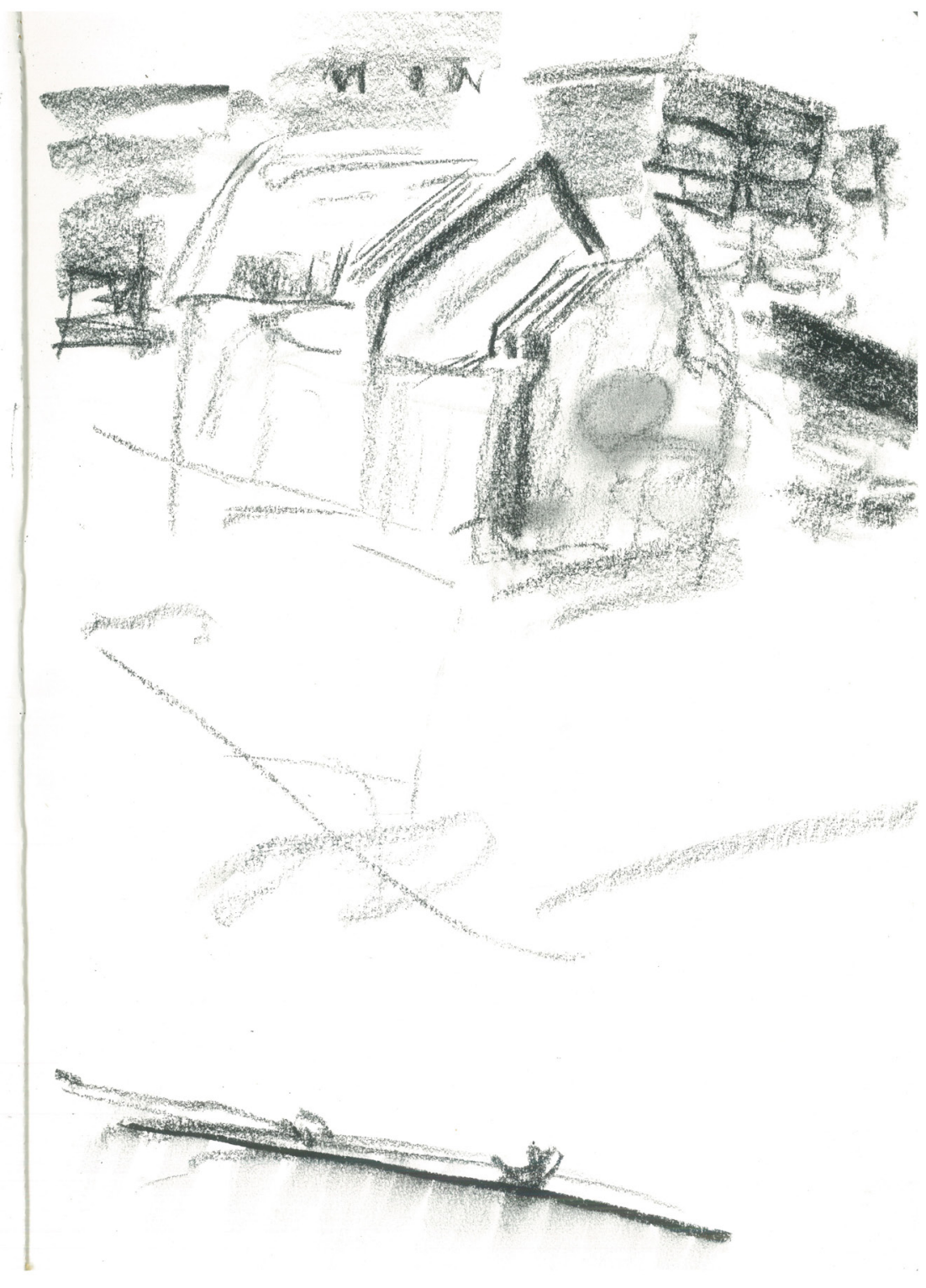

fig. 3.18. Site Visit One. A gem in these vast planes. Compressed charcoal

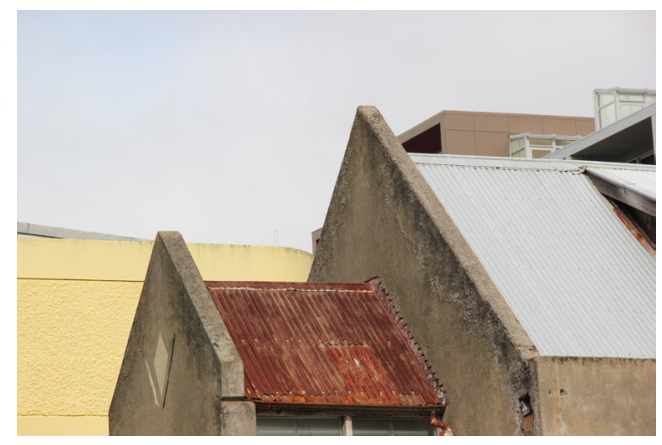

fig. 3.19. Rear view of the Chinese Mission Hall 

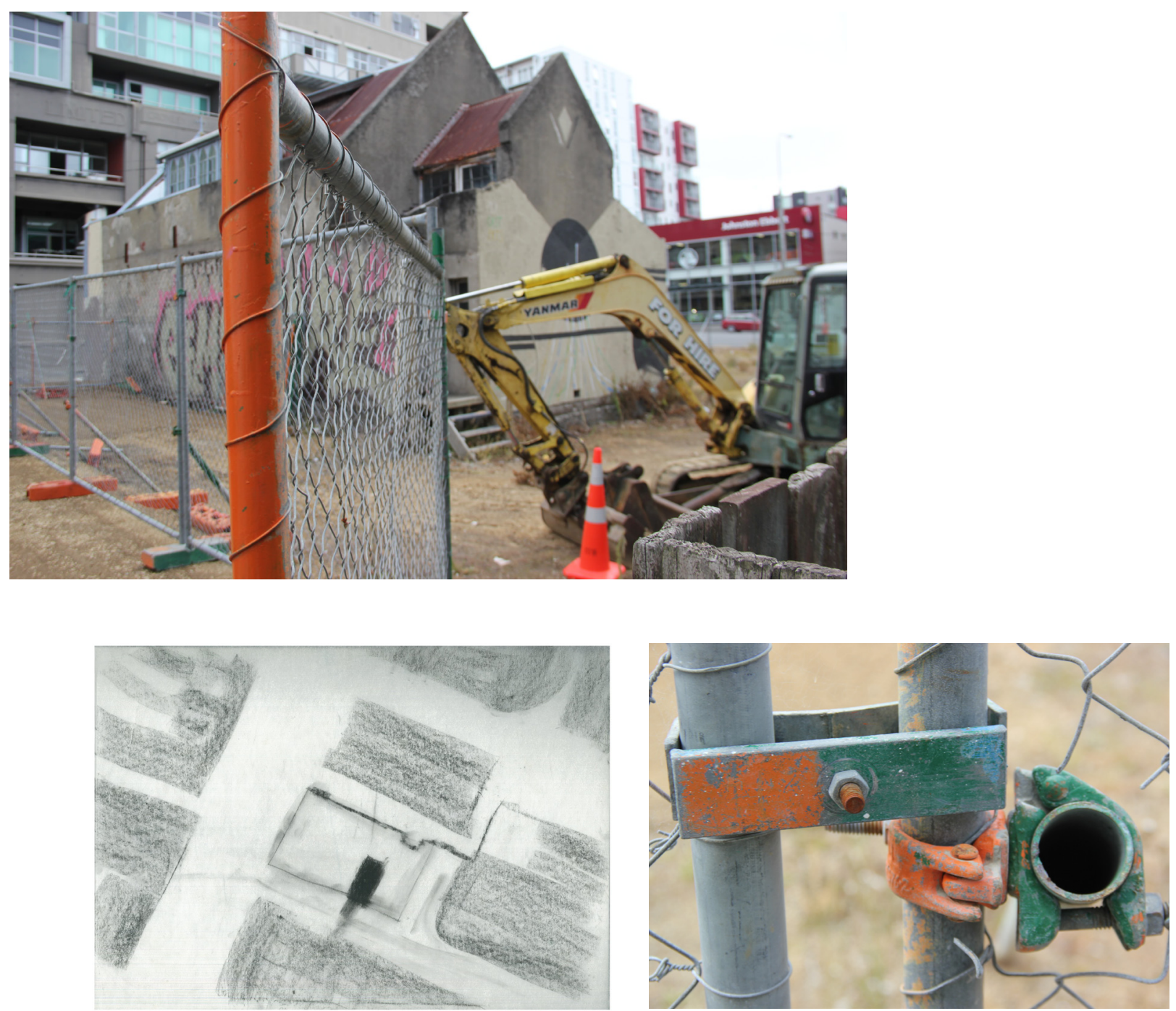

fig. 3.20. Clockwise from top. Peripheral site boundaries 


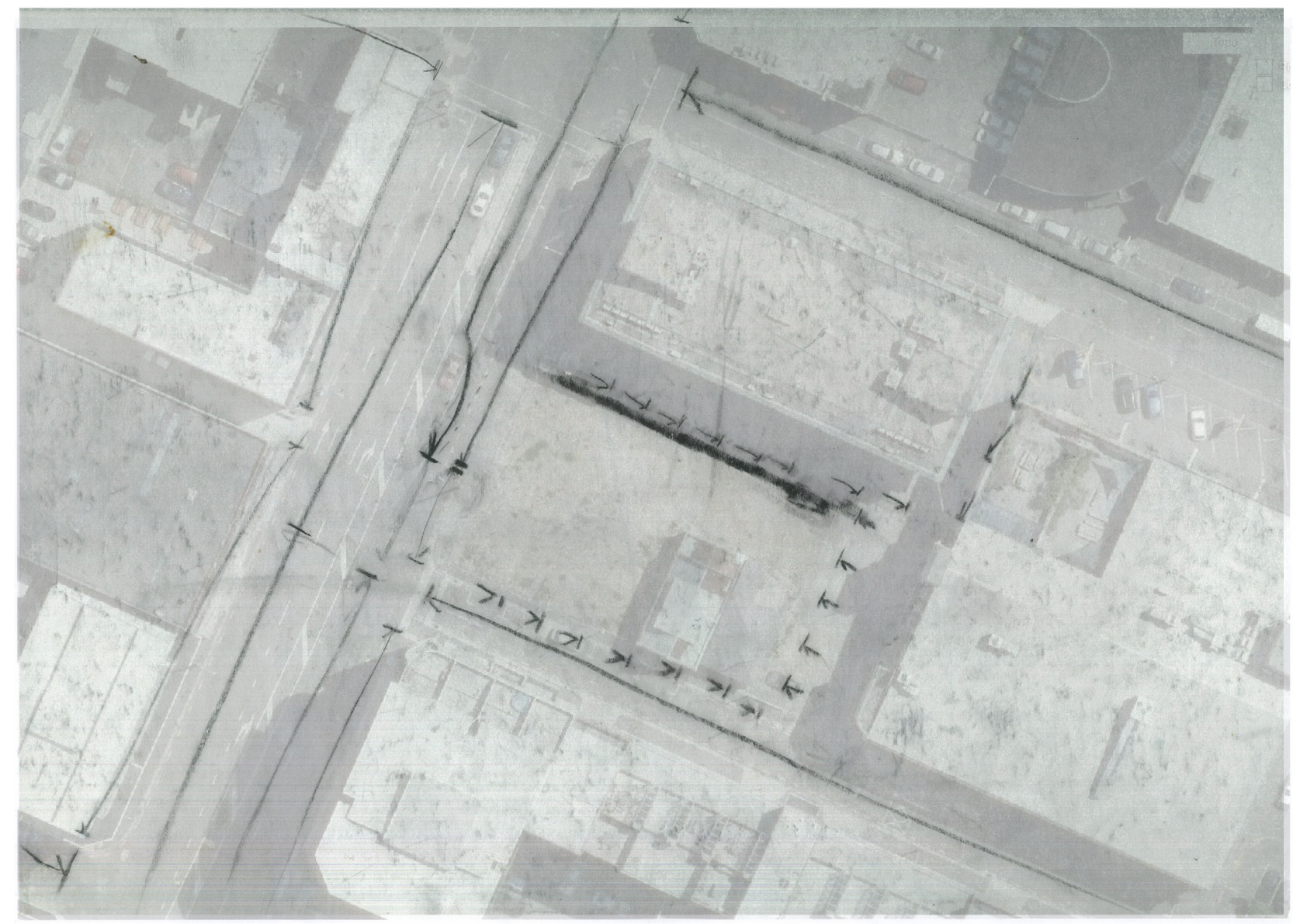

fig. 3.23. Overlay image mapping the vehicular movement patterns around the site

Thresholds

The site's boundaries are defined in various degrees of permeability and endurance. The dense brick walls of the Chinese Mission Hall evoke a fortress and notions of permanence (resilience). Along the north east periphery, a wooden fence presents a similar aged patina yet lean with hesitation. Wire fences dubiously wrap the remaining edges, sealing the site's allotments for public display. ${ }_{\text {fig. 3.7- }}$ fig. 3.9 A transitory boundary is formed by the vehicular movement surrounding the site. Three edges are defined by parking units where vehicles are stationary for hours at a time. fig. 3.10 The bus stop and intersection on the Taranaki Street edges involves momentary pauses; a staccato pulse. These conditions embody the tangible nature of the site. 

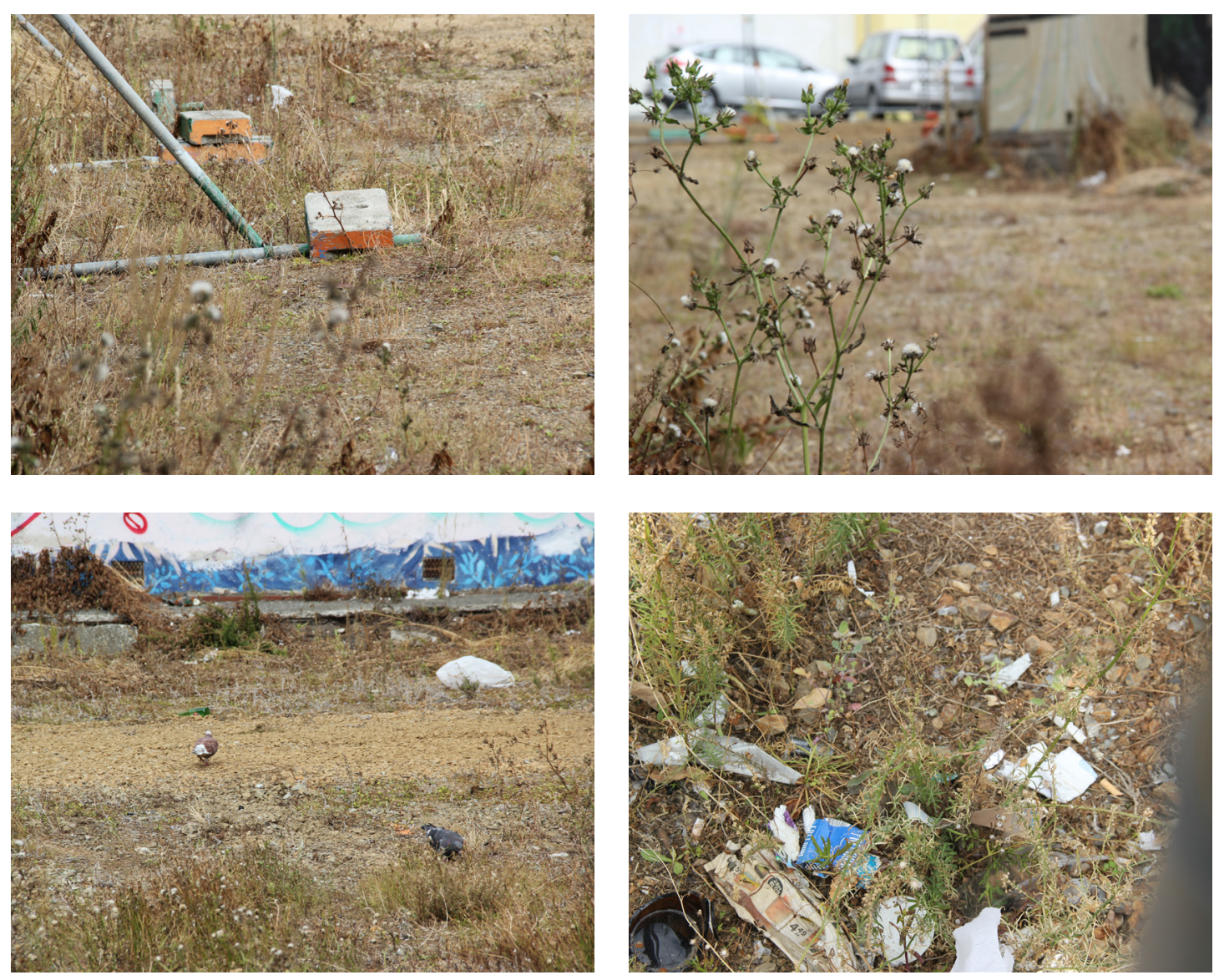

fig. 3.24. Activity in the vast planes

fig. 3.25. The Frederick Street elevation of the Chinese Mission Hall. The facade remains the only component recognised as 'heritage' by the Wellington City Council 


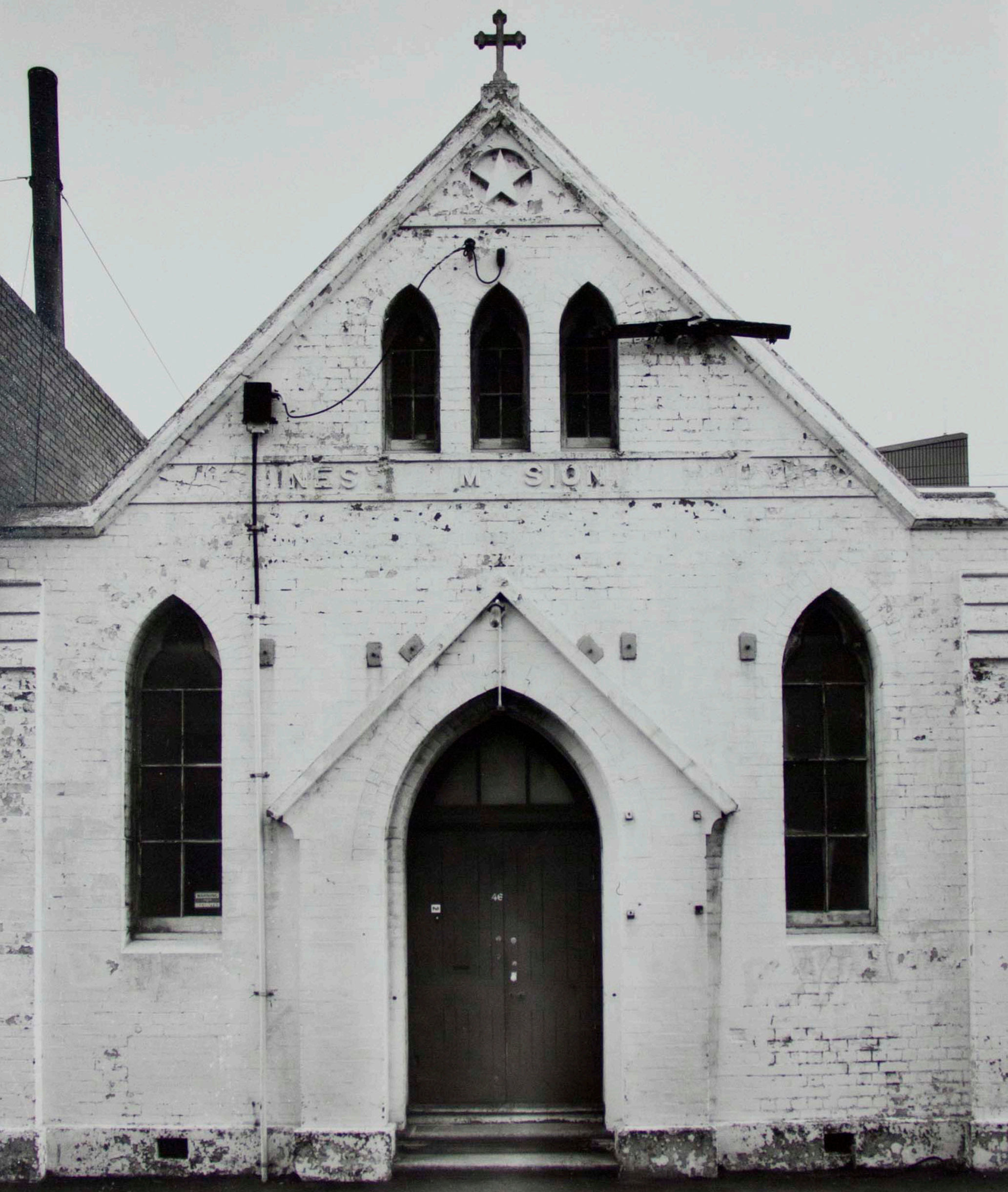



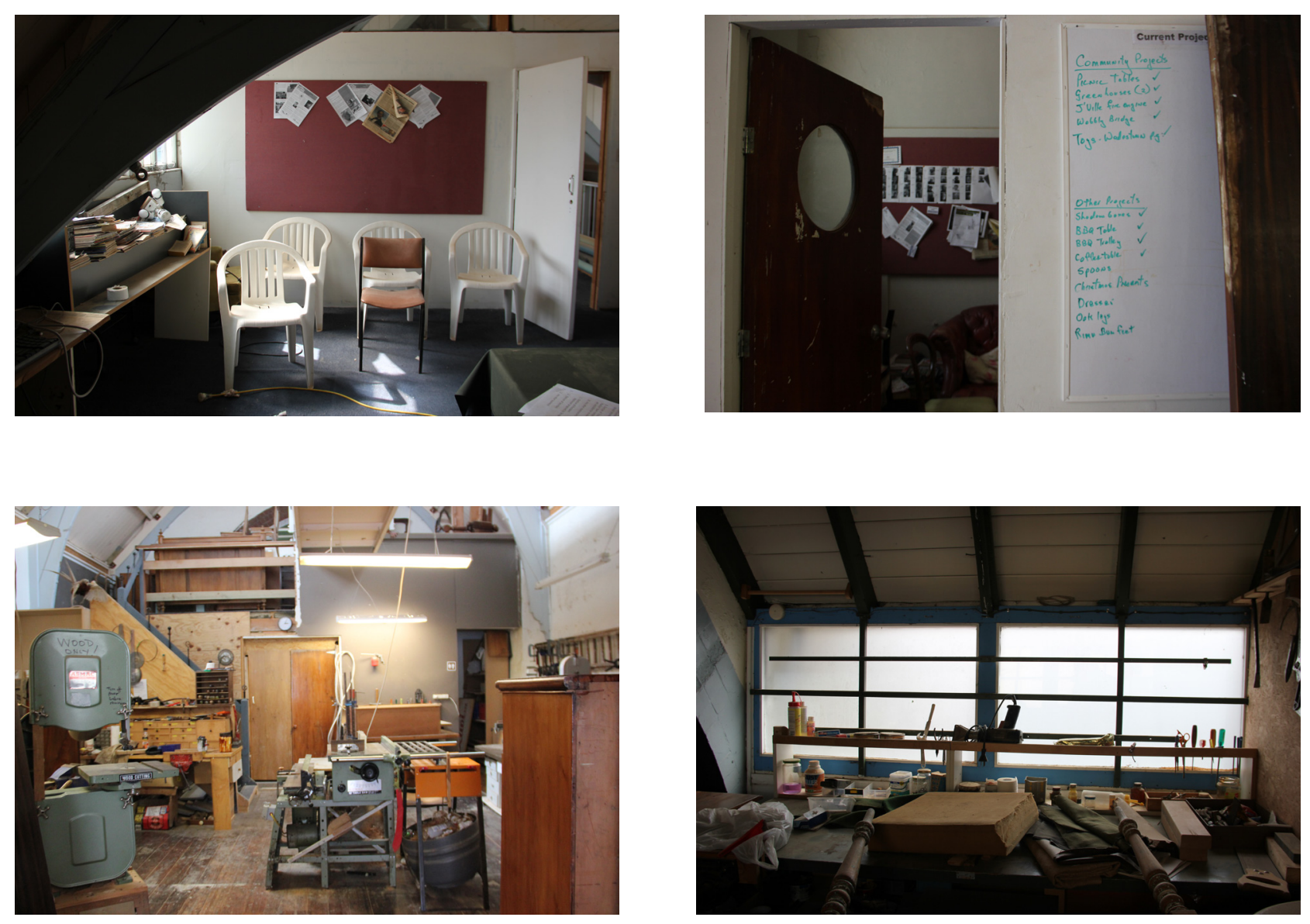

fig. 3.27. Spaces of the Wellington City Menzshed 


\section{Inside the Chinese Mission Hall}

The Chinese Mission Hall is currently occupied by the Wellington City Menzshed; a charitable organisation restoring furniture for local community groups. As stated in their constitution:

The purpose of the Trust is to provide an environment for the older and isolated men of Wellington where they can find companionship, develop new skills, and use their talents to benefit society are (sic)

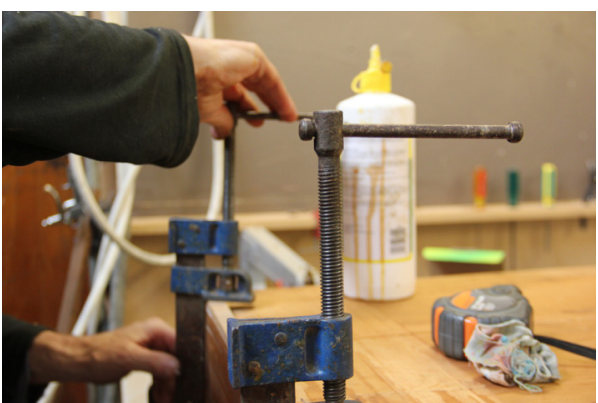

fig. 3.28. In the Workshop large. ${ }^{22}$

The workshop is open Tuesday and Thursday afternoons and for the occasional "Grumpy Old Men Sessions" catered with tea and stale biscuits. ${ }^{23}$ The imminent development and the Earthquake Prone status of the building, the future of the MenzShed has been uncertain. The "sheddies" are searching for a new home. ${ }^{24}$

City MenzShed cares for the older men in our community. Those who have retired, or who have lost their families, and find the world no longer values them. ${ }^{25}$

\footnotetext{
22. (Shrapnell "Constitution")

23. (Shrapnell "Letters to the Editor")

24. (ibid)

25. (MenzShed) A gallant manifesto from their Facebook page but

what an innuendo for the forgotten buildings of Wellington.
} 

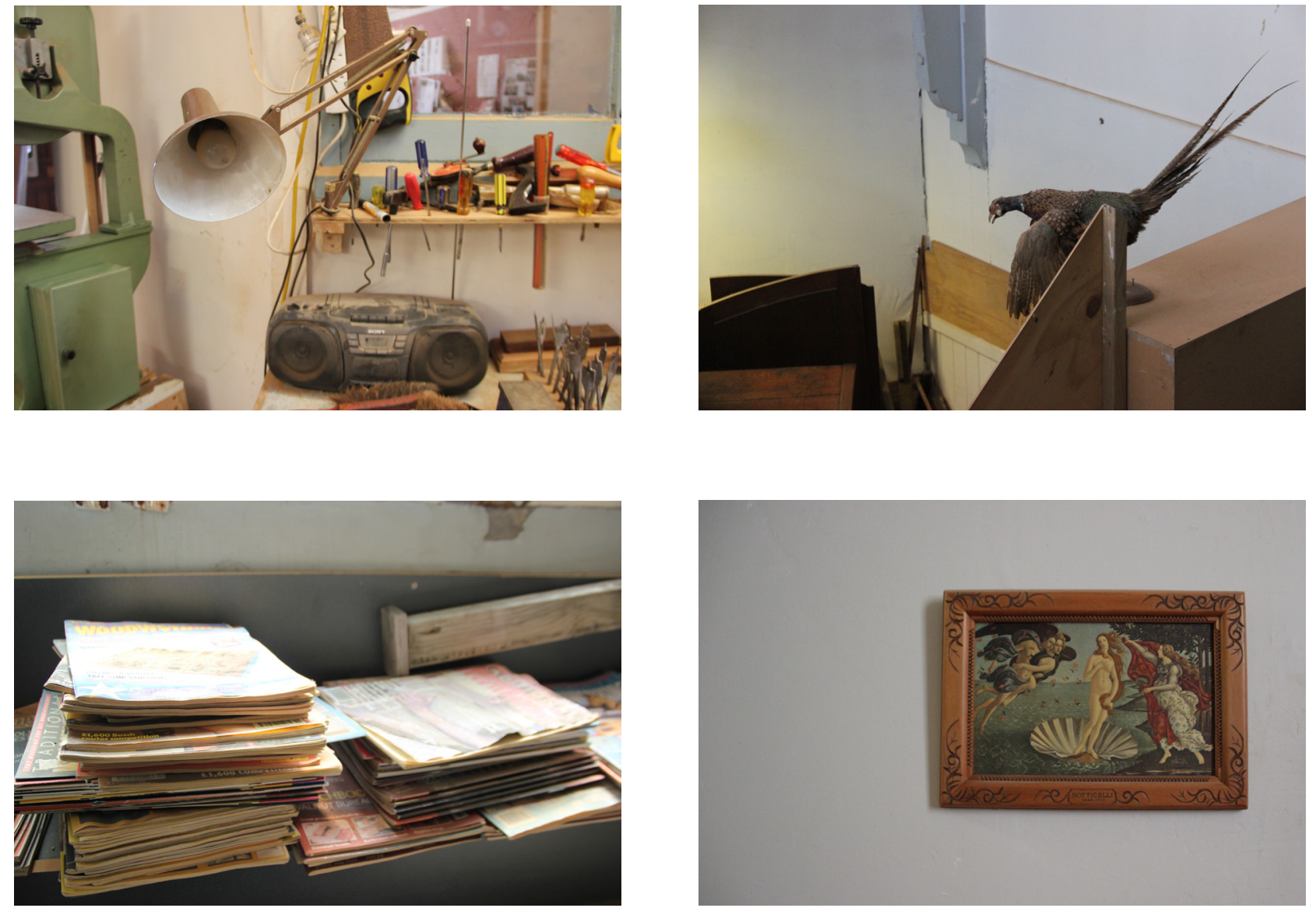

fig. 3.29. Trace of occupation: Objects in Space - Belongings 

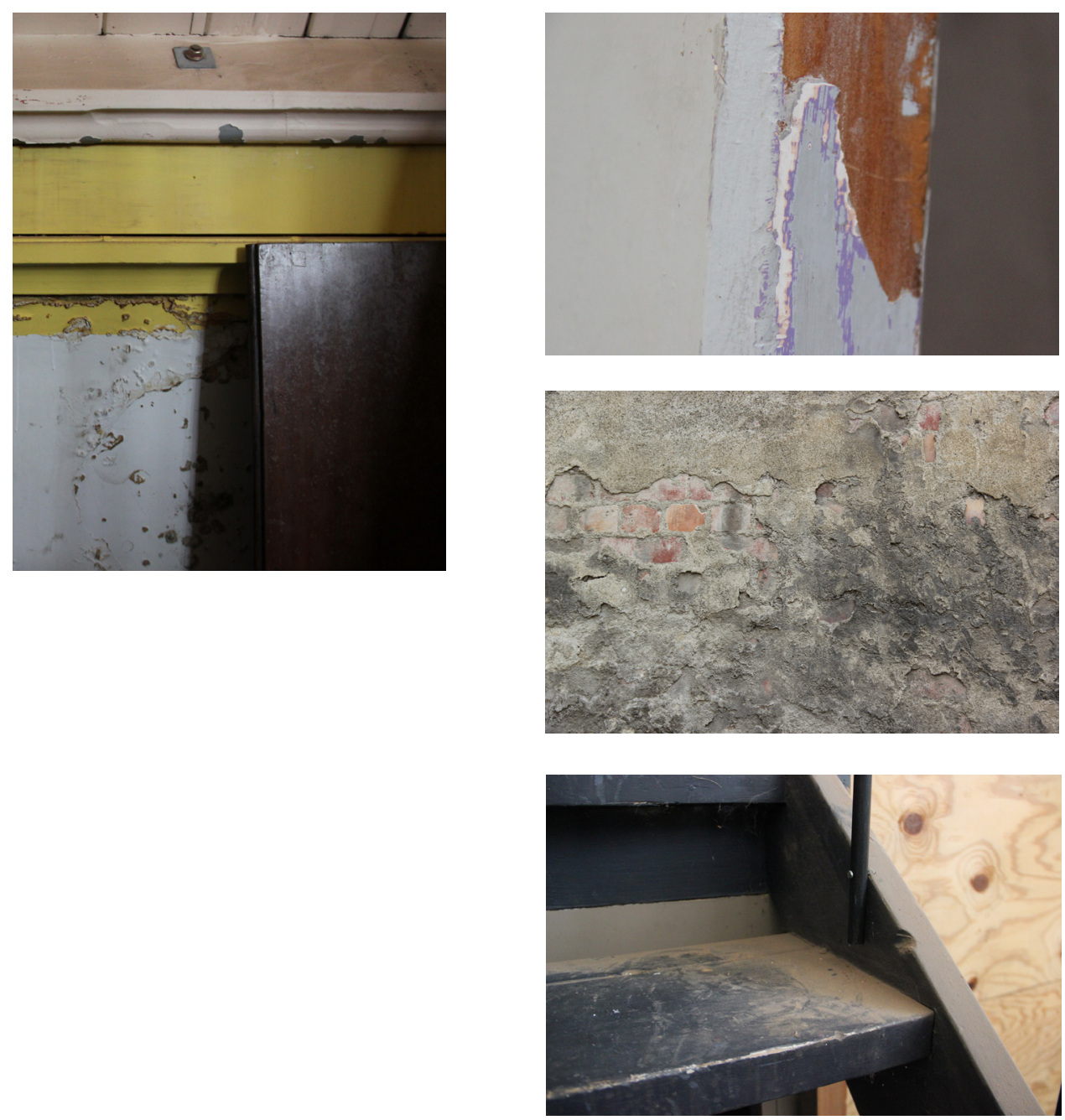

fig. 3.30. Trace of occupation: Surface Patina 

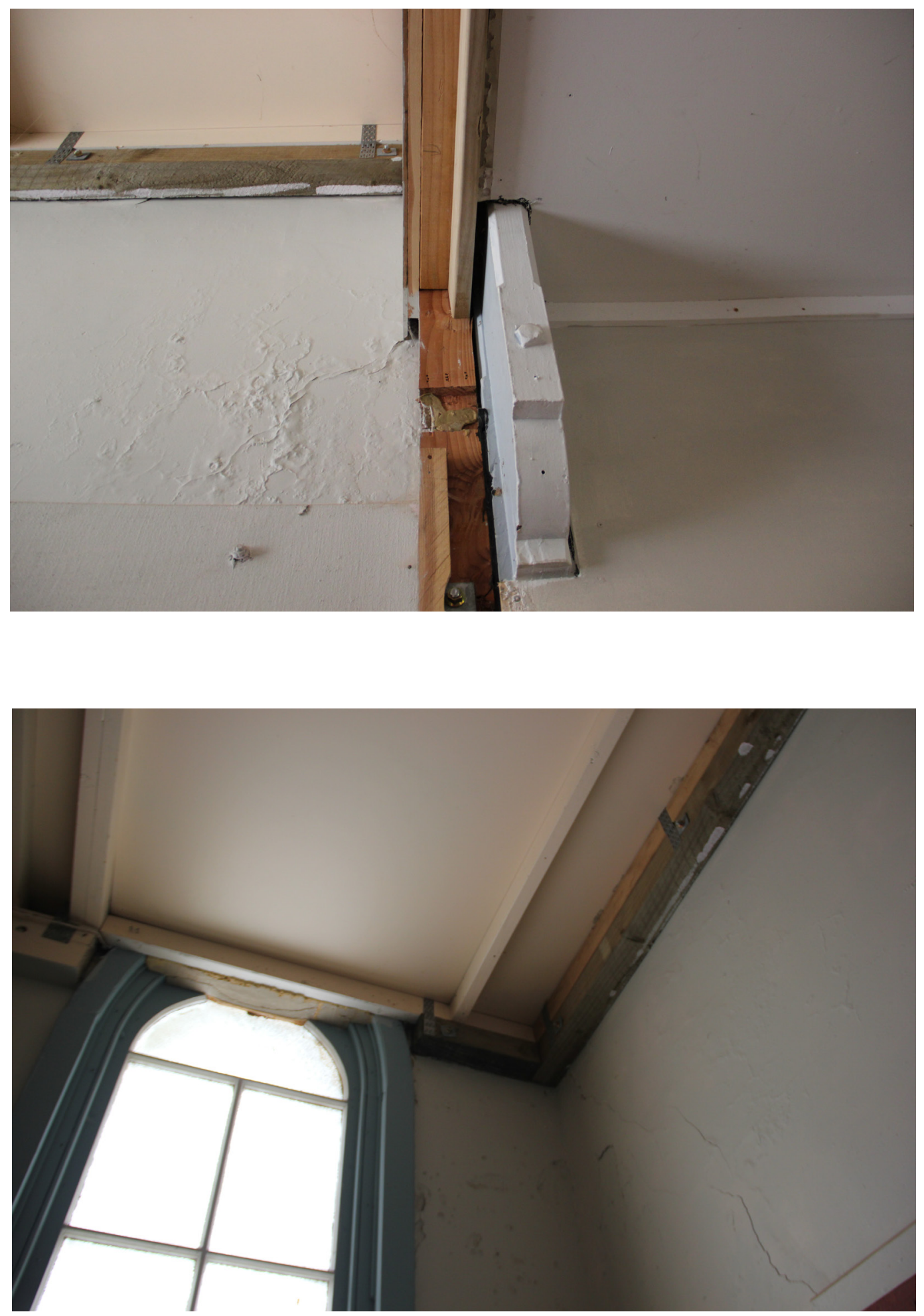

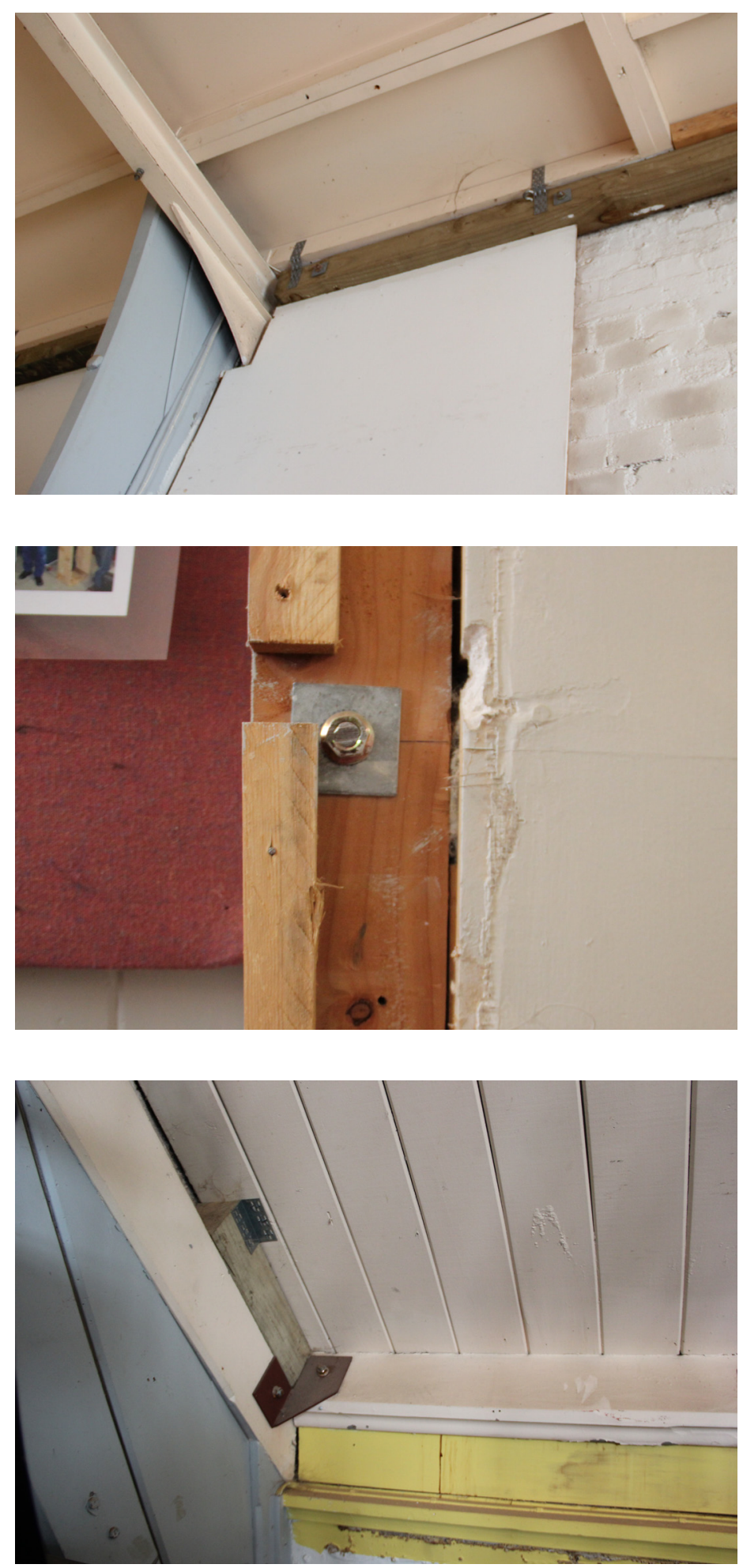

fig. 3.31. (Opposite and above) Pattern of Indifference.

Previous structural retrofits are apparent testifying an enduring ad hoc nature. 


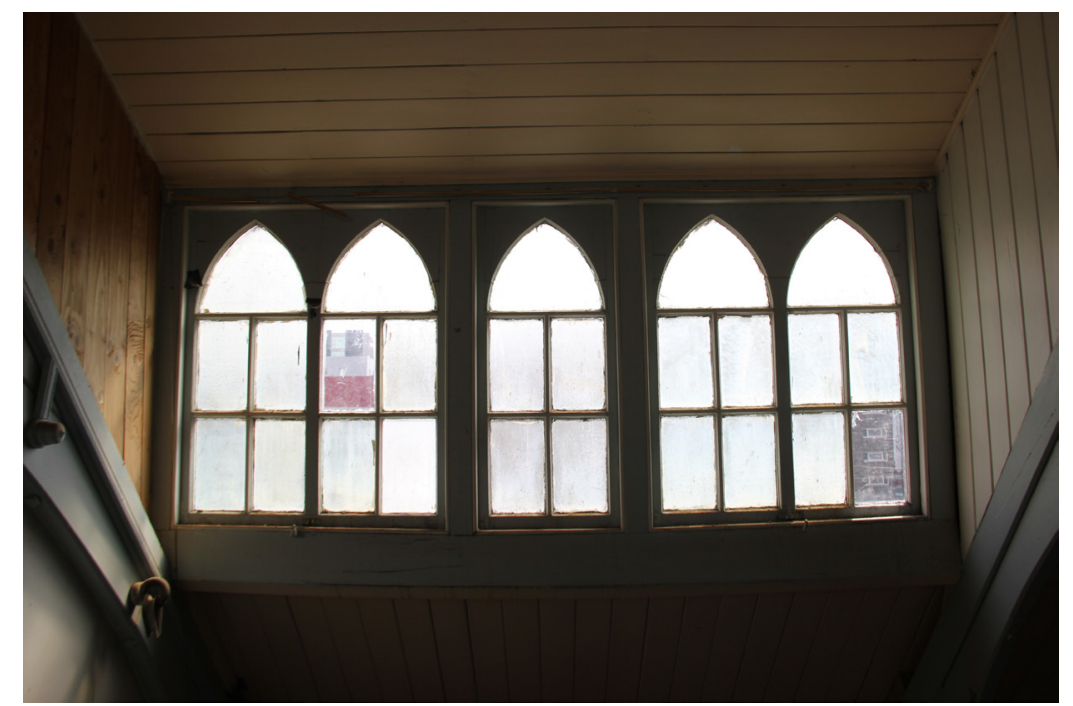

fig. 3.32. Mezzanine windows

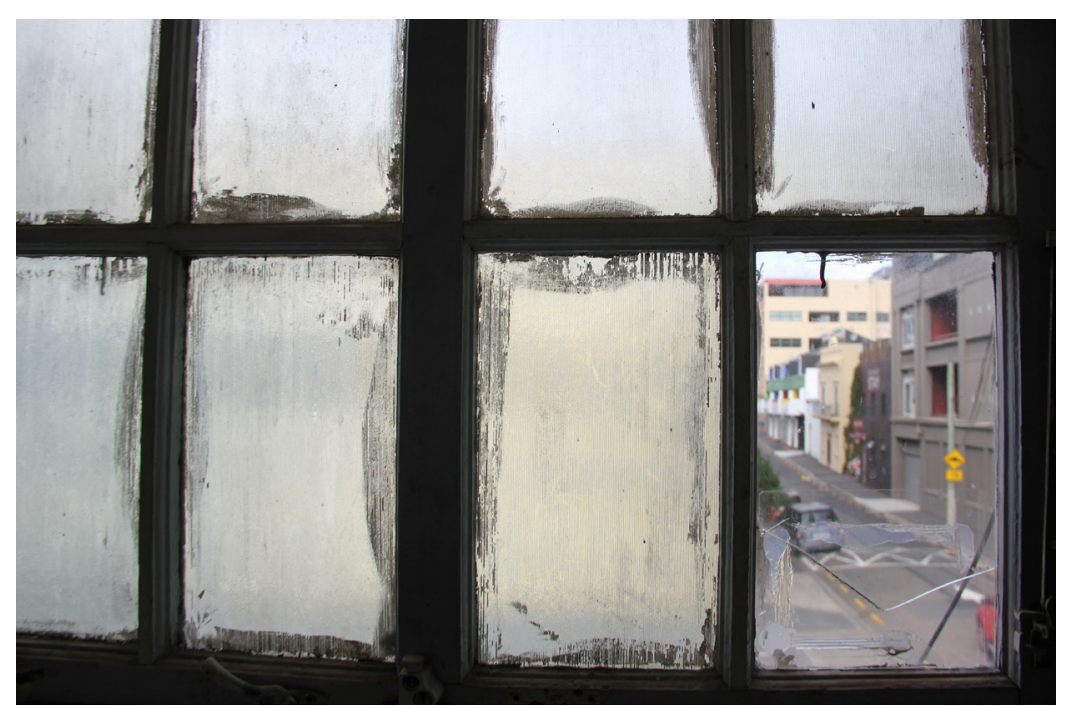

fig. 3.33. A fresh pane of glass reveals the street and a trace of occupation 


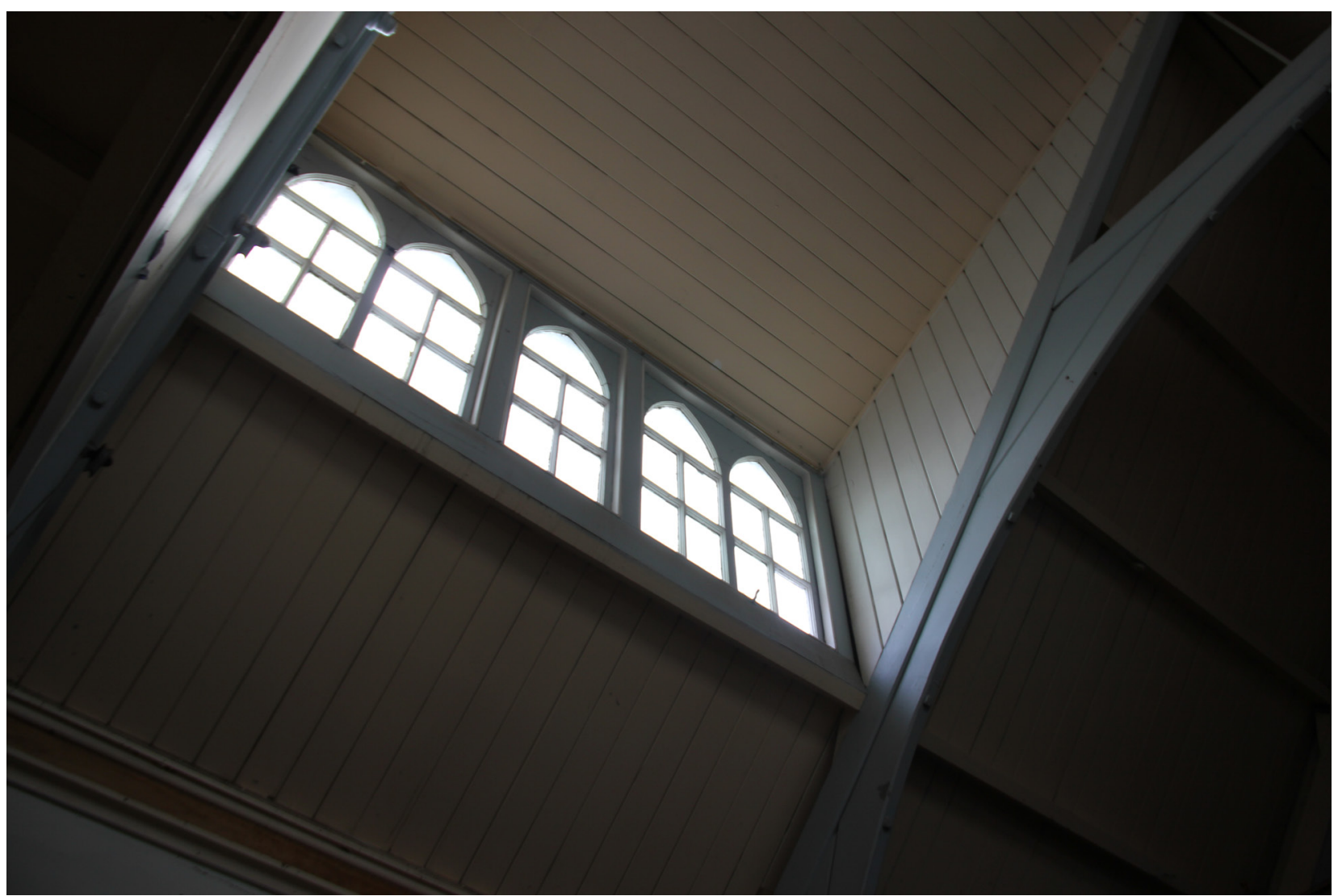

fig. 3.34. The view of the clerestory from the ground floor

\section{The best part}

The windows of the Chinese Mission Hall are the true hero. fig. 3.20-fig. 3.21 Cherished by the gentlemen of the MenzShed, the clerestory captures the restrained gothic style and surely inspired the appeal for the entirety of the building to be included on the New Zealand Heritage Schedule. ${ }^{22}$ The 2007 submission from the Wellington Architectural Centre recognises a notable shift in thinking for the schedule to understand value beyond the facade and it's street appeal. ${ }^{23}$

\footnotetext{
22. (McCarthy 5)

23. (Ibid 1-2)
} 


\section{Timeline}

[dissection of palimpsest]

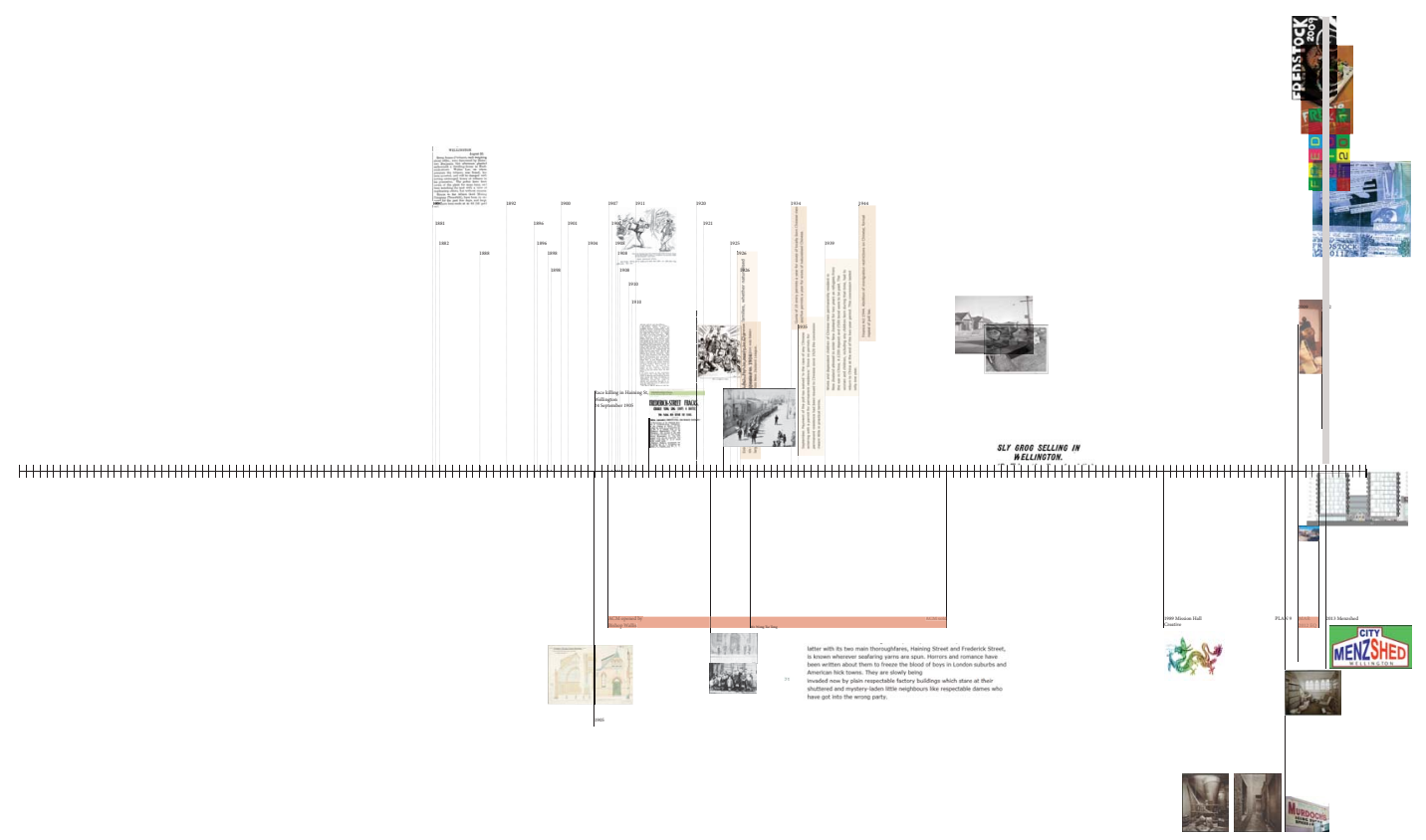

The following timeline presents key episodes of the site's historical narrative: Pre-earthquake, Chinese Occupation, Demolition, Artists, Menzshed. Throught the years, the Chinese Mission Hall has been a refuge for nomadic individuals. The building has nurtured various communities, a place for free-expression, a place to belong. 
4

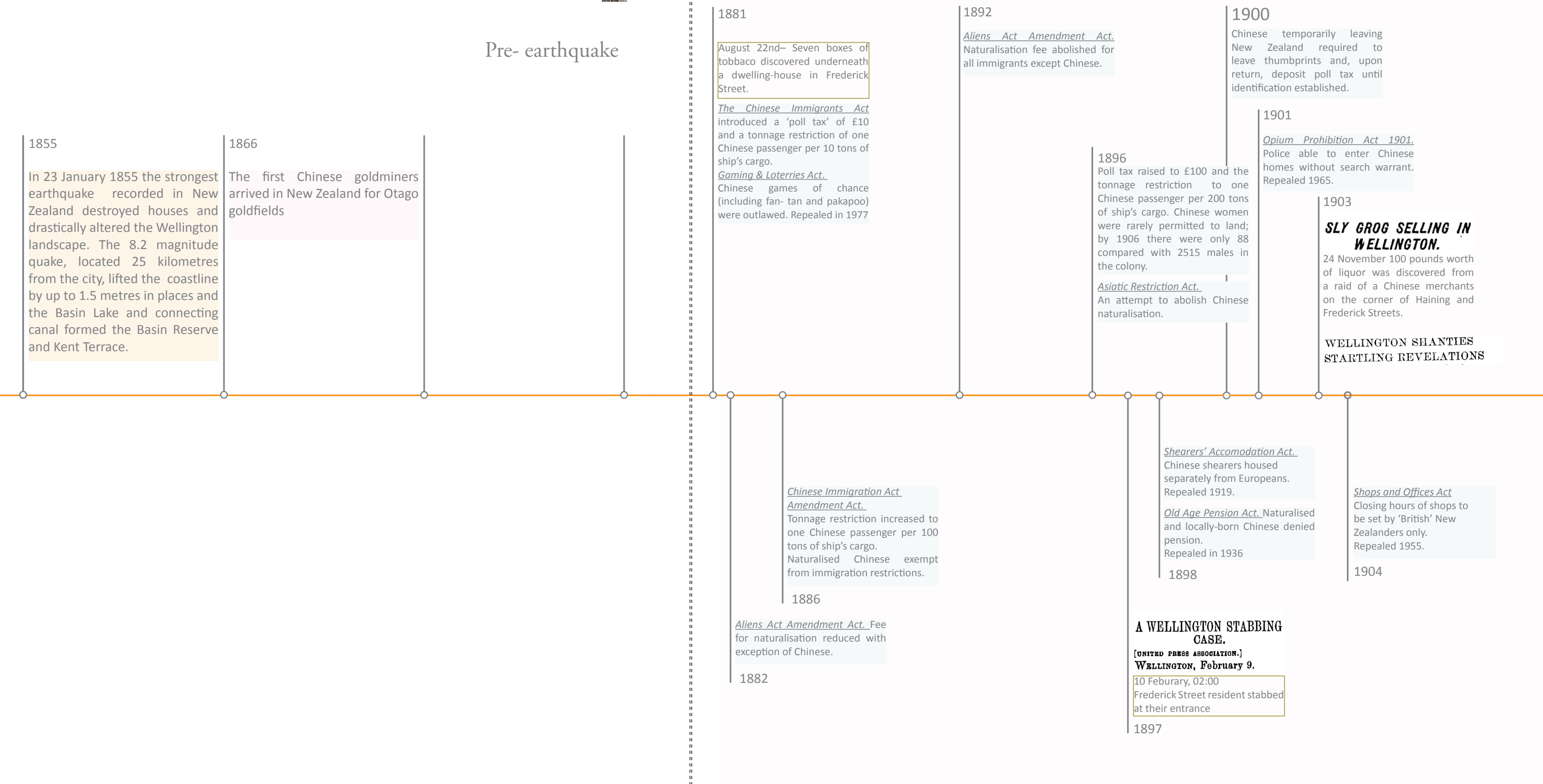

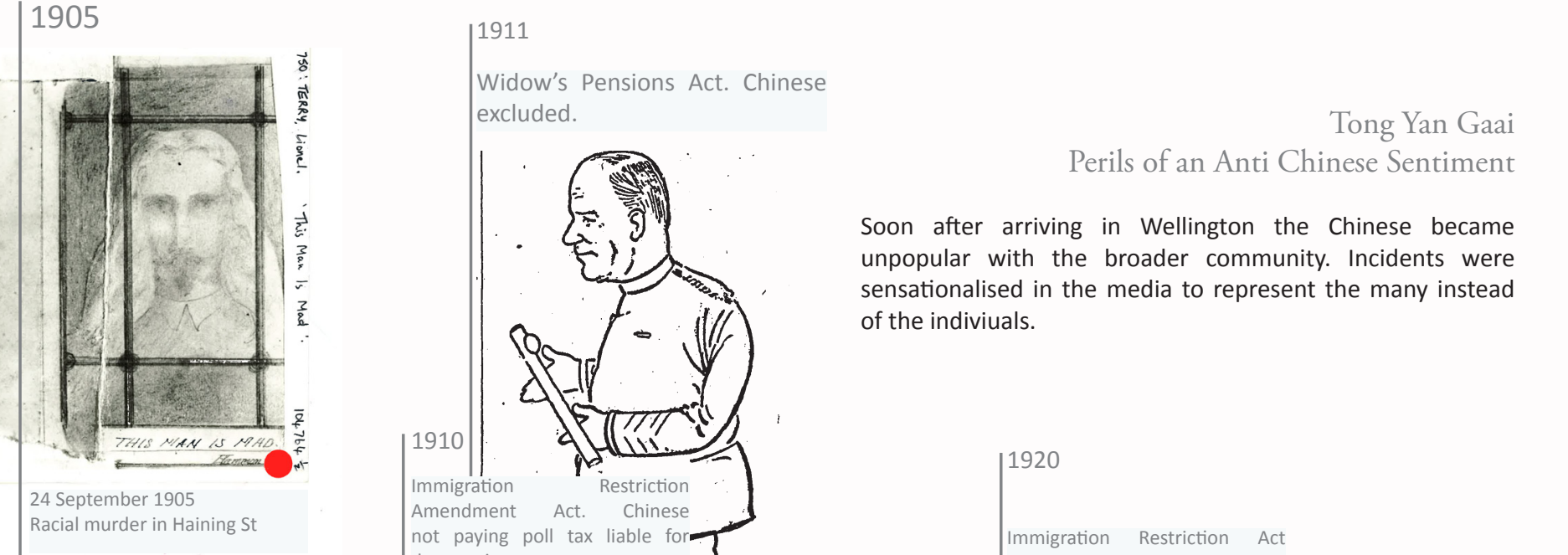

som

$=$

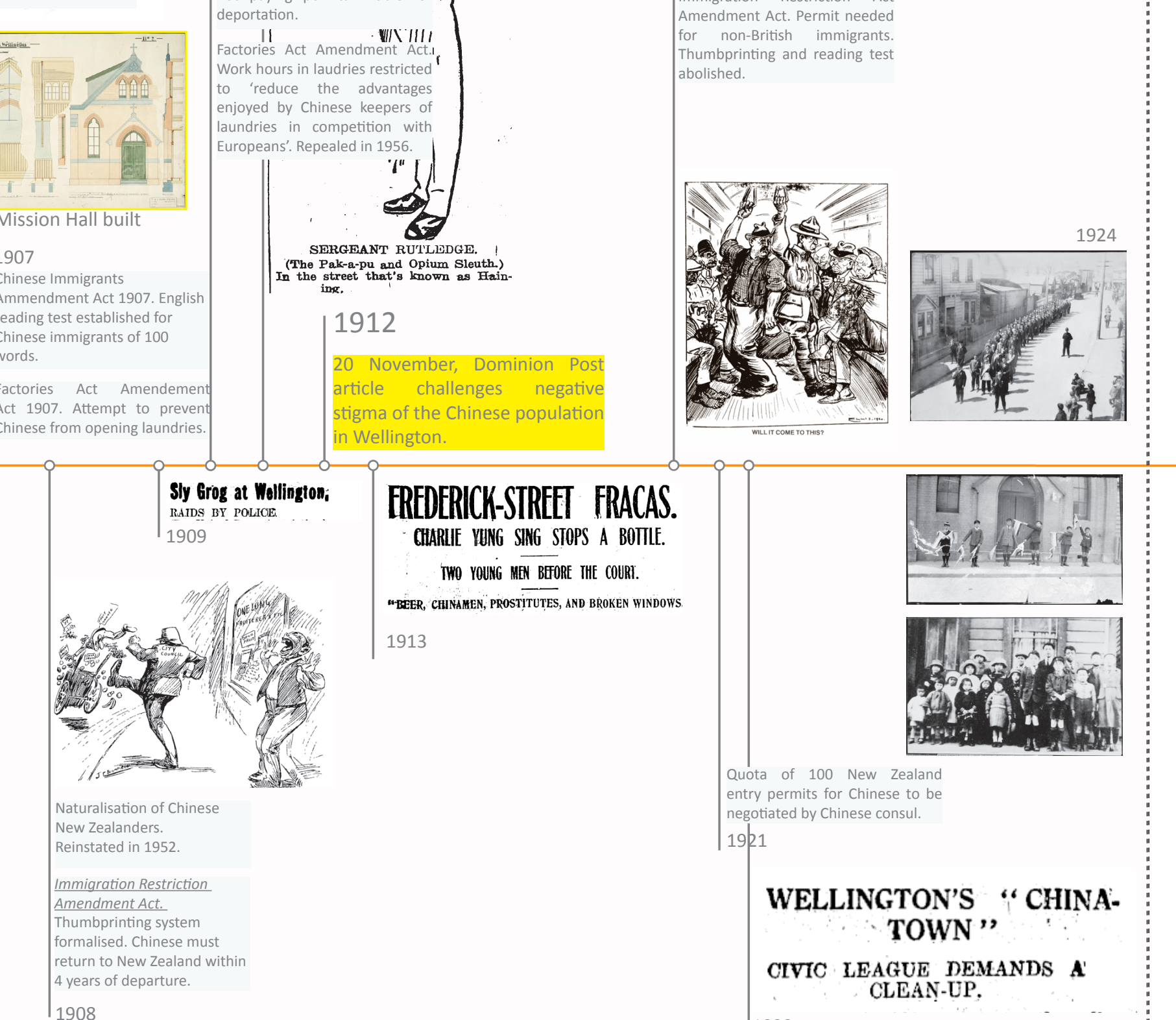

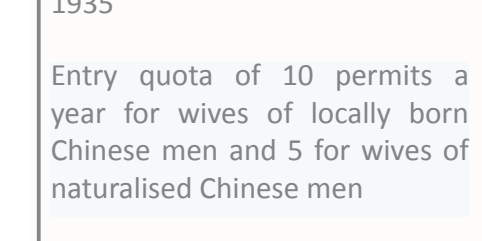

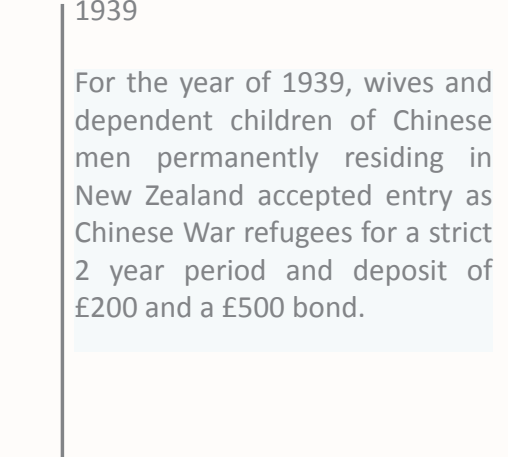




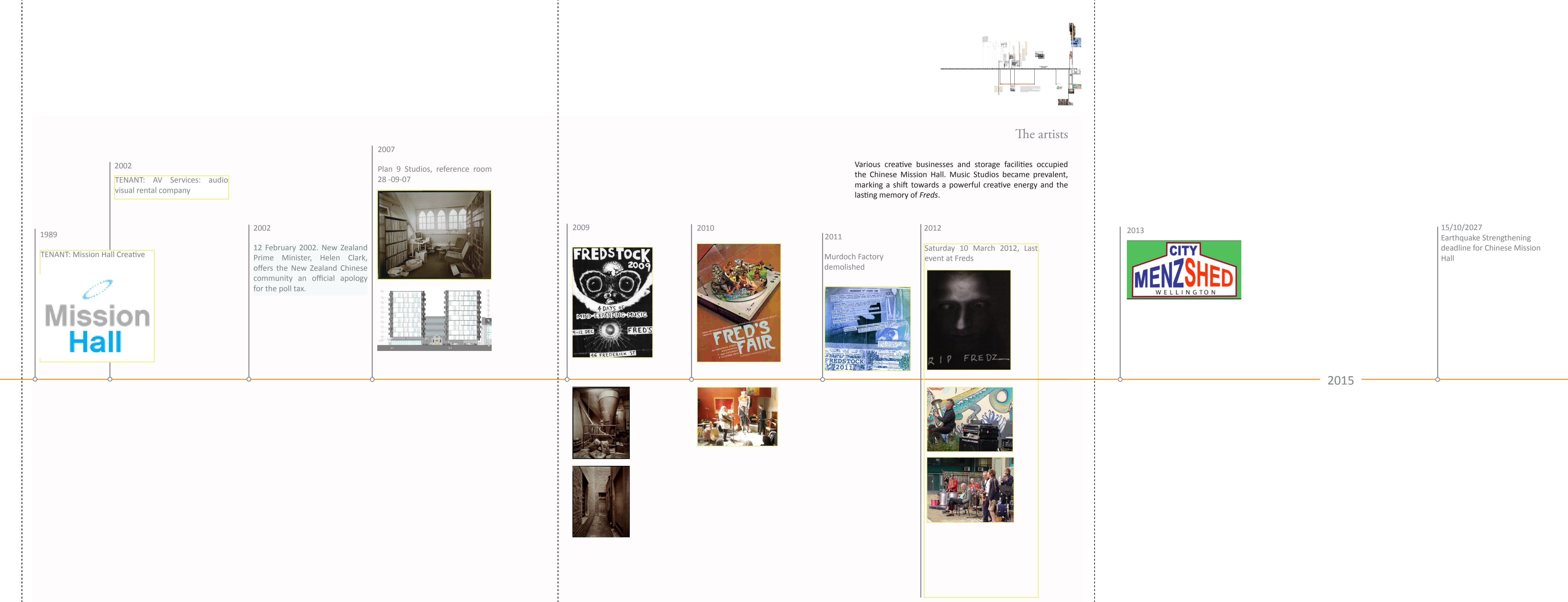




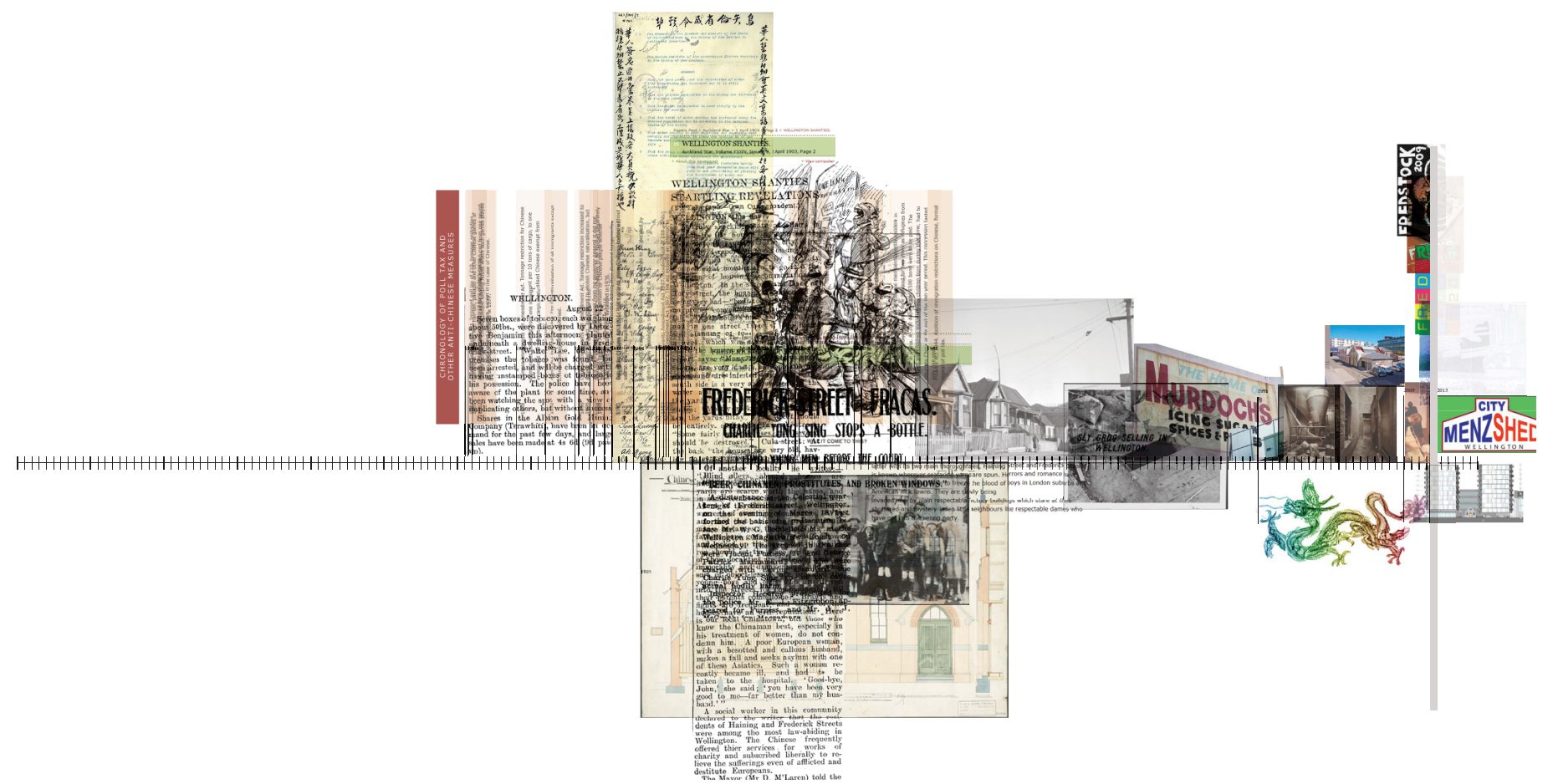

fig. 3.35. Timeline composition reenters the findings into a strata, expressing intensity across key moments in the behavioural history of the site. The process revealed the extent of the Anti-Chinese Sentiment period opposed to my lasting impression of Freds. The timeline was a key point in the research where the potential of layering as a theoretical driver was realised. 


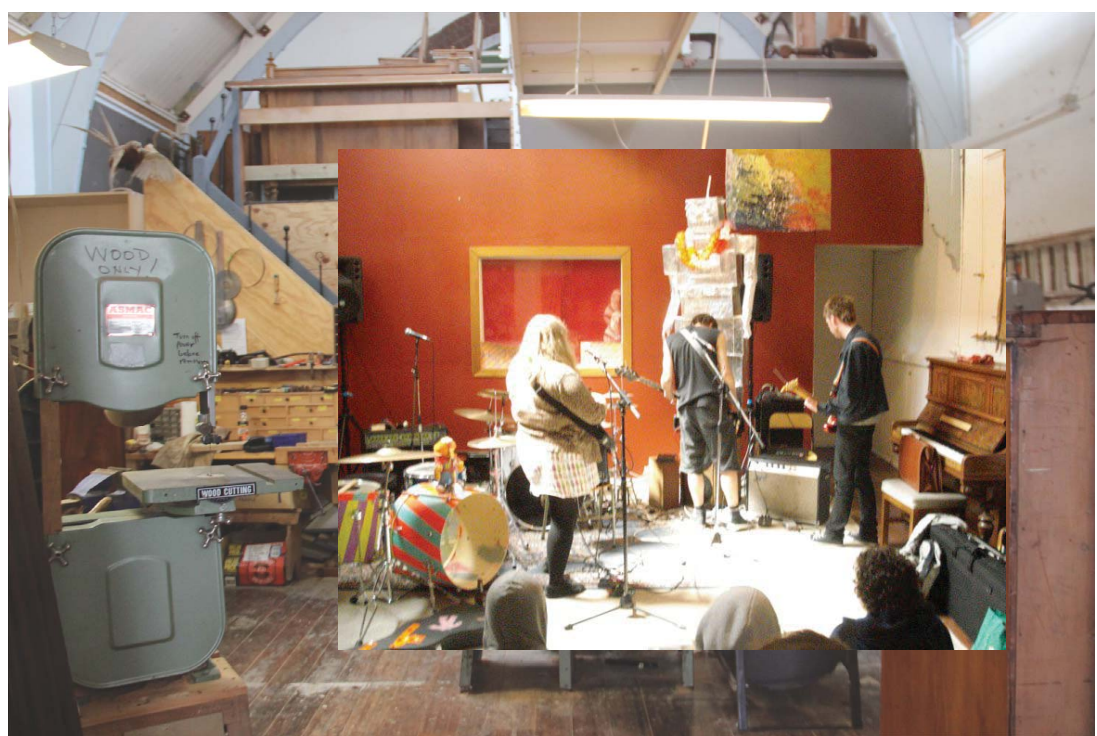

fig. 3.36. Composition 2015, 2010

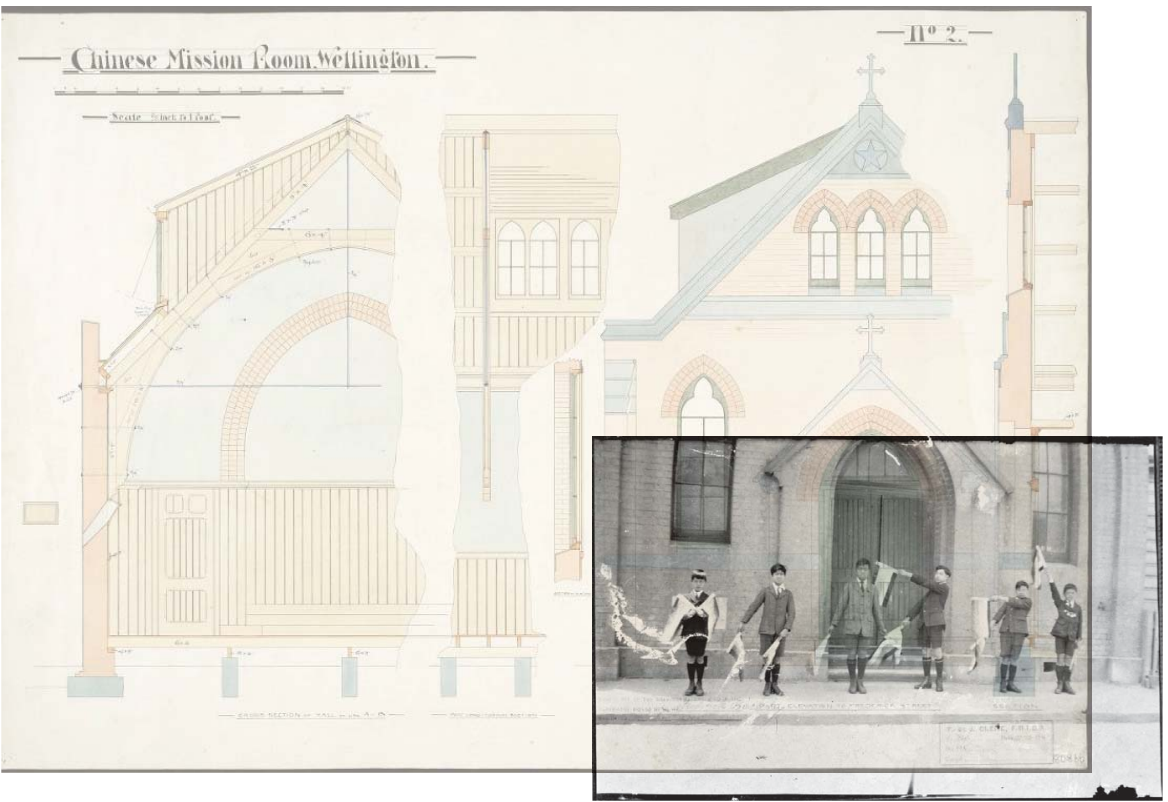

fig. 3.37. Composition 1905, 1922 


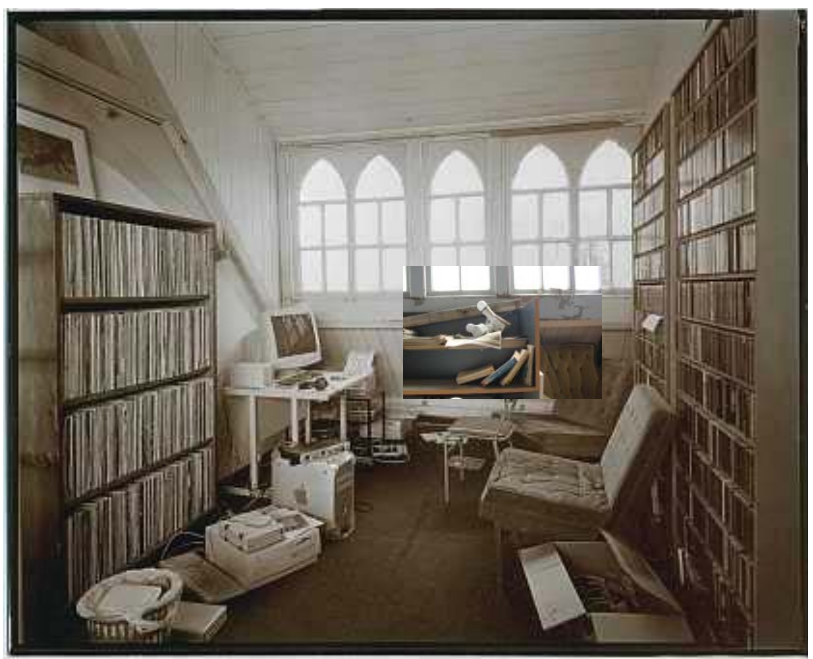

fig. 3.38. Composition 2007

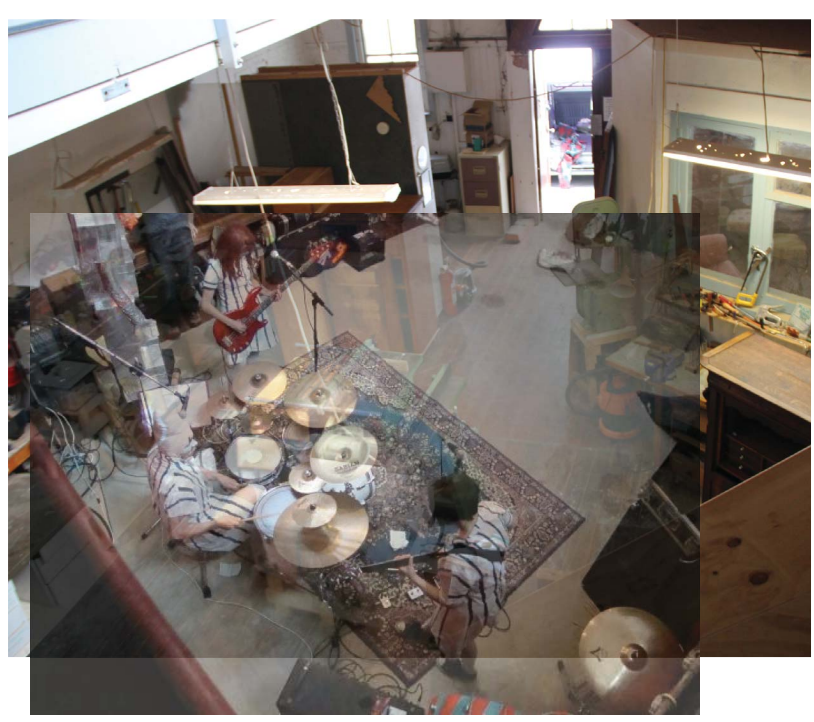

fig. 3.39. Composition 2015, 2010 


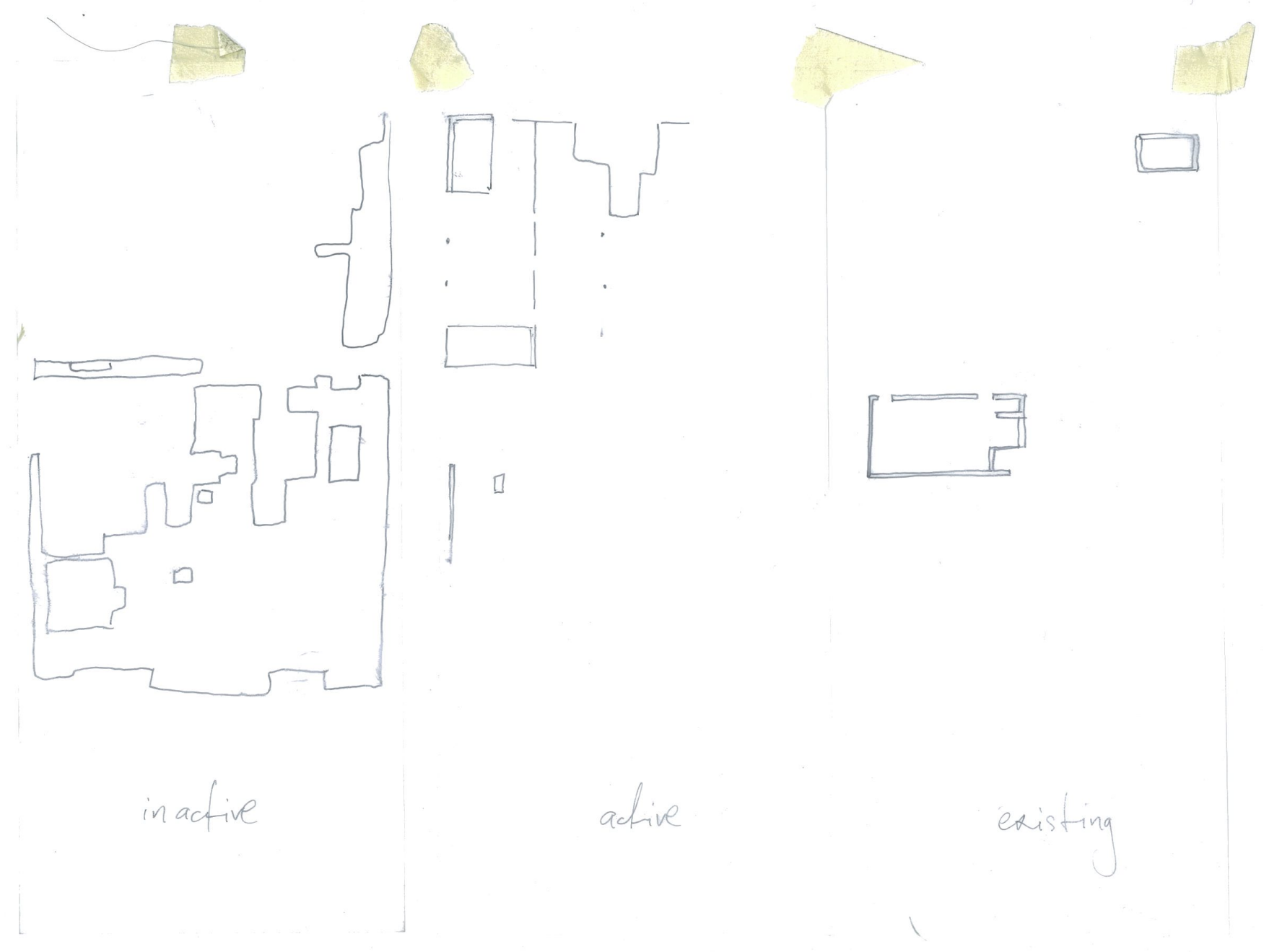

fig. 3.40. Field of Intensities - classified into 3 conditions: In-active (no building occured); Active (multiple alterations); Existing (Chinese Mission Hall and substation) 


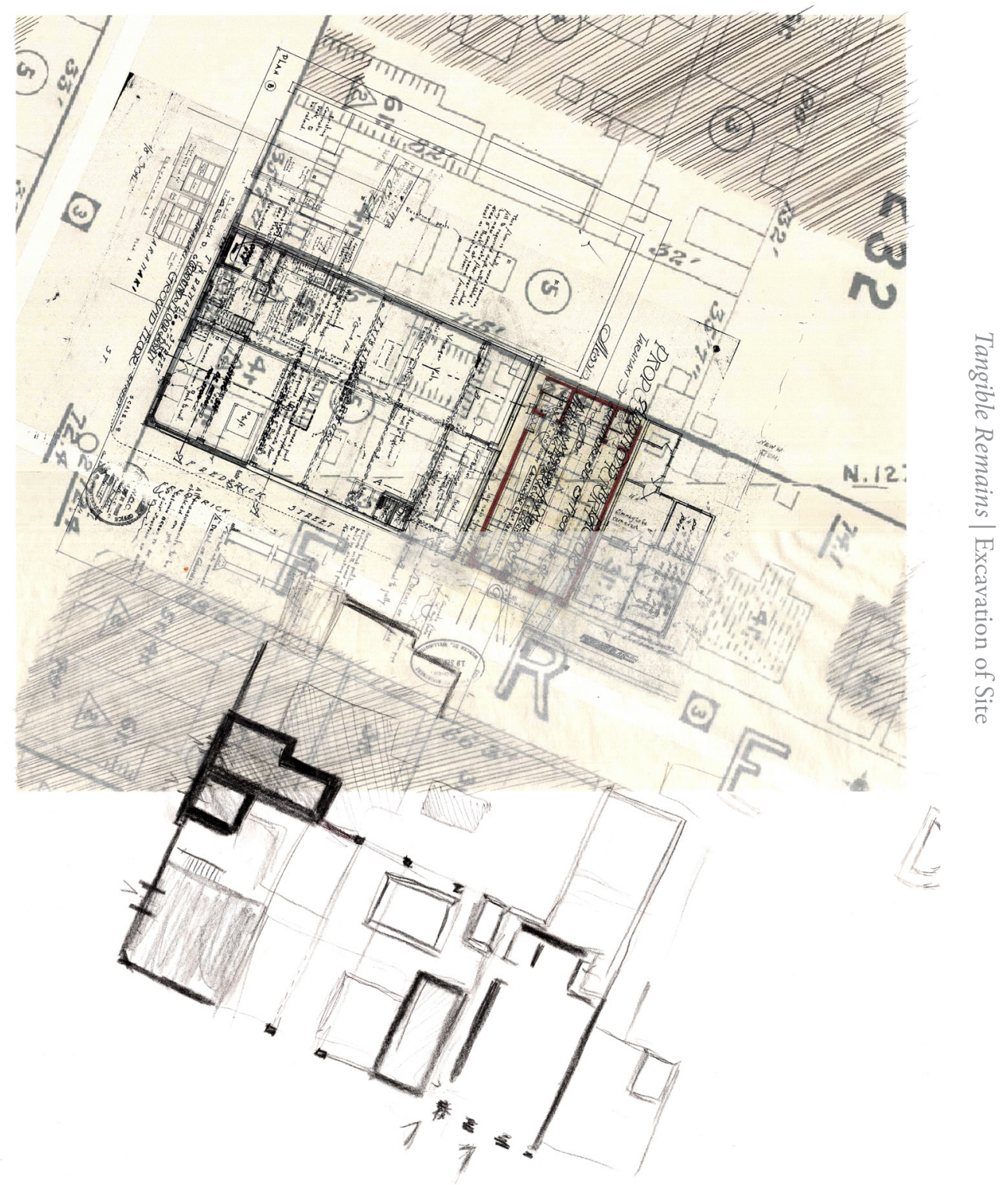

fig. 3.41. Fast-track Panel 1 of 5: Construction documentation superimposed. Lines of intensity/ high activity 'mapped' (Deleuze Guattari) on butter paper and staggered below. 


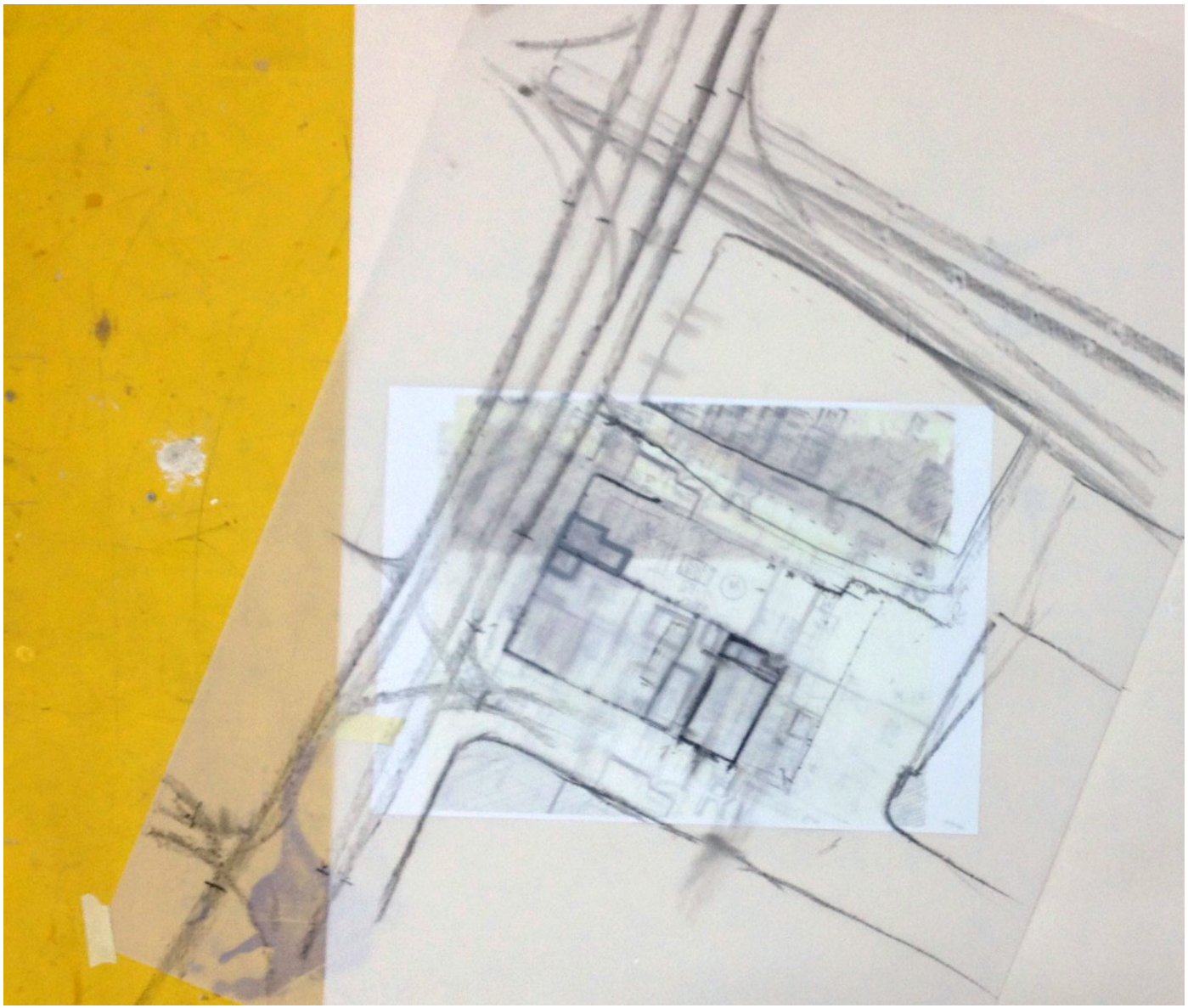

fig. 3.42. Study of vectors; existing patterns of movement; urban rhythm 


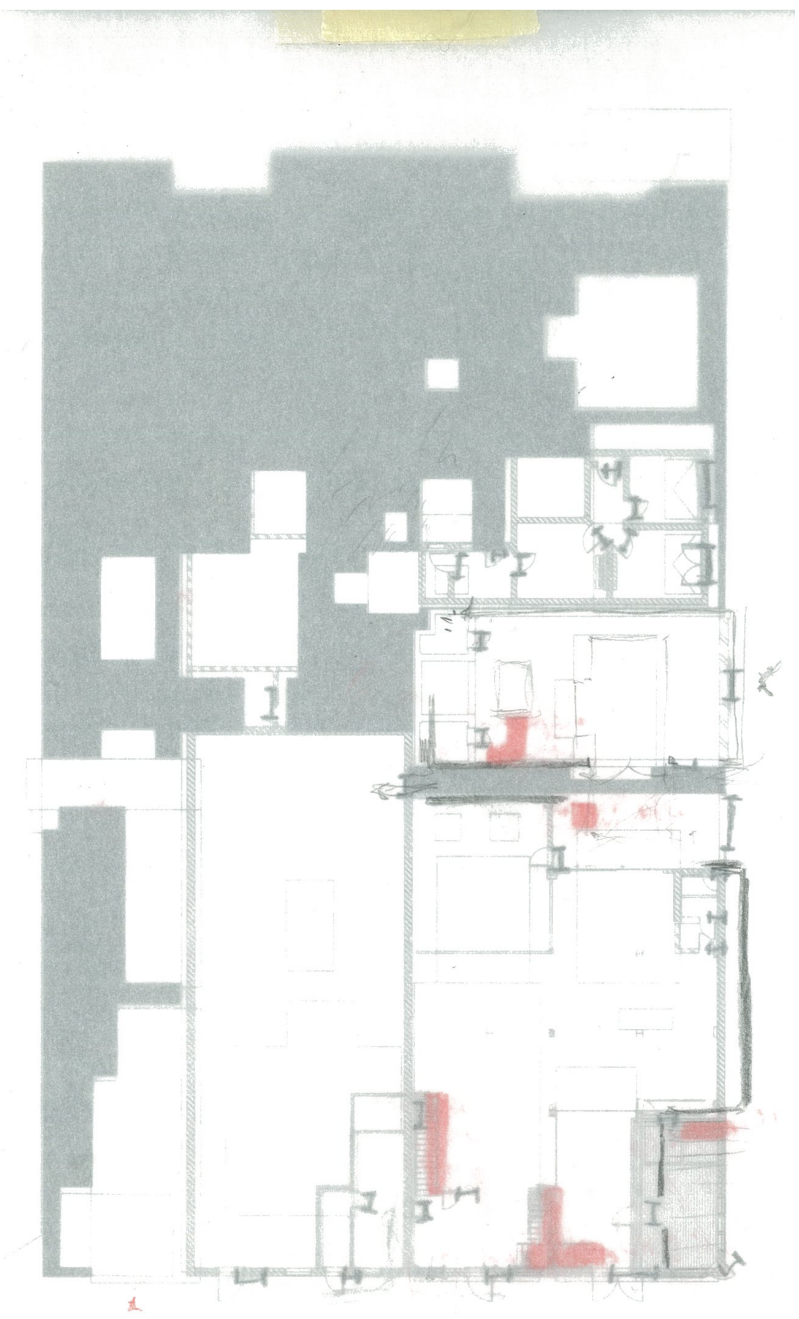

fig. 3.43. Study of vectors; previous patterns of movement and threshold 


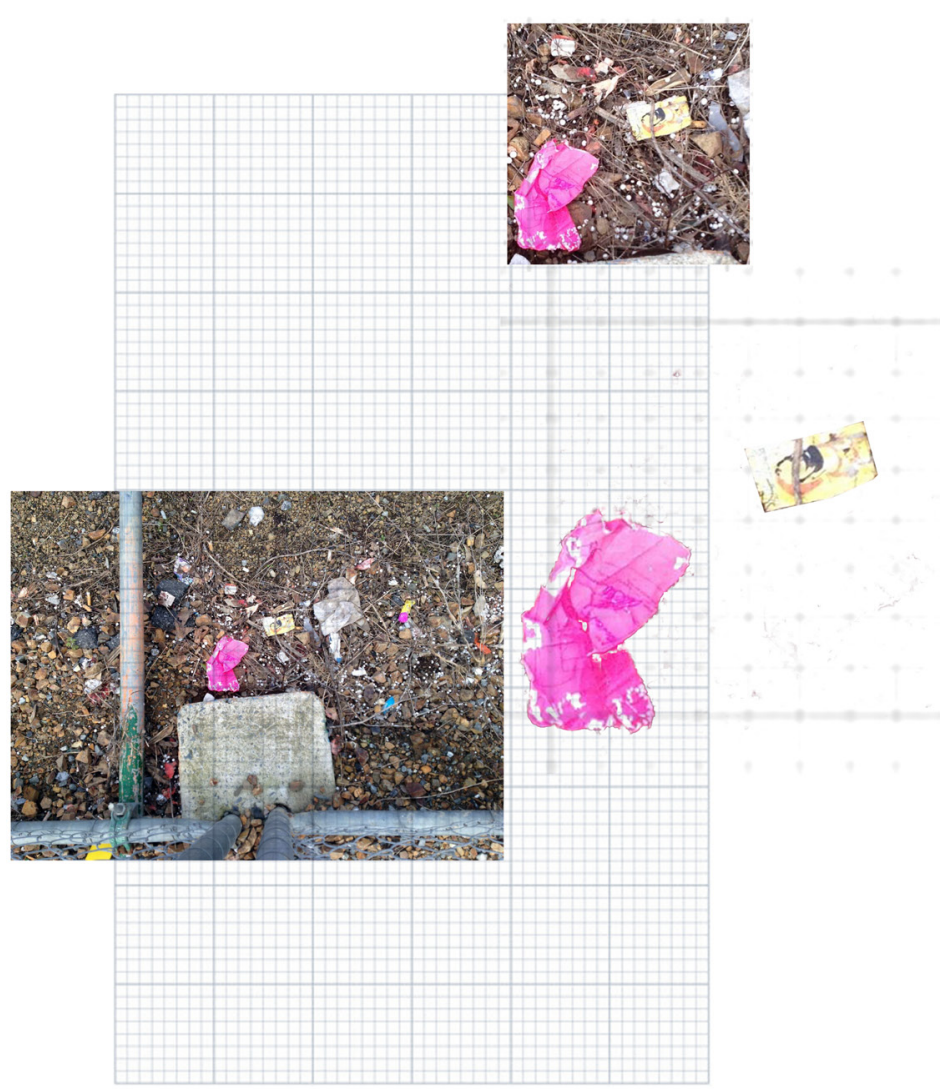

fig. 3.44. Traces of Activity. Collage of found objects. 


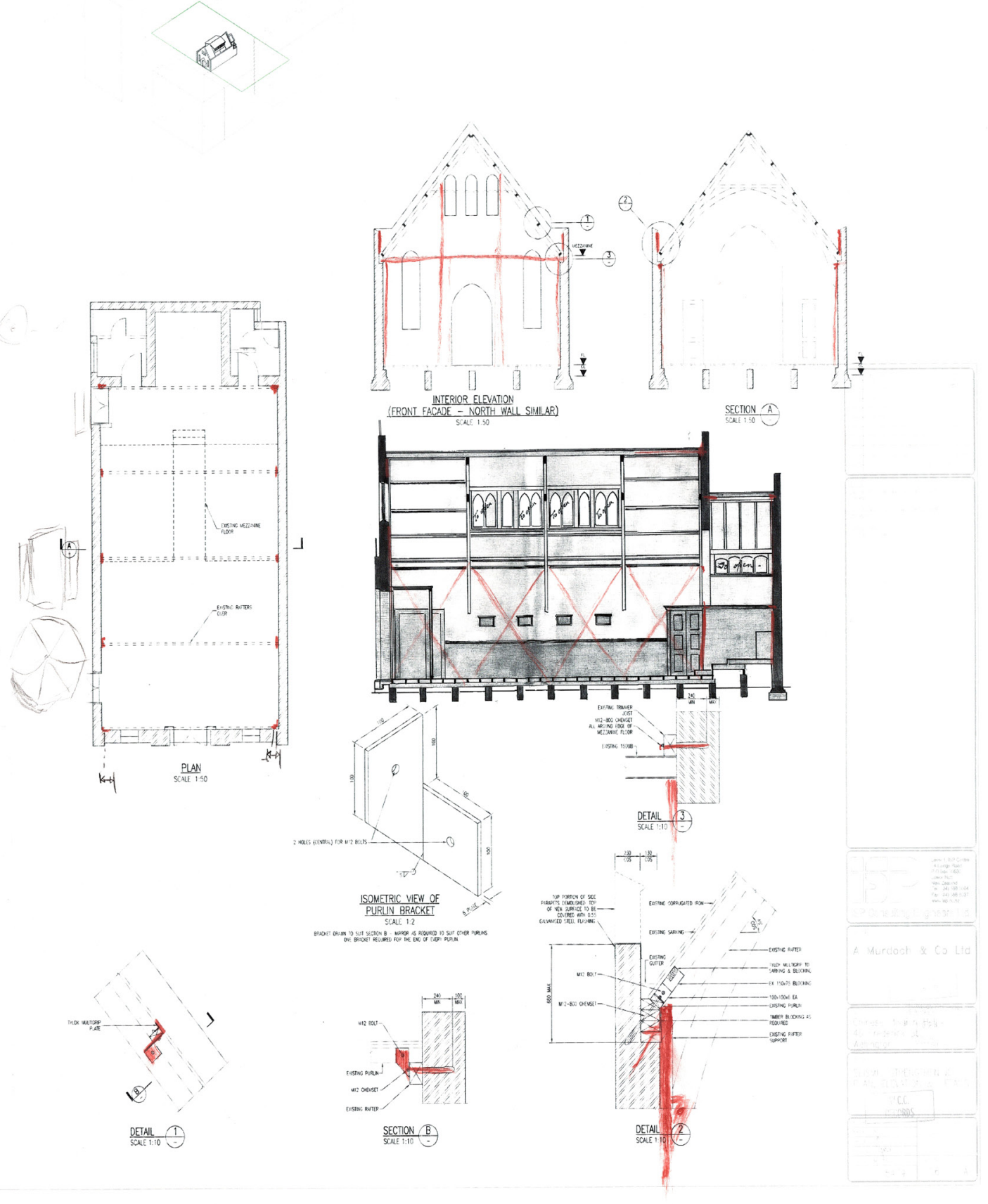

fig. 3.45. Fast-track Panel 2 of 5: Minimal Intervention, present condition. Panel includes an study of the structural layers and a seismic strategy that continues the legiblity of the new with the existing but enhances the architectural qualities. 

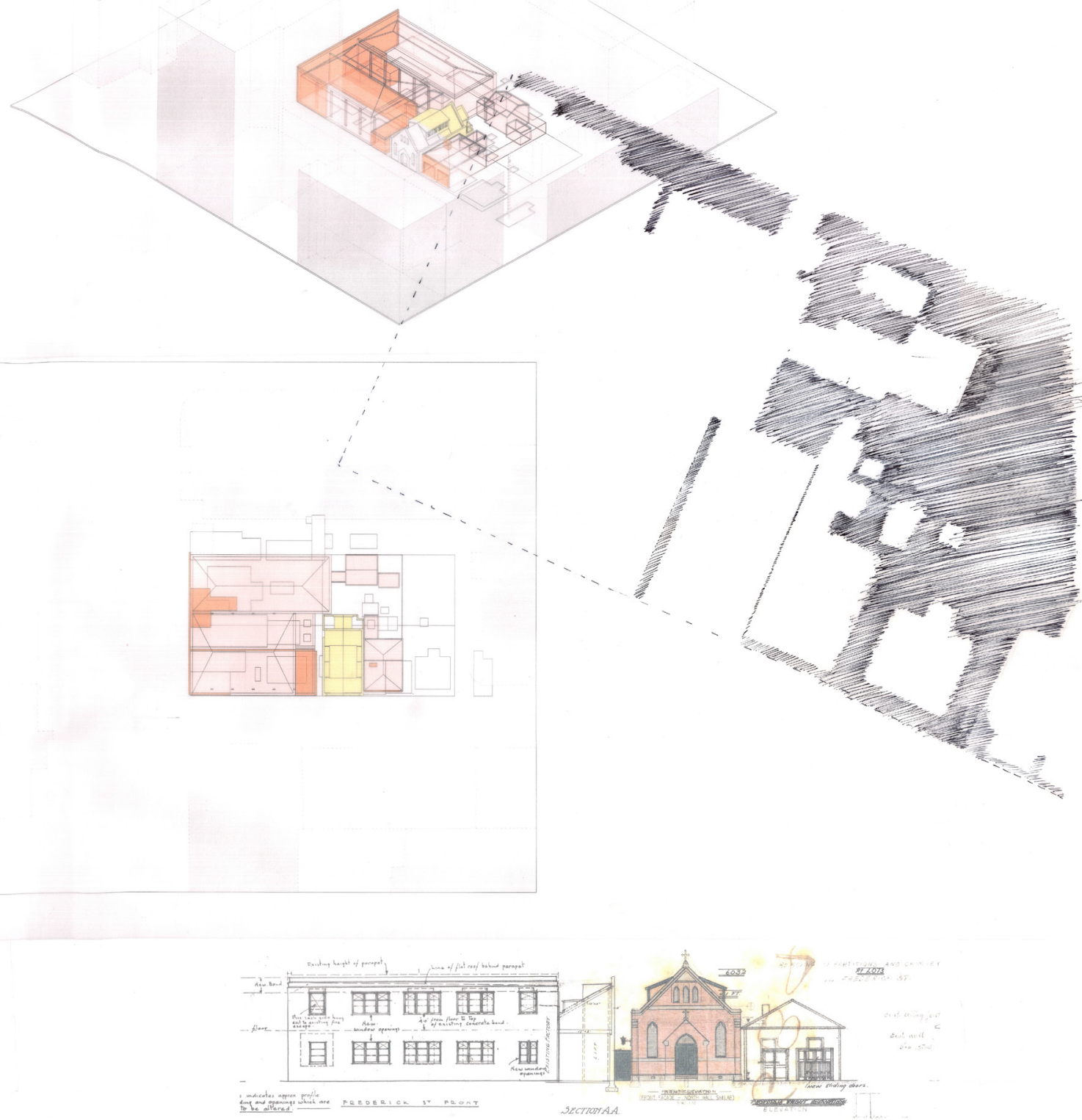

fig. 3.46. Fast-track Panel 3 of 5: Design Phase Two. A study of previous buildings and extruding the lines of intensity 

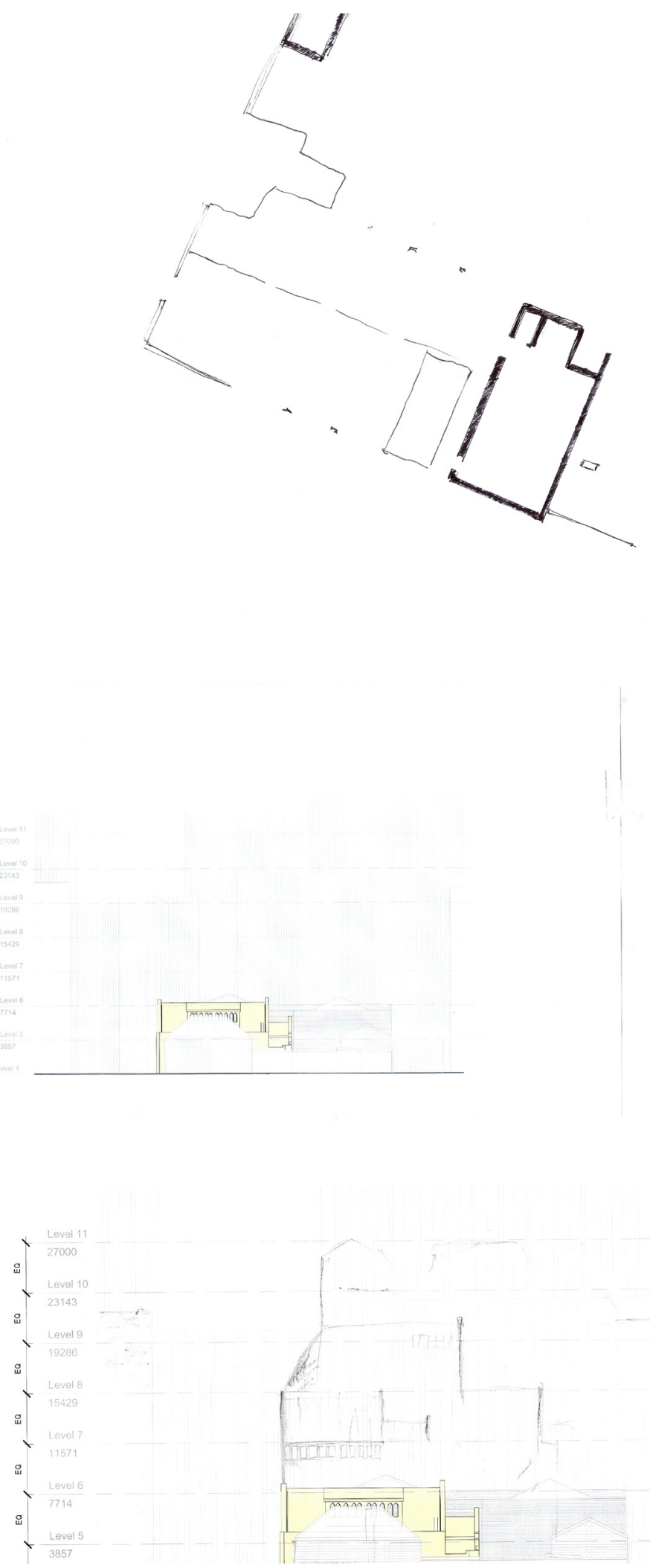

fig. 3.47. Fast-track Panel 4 of 5: Design Phase Three. A study of future potentials; designing to the maximum height restriction with a light quality inspired by the Chinese Mission Hall windows. 


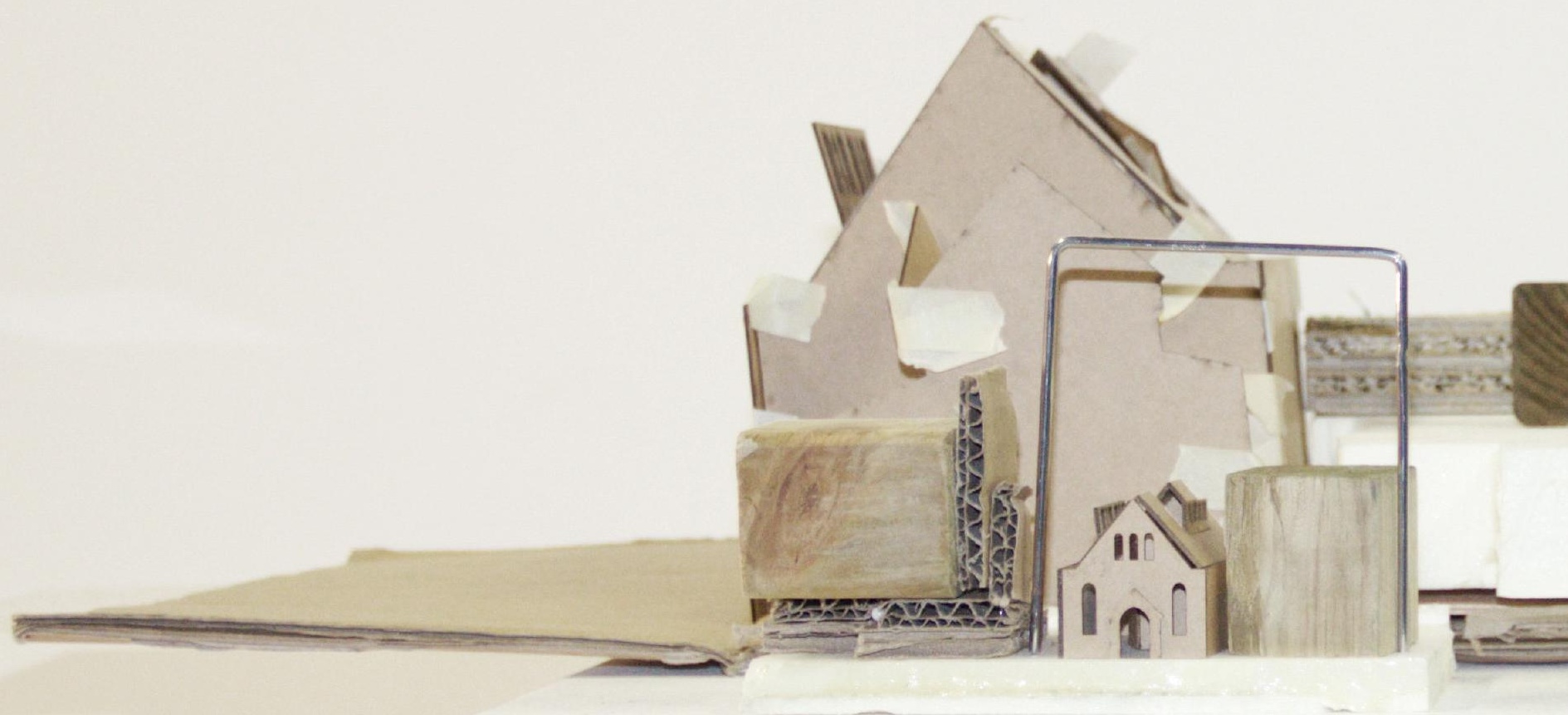


fig. 3.1. (Previous page) Assemblage of models waiting to be documented

fig. 3.2. (Right) Diagrams of Design Phases, introduced on page 7 


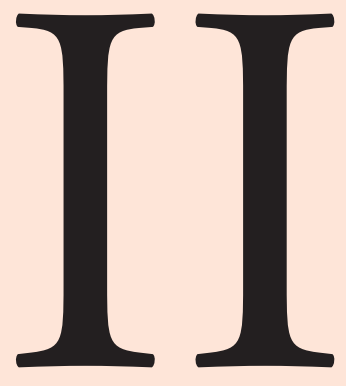

3 Test Buildings 
Program: Chinese Garden

Scale: Micro

Condition: Present Day

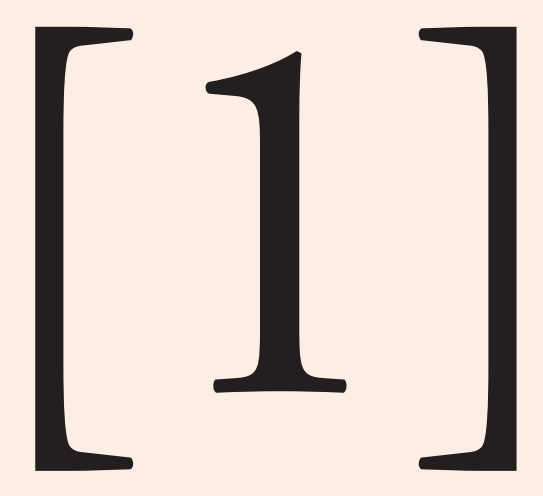

Design Phase 1

low scale 


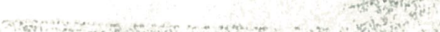

fig. 4.1. Preliminary sketch of Design Phase One 


\section{Four| the ground plane}

This preliminary design phase explores a low scale program of a Chinese Garden to give precedence to the existing condition of the site ${ }^{\text {fig. }} 4.1$ and to the history of Chinatown/Chinese occupation. How can the design articulate layers of intensities within the site whilst preserving the existing singularities? Primarily this concerns the vastness of the unoccupied site, prompting an intervention peripheral of the Chinese Mission Hall - continuing as a Menzshed. Traditional design principles of a Chinese Garden are used to explore the extractions from the site's history and the subtleties of the existing condition; an investigation of the ground plane.

The program was selected in response to a Chinese Garden proposed to be built in 2016 on Wellington's waterfront (see page 90). The thesis recognises an opportunity for a more discrete and contextually appropriate location that realises the Chinese design principles. The contemporary scheme is reflected on in relation to traditional and contemporary Chinese Gardens in China and more specifically a traditional example in Sydney, Australia. The degree of cultural exchange is a key question in the design of expatriate Chinese Gardens which are often developed with support from the relevant Chinese sister city. This discussion draws parallels with the broader research inquiry with the opportunity to express this dialogue in a hybrid design. This section will develop a clear position on this exchange to form constraints for the design test. 

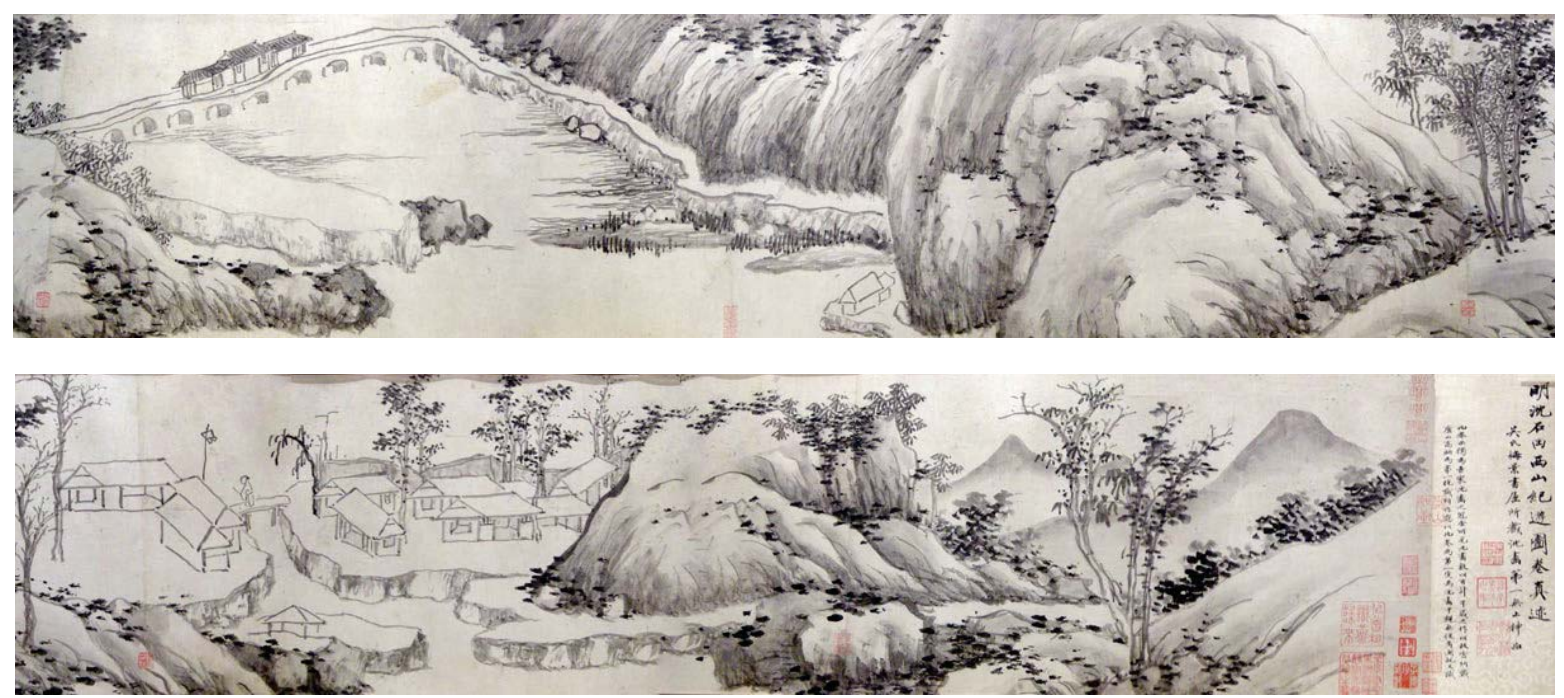

fig. 4.2. The arts are closely tied in Chinese tradition. As the garden, painting uses dynamic composition of foreground and selective views. The priority lies in capturing the essence of the landscape as opposed to a detailed recording.

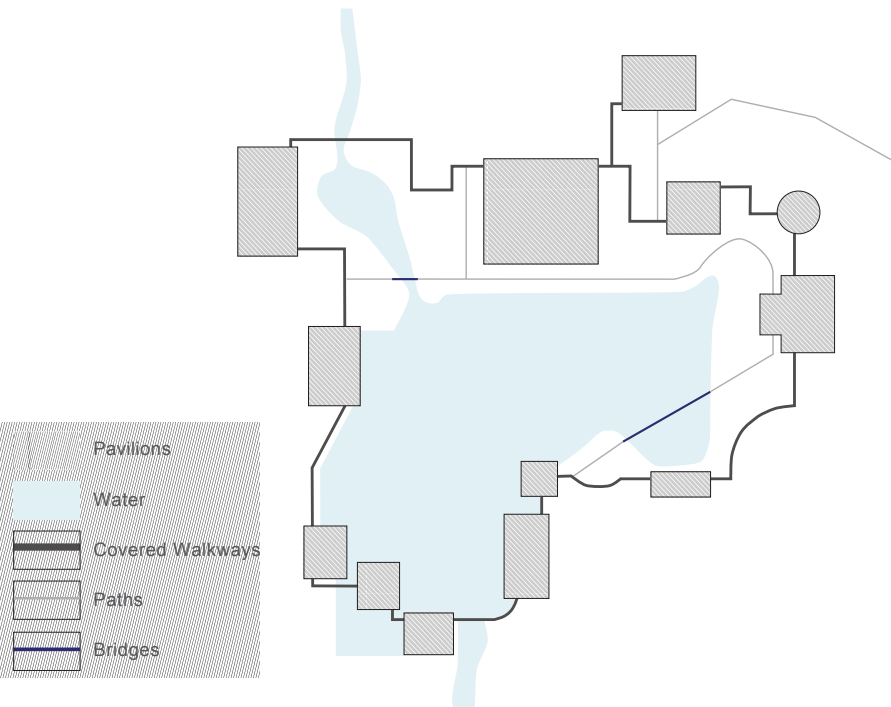

fig. 4.3. Plan diagram of Garden of Harmonious Interest, Beijing. Paths twist between pavilions to make the extent of the garden seem larger than it really is. 
The purpose of a Chinese Garden is to harmonise the relationship between man and nature. The garden takes you to a new world, channelling the essence of an entire landscape into a confined arena. Each component is embedded with intensities of representation and precise purpose in the garden. Framed views and objects are gradually revealed and transformed as one proceeds through, transforming again upon returning in a different light or season. Like a painting, the foreground and background of each aspect of the journey through the garden is carefully composed. Often from the water's edge, a key view is across the lake towards the mountain and beyond. After ascending the mountain (the highest point of the garden) the view over the lake is reversed and the largest aspect of the garden is revealed. 'Borrowed scenery' is used as a strategy to extend the view beyond the garden, yet at no point is the entirety of the garden revealed. Often the physical extent of the garden is much smaller than perceived. In this, the garden expresses its infinite scale, a capsule of the universe. 
Propensity, engaging the involuntary

Architects and even many landscape architects persist in perceiving the landscape as a visual setting for the built object, responding merely to the shape and colour of the hills, trees and flowers within the landscape, as opposed to the processes that animate it - Ann Spirn ${ }^{24}$

Contemporary Western discourse renders Chinese gardens as series of framed views; a scenic pathway. Research by Stanislaus Fung guides the thesis to engage the Chinese notion of propensity, shi, in the critique of this static narrative. Fung recognises Ann Sprin's aim to restore a sense of temporality and James Corner's focus on the experiential, tactile dimension; but aptly advocates for the role of the static. ${ }^{25}$ The discussion of propensity helps to understand the distinction of static and dynamic and the significance of considering how one is drawn between key points.

\section{"The term shi oscillates between the static and the dynamic points of view; in any given configuration there is an inherent propensity for the unfolding of events" Stanislaus Fung}

Deleuze himself explores ideas of propensity with his studies of film. He developed Henri Bergson's, previously overlooked, understanding of the moving-image in cinema to define three types of cinematic images: 'perception-image', 'affection-image' and 'action-image'. The pair believed "perception is fundamentally affected by the body's potential action upon its surrounding objects. Perception depends on the individual's will to act, her potential action in space and her awareness of this potential". ${ }^{27}$

To create these potentials in design it is fundamental to animate the spaces during the design process; what does the subject see/hear/feel/ taste/smell as they move through the space.

\begin{tabular}{ll}
\hline 24. & (Spirn 39) \\
25. & (Fung 143) \\
26. & (ibid 144) \\
27. & (Manolopoulou 32)
\end{tabular}




\section{Project Review}

Chinese gardens present opportunities for cross cultural exchange and contemporary heritage discussion. Gardens following traditional design principals and gardens challenging their relevance in contemporary built environments are found in China and abroad. This section will analyse a spectrum of Chinese Gardens in China and Australasia to formulate my approach.

\section{Contemporary China}

Nestled between two UNESCO ${ }^{24}$ heritage listed gardens, I.M Pei's Suzhou Museum is a contemporary response to the masterpieces surrounding. The building and garden (understood as one in eastern culture) demonstrate a delicate interpretation of the traditional fundamentals through a contemporary but irrefutably Chinese language; "a contemporary ambience, yet with a spirit that seems to have its roots buried deep in 2500 years of local culture" ${ }^{25}$. In critique of the traditional framework, Pei crafts his own palate from traditional colours, materials and strategies with modern technology. The use of artificial rocks as a suggestion of mountain ranges is preserved in the design yet without the jagged angles but clean cuts entering the water. Although losing the imperfection of the traditional story the new composition translates to the modern context.

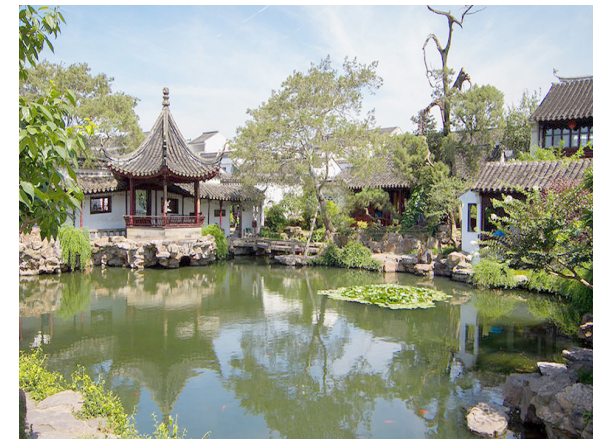

fig. 4.4. Master of Nets Garden, Suzhou (1140)

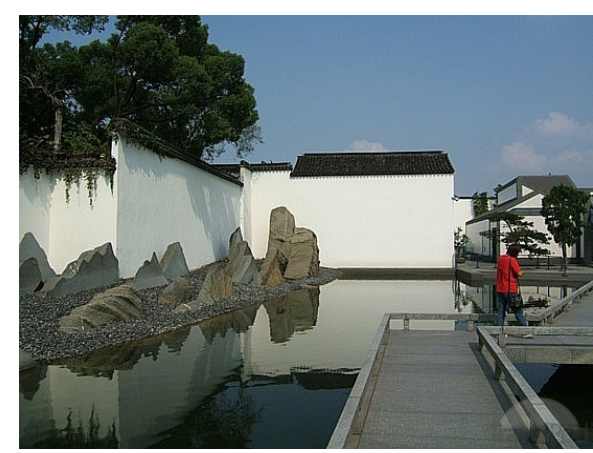

fig. 4.5. Suzhou Museum (2006) 


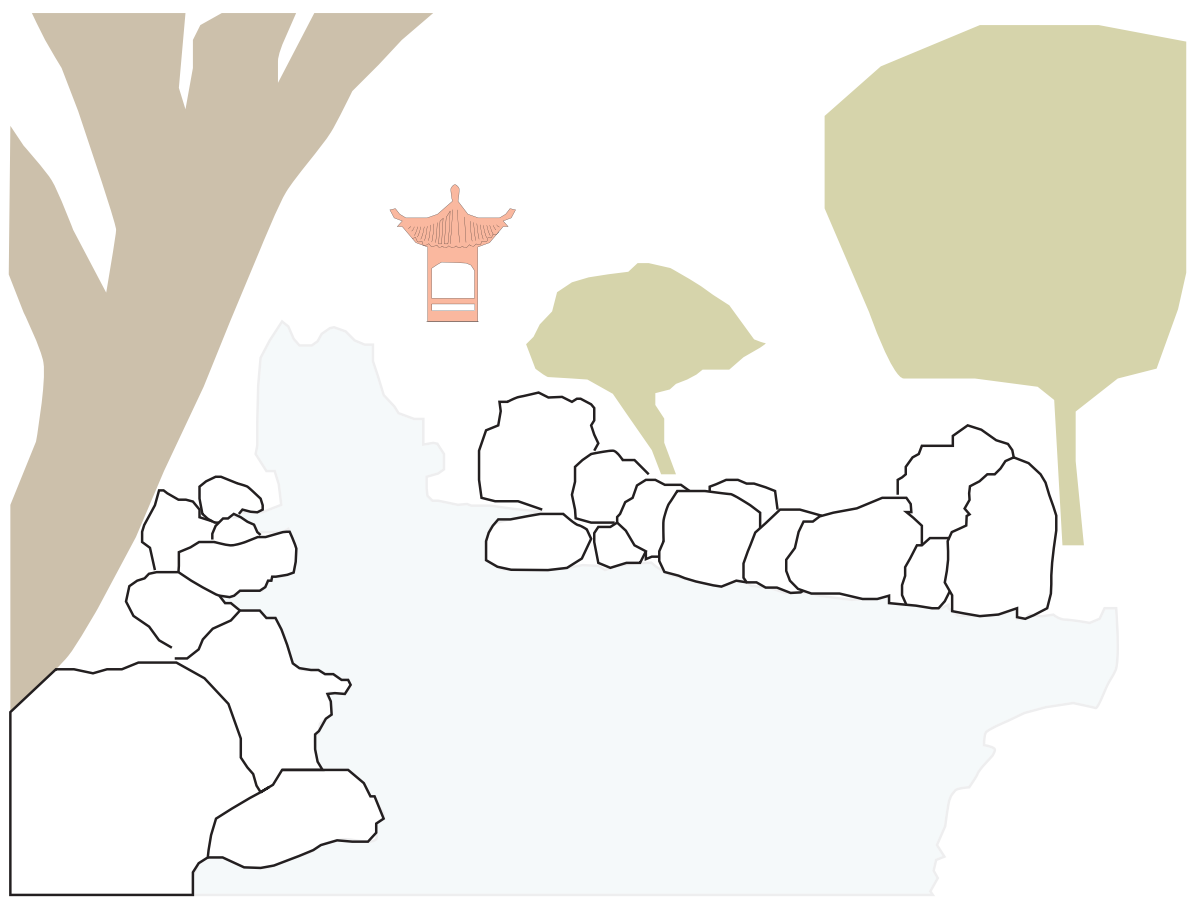

fig. 4.6. Waterfall. Trees are planted to lean towards the water to show them responding to their environment and to frame the view to the waterfall and Rising Jade Pavilion. The reflection of the still water and the rock edge complete the composition. 
Traditional

Garden of Friendship

Darling Harbour, Sydney, Australia

The garden was built in 1988 to celebrate Australia's bicentenary and the bond between Sydney and its sister city of Guangzhou, China. In a careful nurturing of $\mathrm{Q} i$, energy, the design follows the Taoist principles of 'Yin-Yang' to capture a harmony between the five elements of earth, fire, water, metal and wood. The way that each element depends on the rest demonstrates their understanding of coexistence and the dialogue between things.

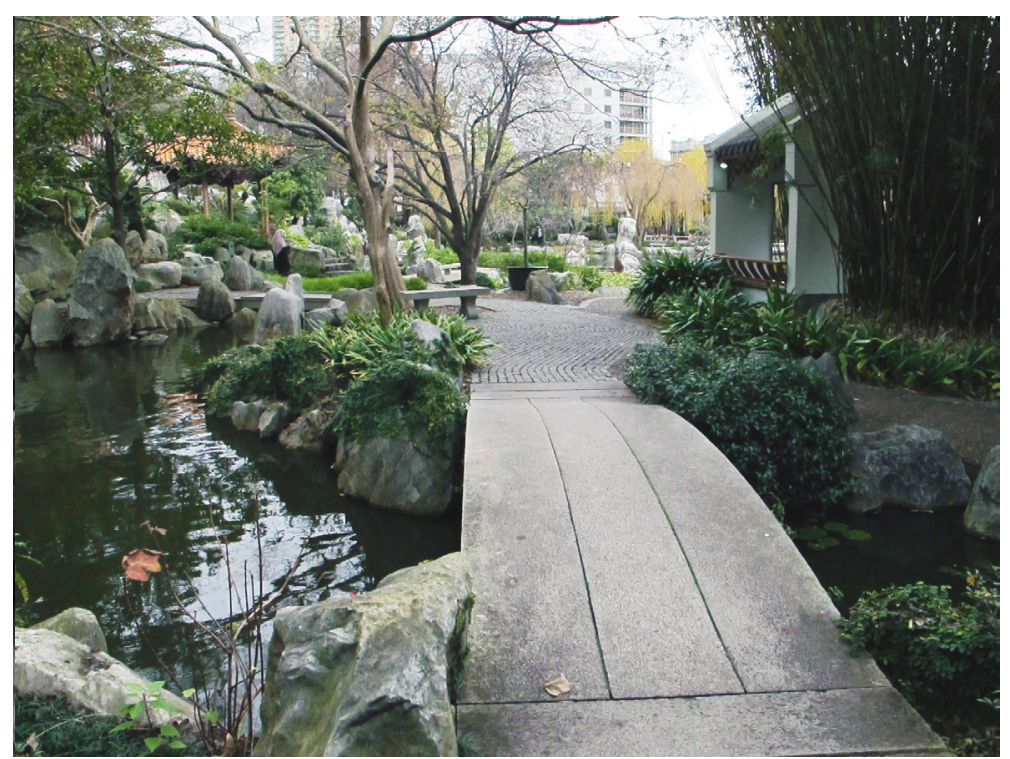

fig. 4.7. Arch bridge invites a moment of pause to view the waterfall 


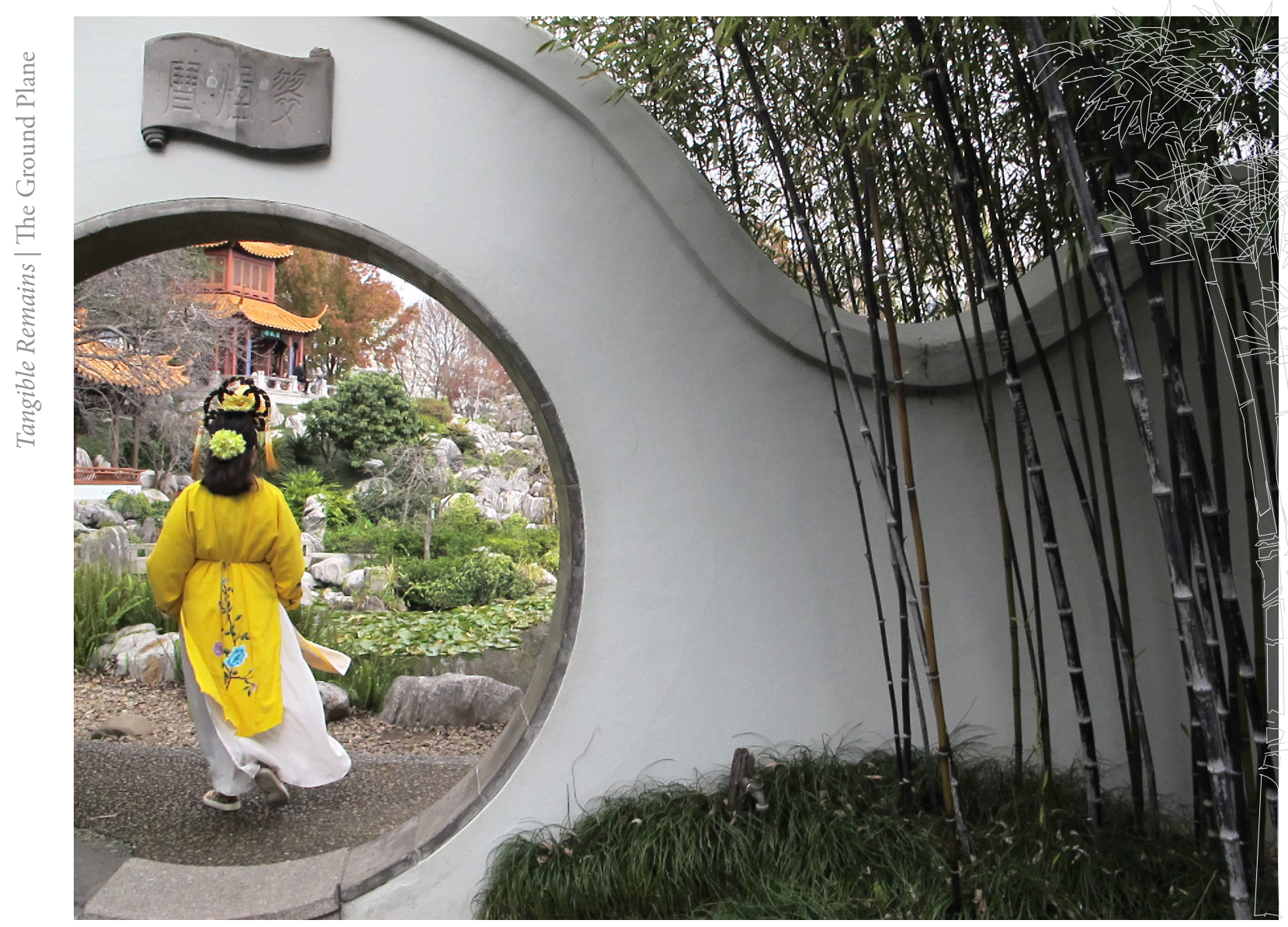

fig. 4.8. A Moon Gate creates a portal from one zone of the garden to another 
Entering the garden a blanket of calm settled over the sounds of the city. Amid the infamous Darling Harbour, the garden was no tourist attraction but a kernel of solace. A penjing courtyard, presenting an ancient collection of the miniature potted landscapes, softens the transition through the peripheral wall and intensifies the infinite scale of the garden beyond. The lake appears and the dance begins. The mountain in view and the city beyond, as I approach the waters edge, components of the landscape appear into view and settle into place. A tranquil world awaits.
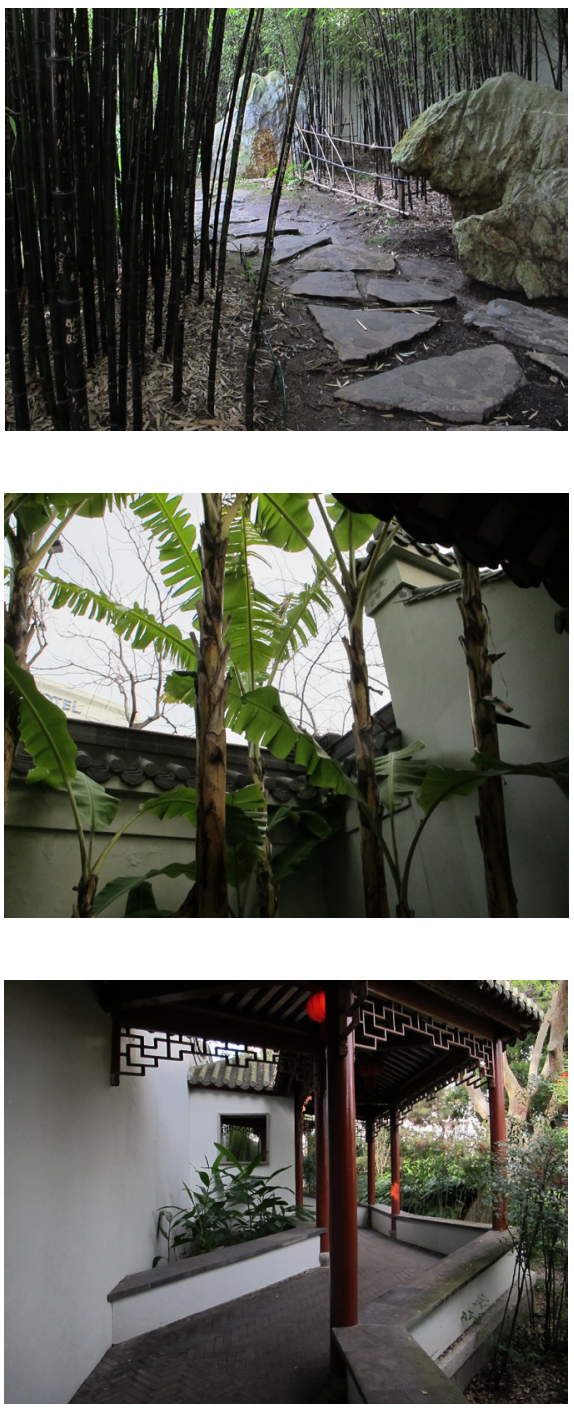

fig. 4.9. Bamboo garden

fig. 4.10. Pocket garden

fig. 4.11. Winding pathway 


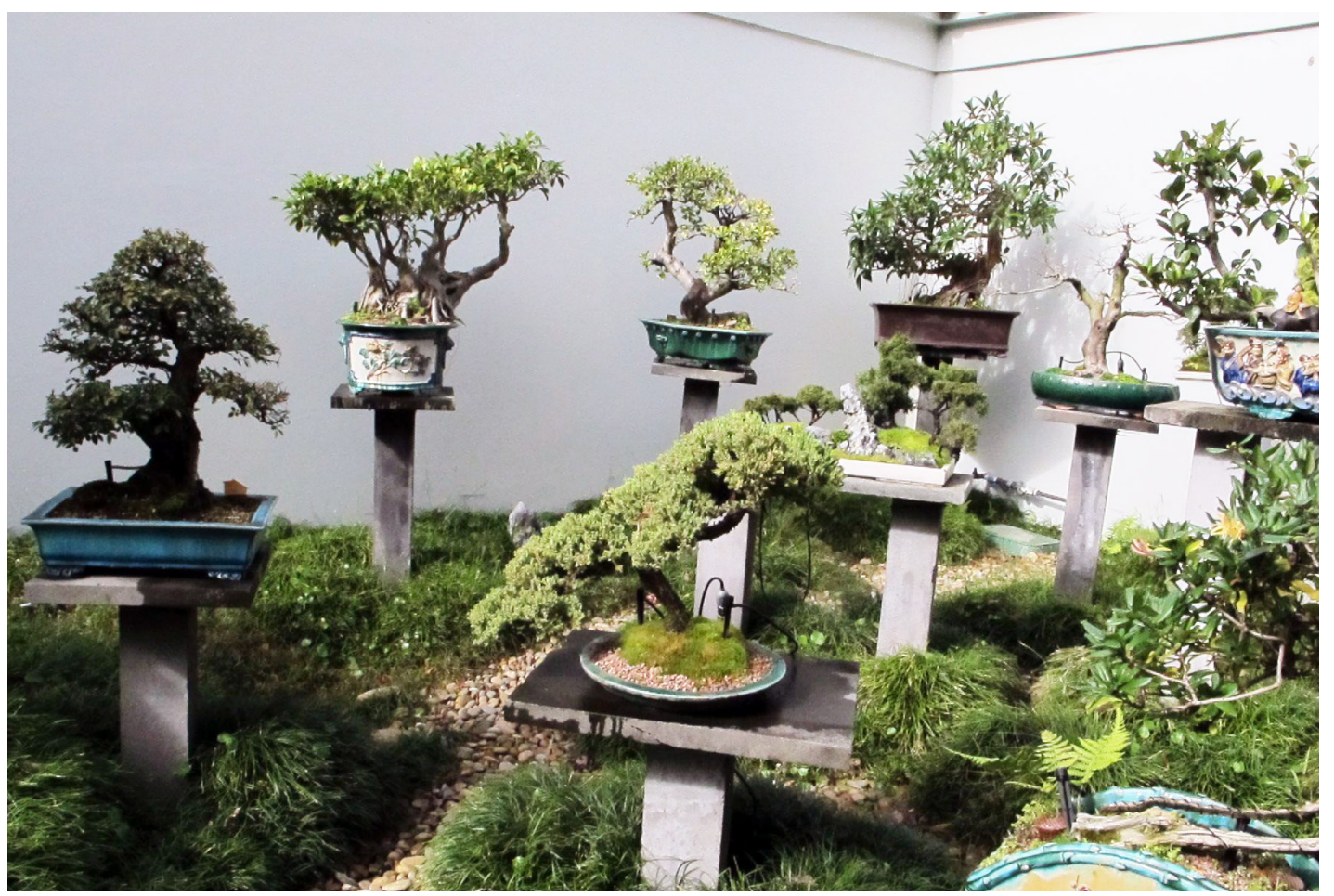

fig. 4.12. Penjing Courtyard 
A mere $500 \mathrm{~m}$ from the lively Chinatown the towering wall of the garden sits adjacent to the motorway running between. This feels like a missed opportunity but presents a discussion on the inter-cultural interaction. The garden is immersed in the viaduct promenade, engaging Darling Harbour visitors rather than fostering the connection to the established Chinese community. If the broader public knew of Frederick Streets history I wonder if they would feel the same disconnect between the Frank Kitts location. Framed views and glimpses develop a curiosity to lead the visitor through the garden. The visitor ascends the 'mountain' where the extent of the garden is finally revealed.

Questions of authenticity appear with this approach to an expat Chinese Garden through the selection of trees available. This presents an opportunity to celebrate the local contribution to the garden; how could the user read the two cultures as one? 


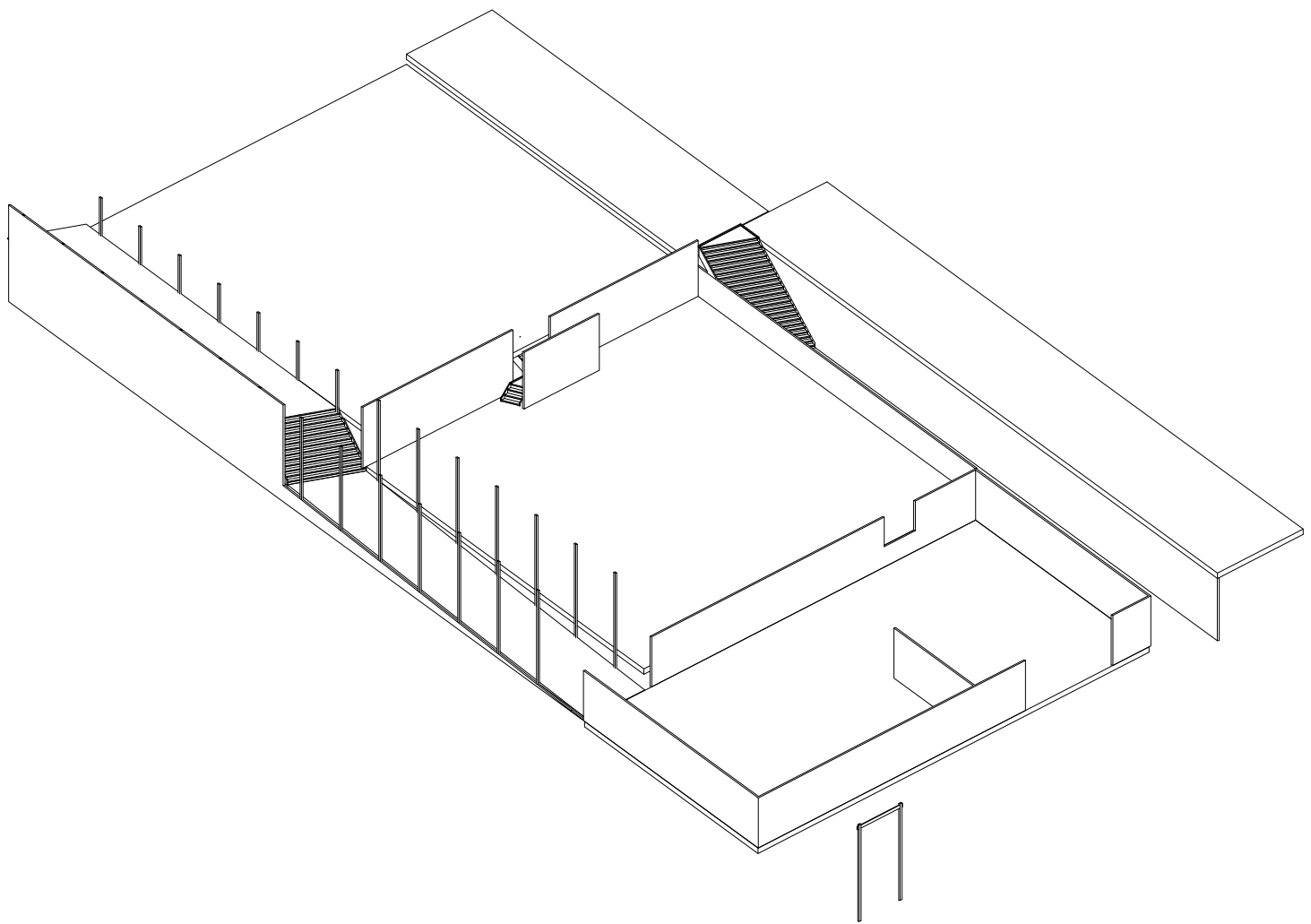

fig. 4.13. Abstraction of the Frank Kitts Proposal

'Touring this space one feels oneself to be like an ant crawling through the twisting eye of a pearl, or to have encountered a screen of tinted glass, for every twist and turn leads one on to yet another splendour' 
Contemporary

Garden of Beneficence (proposal)

Wellington, New Zealand

A garden of two cities, the proposal recognises design principles from Wellington and its Chinese sister city, Xiamen. The winning design entry for the redevelopment of Frank Kitts Park remedies a vital connection in the Wellington Waterfront whilst engaging a dialogue between the present day and Wellington-Chinese heritage. The key theme for the hybrid exchange is the degree of public engagement; visual permeability and accessibility. Traditionally, the perimeter wall has a significant role in enveloping a private but choreographed path of twists and turns. Duncan Campbell describes the design approach to "evoke tradition (through, for instance, the presence of walls) and move beyond this tradition by, for instance, ensuring that these walls enclose and invite within rather than exclude." ${ }^{24}$

The design provides the traditional meandering path as well as a direct route along the periphery; a contemporary intervention for accessibility. The tension between the two creates an opportunity for an intriguing dialogue between old and new. However, the alignment of the entry courtyard with the direct route creates an axis which dominates the twisting path. Such an axis has potential to align with lines of intensity identified on Frederick Street; operating as more of

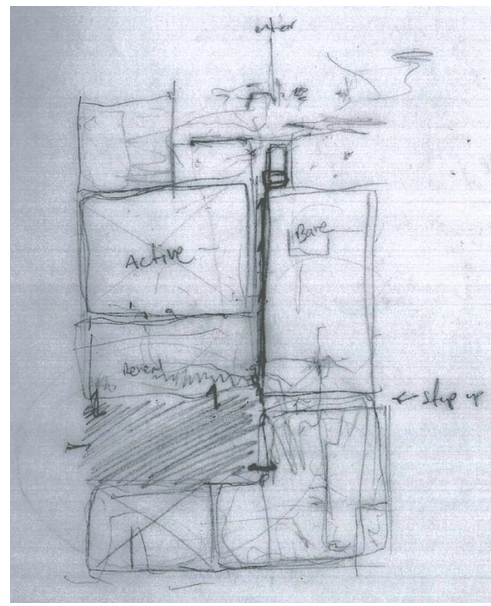

fig. 4.14. Zoning Study testing the use of an axis as a stong spine on the site a spine than an edge. ${ }^{\text {fig. }} 4.14$ The question would be, how to maintain the balance between?

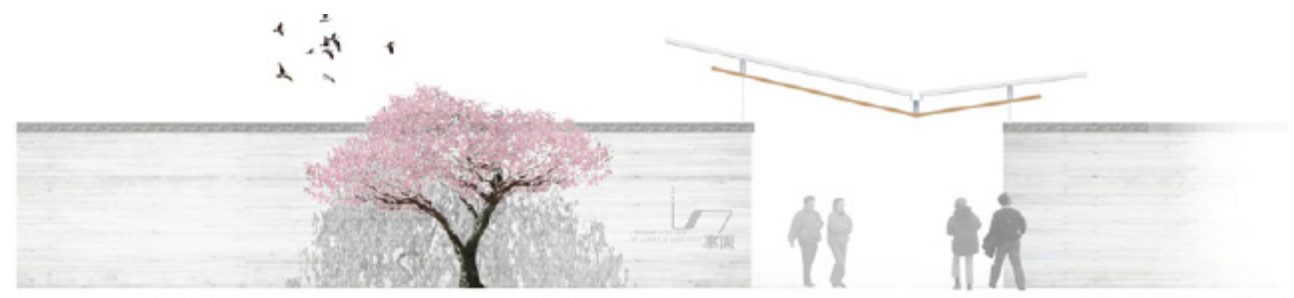




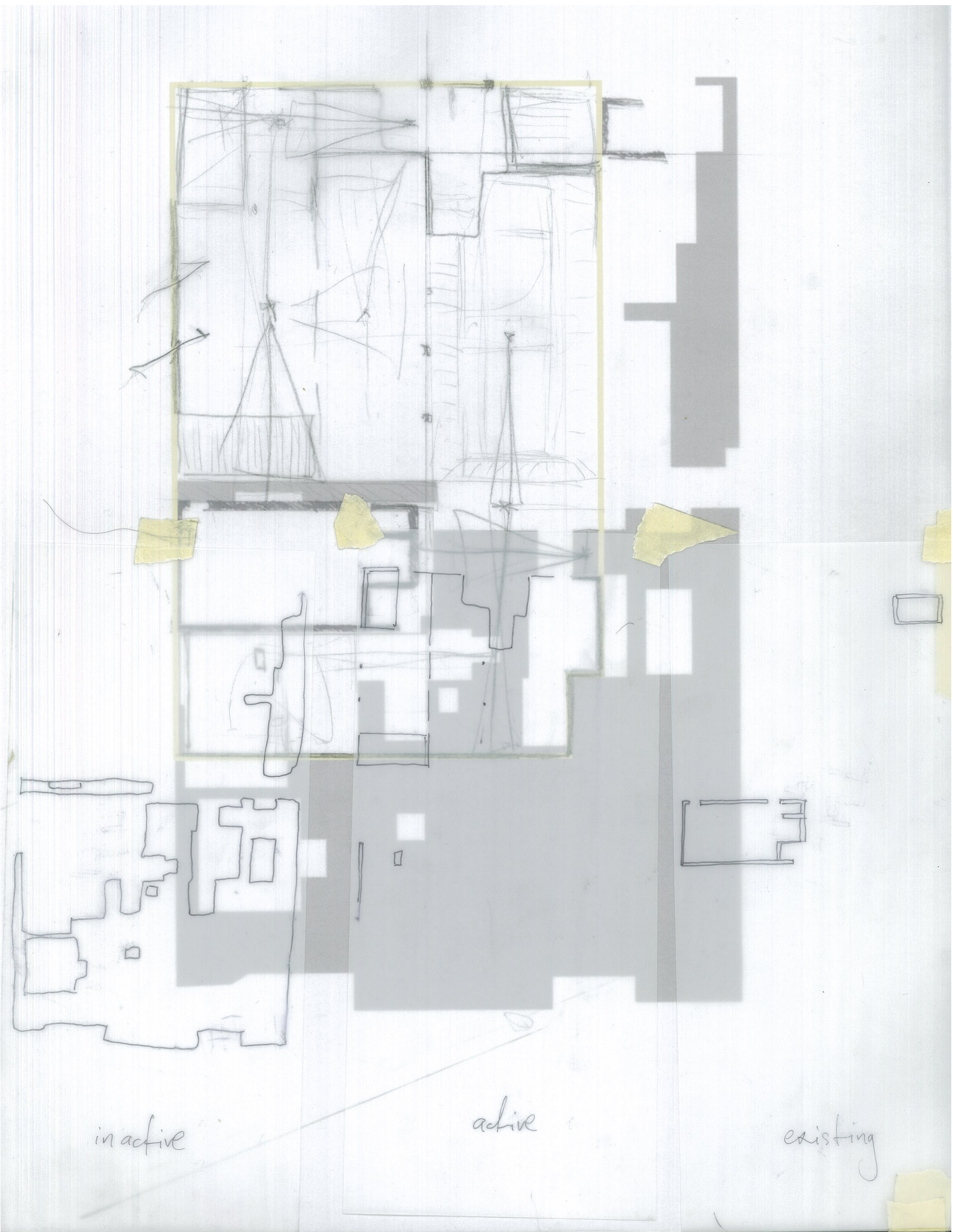




\section{Chinese Garden of Immanence}

A hybrid design

This design was intended to express tensions between traditional Chinese design principles and institutional regulations; framed views and involuntary motion; existing objects and new interventions. The potentials of the sites layers were navigated with the reinterpretation of traditional strategies and palates. The spatial sequencing of such gardens inspired a narrative methodology to be engaged in the design process; inhabiting the spaces in the first person whilst designing.

[The design case study experiments with ways to navigate through the material collected. The process of assigning thematic units in the design provoke a critical understanding of the material to find patterns of intensity. ]

\section{Zoning}

Thematic units are a key part of the Chinese Garden. Each with their own personality or tempo, one transition through the units like scenes of a play. The idea of zoning immediately identifies a way to reclassify the site's layers. 7 zones were thus established based on their embedded narratives and potential in space. 
Taranaki Street

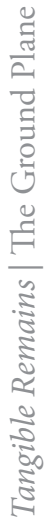

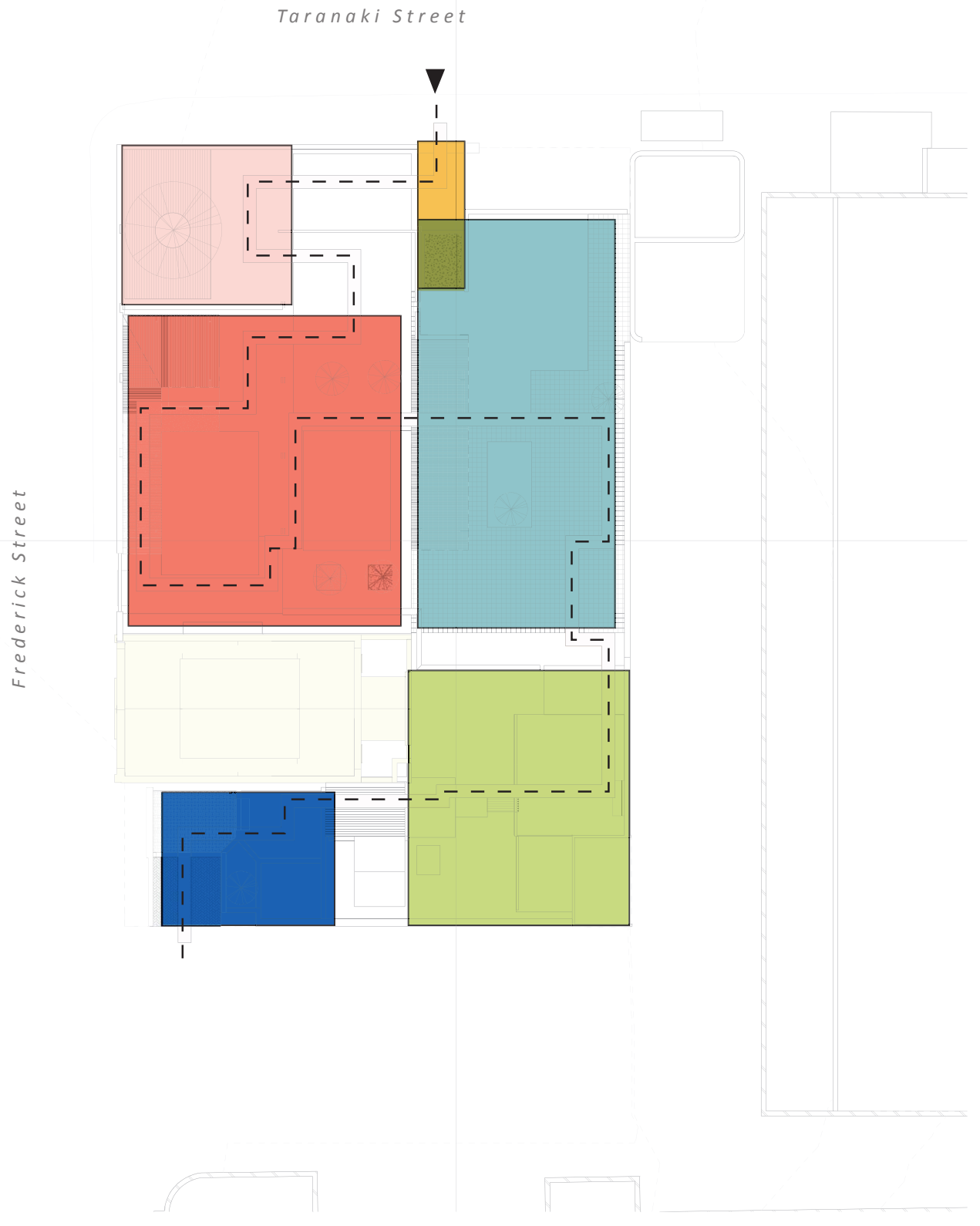




\section{Thematic Units:}

Pai Lau (gateway)

The archway marks the entrance from the bustling Taranaki Street into the garden. The configuration aligns with lines of high intensity to provide glimpses of scenes beyond.

\section{Heavens Well}

Place of solace. A confined space before entering the depths of the garden seeks to ease the transition from Taranaki Street to a calm slow pace.

Focal Point: trace of 1919 villa

\section{Garden of Consolidation}

The high intensity of the zone informs a rich space with twists and turns. The progression through this space will gradually reveal the Chinese Mission Hall and activate the wall.

Focal Point: west elevation of Chinese Mission Hall

\section{Chamber of Erasures}

The zone was classified as vacant due to the lack of detail in documentation. Feelings of vastness and clarity are implored in the space through simple edges and surfaces.

Focal Point: traces of previous perimeter walls

\section{Garden of Future Contemplation}

The highest level of the existing site and the area where no built traces were identified forms the artificial lake and mountain. The space reveals the broadest view of the garden and the Chinese Mission Hall.

Focal Point: Chinese Mission Hall (plus reflection)

\section{The Final Weave}

The zone is rich with intricacies of subtle alterations to the previous garage. These form obstacles to interrupt the movement through to Frederick Street and direct views beyond.

Focal Point: Mountain
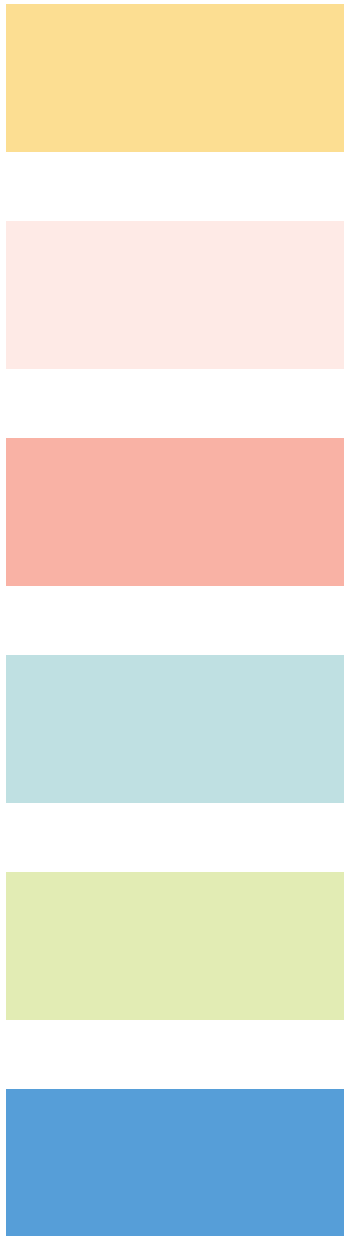


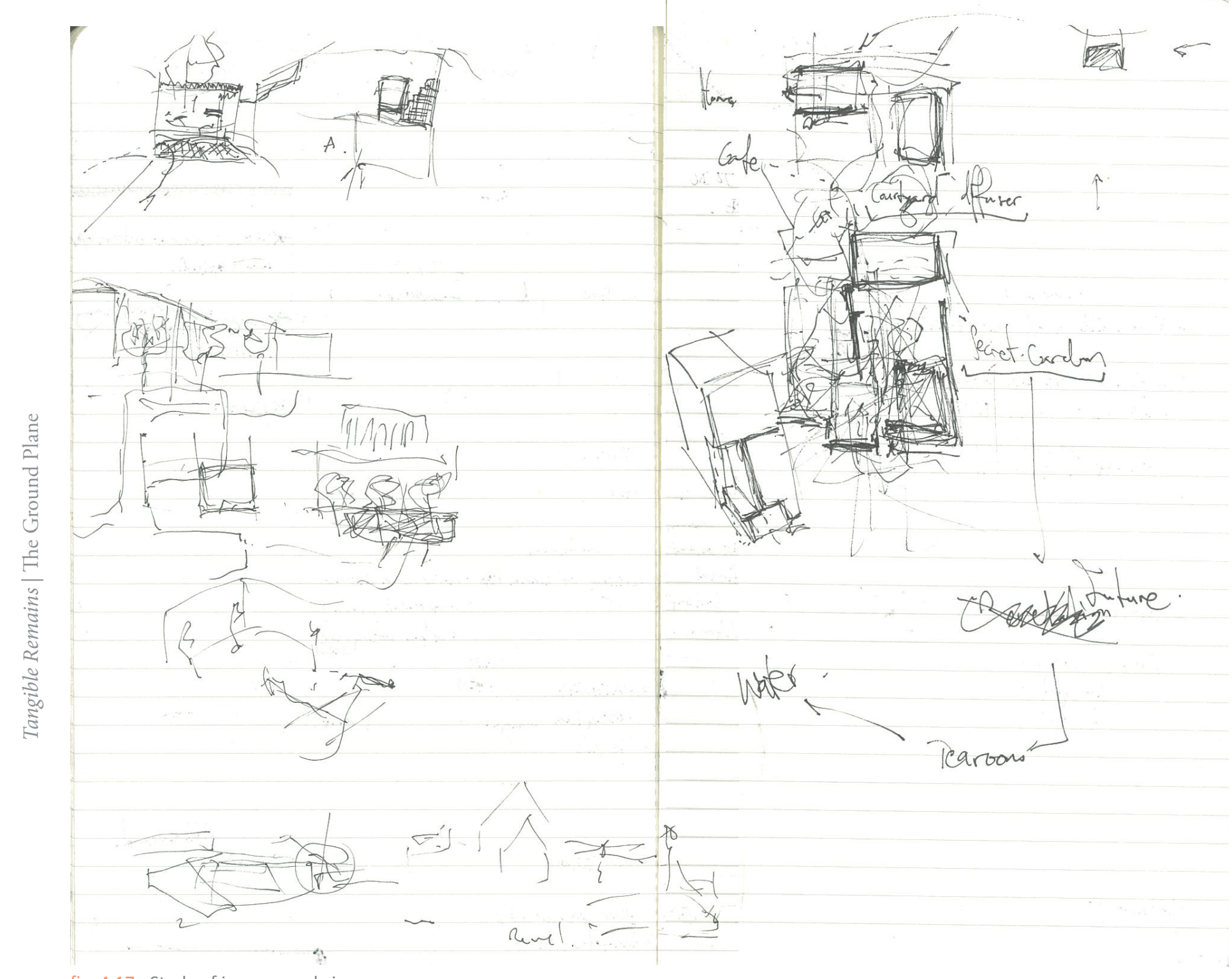

fig. 4.17. Study of journey and views 

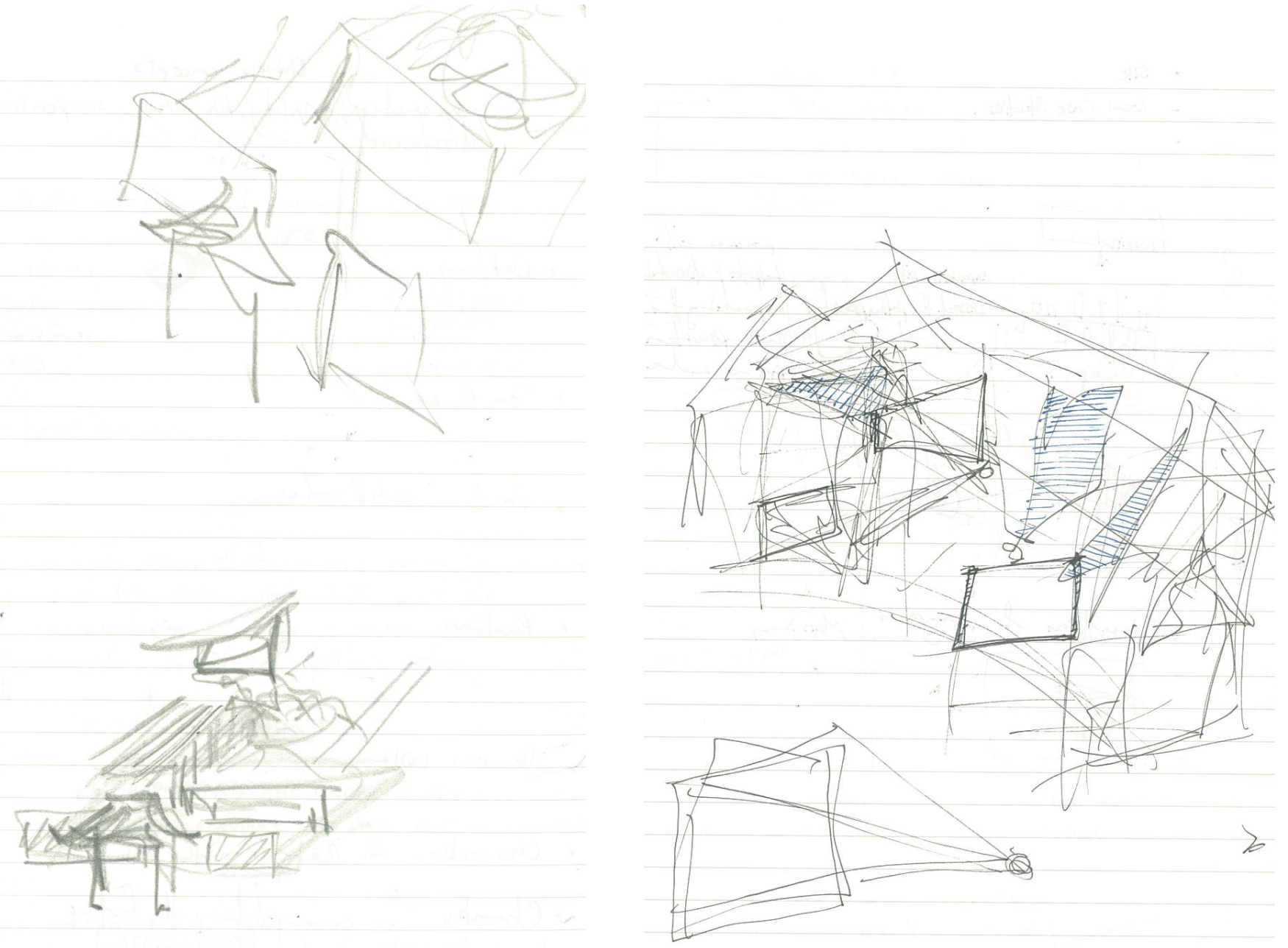

0
0
0
0
0
0
0
0
0
0
0
0
0
0
0
0
0
0
0
0
0
0

fig. 4.18. Gateway study

fig. 4.19. Study of the spatial opportunites of 'framing' 


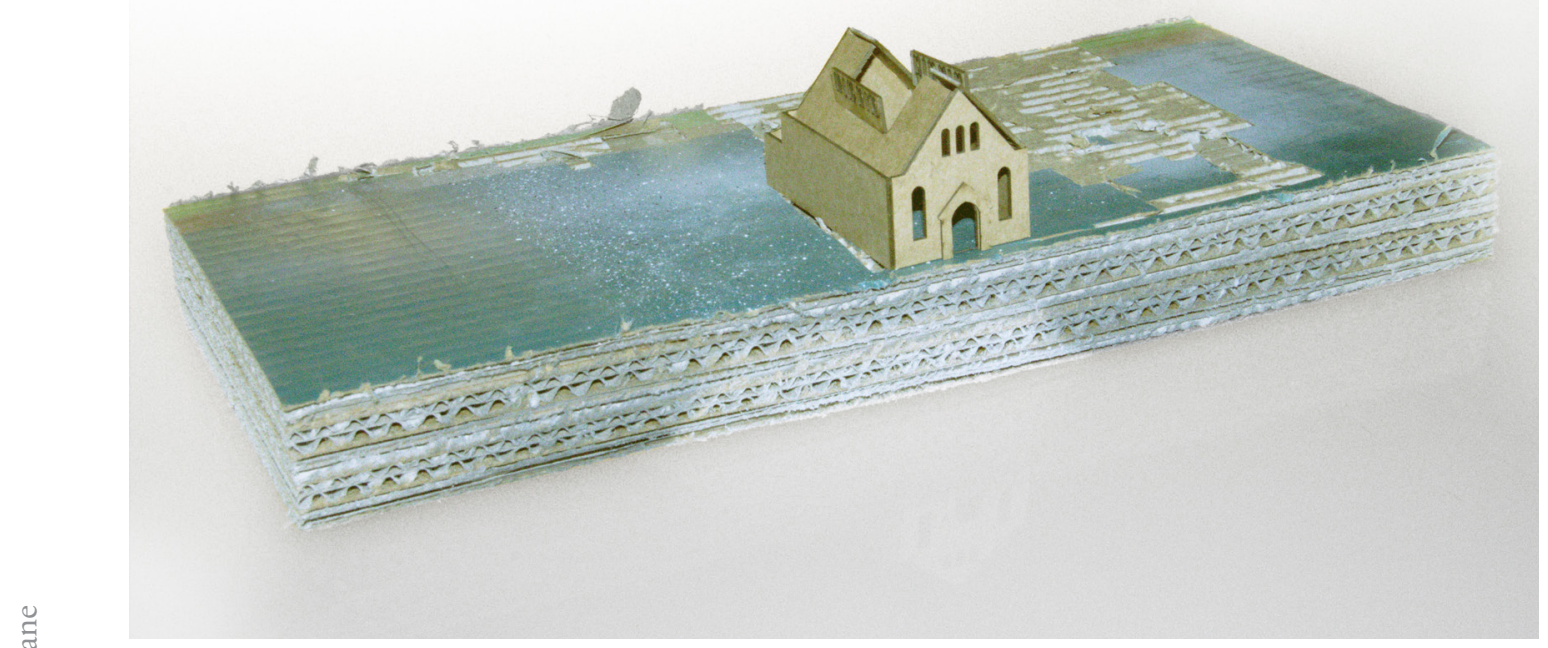

fig. 4.21. Model of figure ground

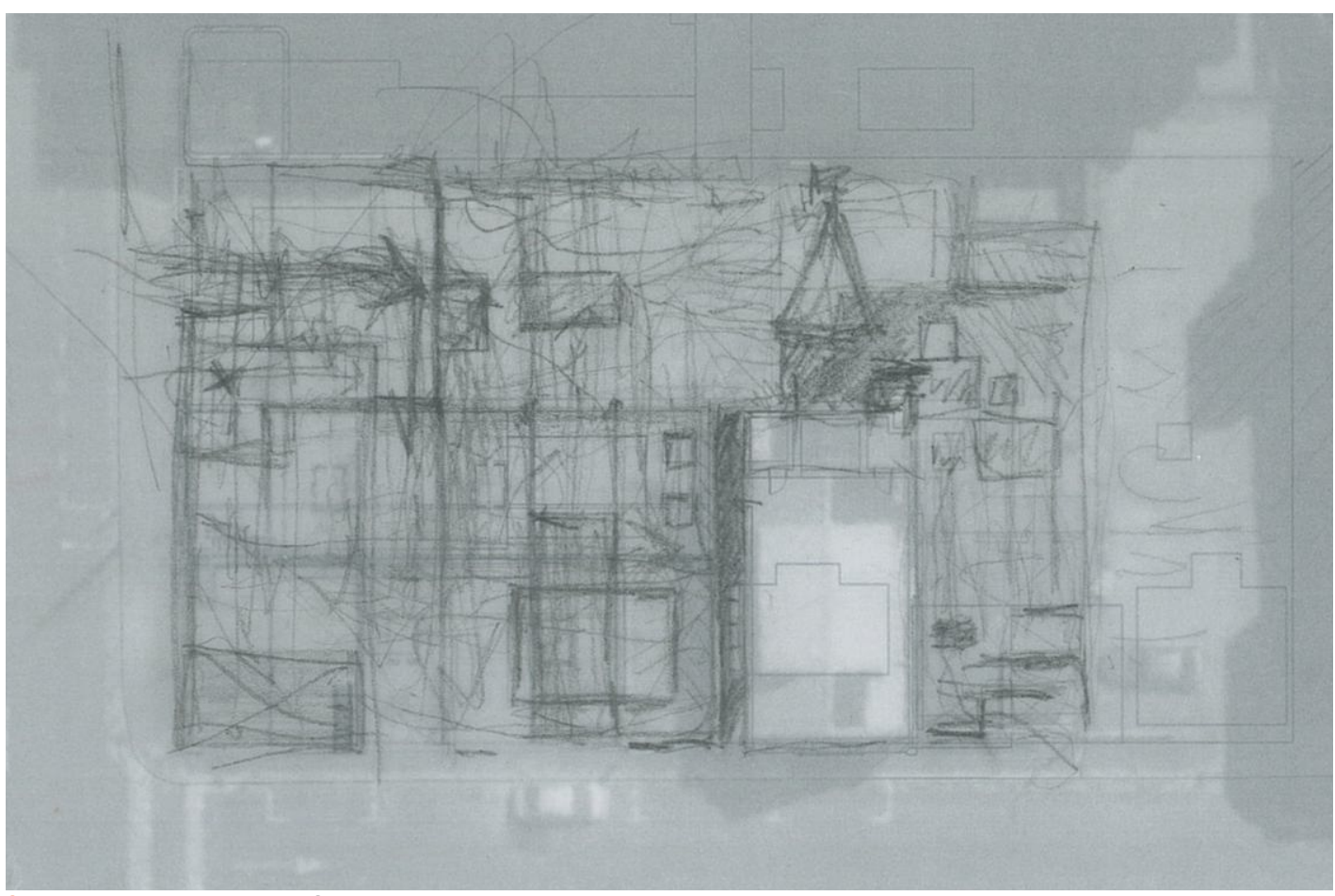

fig. 4.20. Overlay Study of movement through site 
Palette of plants and key elements.

Surface conditions of various components were classified based on the potential of their aural and visual intensities. The potential to damper a space, isolates the audience from the surrounding landscape - whilst the reflection of still water reveals a new universe. Walking pace would be subconciously eased on irregular surfaces: pebbles and grass.

The palette critically selects a range of Wellington local flora and traditional chinese vegetation from the sensorary qualities they bring to the garden. The understanding of how the palette transforms across seasons helps to orchestrate the full extent of the Chinese Garden design.

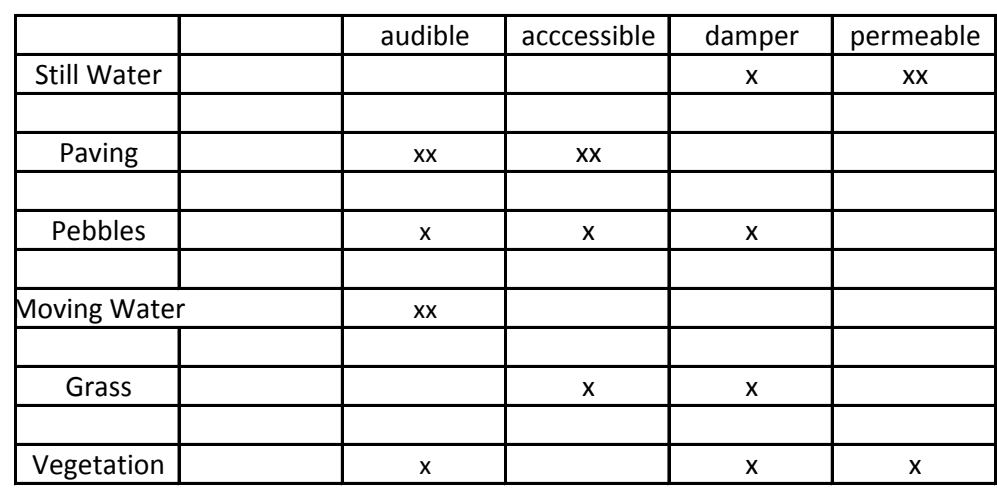

fig. 4.22. Table of components and their characteristics 

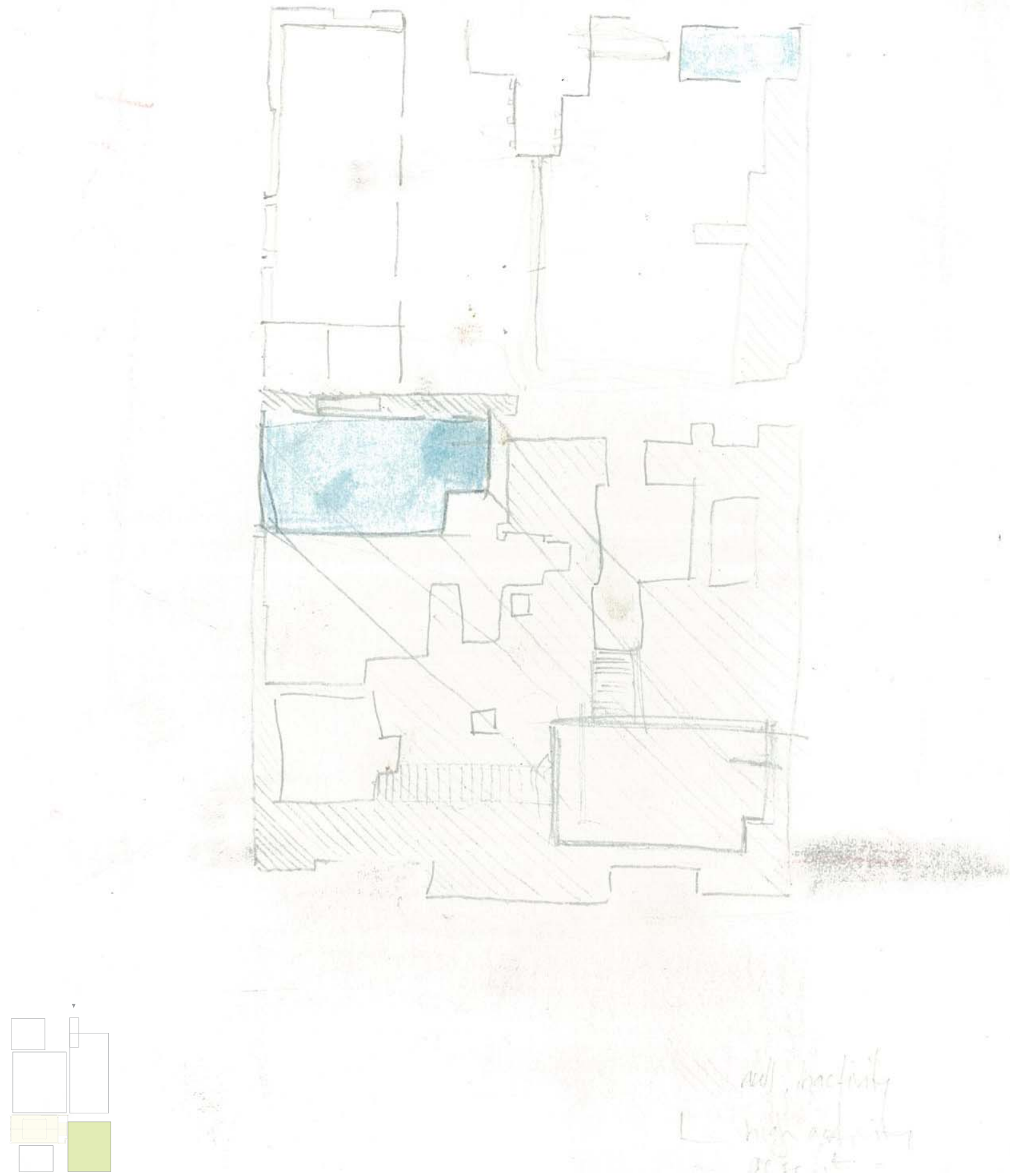

fig. 4.23. Shifting the Chinese Mission Hall to the inactive zone. Concealing the building from the street for a gradual reveal. 


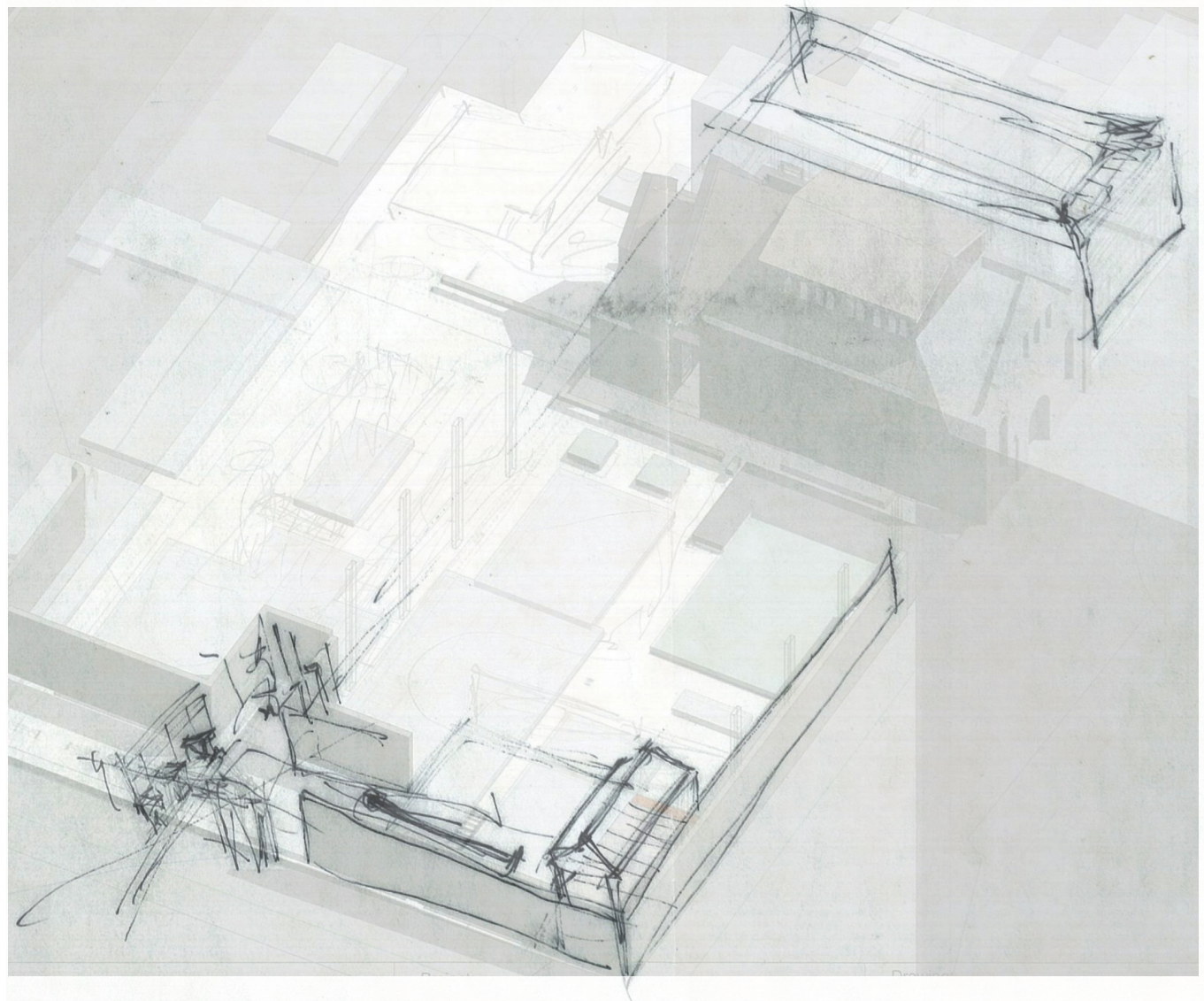

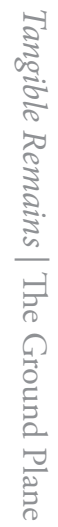

fig. 4.24. Testing main entrance and suggestion of previous corner 

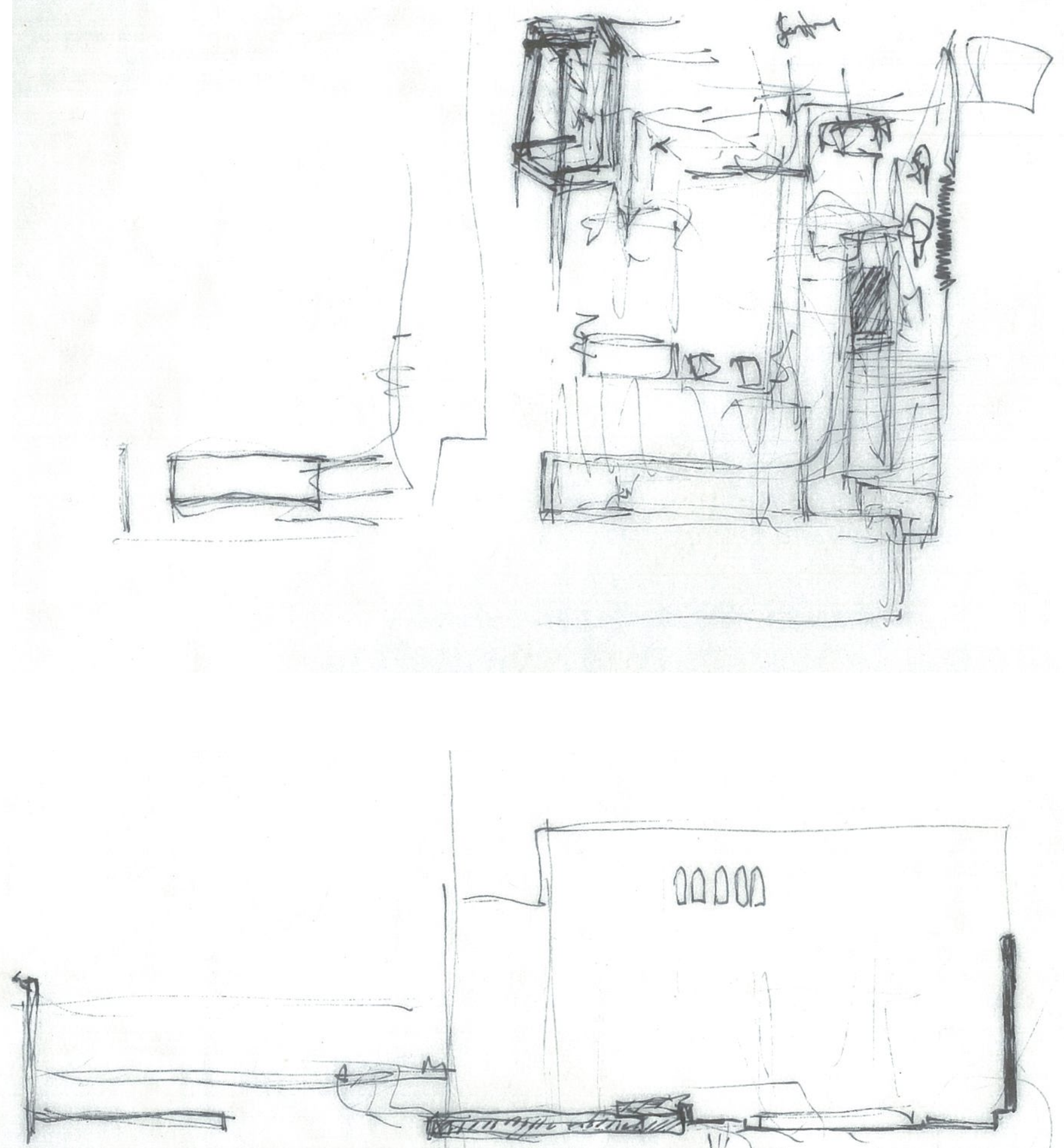

$A M$

OADOA

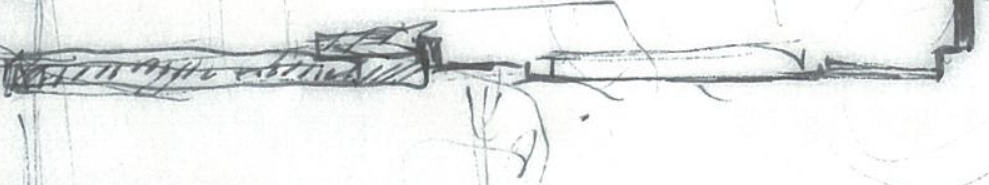




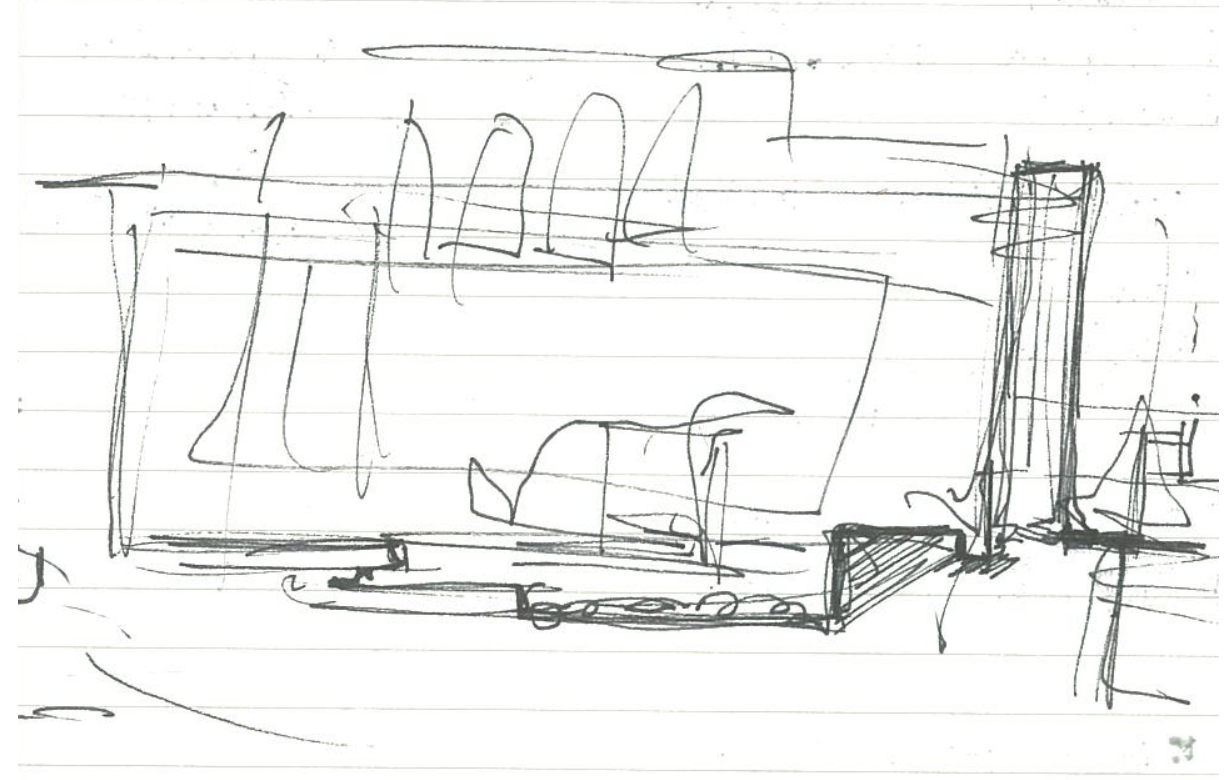

fig. 4.25. (Opposite and Above) Study of Laneway edge and the transition of levels from Frederick Street 


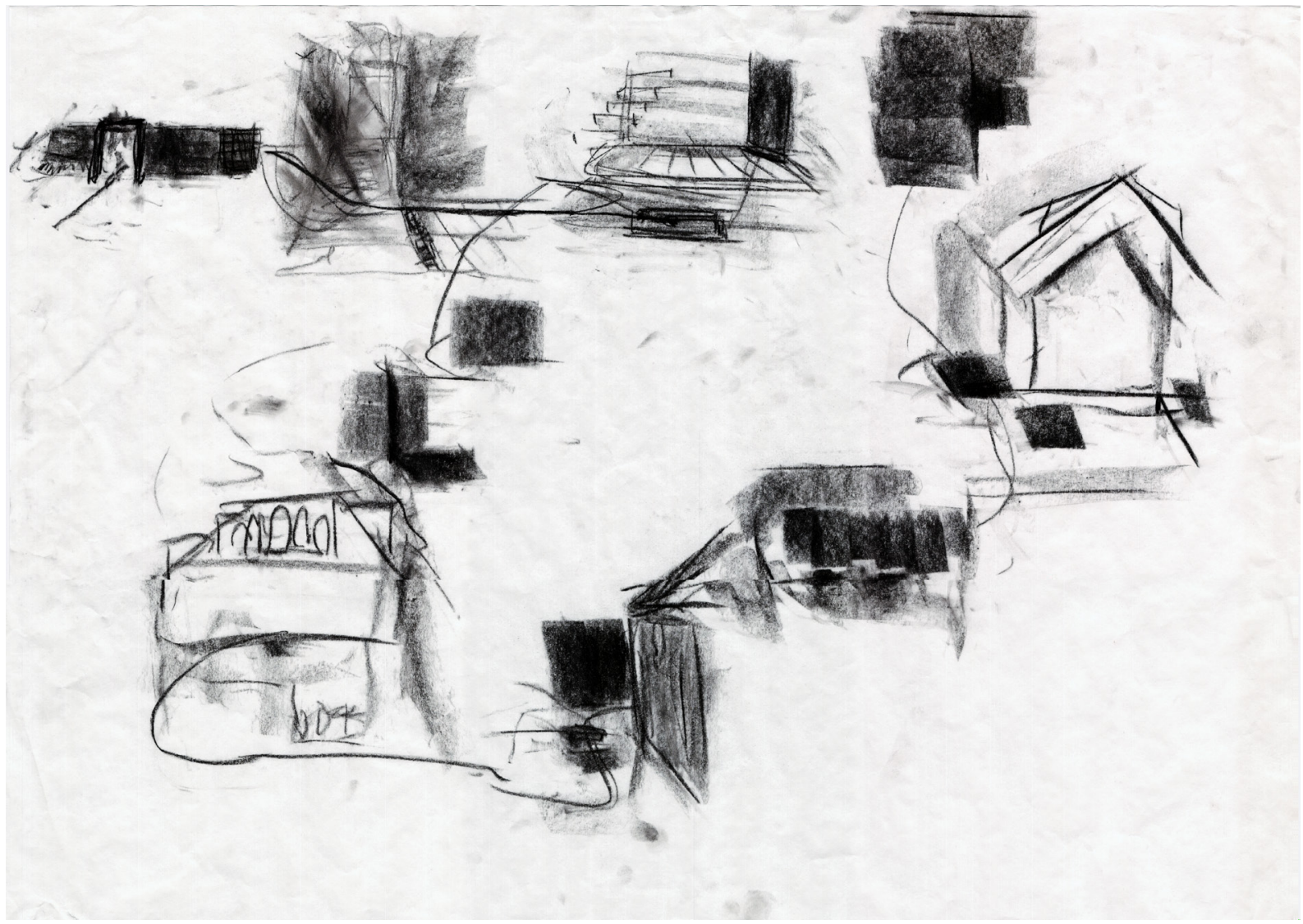

fig. 4.26. Charcoal Study of the journey

1 Pailau (gateway), 2 Focal Point, 3 The 1st Stand, 4 Gradual Reveal, 5 Garden of Consolidation,

6 Forgotten Laneway, 7 Chamber of Erasure, 8 Garden of Future of Contemplation,

9 The Final Weave 


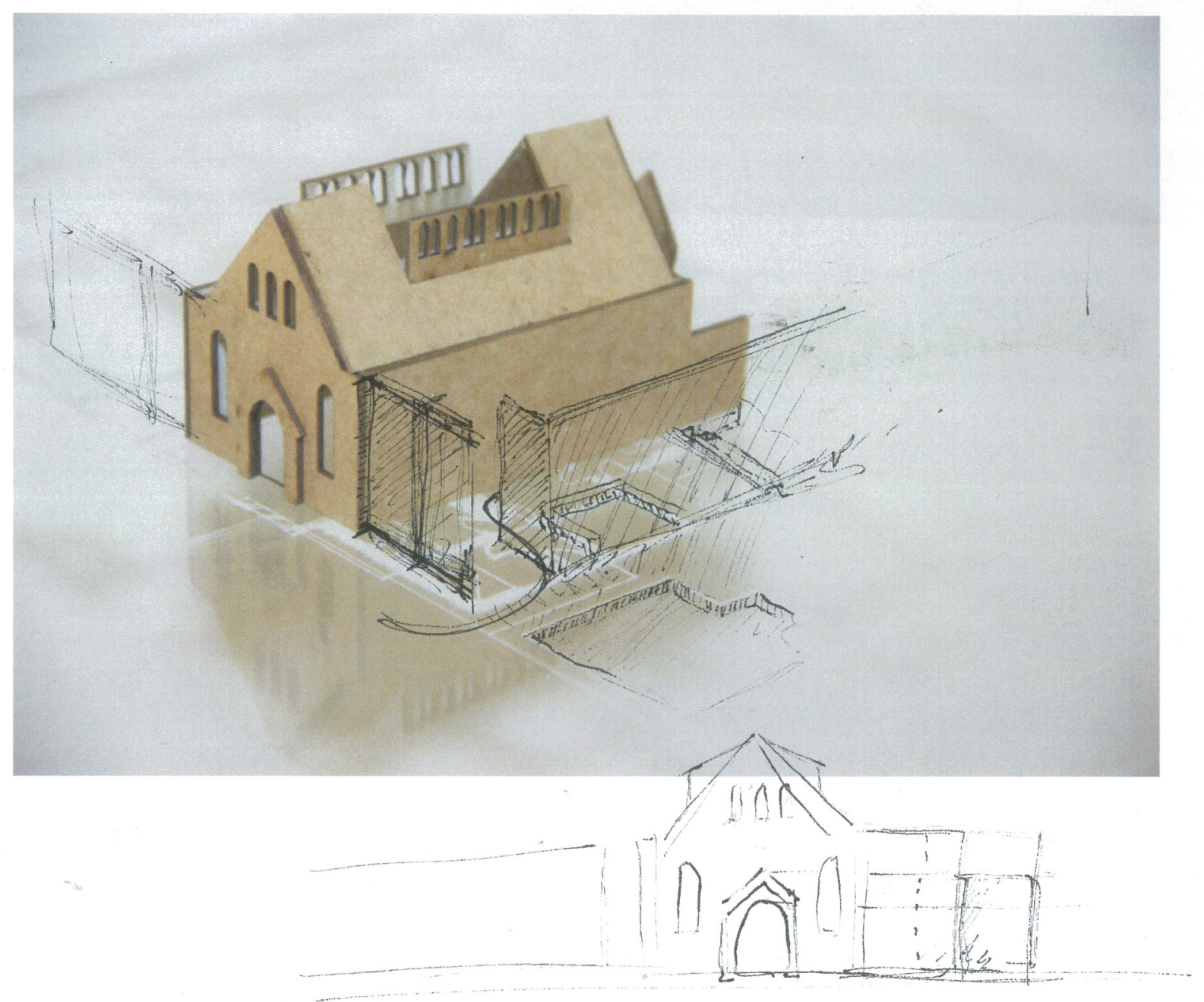

fig. 4.27. Final Weave Study; using sublties of alterations to create obstacles through the space.

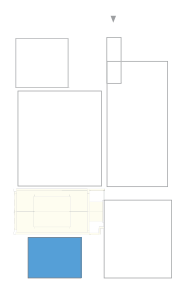




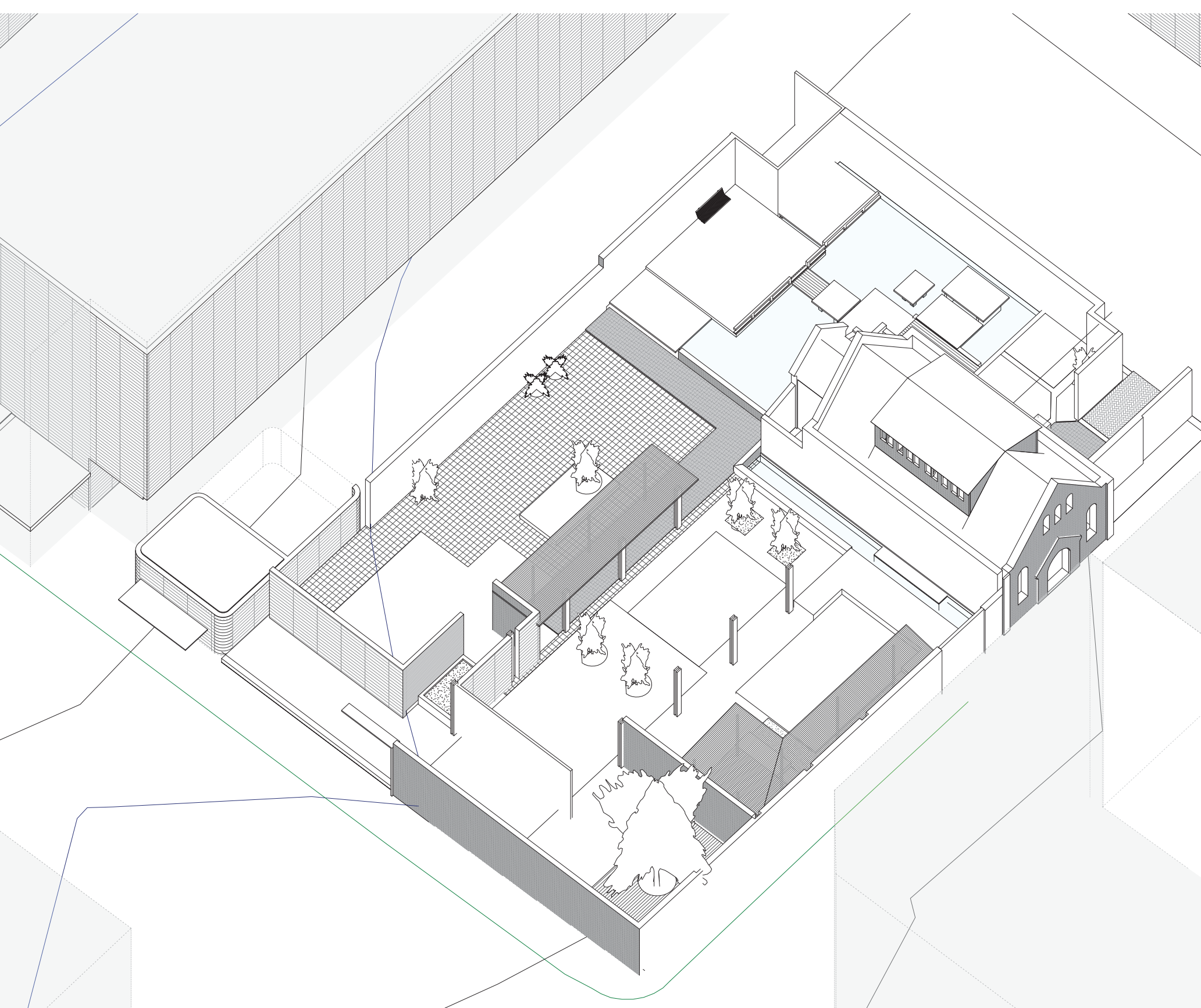



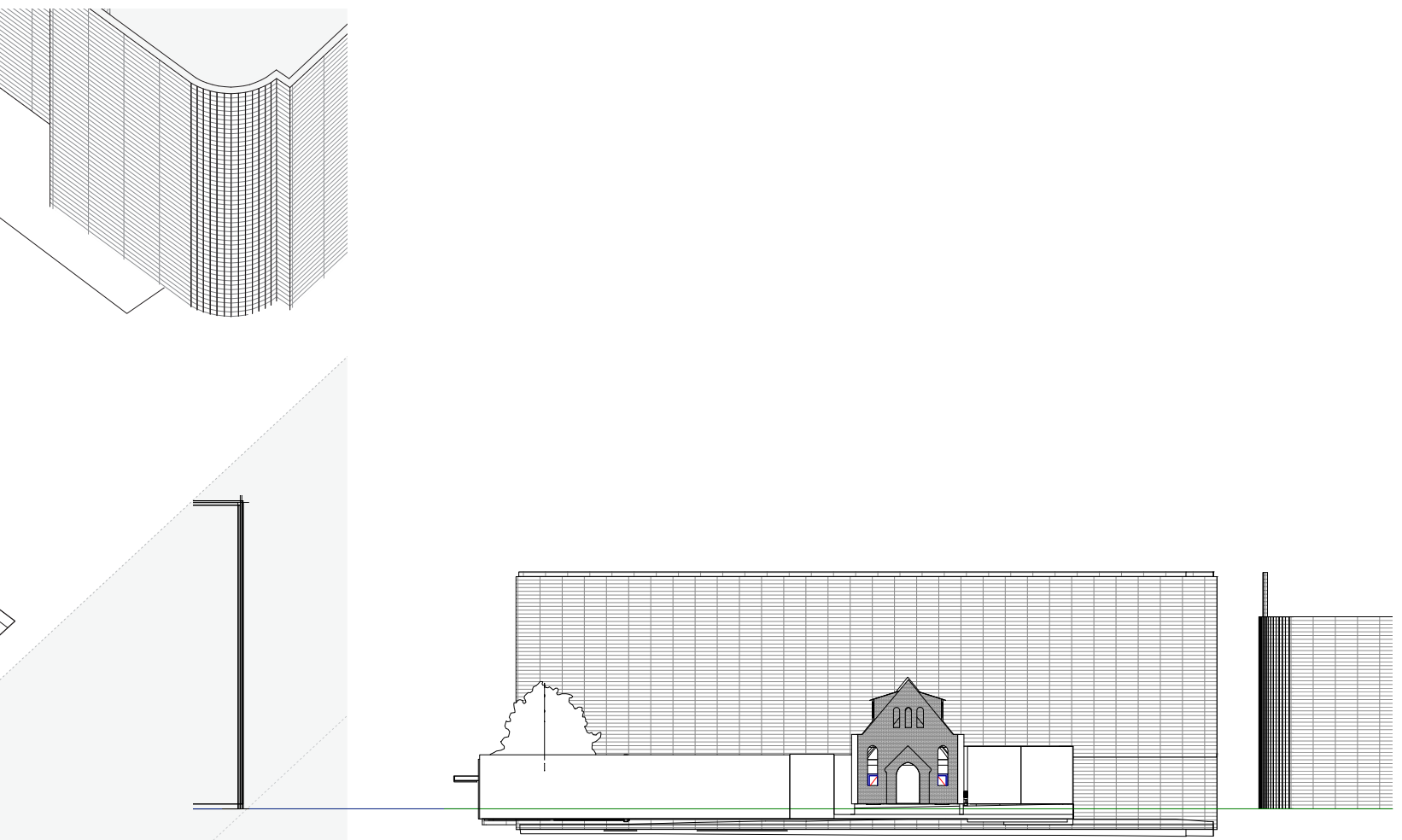

Chinese Garden of Immanence

fig. 4.28. Design Phase One: Chinese Garden 

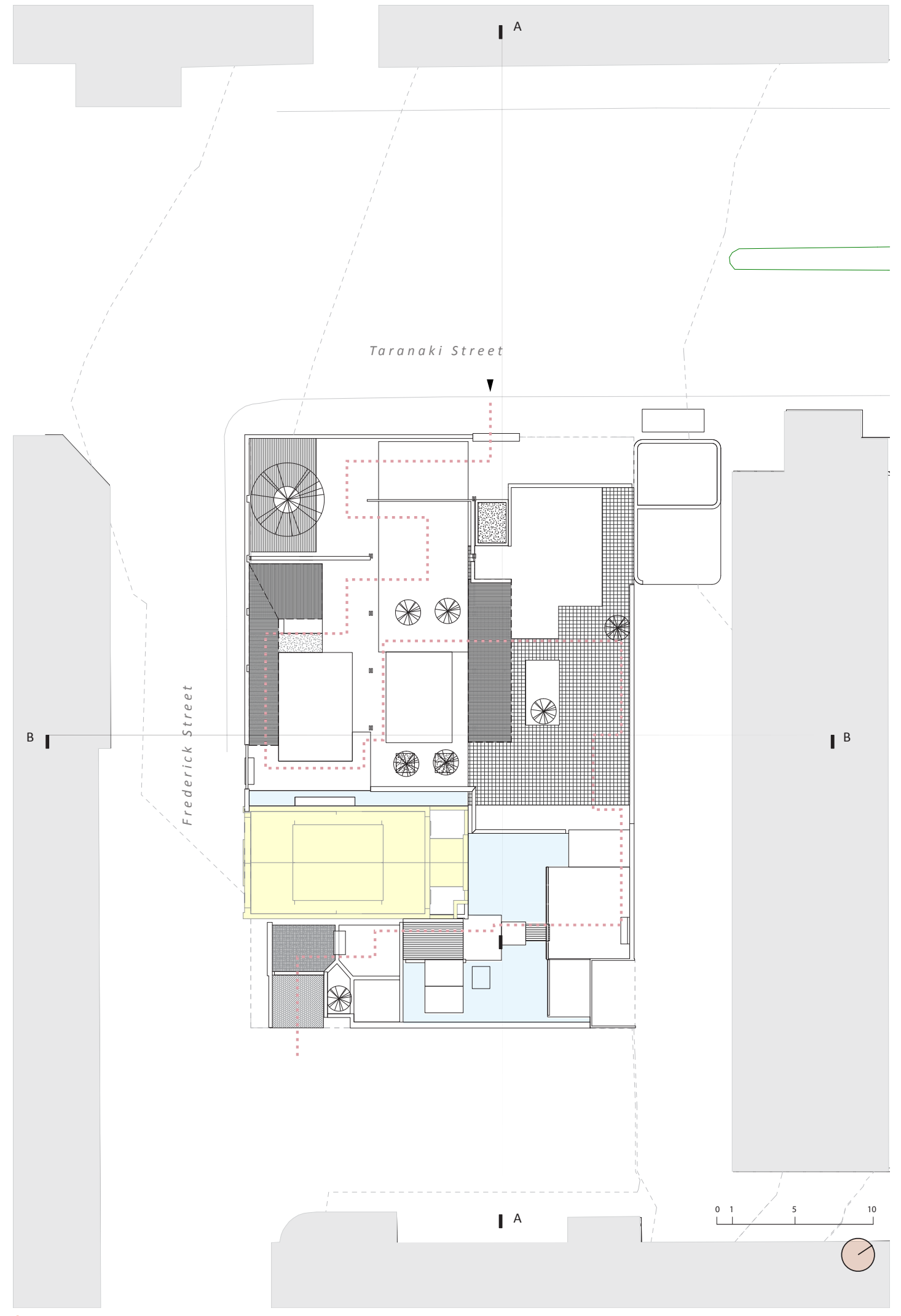

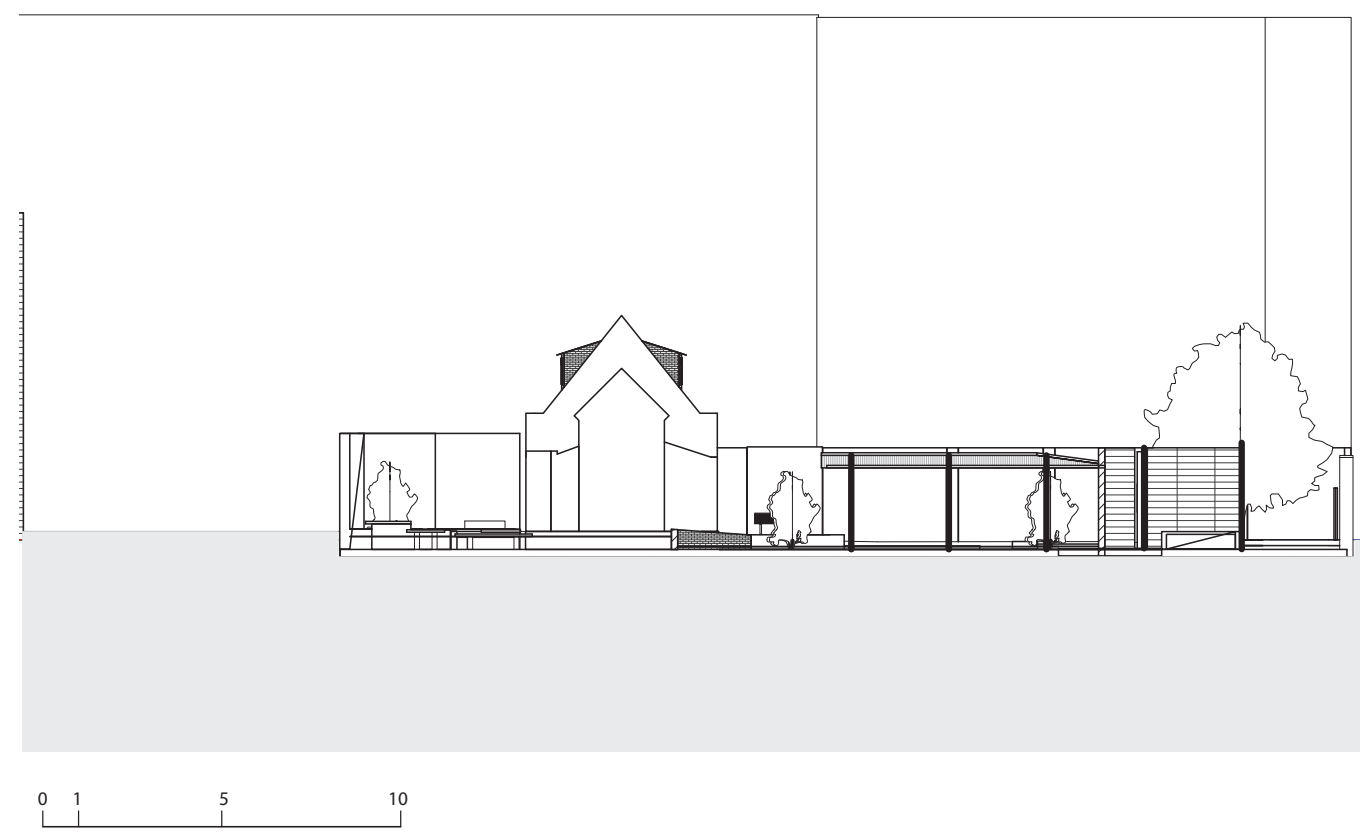

fig. 4.30. Section A.A
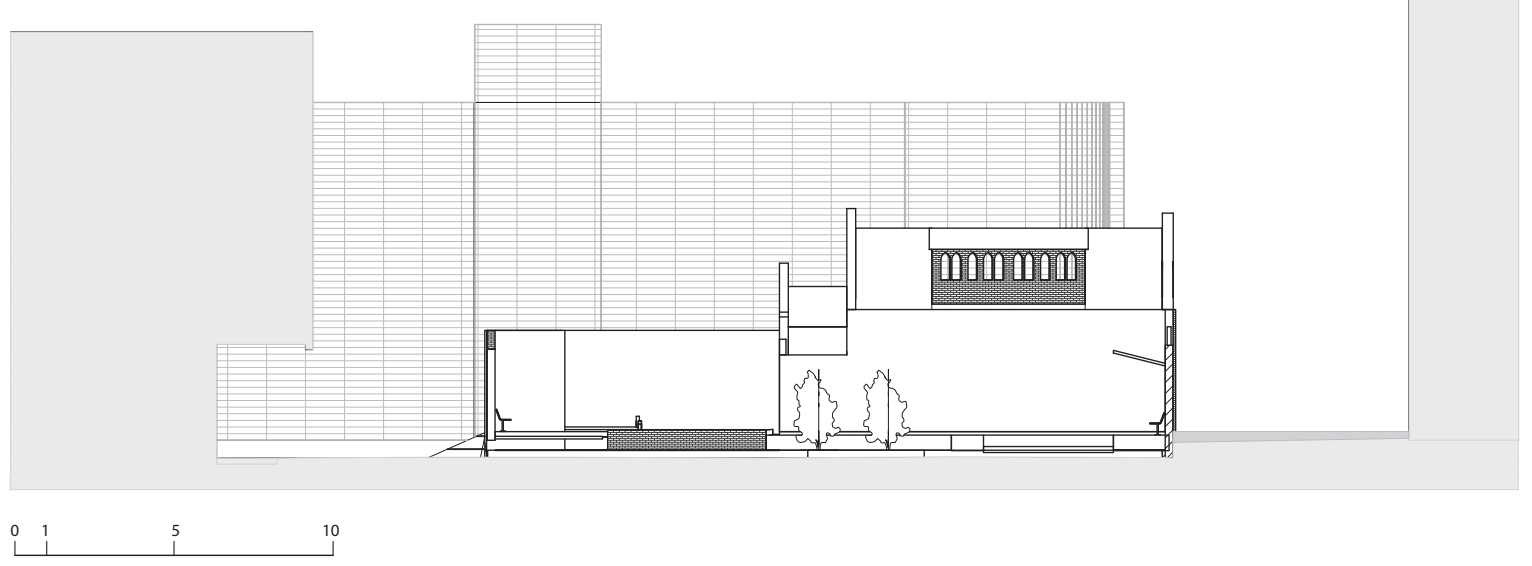

fig. 4.31. Section B.B 


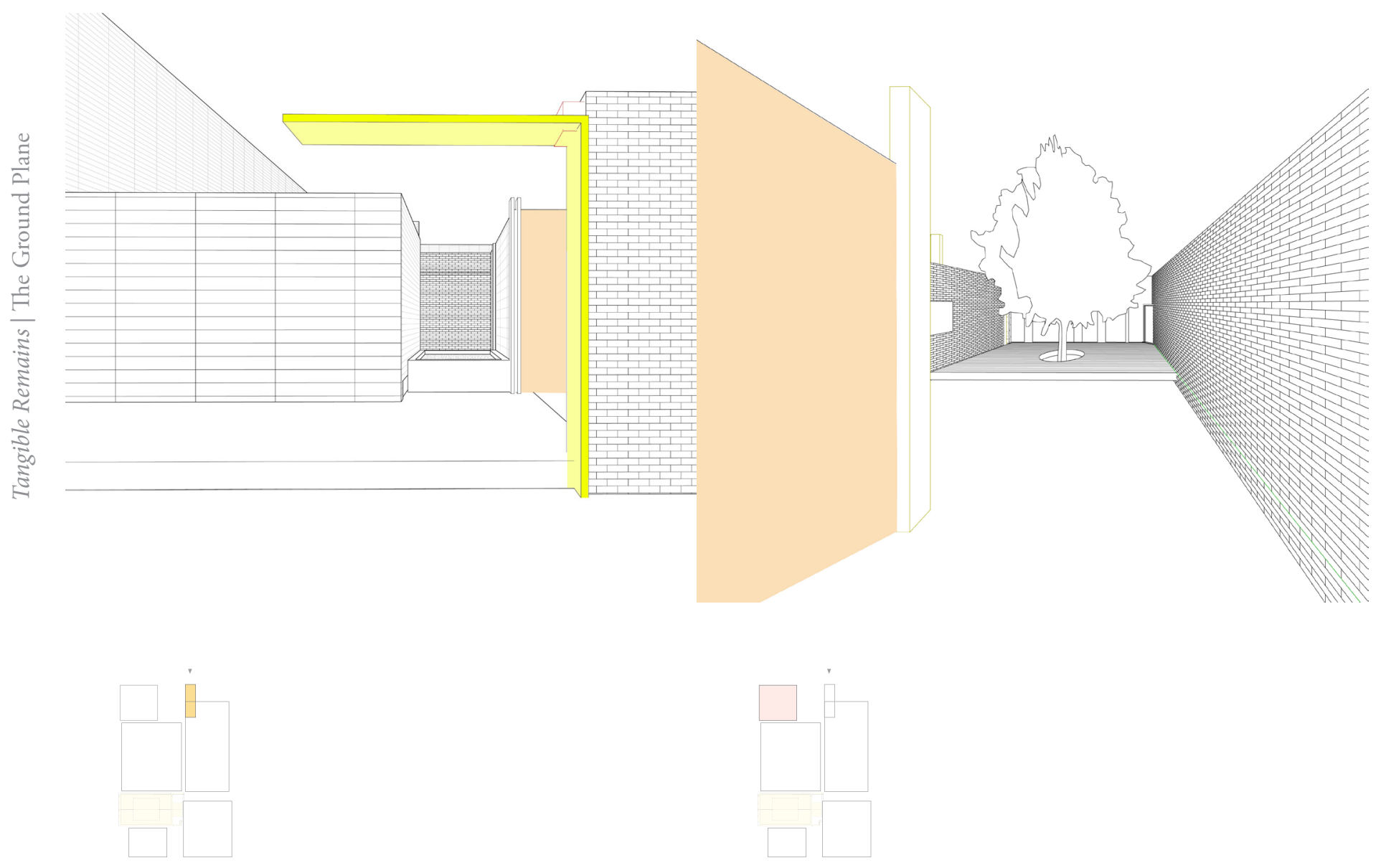




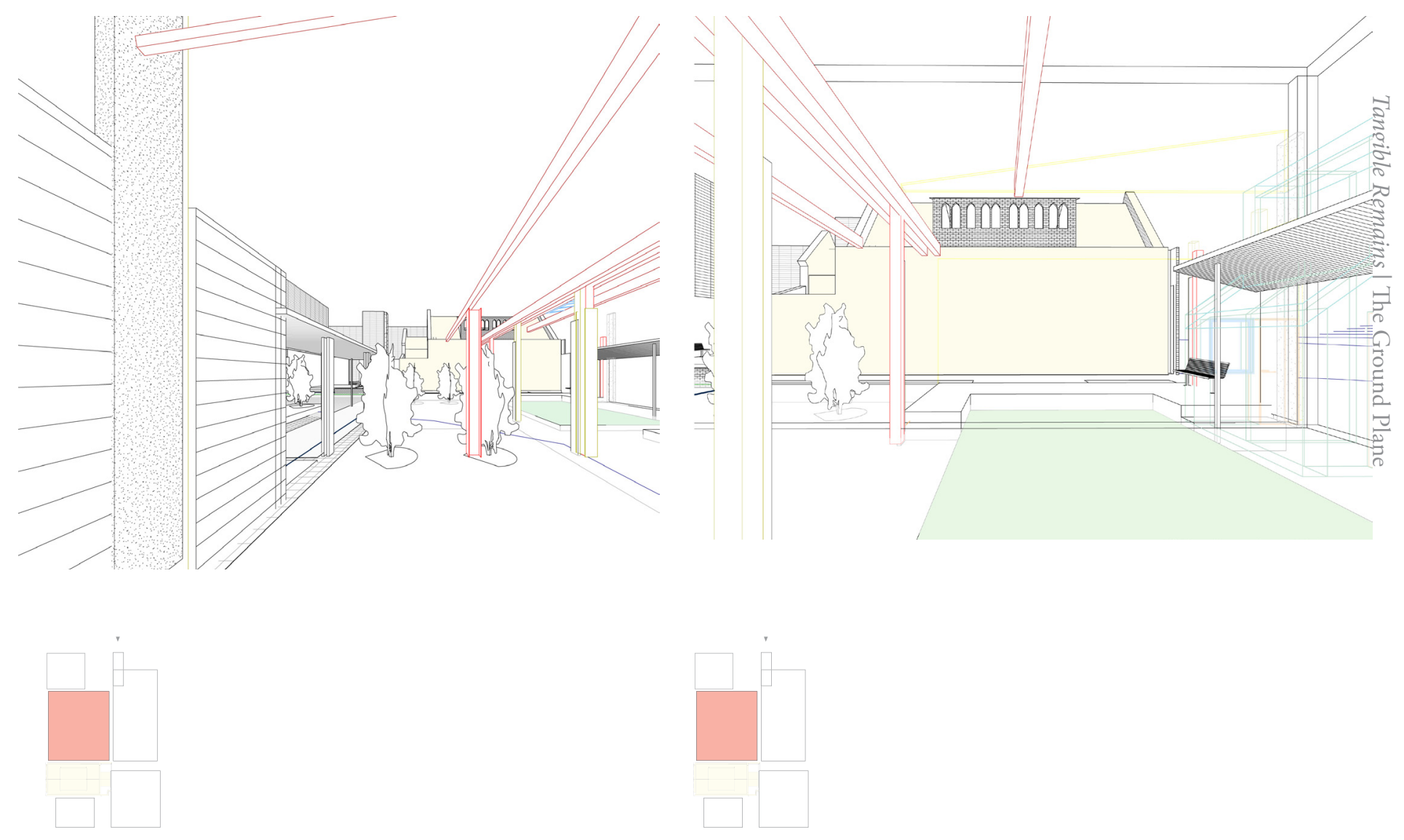




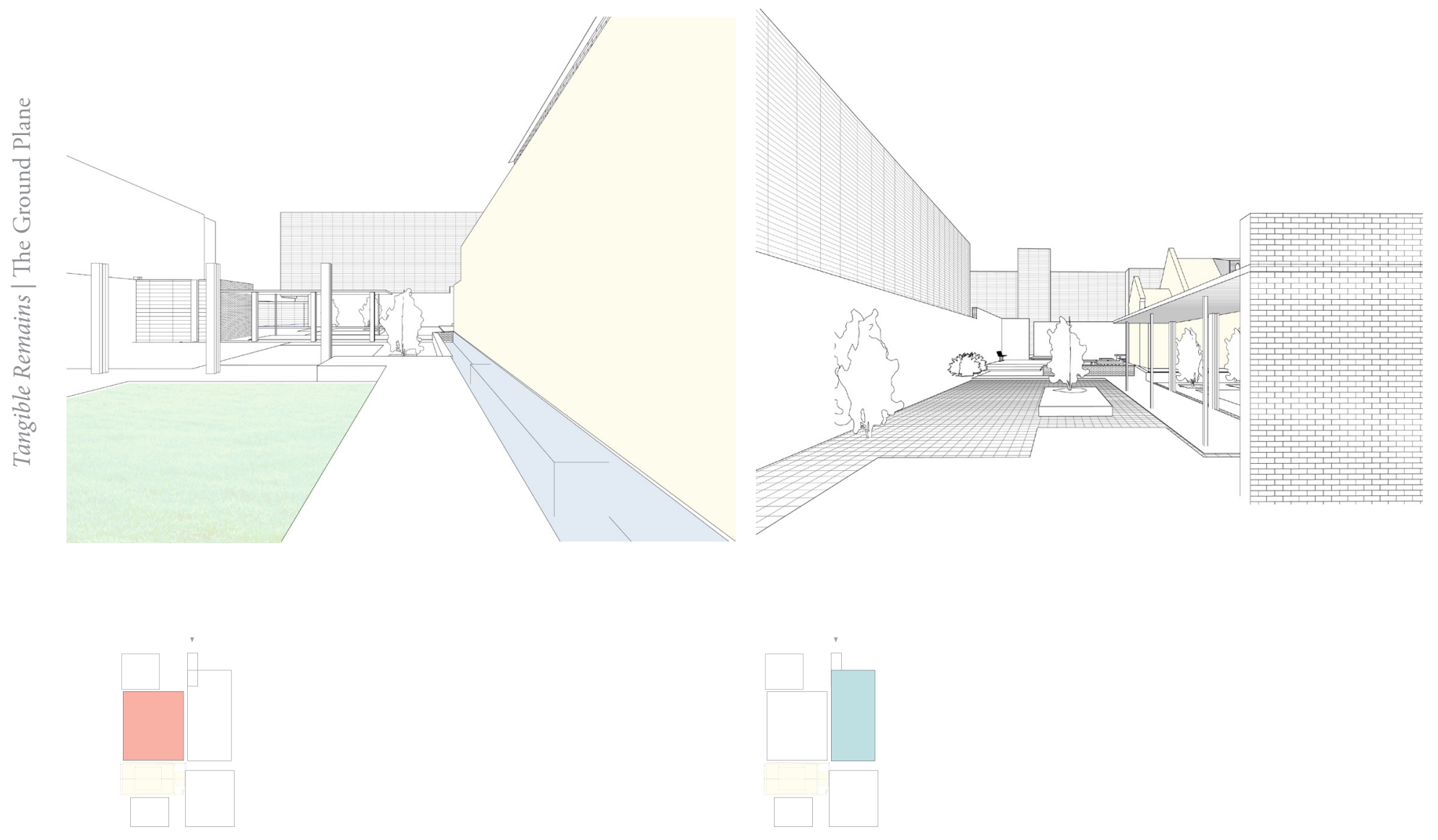



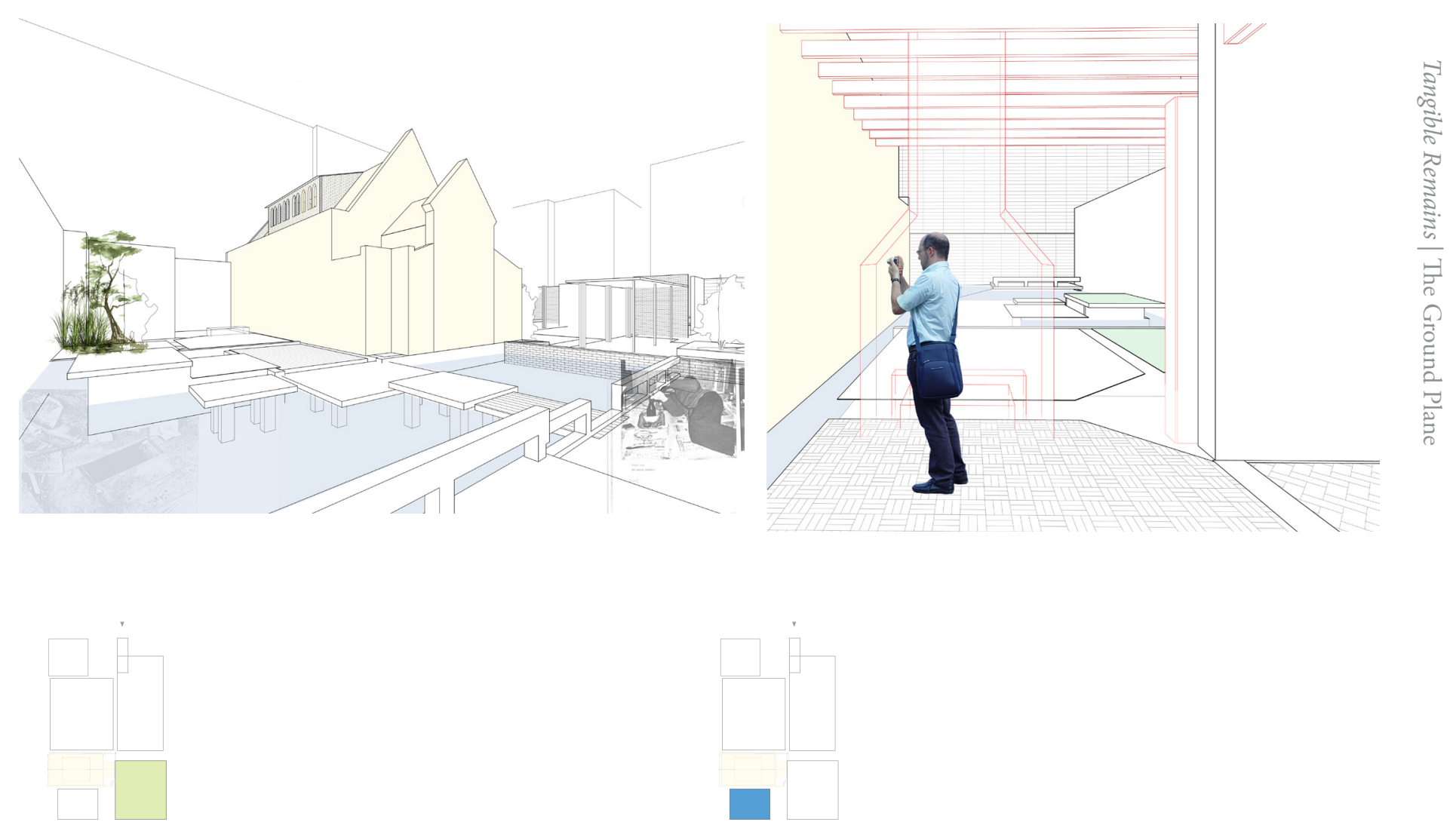


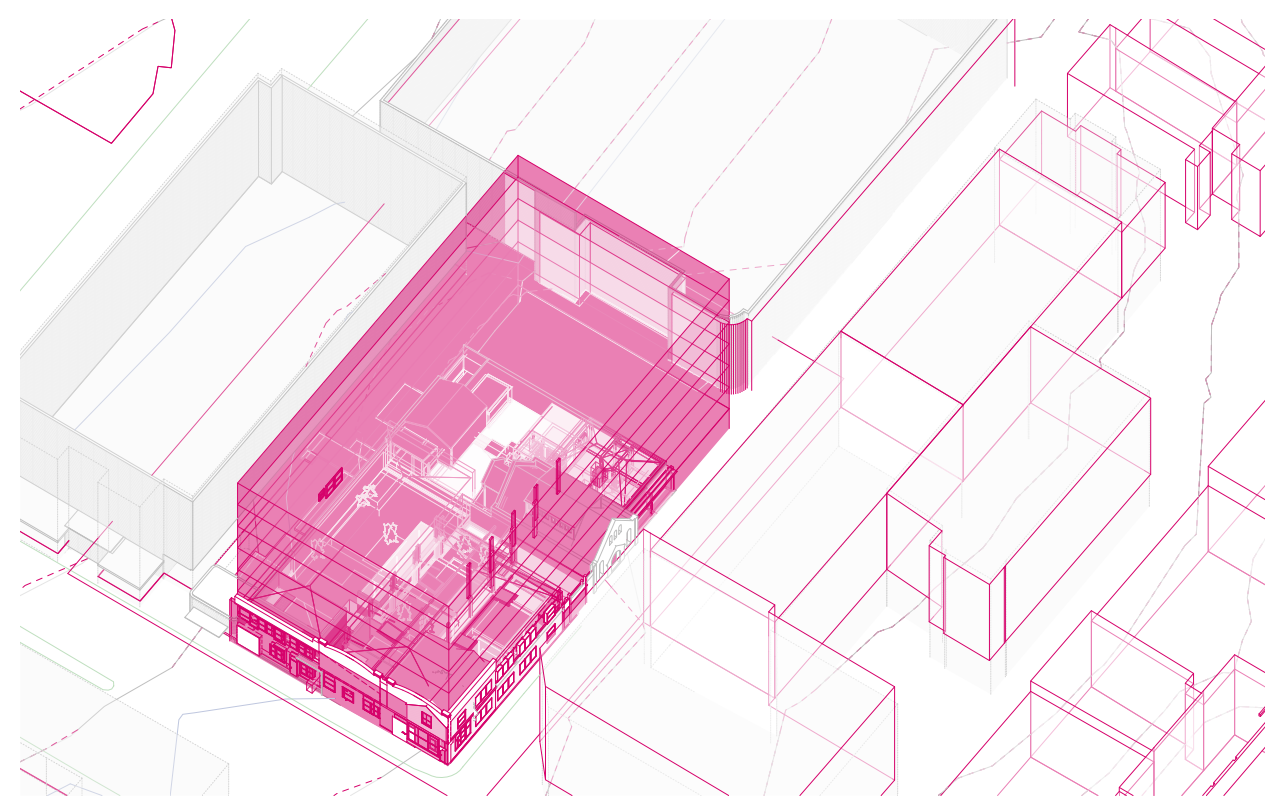

fig. 4.33. Diagram of the Chinese Garden of Immanence overwritten by the previous buildings and massing of the floors stacking towards the maximum height restriction. The three dimensional palimpsest marks the transition to the next design phase. 


\section{Conclusions}

The conclusion of this experiment is a light intervention that preserves aspects of the existing site. The historic design principles of the Chinese Garden introduced a rich set of parameters for navigating and drawing upon the complexities of the site. Significantly the idea of establishing zones and the process of designing through a singular narrative: an individual journey through the garden.

The design developed a considerate relationship with the Chinese Mission Hall; the hidden gem. By shifting the focus from the heritage listed façade, to the western elevation (rich with memories and activity) and the form in its entirety from the mountain, the design celebrates the exposed beauty.

The delicacy of level changes materialised the idea of extracting traces out of the collapsed palimpsest. The tensions between the layers and between the programmatic requirements were touched on lightly yet present opportunities to be aggravated. The design is thus a very polite test of the material, a garden working too well.

The garden is rich with meaning yet the subtly of the architectural translation is a key focus progressing forward. Where Eisenman provides an inventory of key gestures, this design engages the involuntary by focusing on a more individual journey. The use of memory and live traces through the narrative is thus important and needed to be developed further. Repeated notes or sequences (materials, spatial arrangements, and combinations) provided opportunities to echo moments from the past in the present. 

Program: Art School

Scale: Mezzo

Condition: Previous

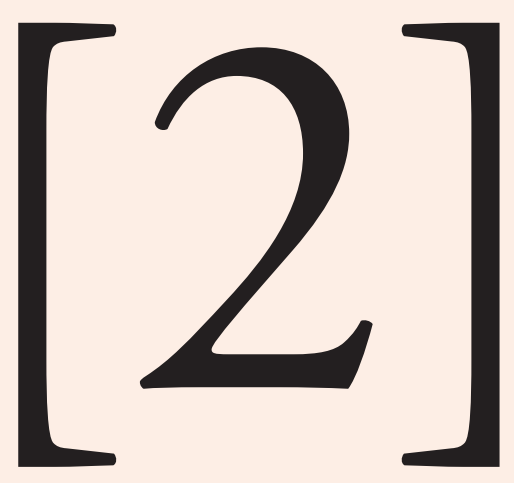

Design Phase 2 medium scale 


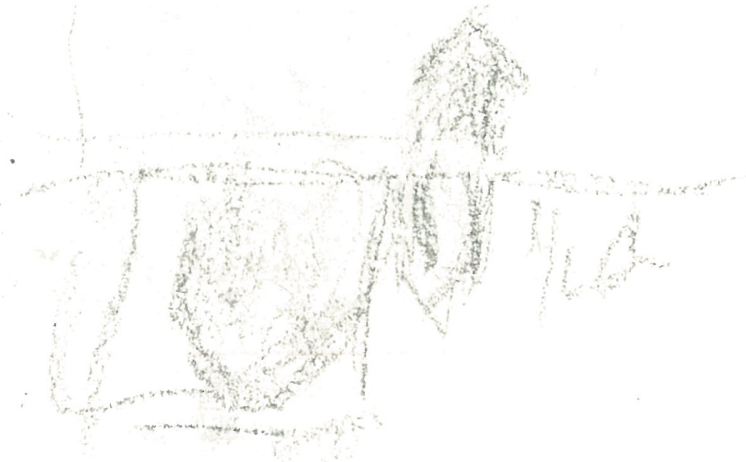

fig. 5.1. Preliminary sketch of Design Phase Two

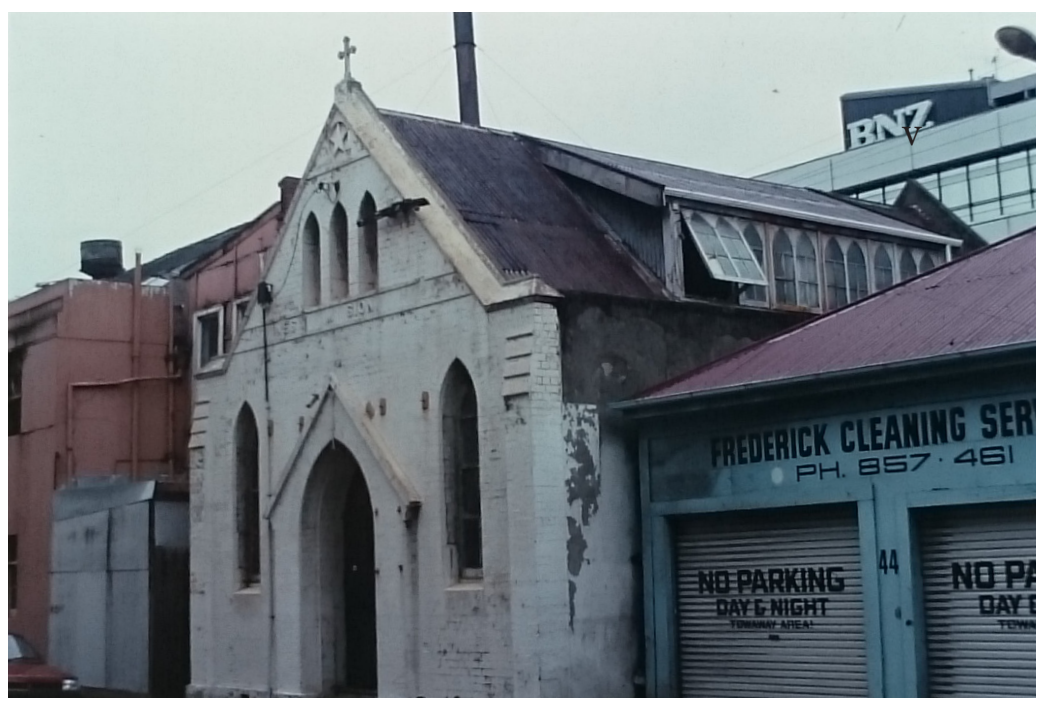

fig. 5.2. Chinese Mission Hall (1980s-1990s) 


\section{Five | Introducing volume; an Art School}

The art school investigation presented an opportunity to explore the potentials of the research with greater programmatic intensity. Narrative structure and traces of occupation and intensities were next explored through level changes and an extended third dimension. A ghosting of past architectures directed the scale of the project, presenting spatial volumes familiar to the site. An understanding of movement through these volumes and zones became inherent in this section. How can the movement be considered as bodies themselves, intercepting with the program? How can the art school nurture the collective disciplines and evoke the intensities of memories past?

With the introduction of multiple levels and the previous scale, the vertical circulation of the site over time was a focus. Could these correlate with the programmatic needs of the art school? How could the new co-exist with a suggestion of the previous movement; a brush of a ghost?

\section{Re-enchanting the Academy ${ }^{25}$}

The current discourse around New Zealand Art Schools declares the need for collaborative practice. Artist's, academics, teachers and industry stakeholders from across New Zealand congregated in Wellington this year to discuss the future of New Zealand Art Schools at Art School of the Future Symposium. Usually operating in 
isolation of one another, the hui was the first event of its kind in New Zealand and included speakers from a diverse range of international schools. Three key areas for improvement were concluded over the two days; a declassification of disciplines, community involvement and the idea of an 'after sales care'26. The consensus was for an ultradisciplinary system to inspire inventive practice that embraces future development in the art world. A desire was also expressed for the provision of 'intangible spaces; where the magic can happen". ${ }^{27}$

As the Chinese Garden extended the discussion of dialogue between the old and new to include cross-cultural hybridity, the art school introduces institutional dialects between public:student:staff. The design questions hierarchies and the thresholds between disciplines and year levels. How can the art school engage layers of the site with the diverse narratives within the art school and broader community?

The design phase builds on the orders set by the Chinese Garden by first developing design criteria from the institutional requirements of the Art School then negotiating with the garden design. The process will identify the synergies between the two and explore potential components to be developed or omitted. Maquette modelling is to be introduced into the methodology for initial explorations of this editing procedure.

\section{Case Studies}

To define constraints for the design experiment, precedent studies are fundamental in understanding the spatial and pragmatic requirements for the disciplines and common areas.

\footnotetext{
26. A term coined by Prof David Cross to express the responsibilty of institutions to nurture recent graduates.

27. Ngataiharuru Taepa artist and Director of Maori Arts at College of Creative Arts, Massey University of Wellington
} 

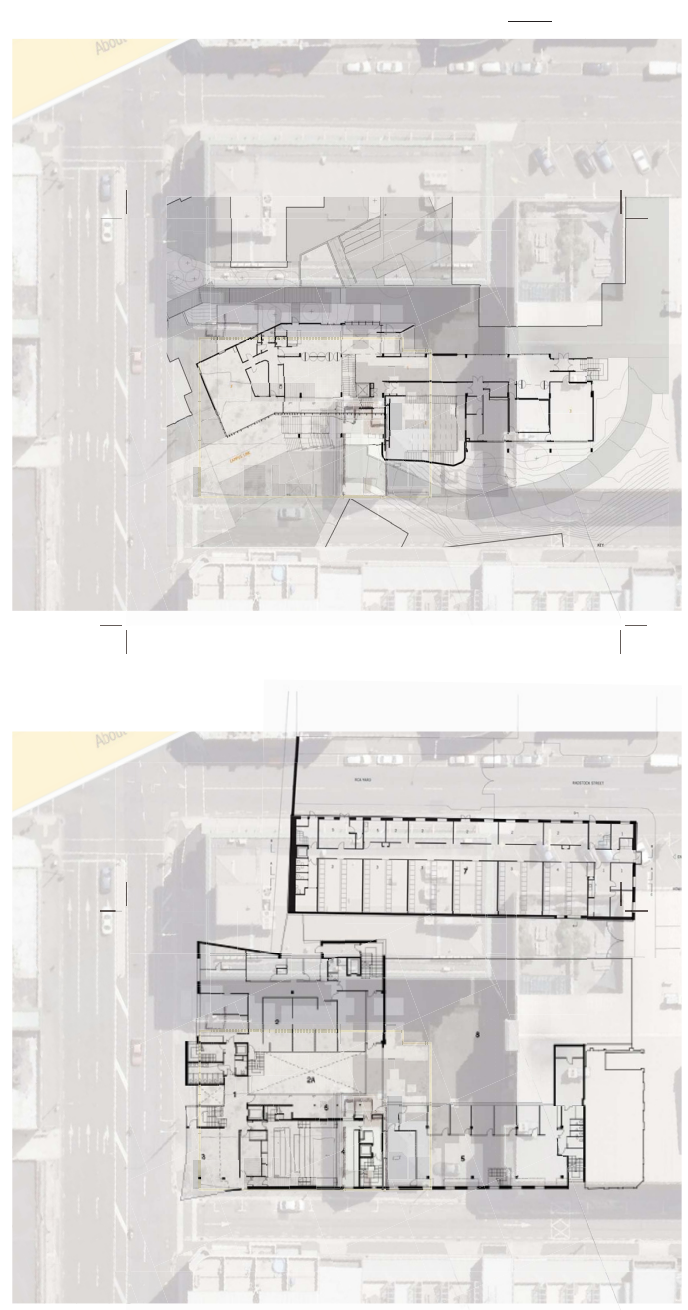
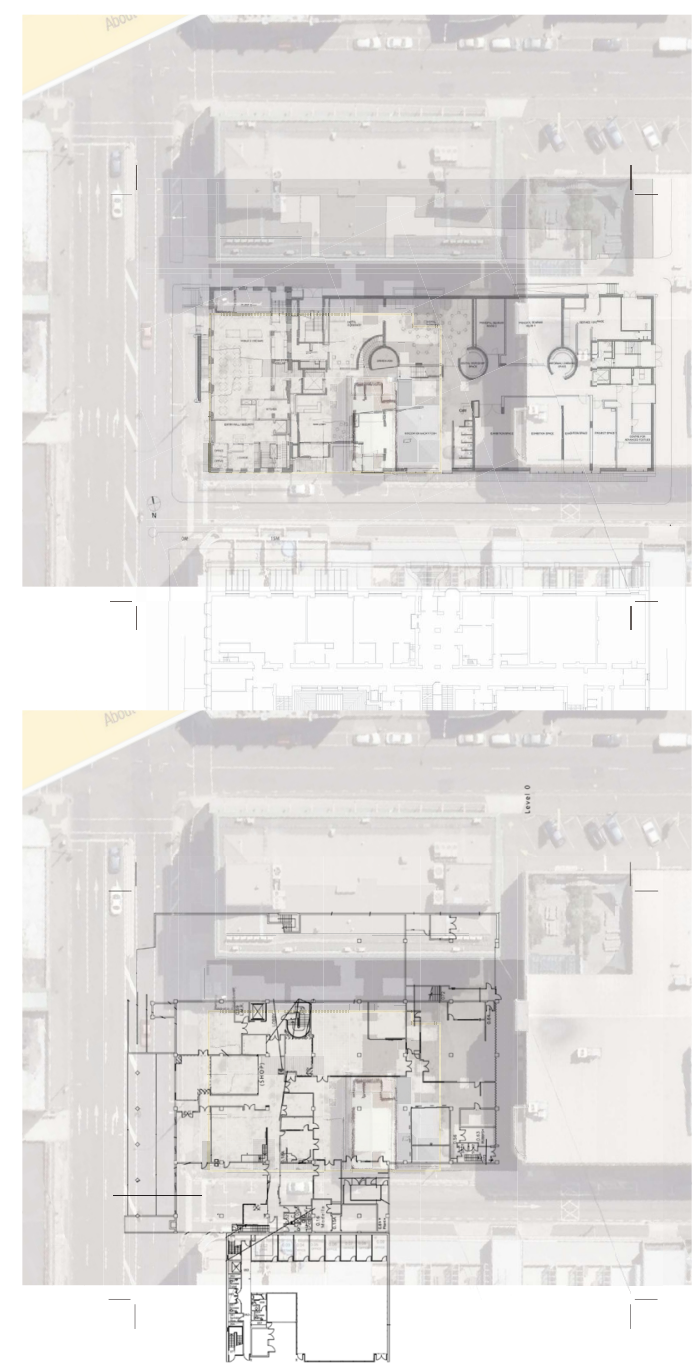

fig. 5.3. Illustrates the small scale of the site in relation to scale plans of similar fully equipped institutions. Clockwise from top left: Te Ara Hihiko, GSA, VUW SOAD and RCA 

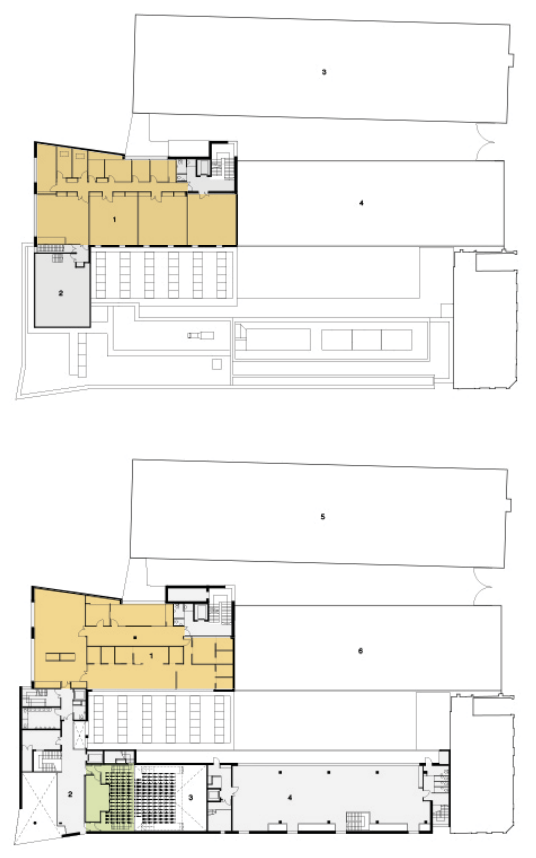

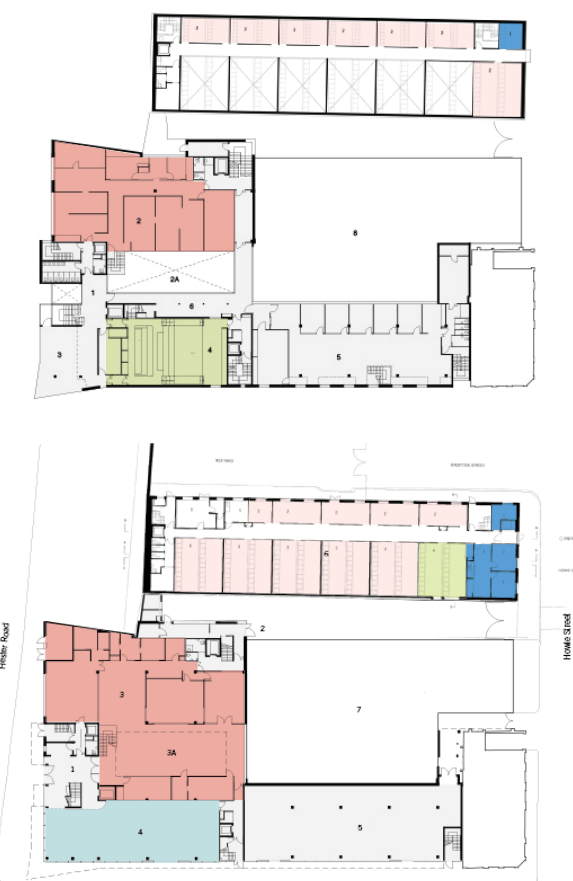

Bastersea Brige proas

Tutorial

Office Gallery
Print making Photography Painting

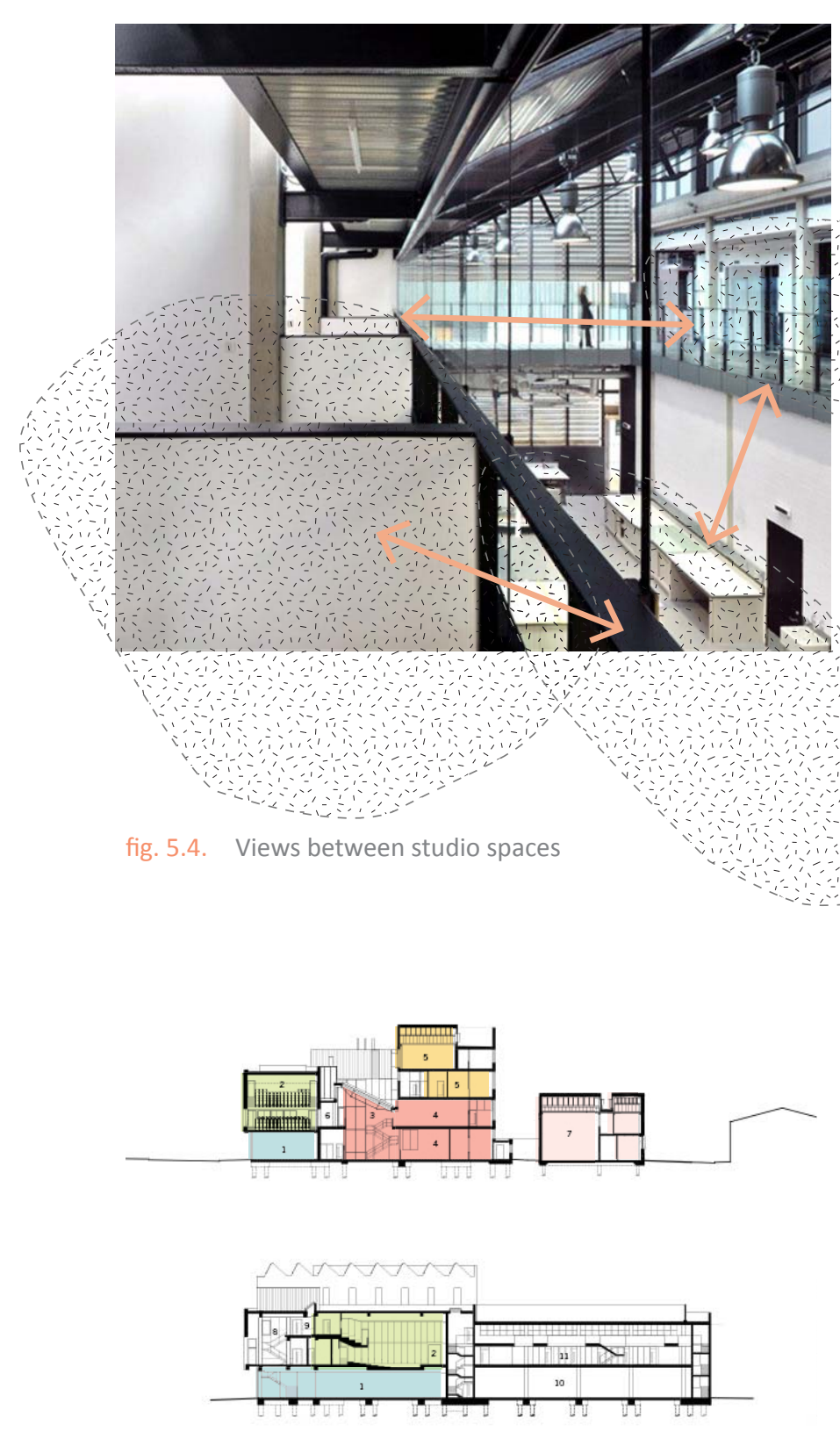

fig. 2.5. (Left and Above) Study of spatial allocation 
$\underline{\text { Royal College of Art Battersea Campus }}$

Haworth Tompkins

London, England 2009-2015

The three-stage masterplan brought together all the fine art programmes to a single site for the first time in RCA's history. The interdisciplinary success can be accredited to the planning of a fluid relationship between the programmes with the Head of Schools ${ }^{25}$. The 'horizontal drift'26 sought to eliminate the boundaries traditionally between disciplines and is achieved through the interlocking spaces and broad views between ${ }^{\text {fig. 5.4. }}$.

a creative factory

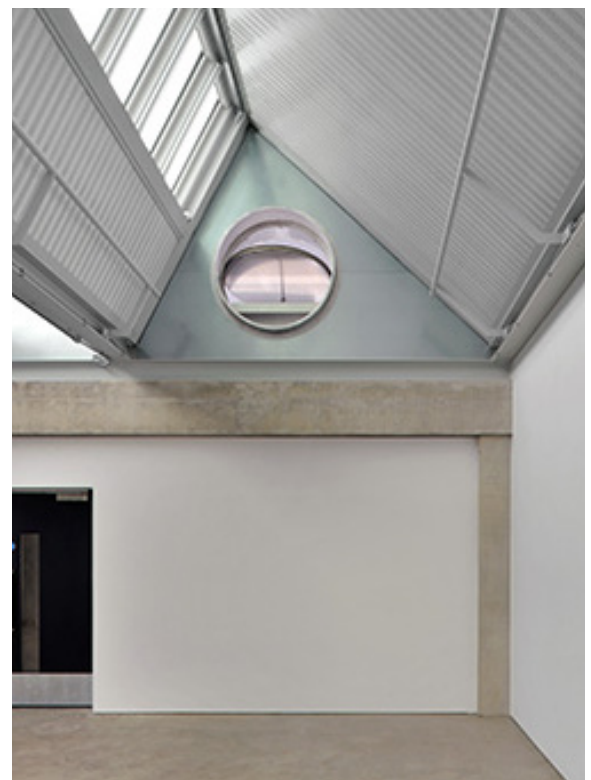

fig. 5.2. Painting Studio, Sackler Building

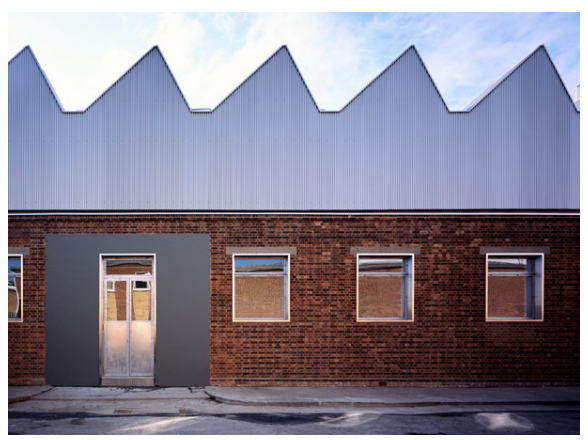

fig. 5.1. The Sackler Building Elevation 


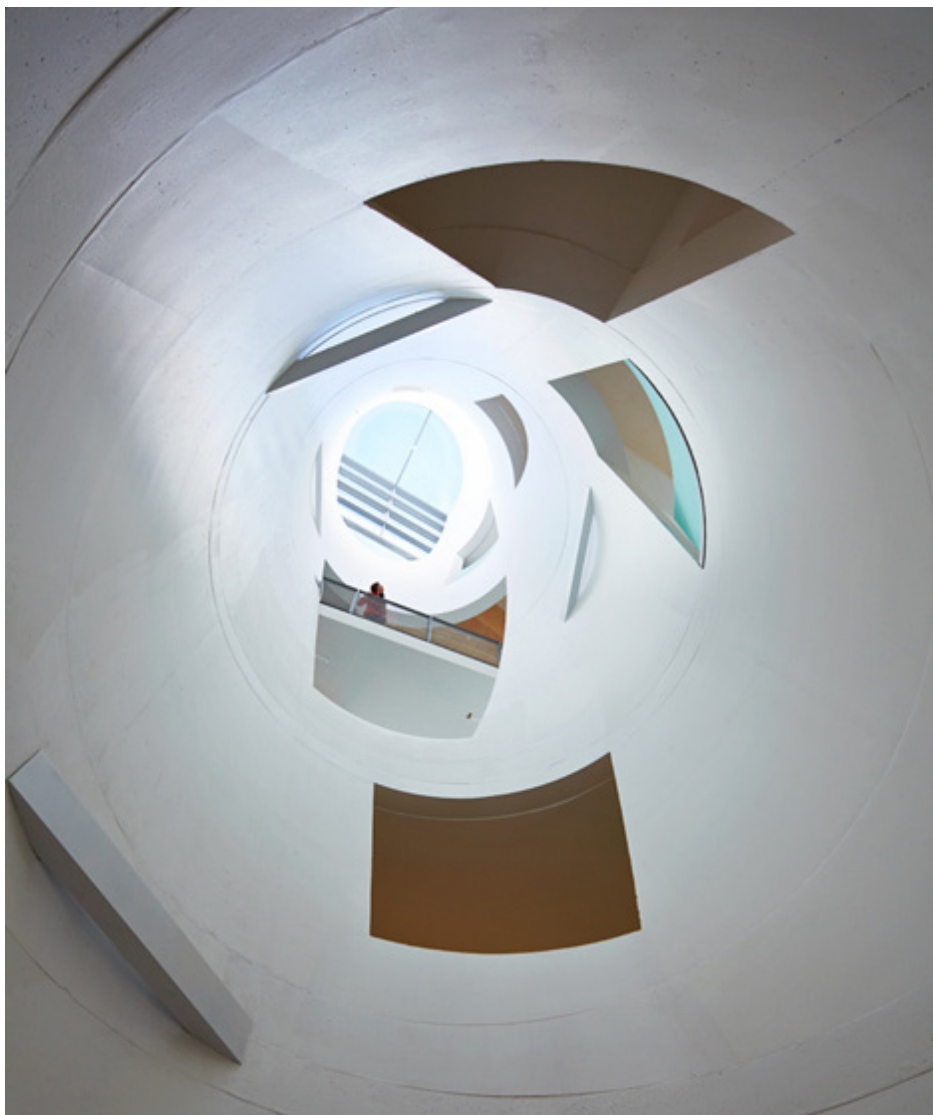

fig. 5.4. Driven void allows sound and light to move between the levels

Tutorial

Office

Spraybooth

Photography

Woodwork Shop

Metalshop

" "I" "I": Assembly Space

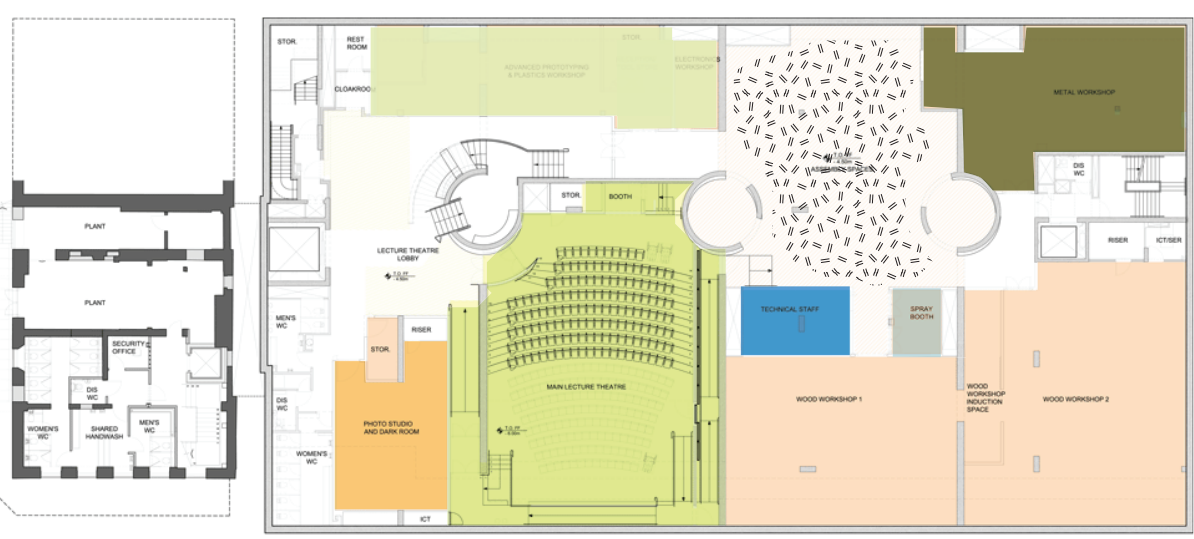

$\theta_{N}$ fig. 5.3. Basement Plan 
Glasgow School of Art

Seona Reid Building

Steven Holl Architects

Glasgow, Scotland 2014

Light wells are an integral component of the Seona Reid Building, the hub of collaboration. The driven voids send volumes of light to the lower levels, enhancing connection with the outside and between studios. Stairways carve through or around the voids, activating the spaces and fostering interaction between disciplines.

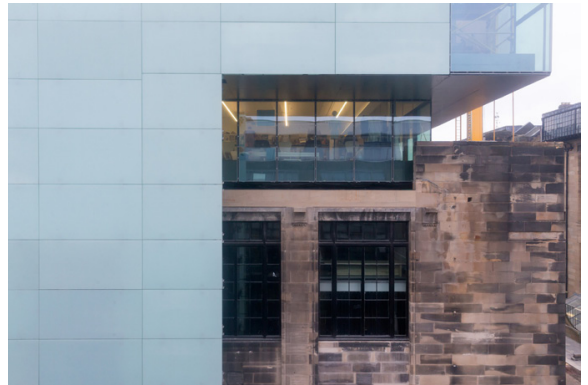

fig. 5.5. New intervention with existing

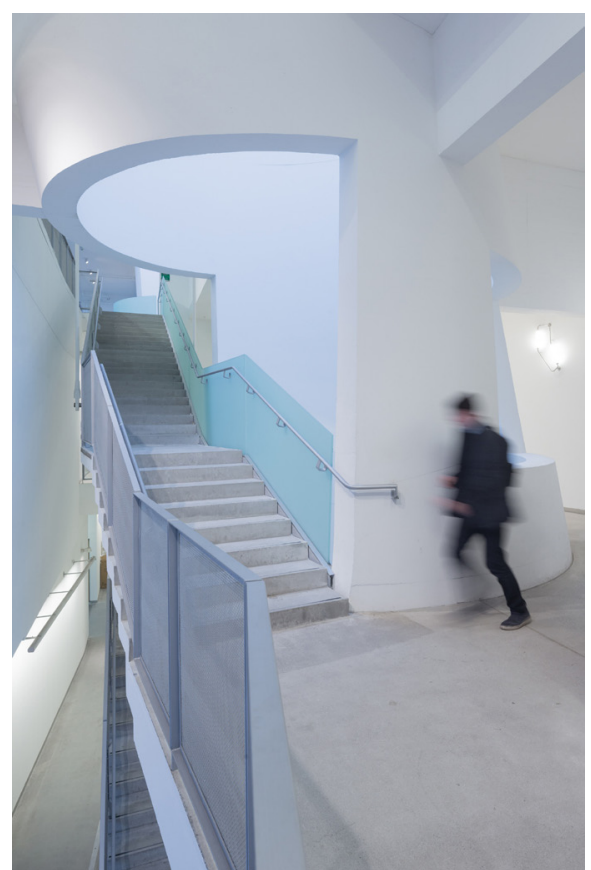

fig. 5.6. A stairway intersects a driven void 


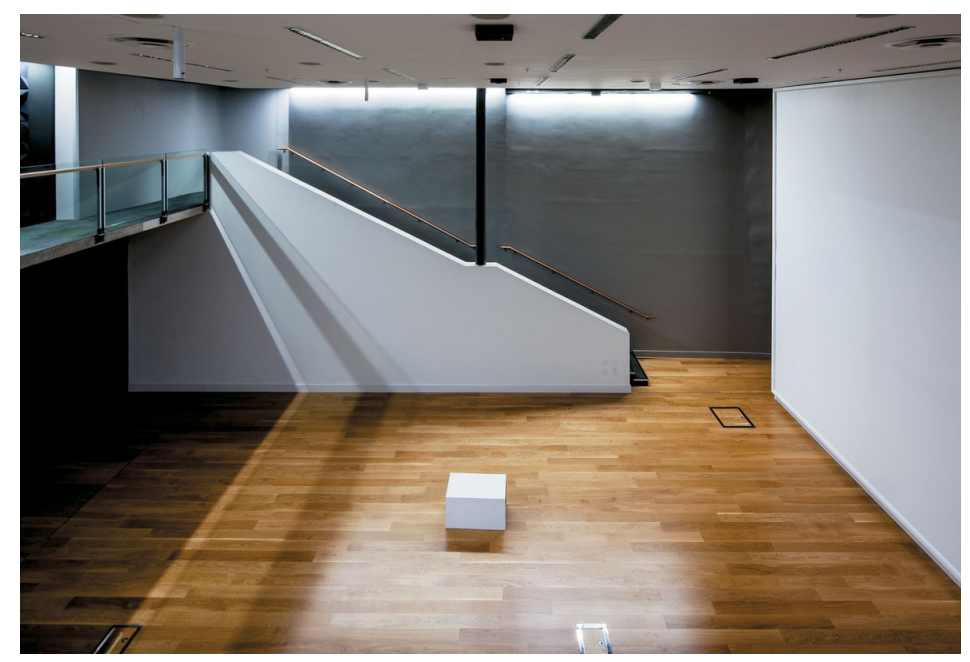

fig. 5.7. 'The Pit', seating is cleared to transform the auditorium into a project space or gallery
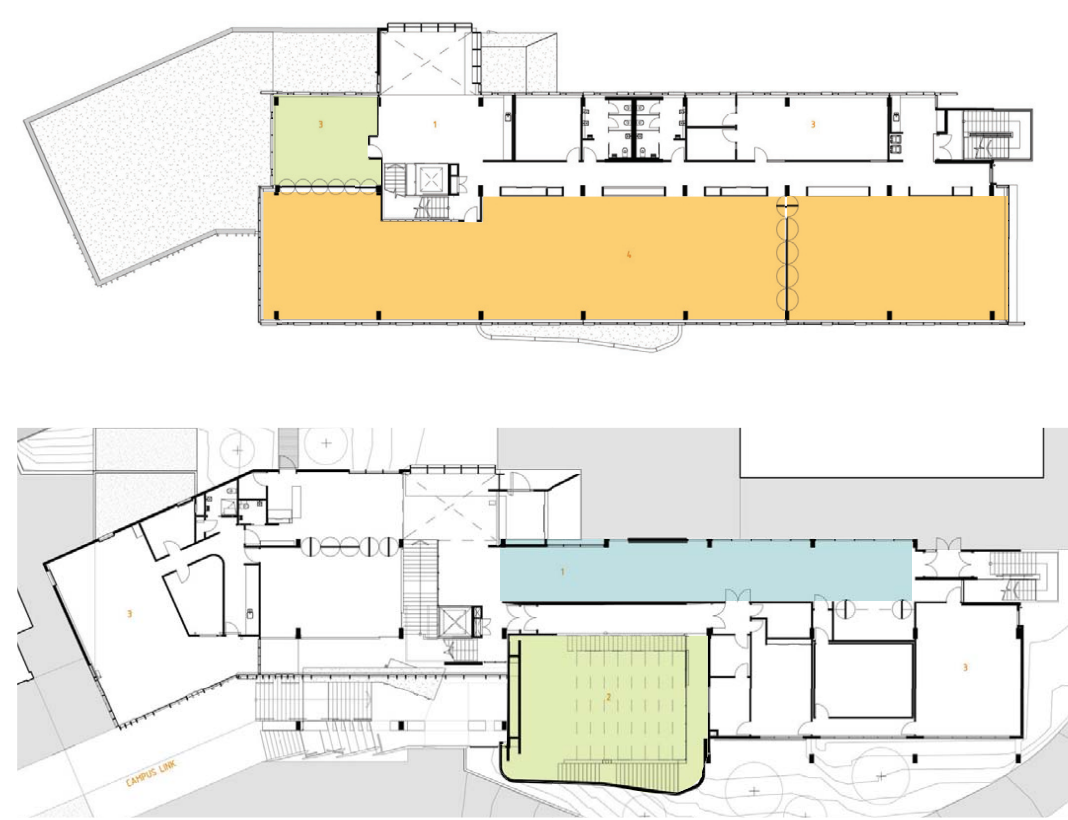

fig. 5.8. Plans identify key areas 
College of Creative Arts, Massey University

Te Ara Hibiko Building

Athfield Architects

Wellington, New Zealand 2012

The Te Ara Hihiko Building provides adaptable spaces by recognising potential programmatic overlaps. The width of the ground floor corridor allows it to hold exhibitions, couches or gatherings. The studios above run the length of the building, presenting the option of various configurations. The temporality and manoeuvrability of architectural components inspires a spatial creativity in the students as well as a sense of ownership in the building.

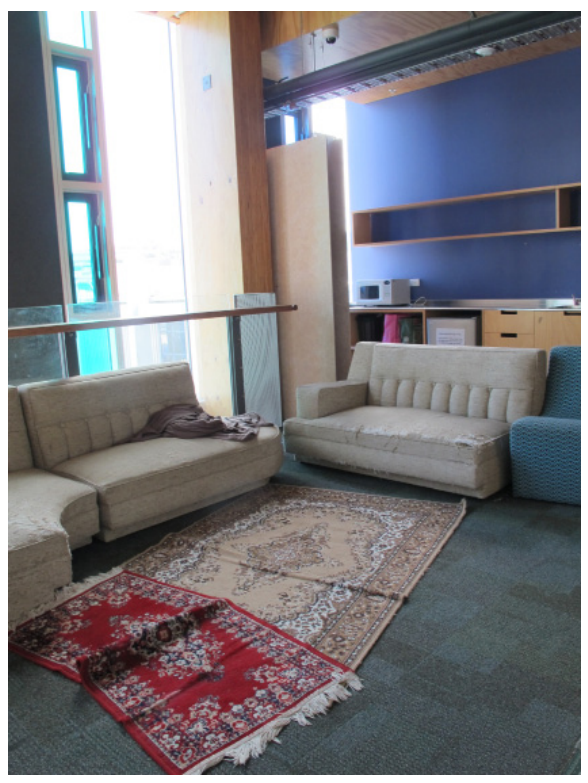

fig. 5.9. Students take ownership of Te Ara Hihiko by forming a lounge

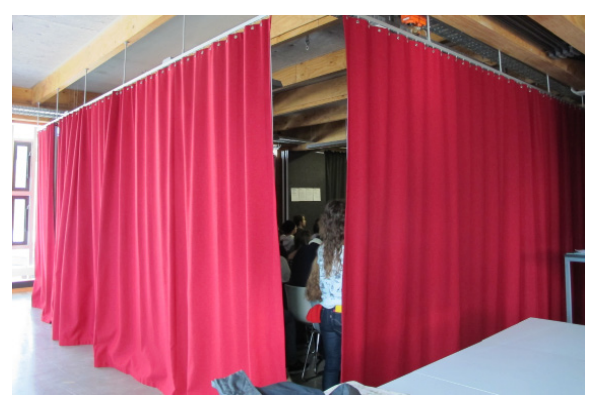

fig. 5.10. Curtain divides space in the studios 


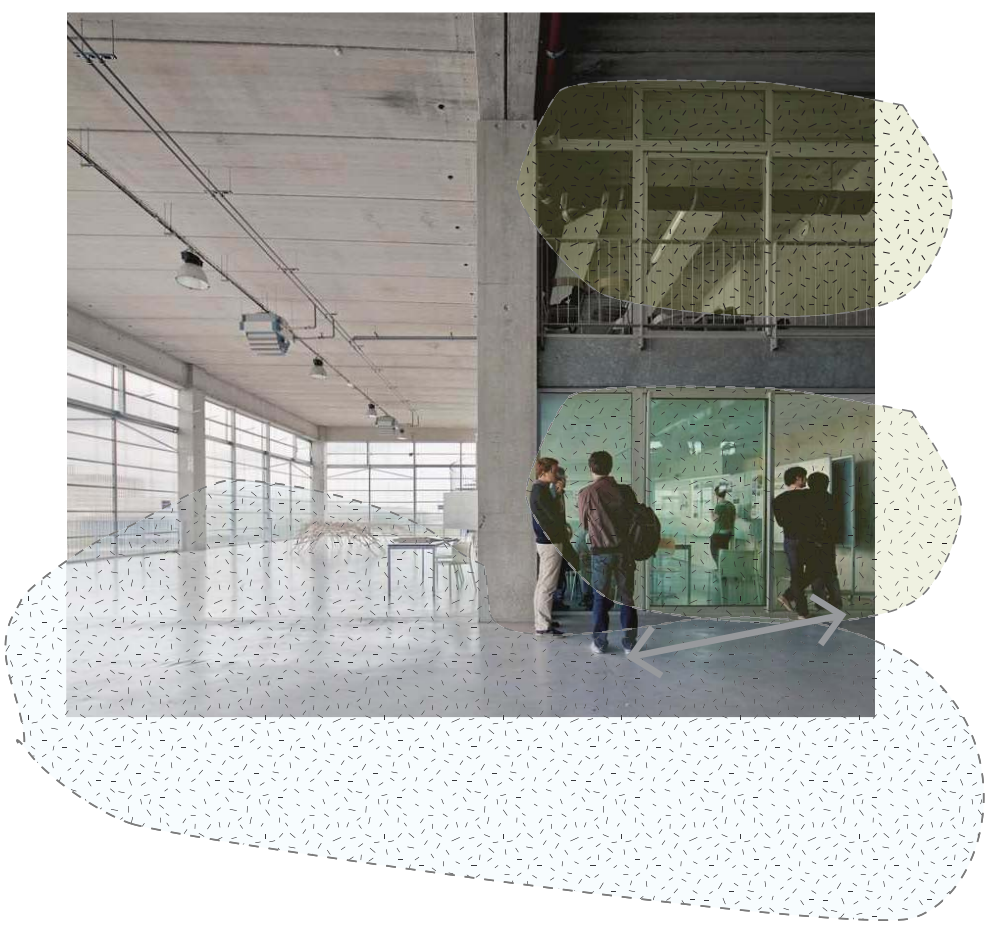

fig. 5.11. A studio, 'programmed space', overlooks a 'free area'
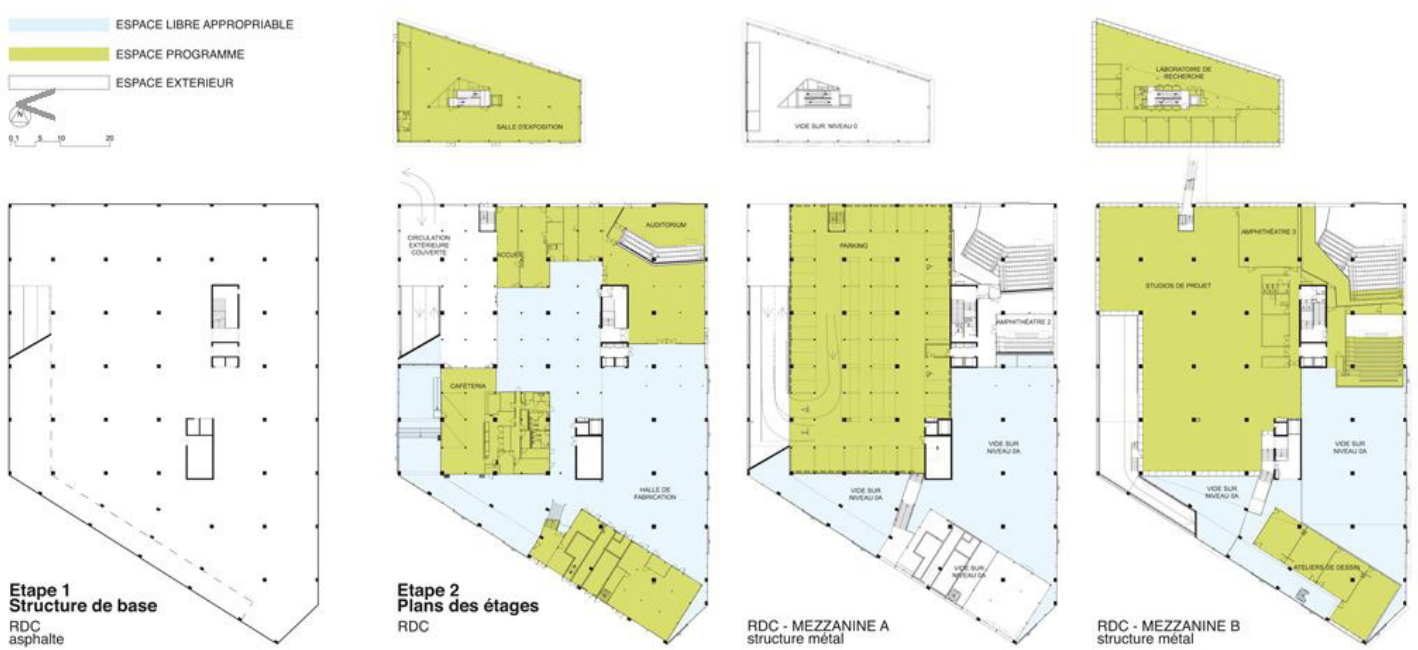

fig. 5.12. Plans depict the programmed spaces in green, free areas in blue and exterior terraces in white. 
Nantes School of Architecture

Lacaton \& Vassal

Nantes, France 2009

The Nantes School of Architecture is an extention of the public realm. Generous carpark ramps lead in and around the school, dissolving interior: exterior boundaries ${ }^{\text {fig. }}$ 5.11-fig. 5.14. The ramp forms exterior terraces to freely intertwine programmed and un-programmed spaces.

Paradoxically, it is precisely this primal move to create excess space that makes the building ecologically, socially, and financially sustainable. The building's double-height unprogrammed volumes...provide the school with adaptable and multifunctional spaces that will allow the building to be repurposed rather than destroyed and built anew. ${ }^{27}$

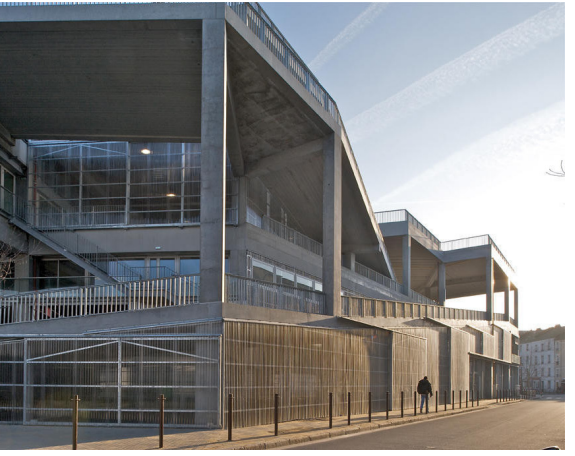

fig. 5.13. Photo. Street view of Nantes

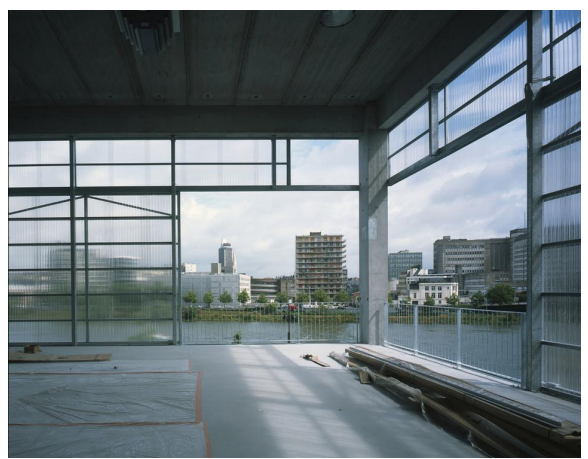

fig. 5.14. 'Free area' opens as an exterior terrace

27. (Janson 26) 


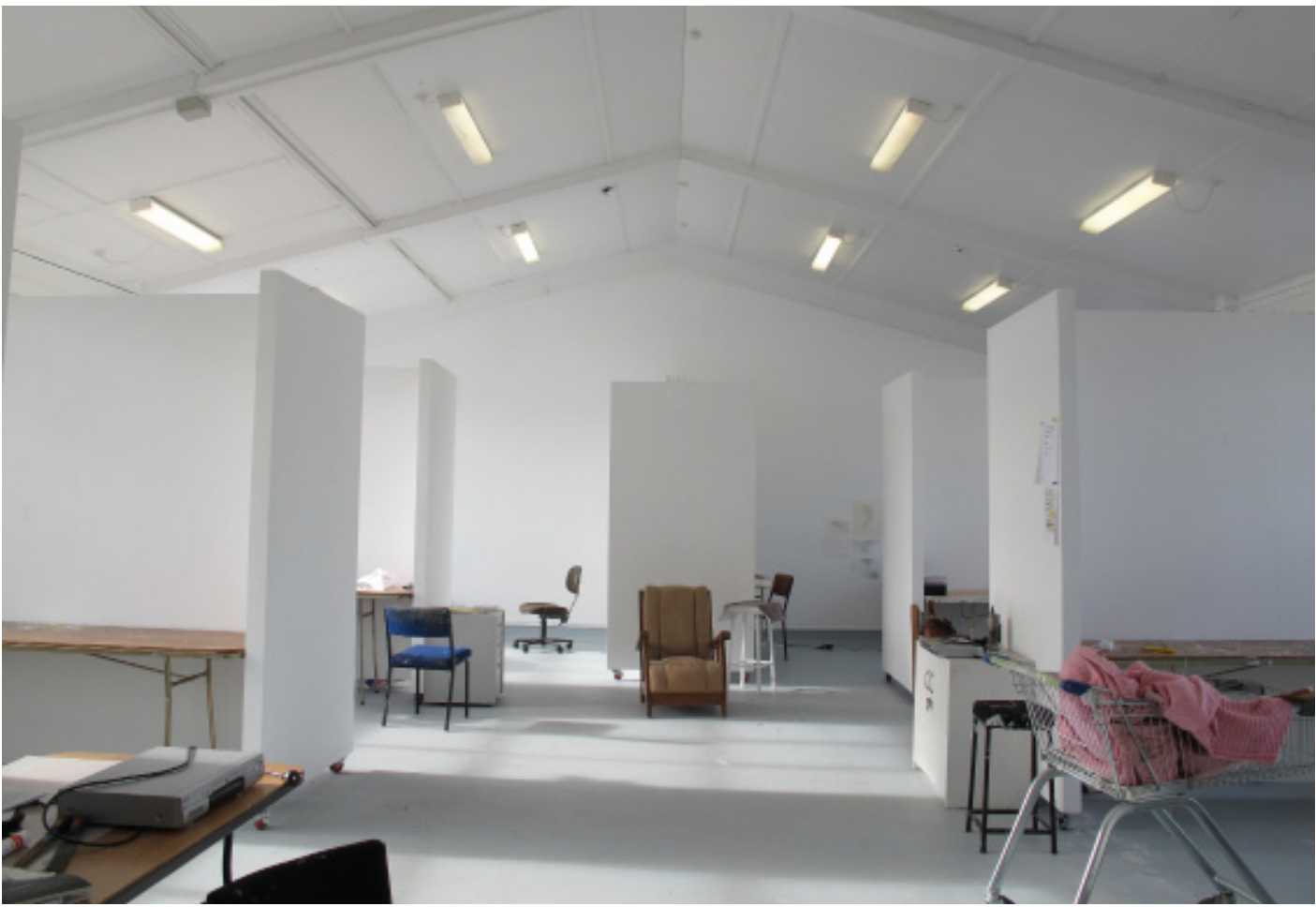

fig. 5.15. Masters of Fine Arts Studio at Massey University. Transient walls subdivide the space into dedicated studios for creative independence. The space is theirs to 'own' for their enrolment before being cleared and reconfigured for succesive students and exhibitions.

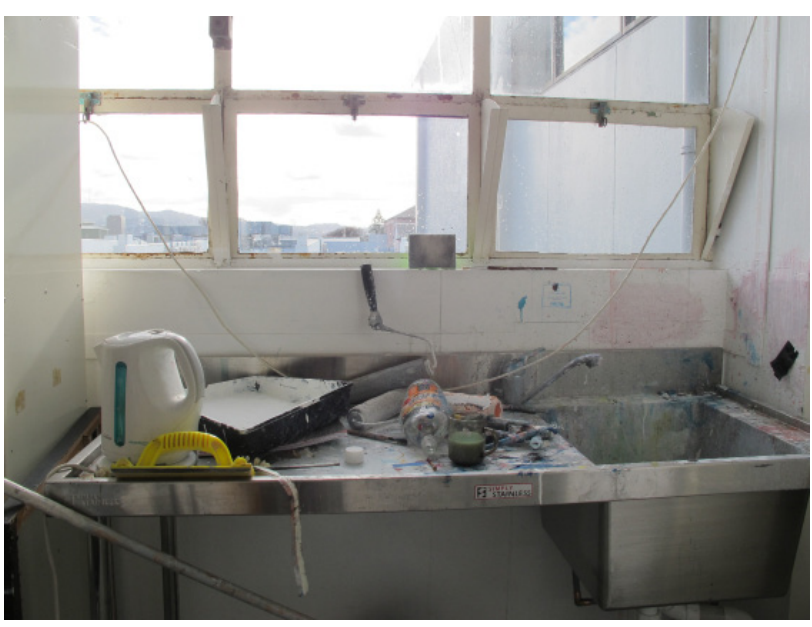

fig. 5.16. Communal sink at the painting studio, Massey

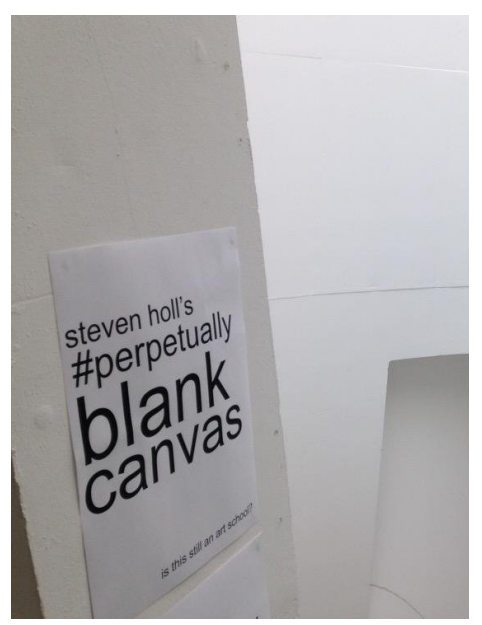

fig. 5.17. GSA poster campaign 
Materiality

Attendees at Art School of the Future Symposium expressed polar views on the topic of dirty spaces. Students expressed a craving for the patina from previous residents; surfaces which allowed the traces of use to enrich the architecture and invite experimentation. The blankcanvas-space motioned by the academic speakers is well rooted in the intention of relaxing the mind for thinking yet it presents risks of visually sterilising spaces of the creative energy and enchantment of the practice. The pristine white surfaces of Holl's Seona Reid Building bring natural light and formal articulation to the building. However, the surfaces are too dear. The institute itself felt inspired to prohibit students affixing items to the light wells to keep them sacrosanct. The students retorted with a poster campaign "Steven Holl's perpetually blank canvas: who are we preserving this space for?" The white space is a classical model for studio spaces, allowing students to take ownership of their space for their residency then painted clean. Te Ara Hihiko reinterprets the classical blank space model by introducing a palate of durable materials. Mark-able surfaces are threaded with the acclaimed timber structure - voluntarily respected by the students. Differing translucencies and textures create a rich layered space with a warmth. This model is crucial for nurturing innovation and collaboration between students.

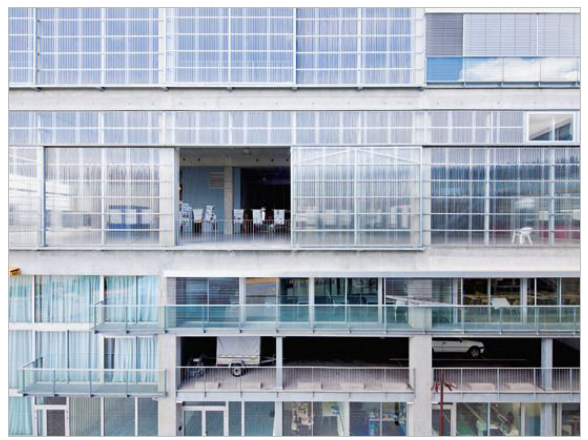

fig. 5.18. Movable polycarbonate panels on the Nantes Architecture School

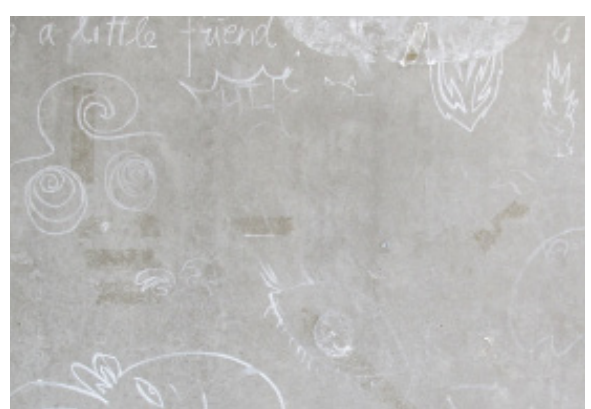

fig. 5.19. Chalk markings on a concrete wall at Te Ara Hihiko

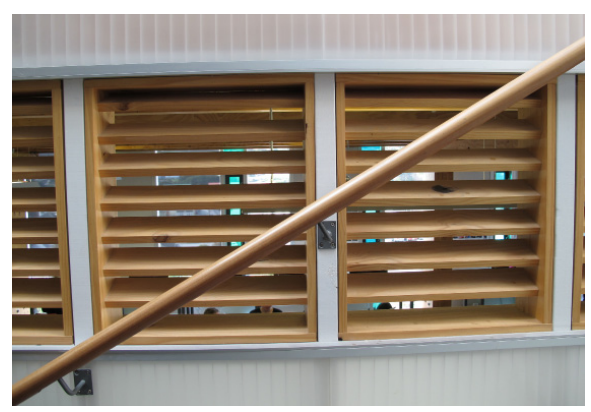

fig. 5.20. Polycarbonate and timber slates indicate activity in the studio beyond at Te Ara Hihiko 


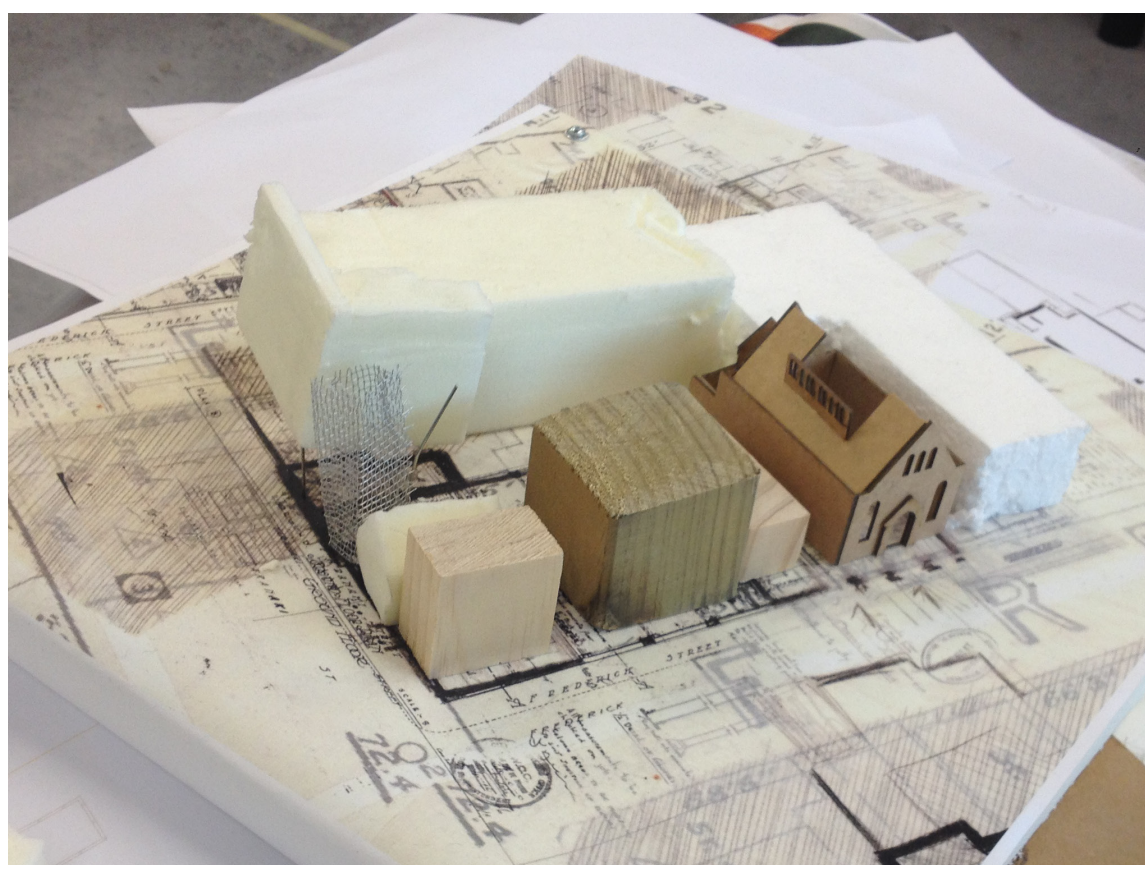

fig. 5.21. Initial massing study considering the thematic units of the Chinese Garden 


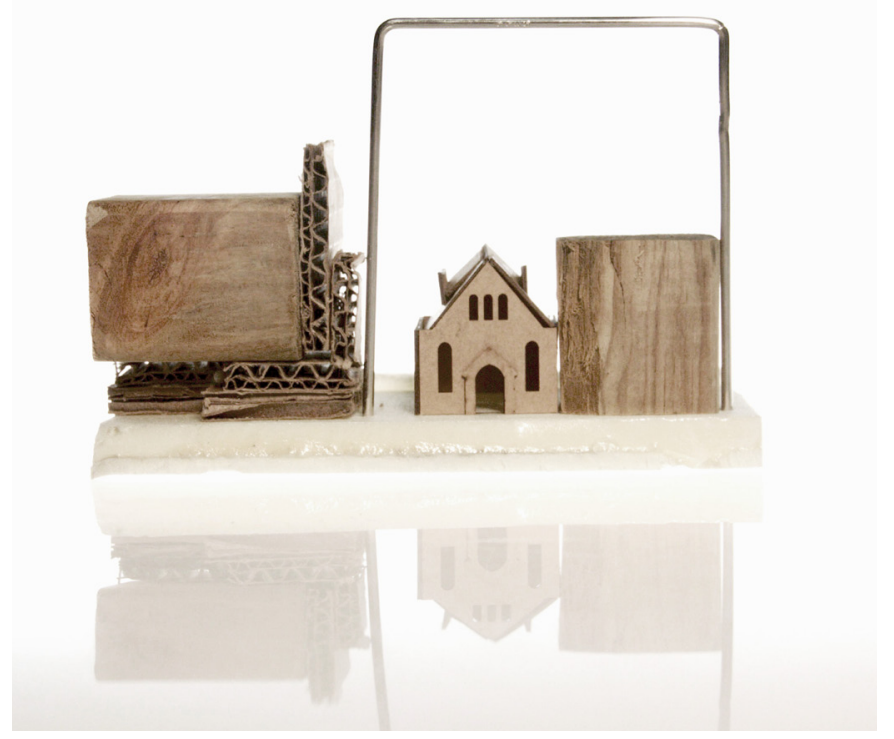




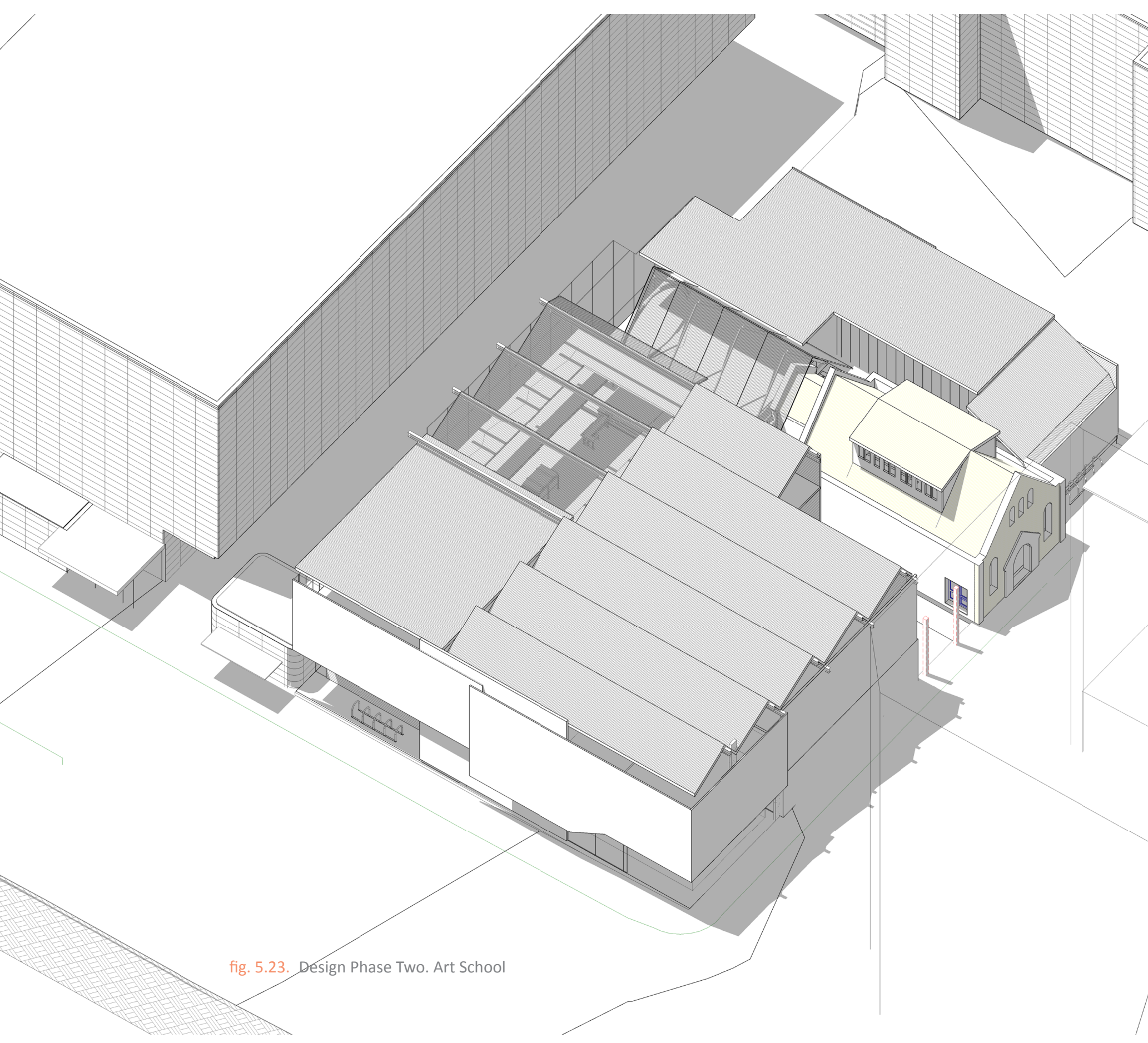




\section{Design Approach}

The design will extend the narrative methodology of the Chinese Garden to overlay three narratives: staff members, students and public. Specific requirements for the separate trajectories and disciplines were derived from the precedents and negotiated with the spatial restrictions of the site. The approach was initially conceived for the Art School to be developed on a clean slate (without the Chinese Garden), however the potentials of a programmatic assemblage drawn from the Chinese Garden palimpsest were clear.

The Art School will implore concepts of 'horizontal drift' between the narratives and disciplines to encourage cross-discipline collaboration and experimentation. Public engagement will be addressed and the building and school will become part of the broader community. The previous buildings on the site will inform the scale of the Art School and inspire spatial, surface and tectonic conditions.

\section{[public] [student] [staff]}


THEMATIC UNITS

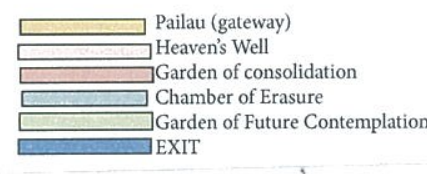

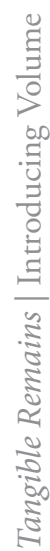

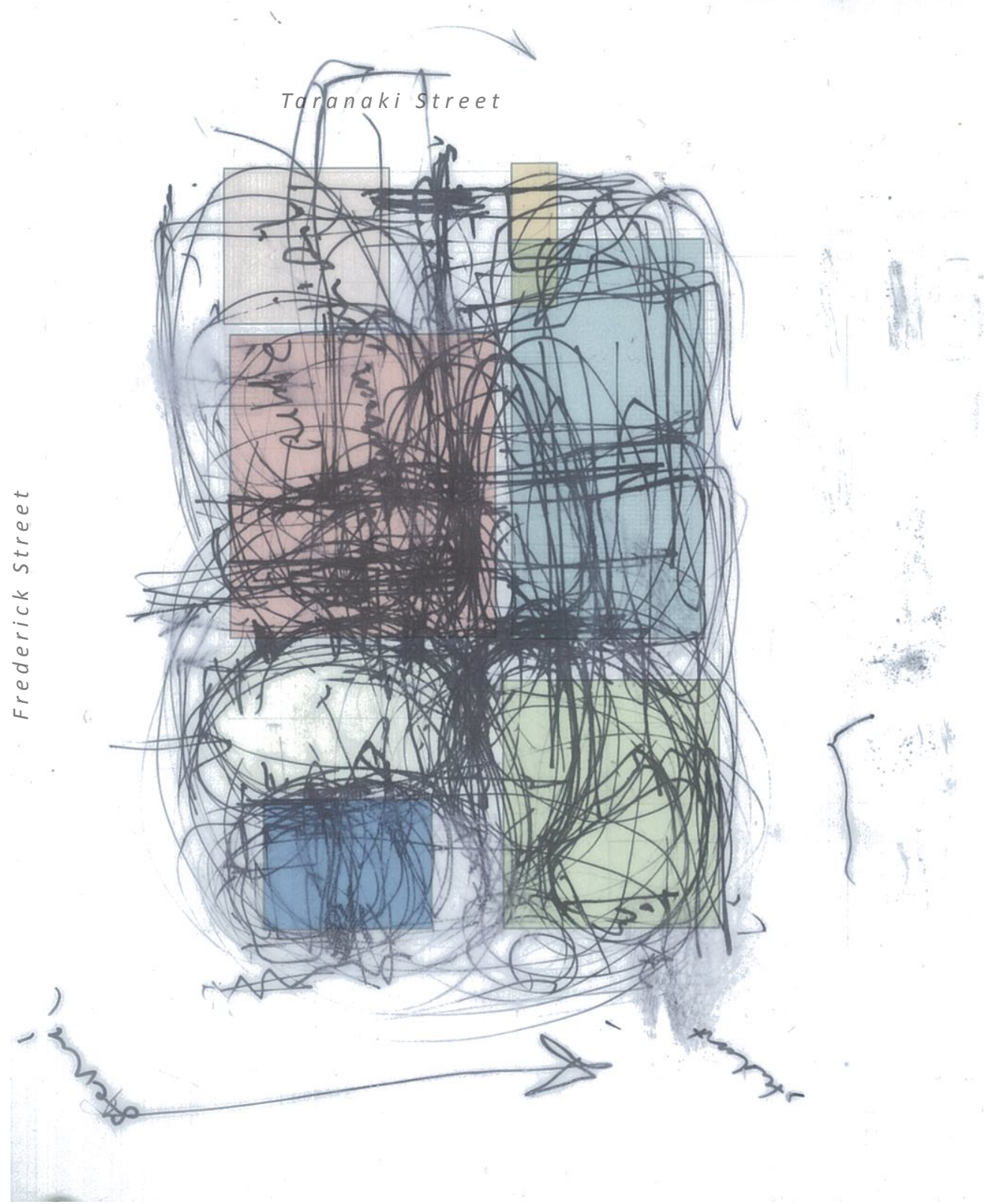

fig. 5.24. Overlay technique sees thematic units from the Chinese Garden translate into the Art School 


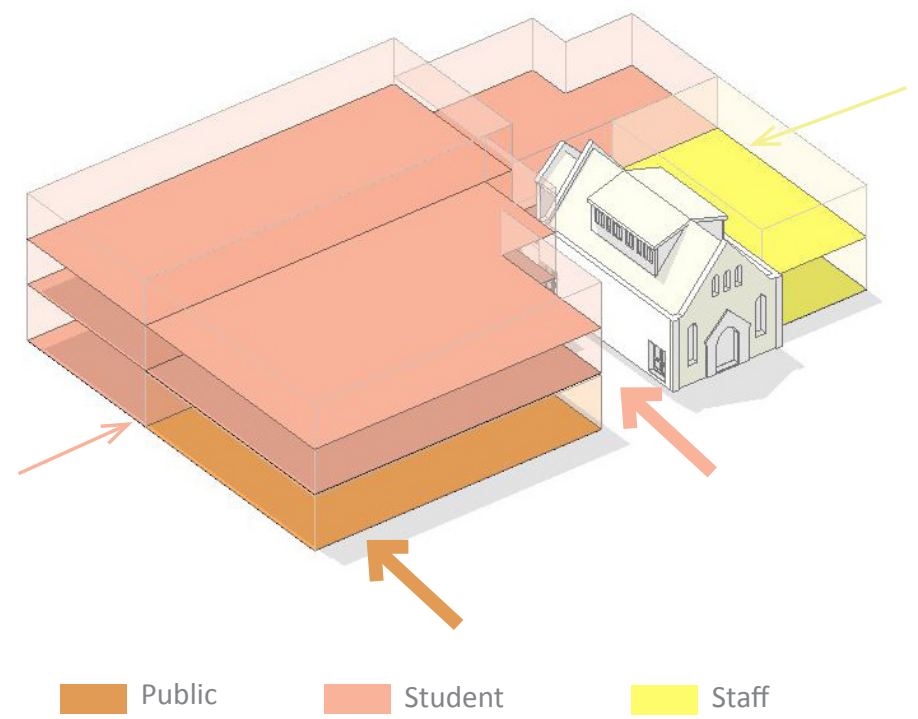

fig. 5.26. Diagram of zoning and street access for the three narratives

\section{Zoning and Circulation}

At this point the occupation of the previous buildings was reanalysed, a hierarchy of thresholds and movements were established to understand how the spaces were animated. The significance of the laneway was confirmed and thus the opportunity for the space to create a student hub identified.

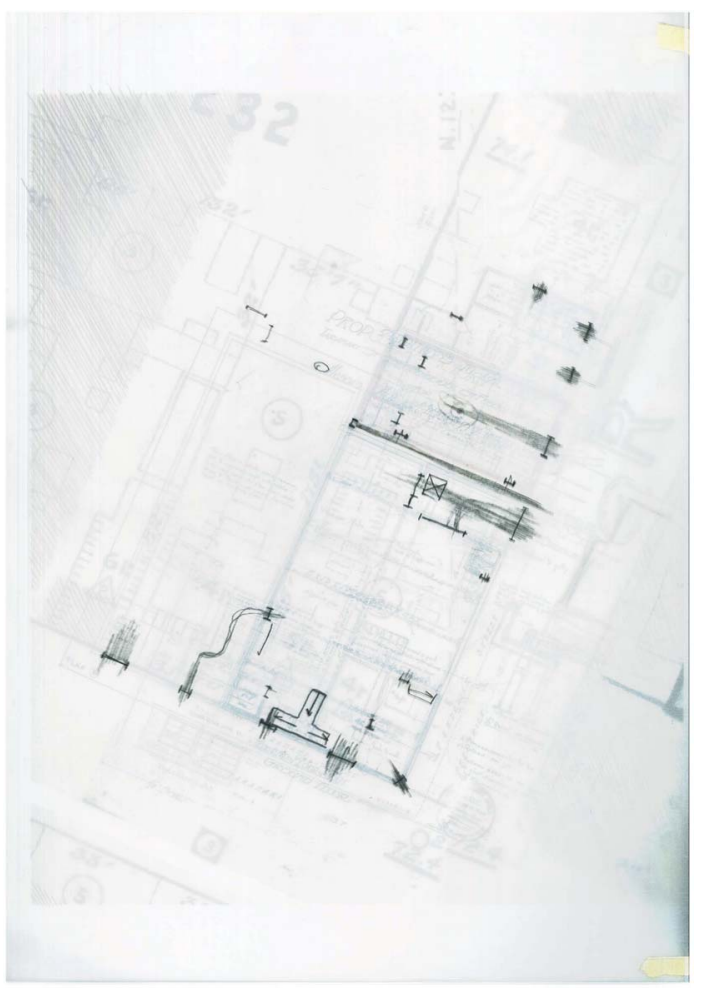

fig. 5.25. Circulation analysis of previous buildings. Key thresholds and flows of movement expressed with varying line intensities 


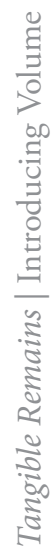



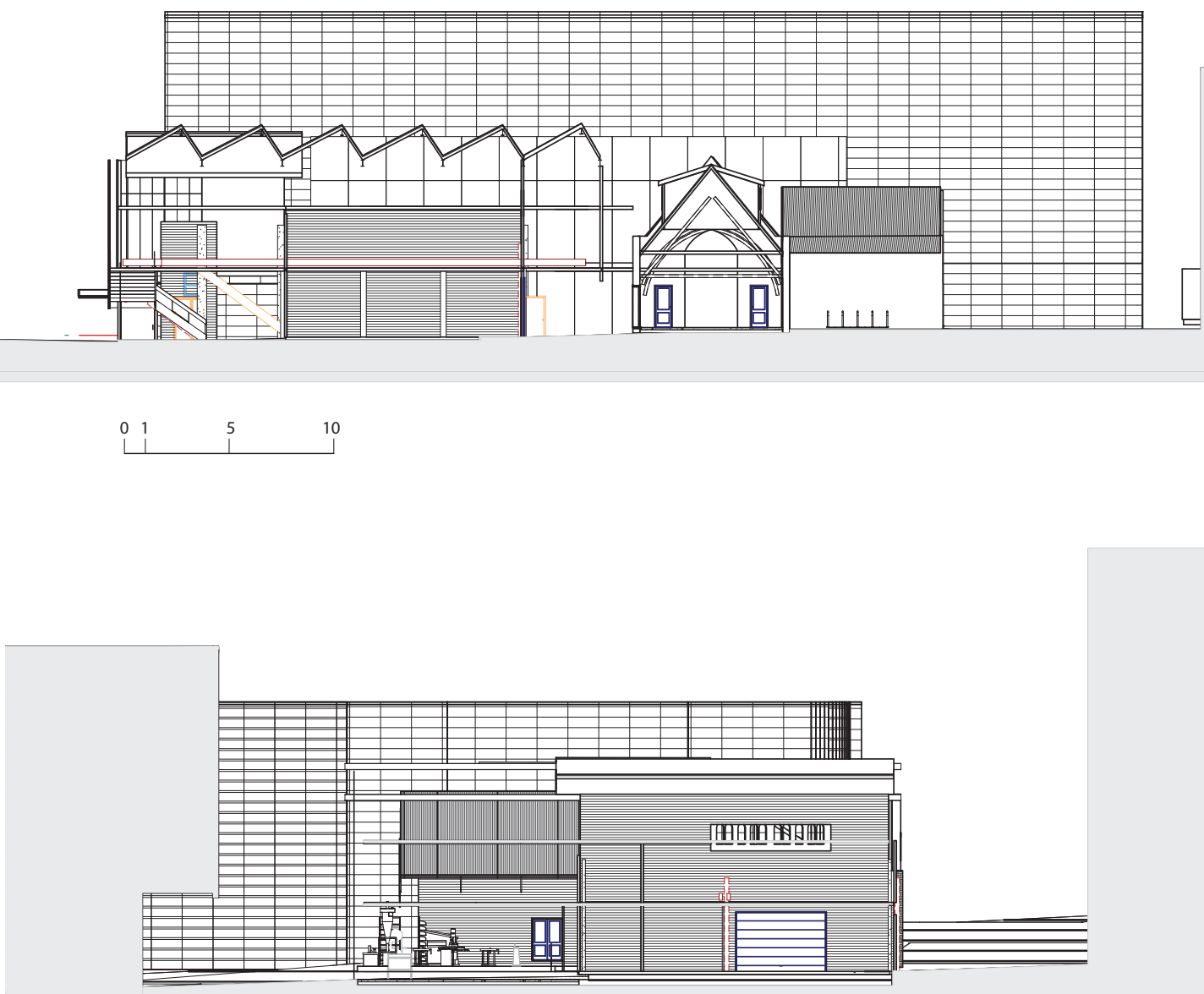

fig. 5.27. Key Sections through the Art School 


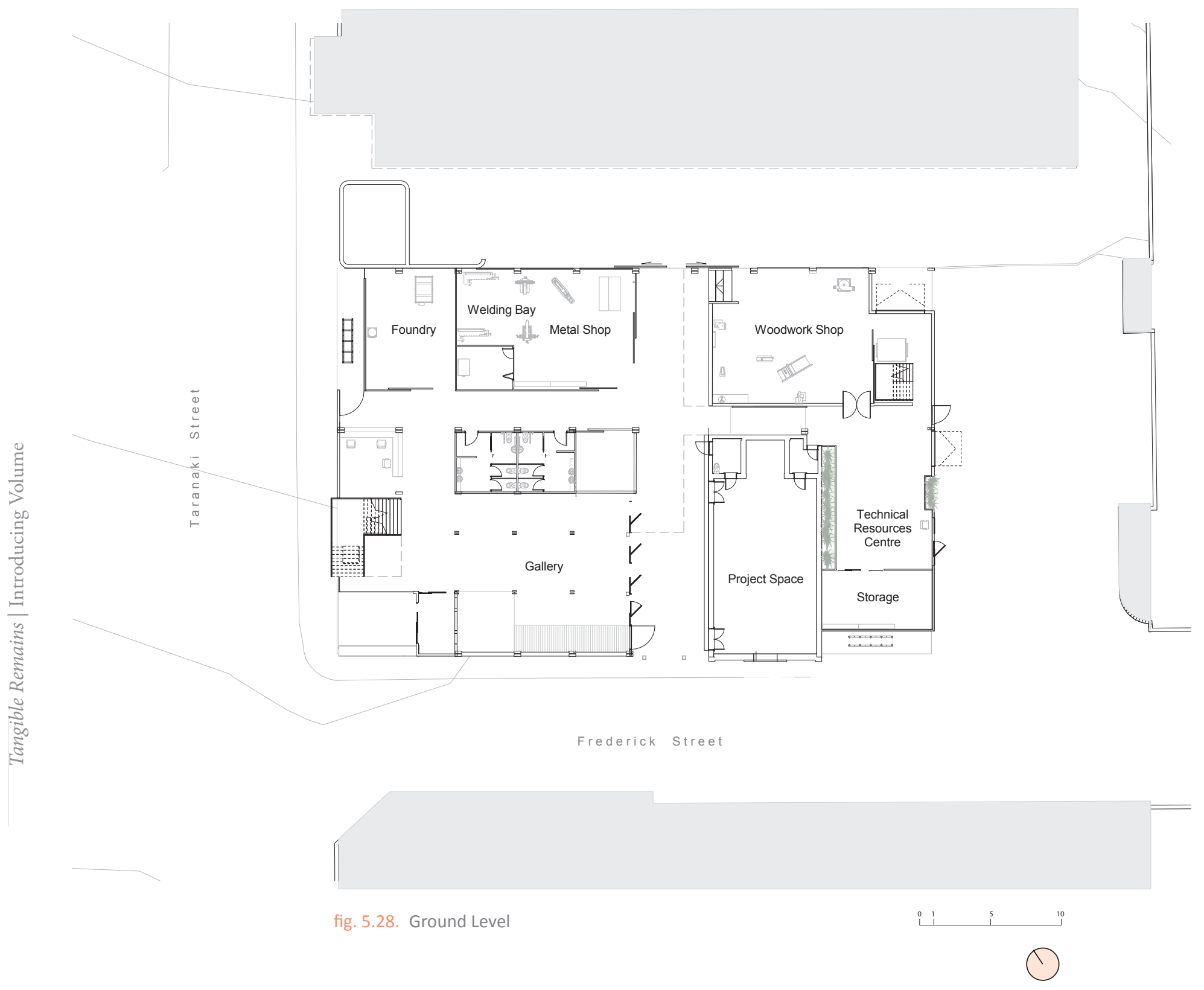



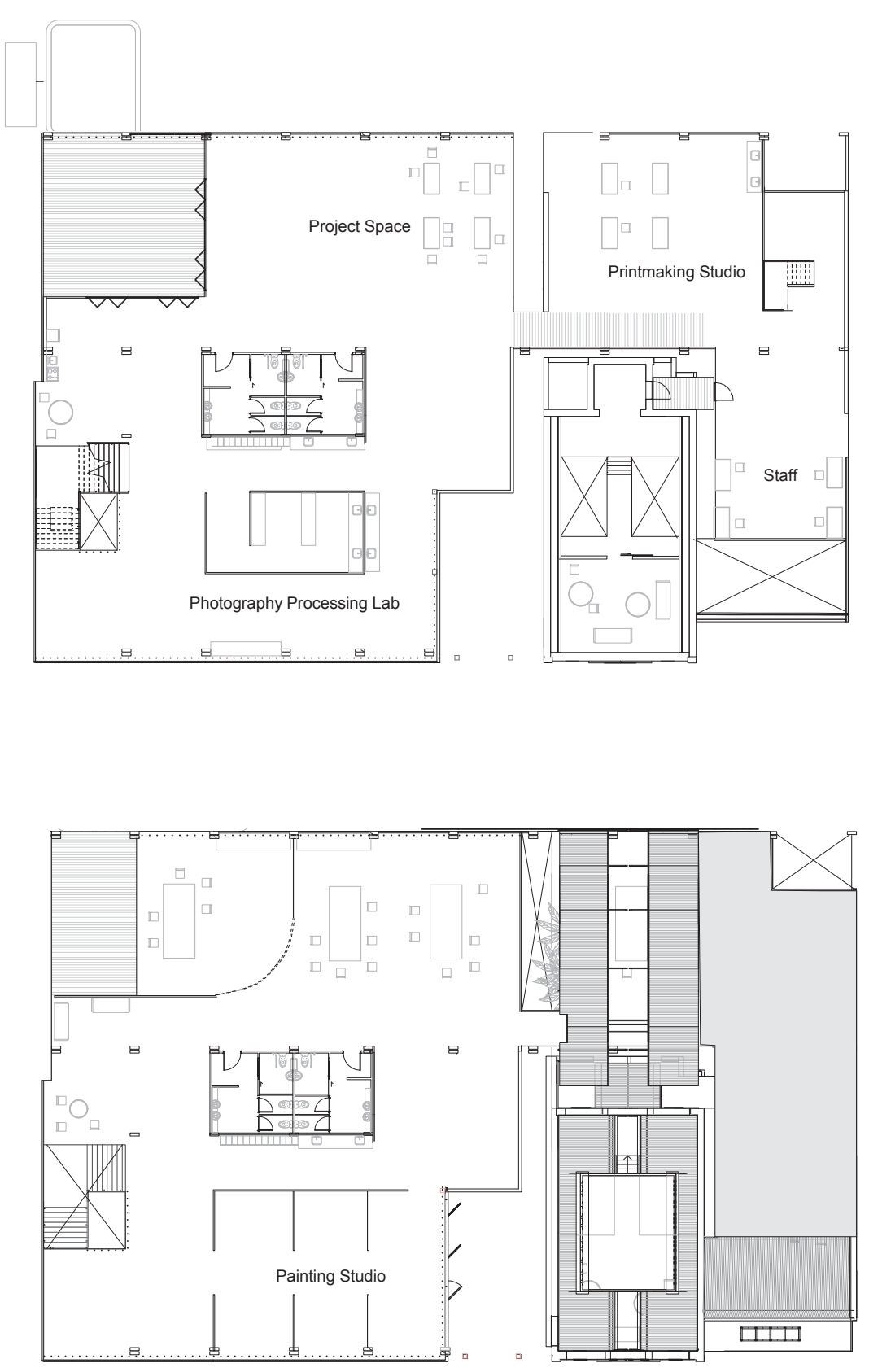

fig. 5.29. Level One fig. 5.30. Level Two

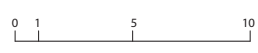

0 

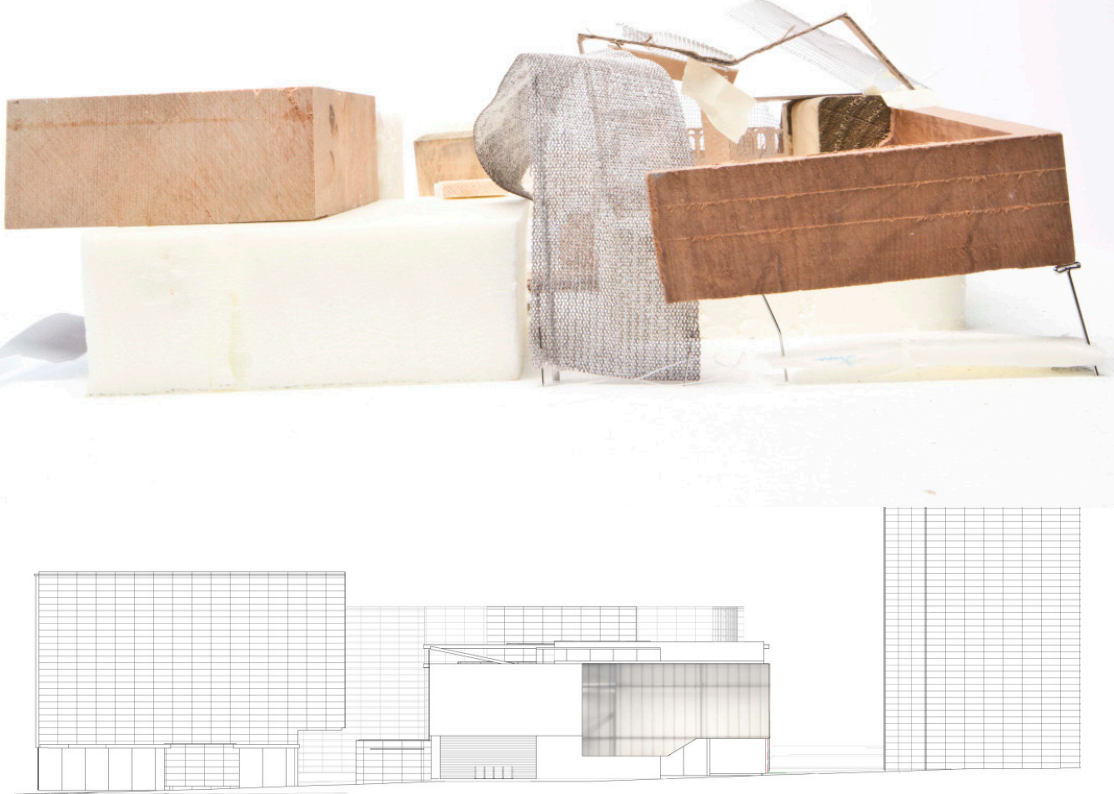

fig. 5.31. Key gestures identified in the maquette model were refined in the final 


\section{[public narrative] + entrance}

Public narrative

The interpretation of the first building.

The art school required a more prominent entrance and thus presented an opportunity to activate the street edge. The corner where the 1900 villa stood was defined as the main public entrance from two factors. Pragmatically, it was identified as a prime position to draw attention from Vivian Street as the descending traffic from Mount Cook. Through modelling, a tendency was also found to express the intense zone as a weighted corner, vacant on the ground floor. The corner was thus developed as the key entrance for the public. Set back from the corner but allowing a wind break. ${ }^{25}$

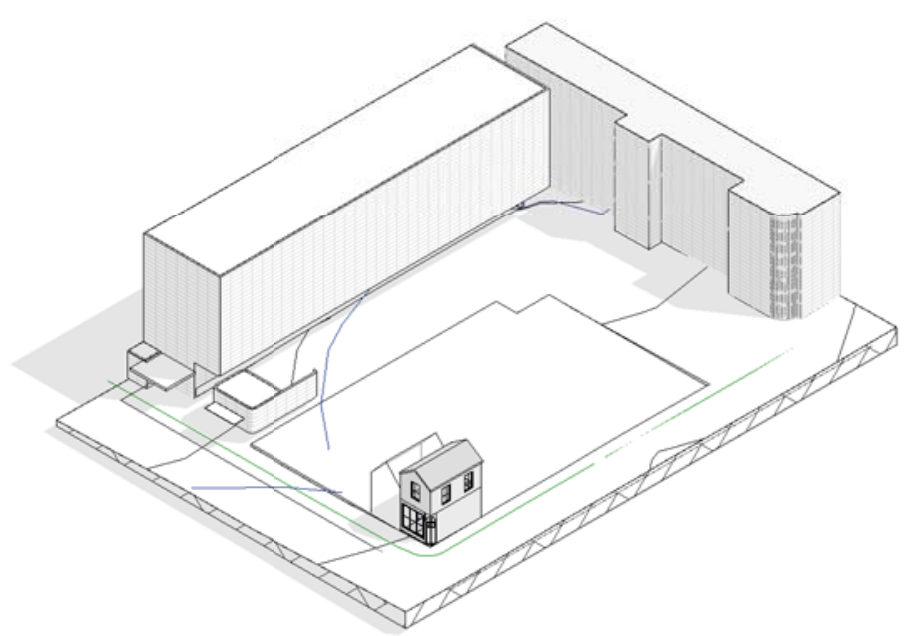

fig. 5.32. The significance of the 1919 Villa is upheld in the development of the Art School

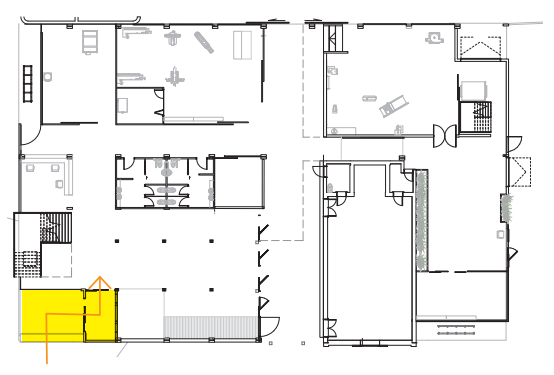

25. The height of the villa was expressed with a tree in the Chinese Garden. 


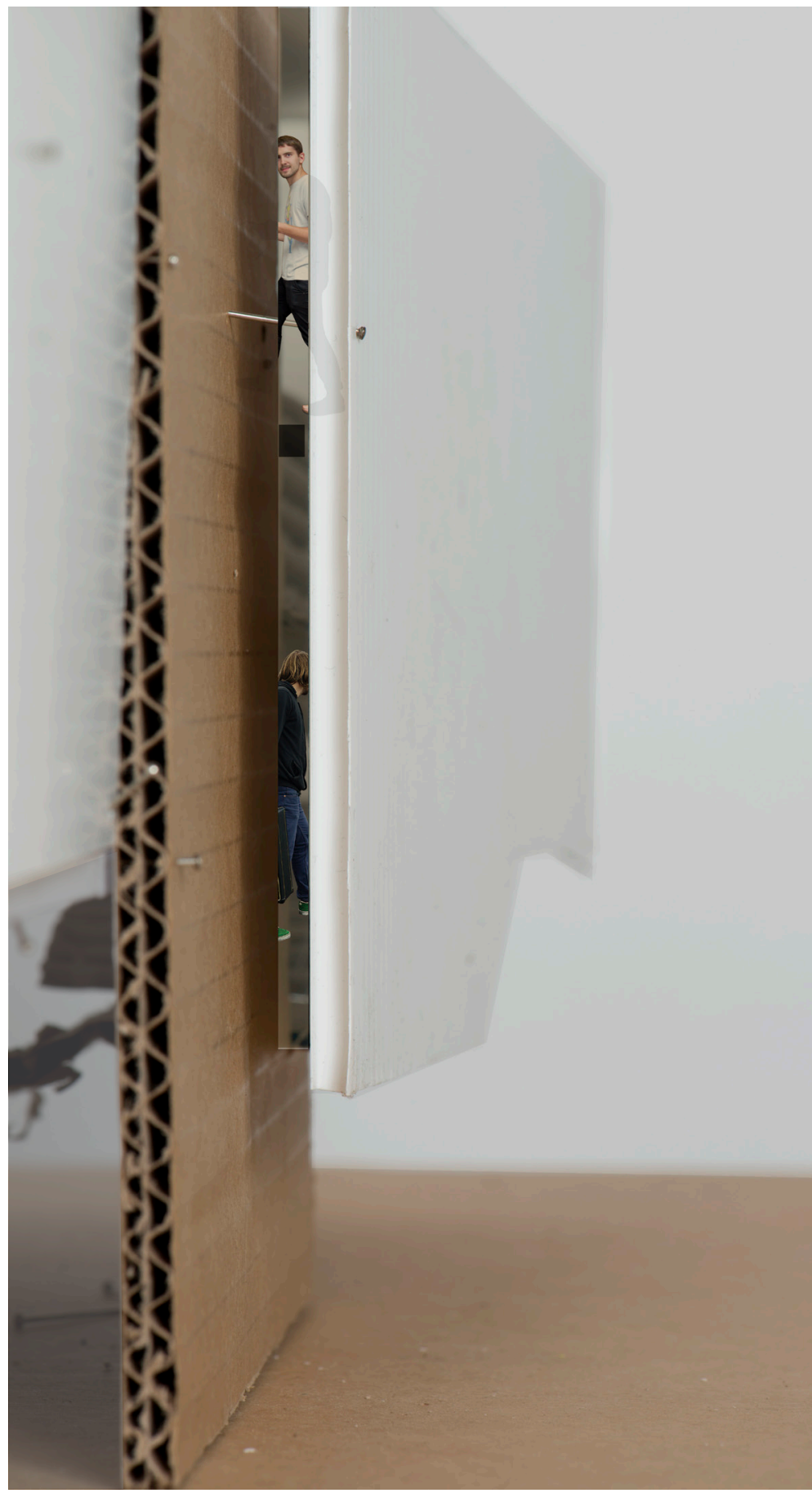

fig. 5.33. Taranaki Street edge. Approaching the entrance 


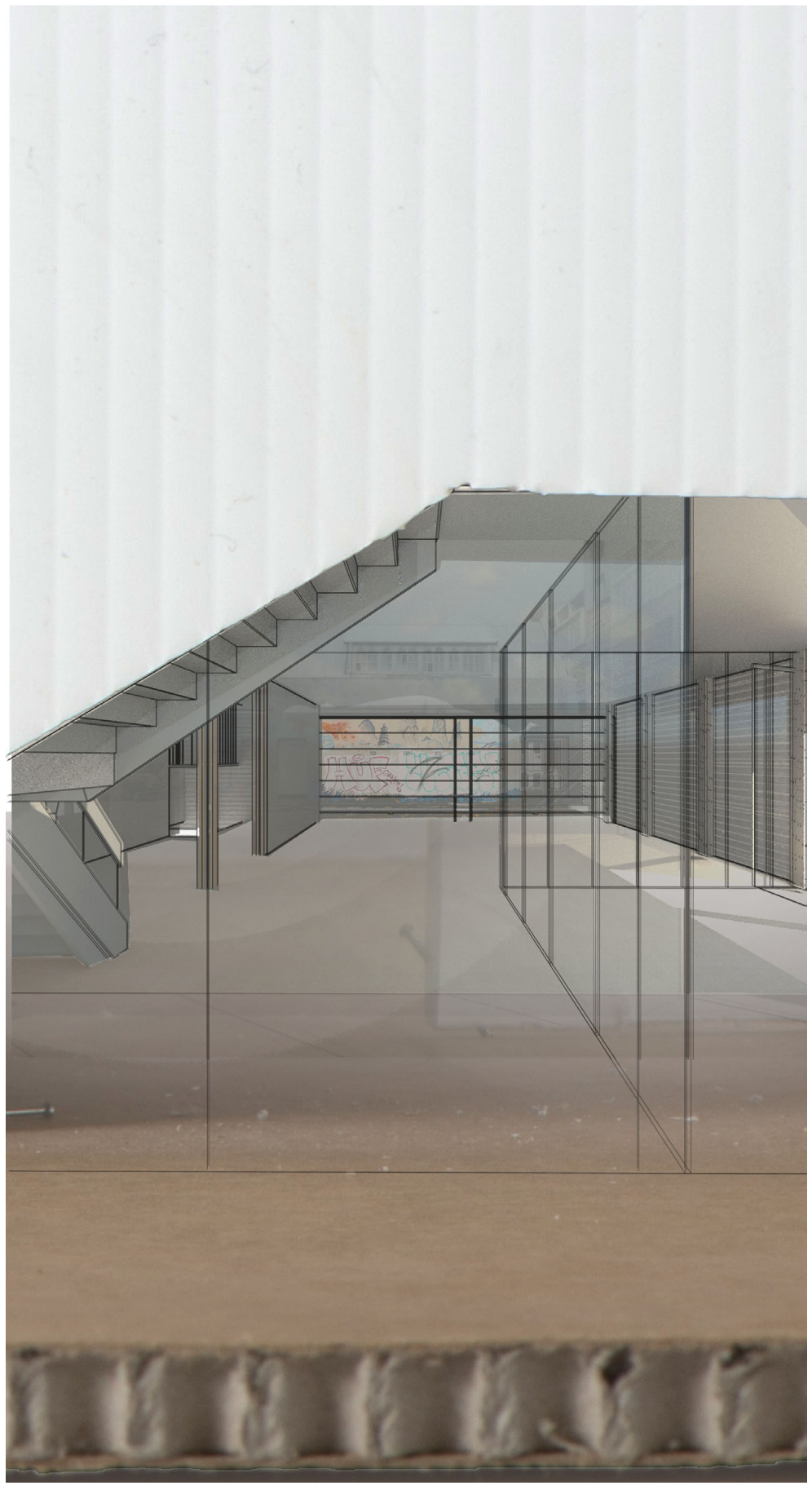

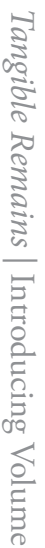

fig. 5.34. Entrance foyer 


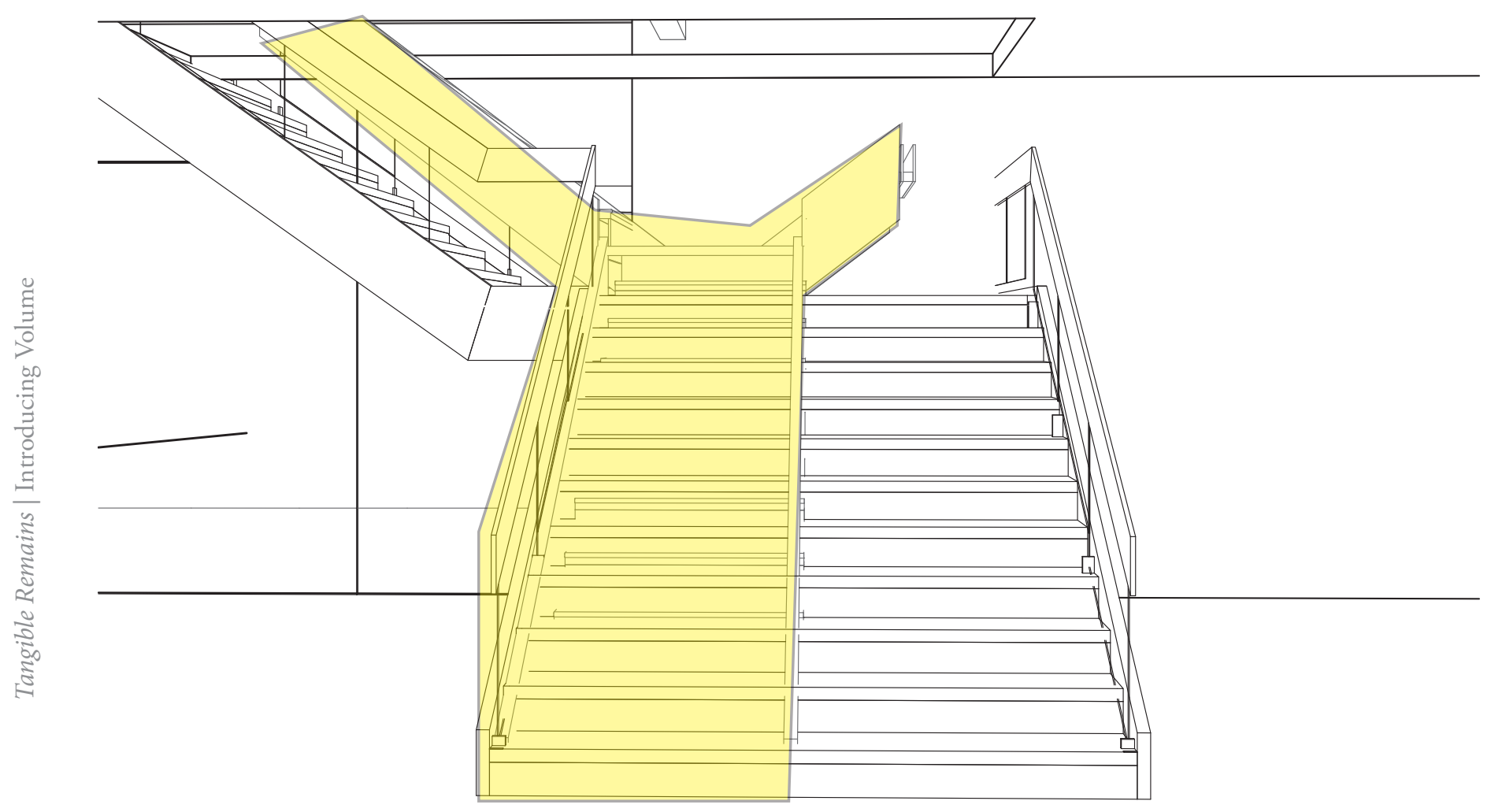




\section{[public narrative] + stairway}

Public narrative

The tension between the accessible stairway to the gallery space and the ghost of the previous movement is expressed in the Taranaki Street facade and the misalignment of the steps.

The stairs push out the street edge, giving expression to the movement. This puncture through the perimeter boundary of the site reveals a visual connection to the northern corridor of Taranaki Street and a view to the harbour.

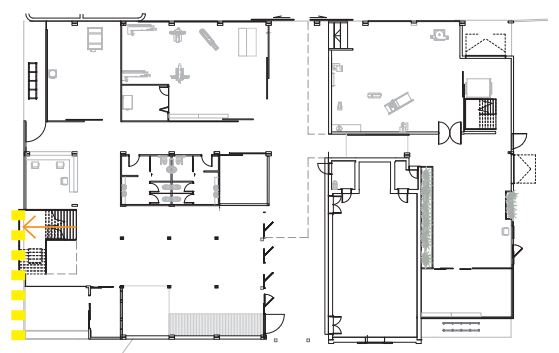




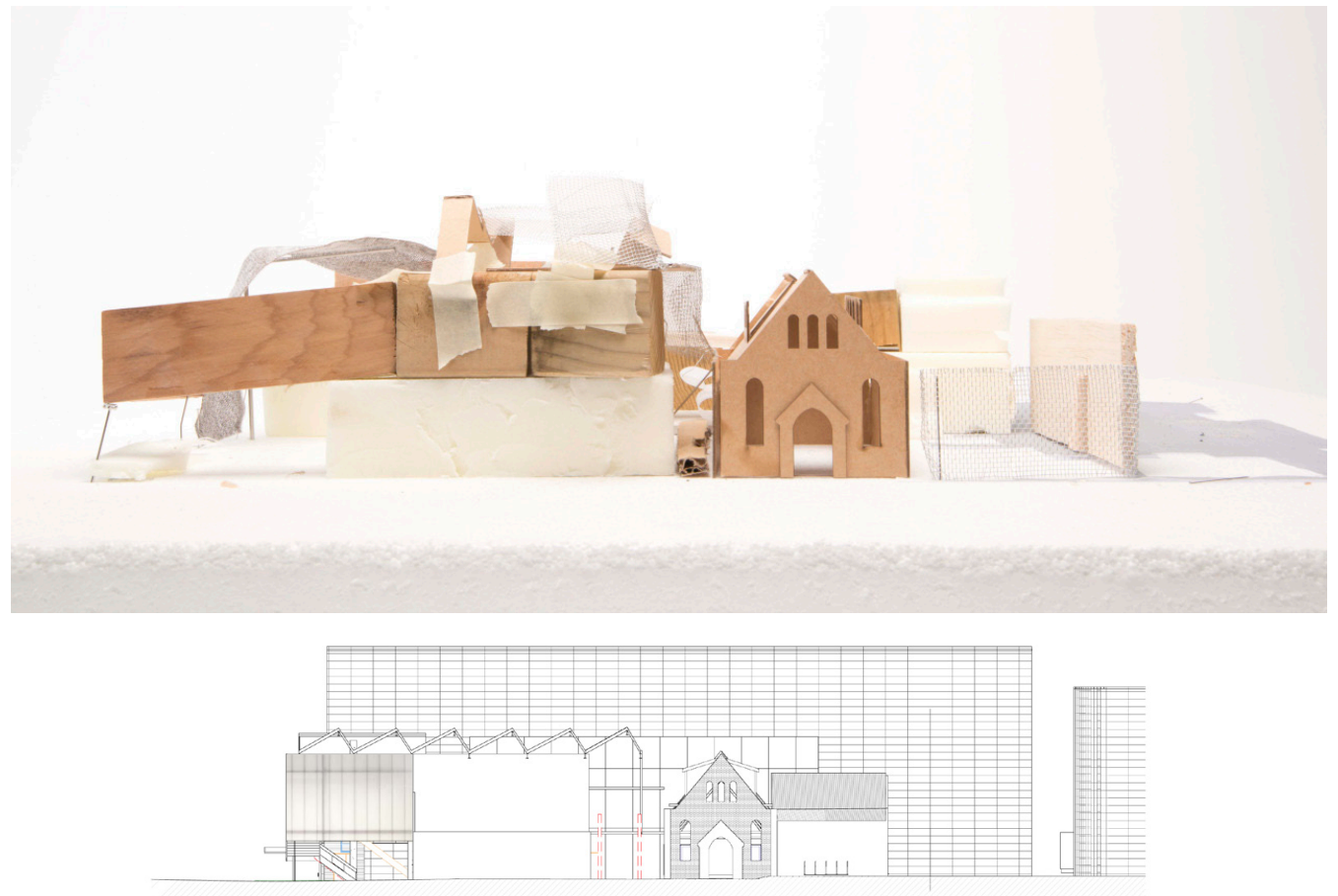




\section{[student}

narrative]

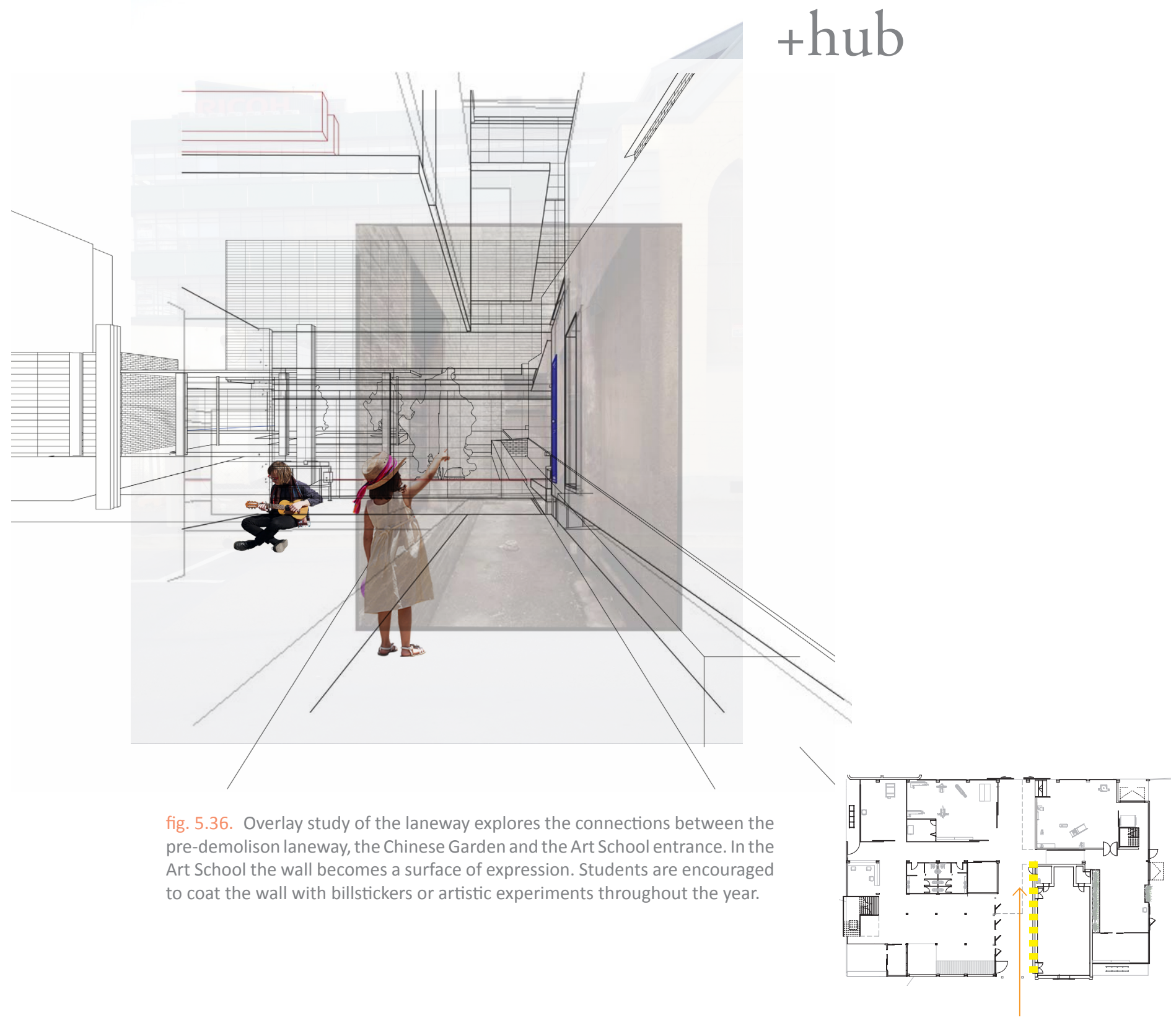




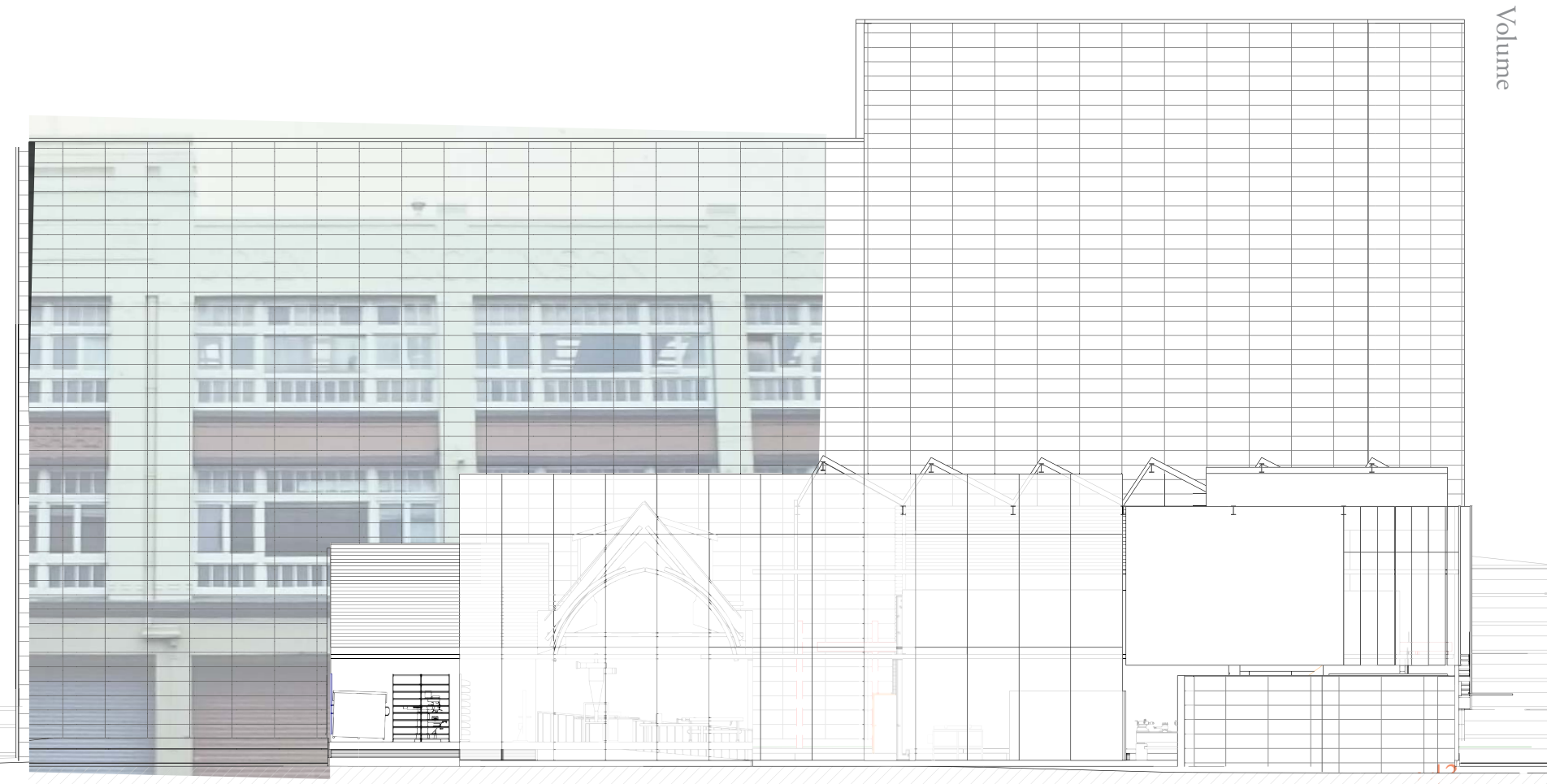




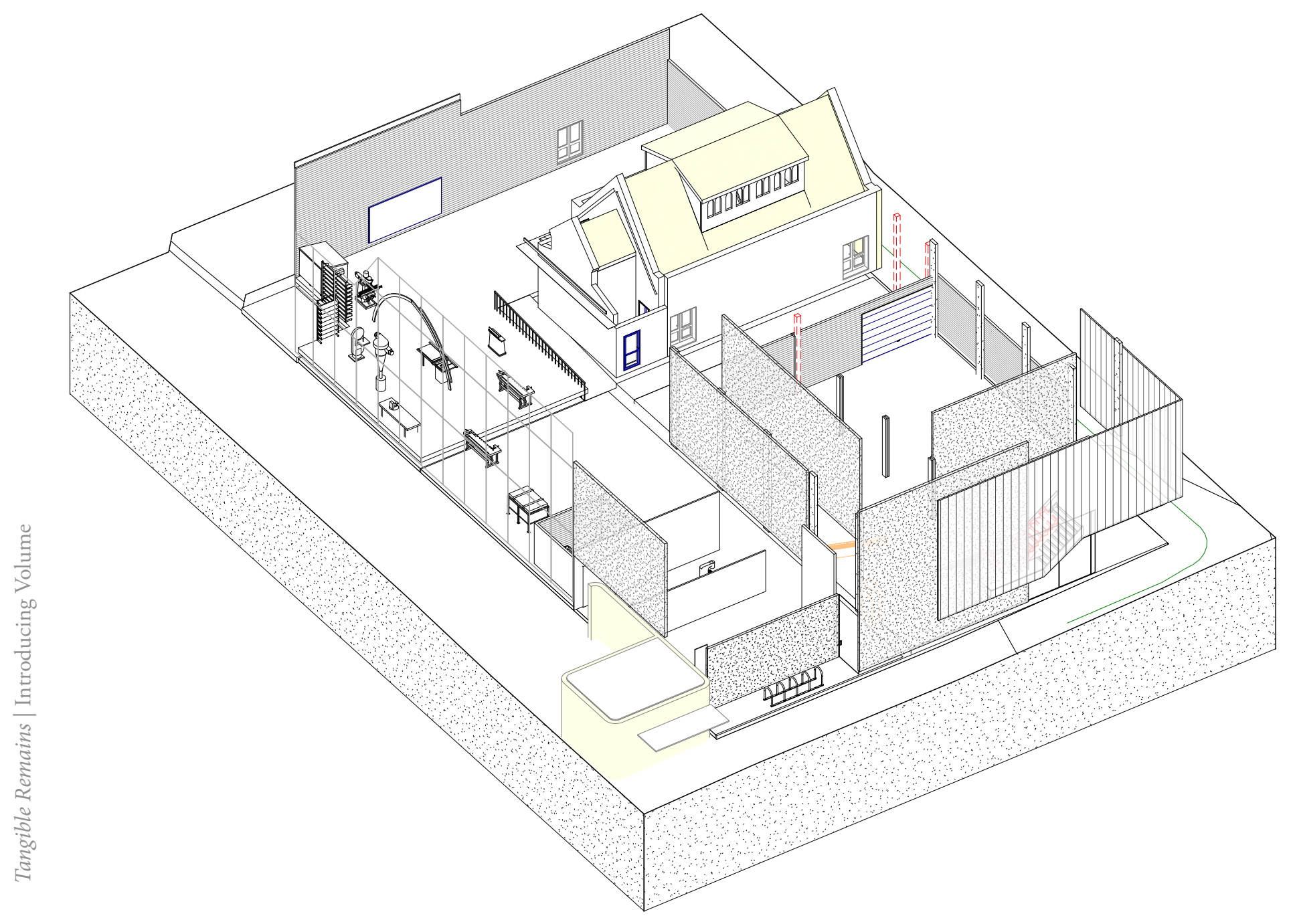

fig. 2.6. Axonometric of Ground Level

The configuration of the workshops encourages collaboration and intrigue between disciplines. The dust from the wood workshop is isolated from the high heat metal shops with a shared project space between. Students can extend into the work space for larger projects or tasks not needing machinery. The unfixed workbenches allow for future adaptation of the floor as new technologies or workflows are introduced. 


\section{[student}

narrative] +workshop

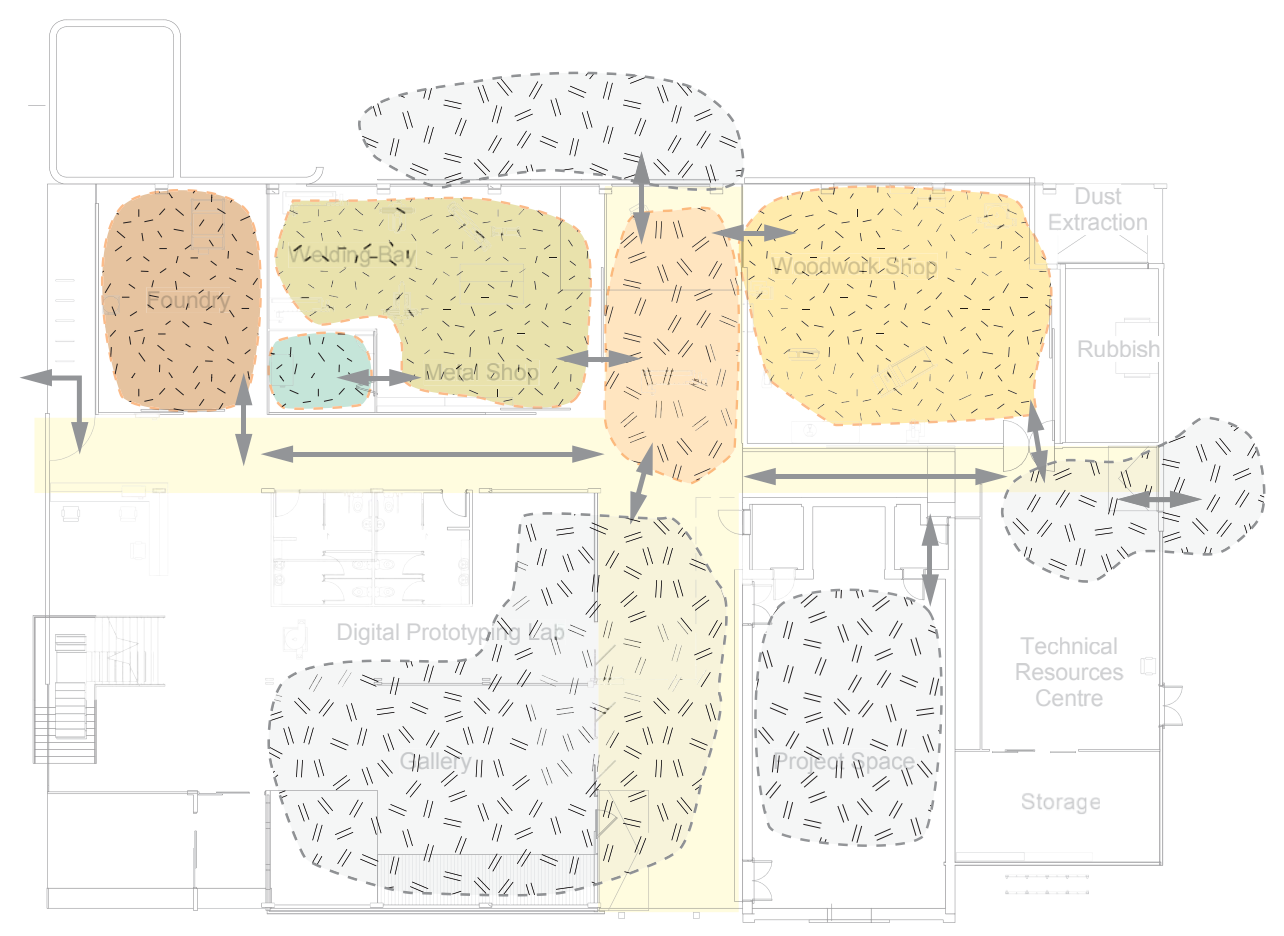

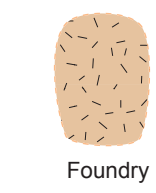

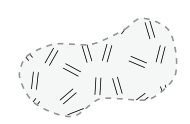

Temporary assembly space

fig. 5.1. Diagram showing the relationships between the workshops and project spaces 


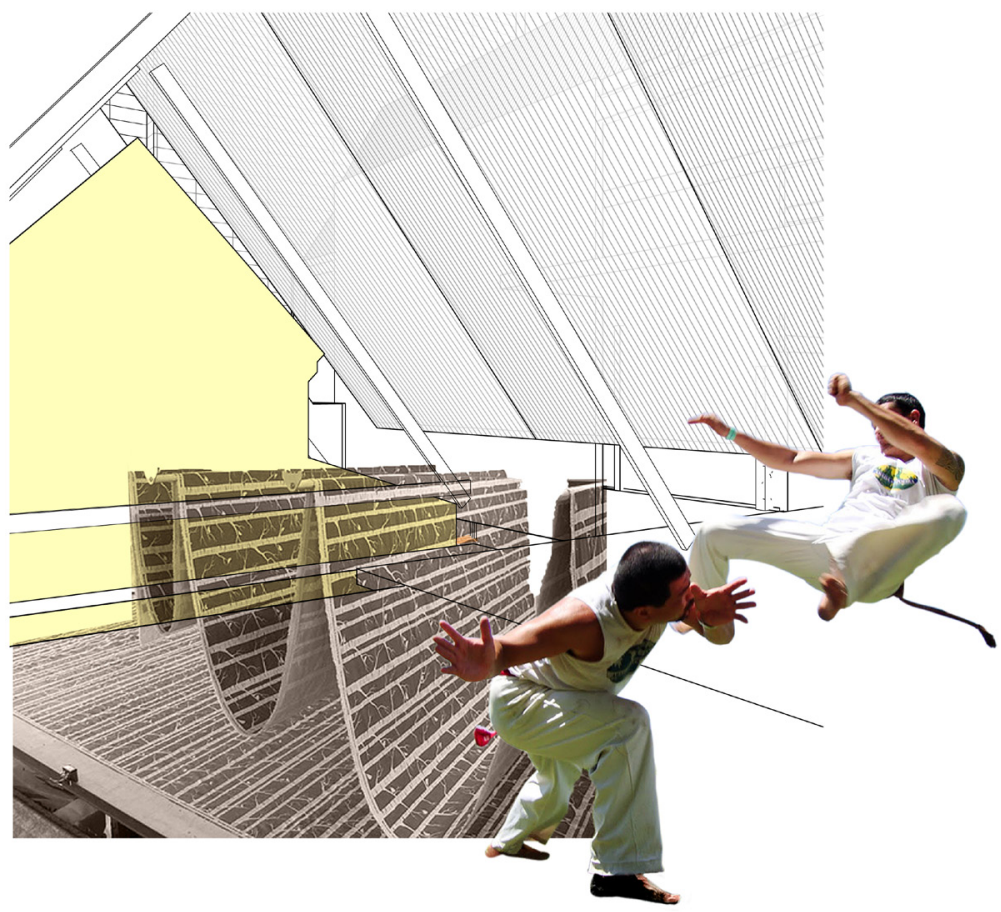

fig. 5.2. Printmaking Studio

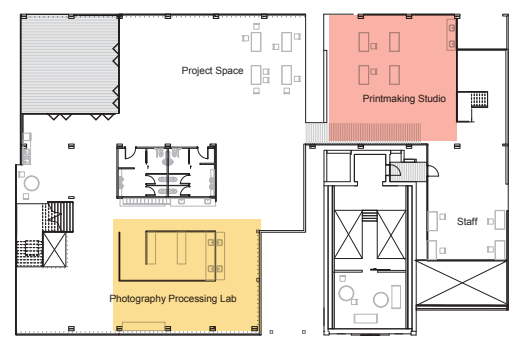




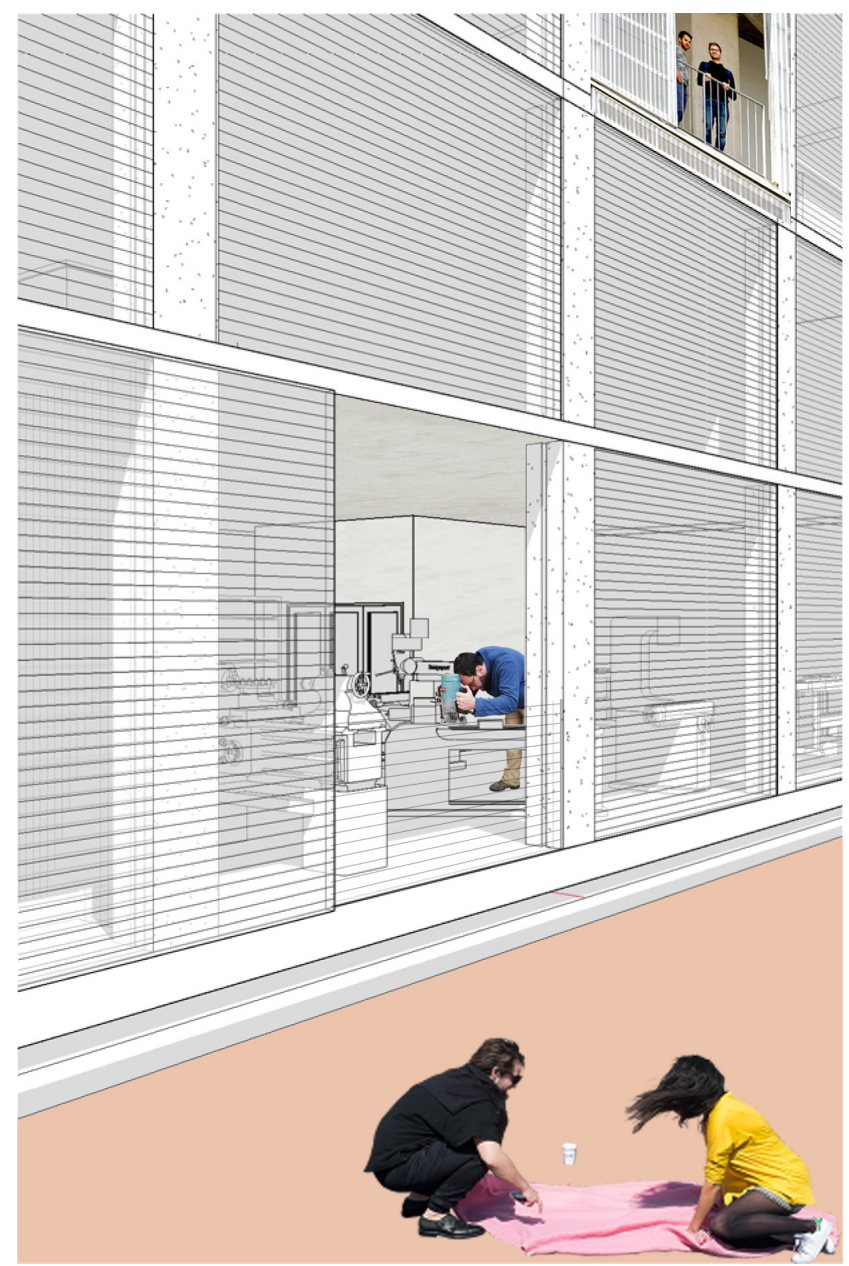

\section{[student}

\section{narrative]}

\section{+studios}

fig. 5.3. Workshop and laneway spill out into Assembly Space

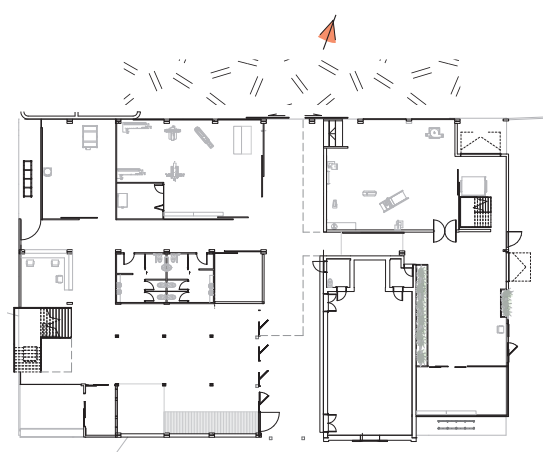




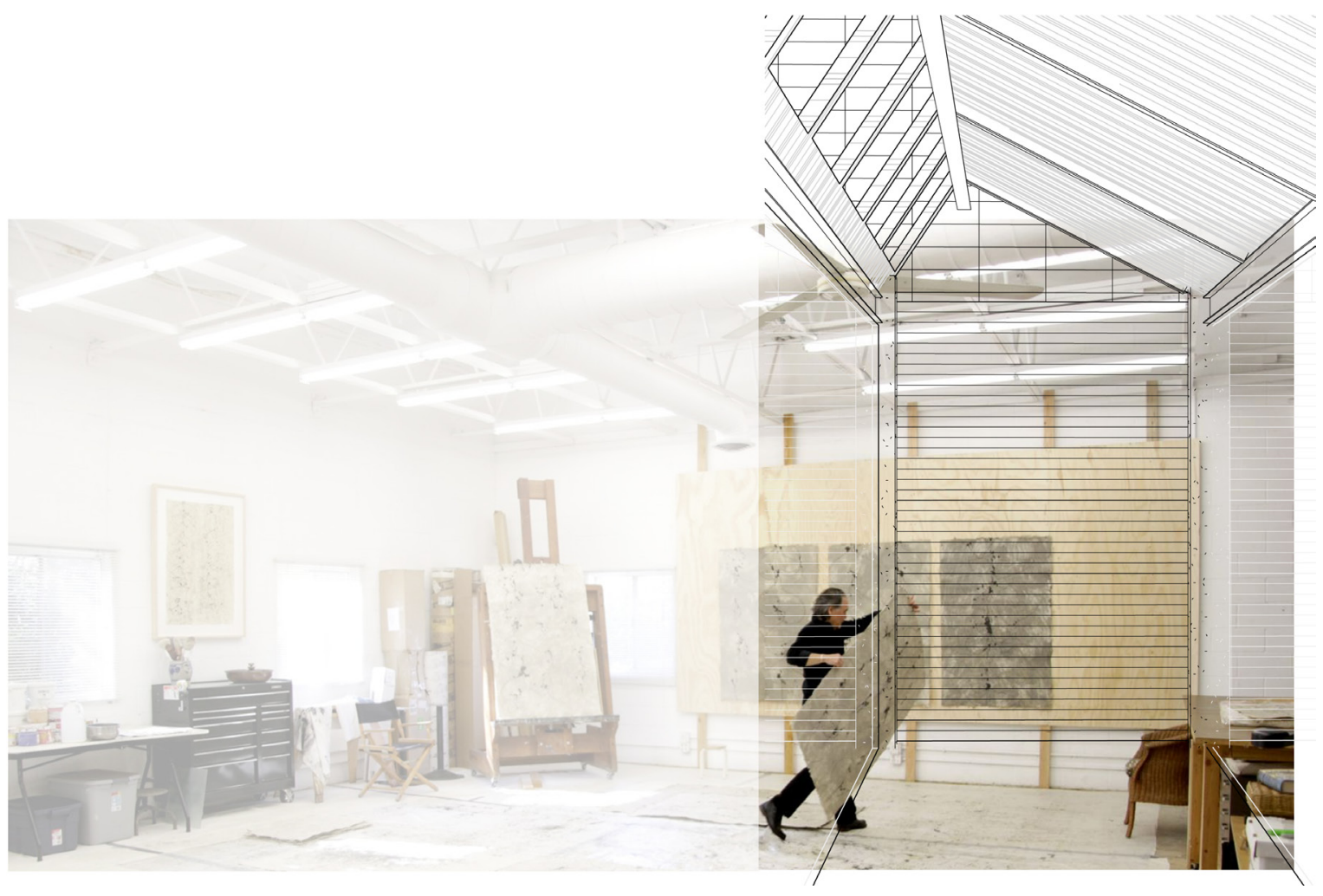

fig. 5.4. Painting studios amalgamated for larger works or group collaboration

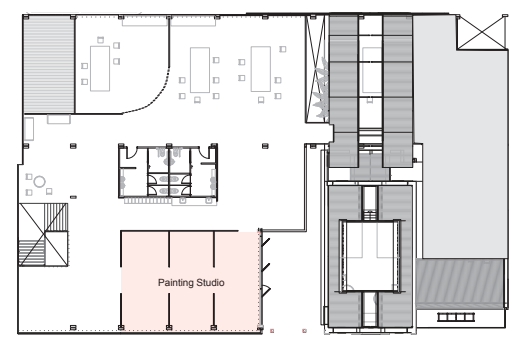




\section{[student}

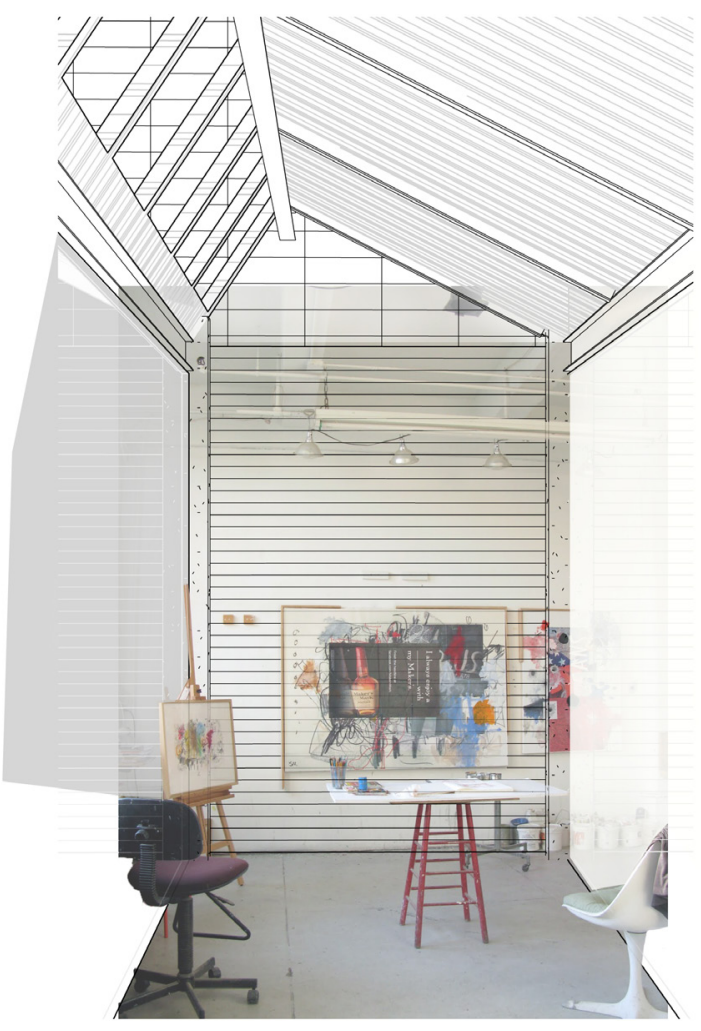

narrative] +studios

fig. 5.5. Dedicated painting studio 


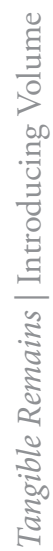




\section{[staff narrative] + privacy}

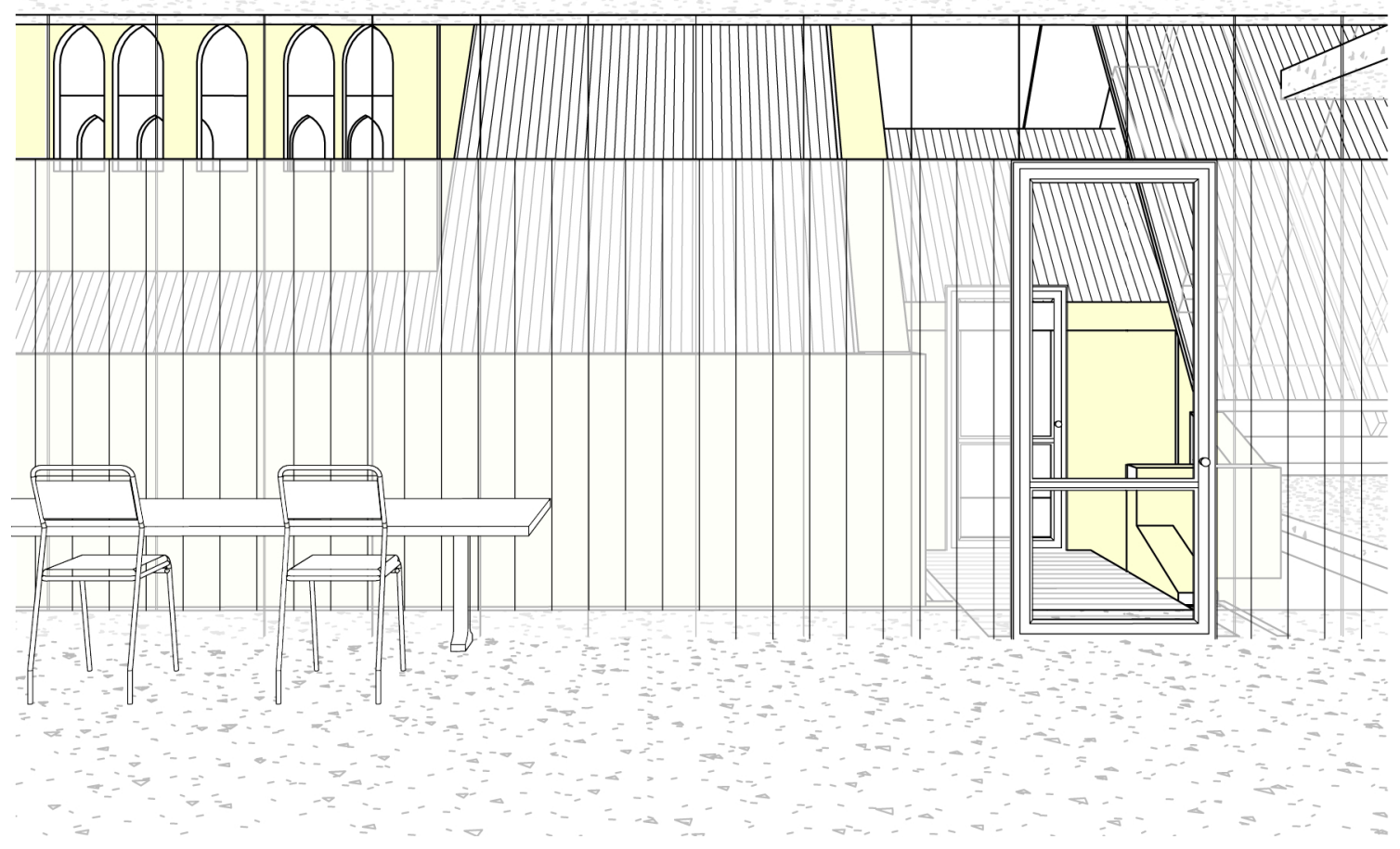

fig. 5.6. Staff zone connects to the mezzanine of the Chinese Mission Hall, to be used as a Resource room with shared project space below.

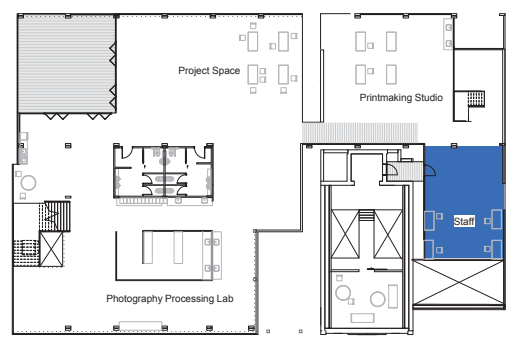




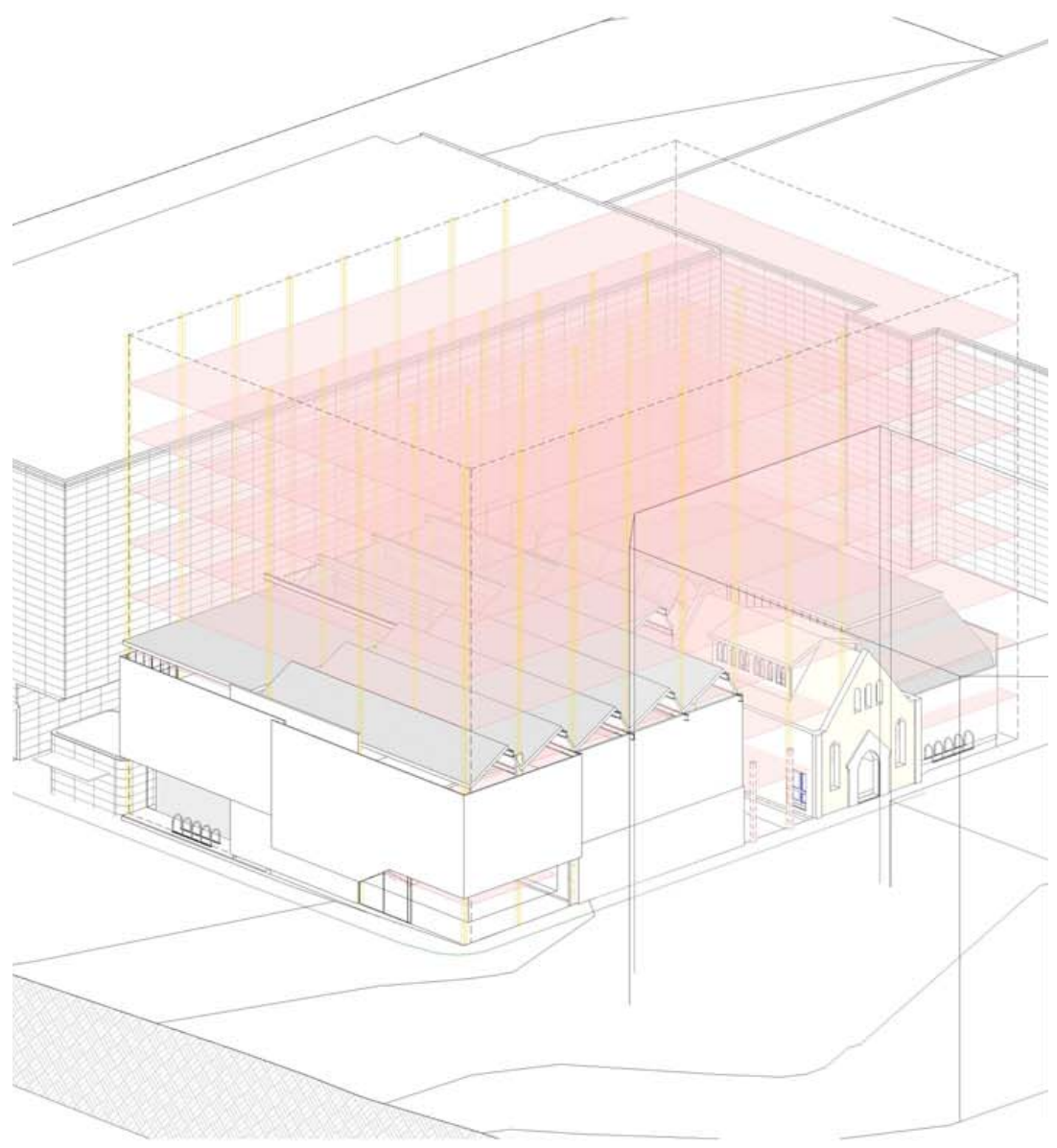

fig. 5.7. Test of potential volume 


\section{Conclusions}

This experiment concluded in an operable Art School recognising a scale reflective of the sites past. Weighted volumes and voids became keys tools in the formation of narratives through the site. In areas, opportunities were missed to express points of conflict between the pragmatic concerns of the building and the initial investigation of the Chinese Garden and the related fields of intensity. The saw tooth roof, for instance, would ideally be facing due south yet was purposefully nudged South East to relate to the Chinese Mission Hall and previous structural grid. How could such shifts be captured and expressed? This design move expresses an exchange between the program and site, principles are critiqued in a push and pull interchange - through this, the art school extended the dialogue with the site histories and tendencies. 

Program: Artist Colony

Scale: Macro

Condition: Future Projection

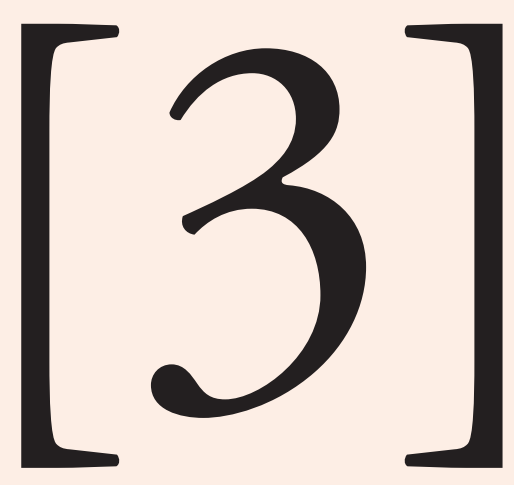

Design Phase 3 large scale 


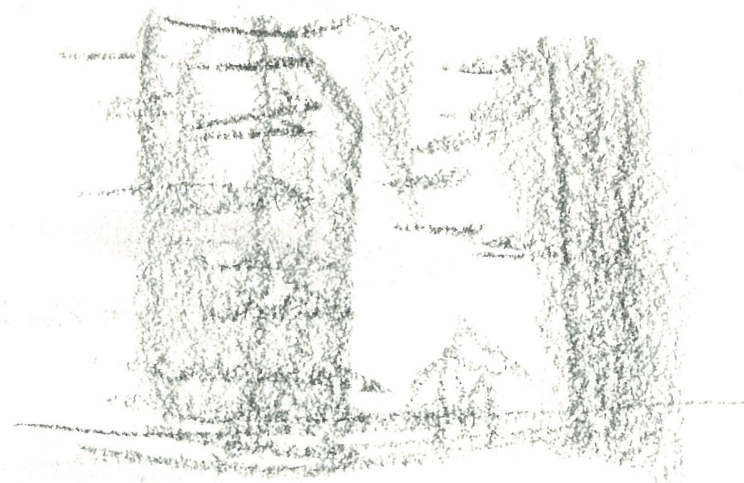

fig. 6.1. Preliminary sketch of Design Phase Three 


\section{Six | Future projections; introduction of the domestic}

This chapter engages the future condition of the site by introducing economical and intensification pressures acting in the existing cultural context. Residential units are introduced to the project while avoiding being subsumed by the pressures of development and issues of intensity as occurred in a preliminary proposal for the site in 2007. The final design phase is a response to this proposal and the 'shoebox slum' that was proposed (refer to page 172).

Marked for intensification since the 1990's, the forecast for Te Aro's skyline has been prime real-estate ${ }^{26}$. The District Plan declares a 27 metre height restriction for the site yet this is under constant dispute due the low-scale character of parts of this area such as Frederick Street. 'Architectural merit' is a common term used to mitigate extra levels however the basis of this is regularly exaggerated. The adjacent apartment building succeeded in their addition yet joined the list of Wellington's worst buildings in 2007 fig. 6.2 27. Most often sites are combined and intensified in scale; erasing any trace of the historic narrative.

The following section begins by setting the economic scene, it considers how other designers have approached the increased density with respect to an existing smaller scale heritage building. The gestural intent of the proposed building is developed before delving into how elements of circulation and program operate. The addition of the domestic accommodation is an intriguing addition to the public private exchange existing in the design of the art school to date. The dialogue between the design phases poses another question - how do I articulate the new components of the assemblage?

\footnotetext{
26. "Residential development forecasts (2014) assume the number of dwellings in Te Aro will increase by an average of 150 dwellings per annum to 9,180 in 2043." (id.)

27. The Architecture Centre compiled a list of the 10 worst buildings of Wellington. (Dickens)
}

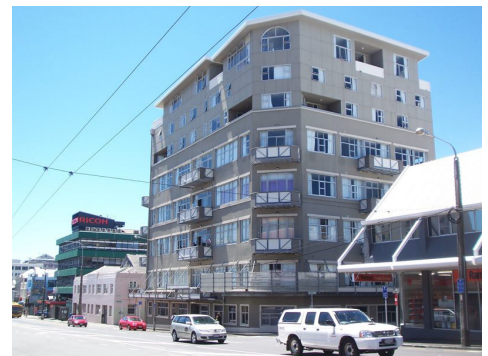

fig. 6.2. Mackarin Apartments, 135 Taranaki Street 


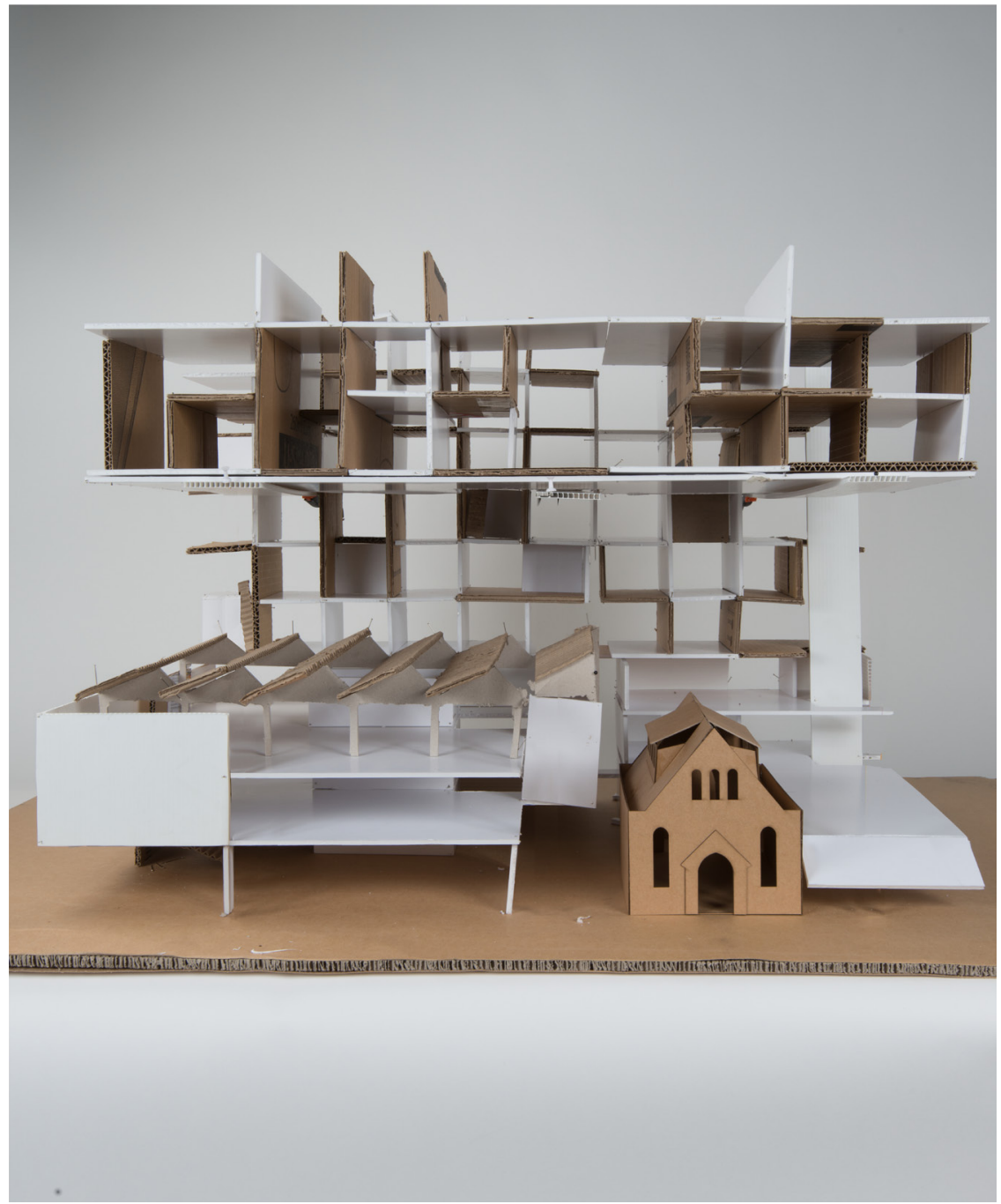

fig. 6.3. 1:50 physical model. October 2015. Cardboard, foamboard and drawing pins. 


\section{Methodology}

Design phase 3 continued to explore scale through iterative design. It introduced a dialogue between plan thumbnails and 1:50 modelling. This gave expression to the shifts within the design process, articulating the subtleties at play.

Shifts in scales are amplified in the design phase with the introduction of small scale diagrams and drawings and 1:50 models. A digital model was printed on contact sheets to facilitate fast and focused iterations to be explored alongside each other with critical reflection as annotation. This process fed into a sketch model at 1:50 scale before reengaging the computer. Dwelling units were designed and configured through this physical modelling process. The scale and contingency of the process stressed moments of tension when spaces or conflicting requirements overlapped. Through modelling the potentials of these moments were explored. 

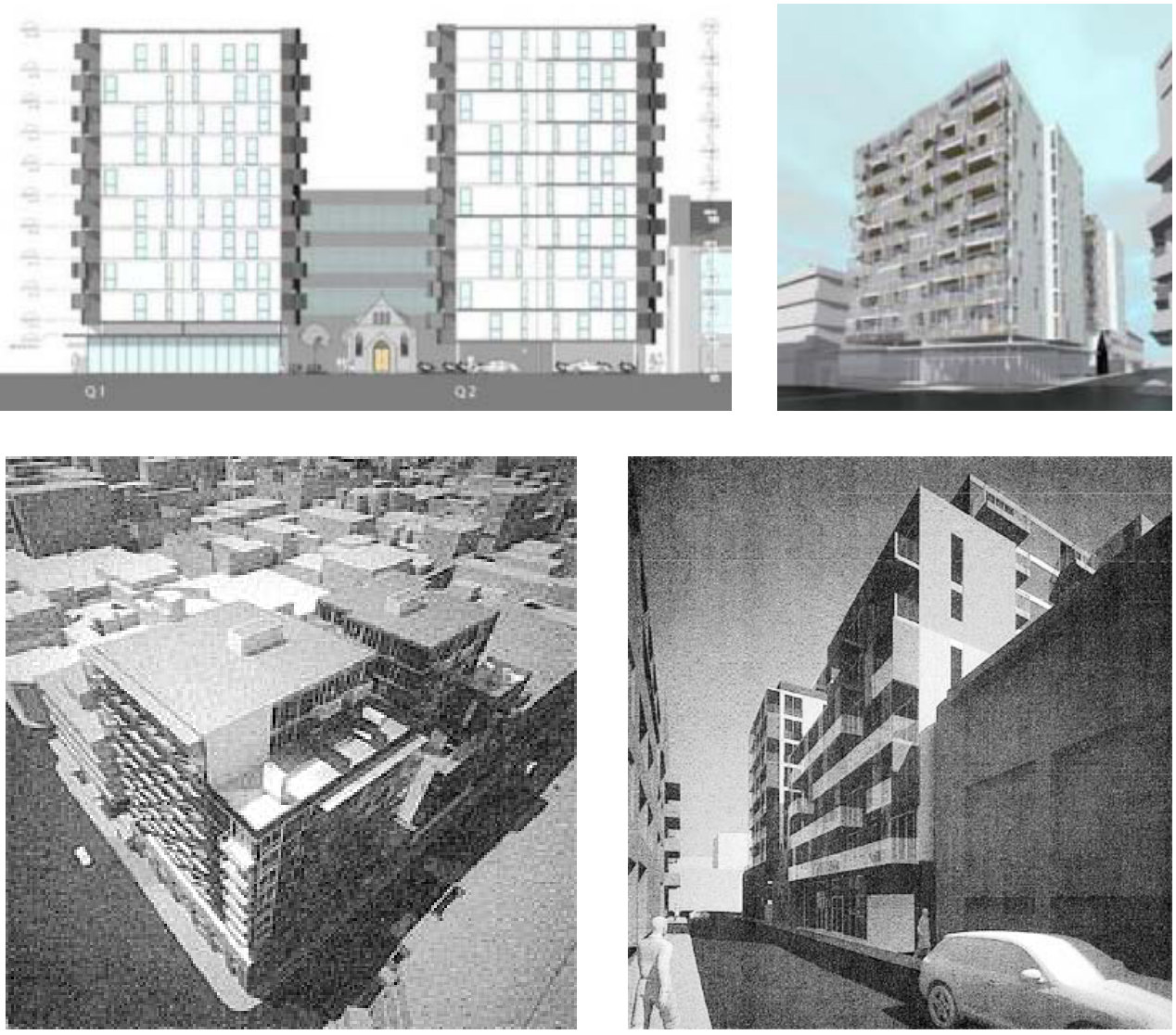

fig. 6.4. Rendered images of two iterations of the proposed design: $Q$ on Taranaki. 


\section{Precedent}

The following precedents present differing formal approaches to densifying with consideration to a heritage building. They offer techniques for the consideration of new design work in relation to the Chinese Mission Hall as well as the low to mid-rise character of Frederick Street (and the tension between scales of the high rise Taranaki Street). How can the building encroach the 27 metre height restriction whilst preserving this character? The precedent exploration will help reflect on the $\mathrm{Q}$ on Taranaki proposal and define a formal strategy for the final design.

\section{Q on Taranaki}

Archaus, 2007

The section responds to a short lived proposal for the site including 233 studio apartments of a mere $26-29 \mathrm{~m}^{2}$; Q on Taranaki. The project was met with public grief due to the inappropriate scale and likelihood of a slum-like development [re] occurring ${ }^{26}$. The proposed design treated the Chinese Mission Hall as an object, dwarfing it beneath two bookends (twin towers). The fate of the now demolished Murdoch Factory 'Pink Pickle Palace' was set in the design prompting a public response supporting it's preservation. ${ }^{27}$

\footnotetext{
26. (Patterson)

27. (Wellurban)
} 

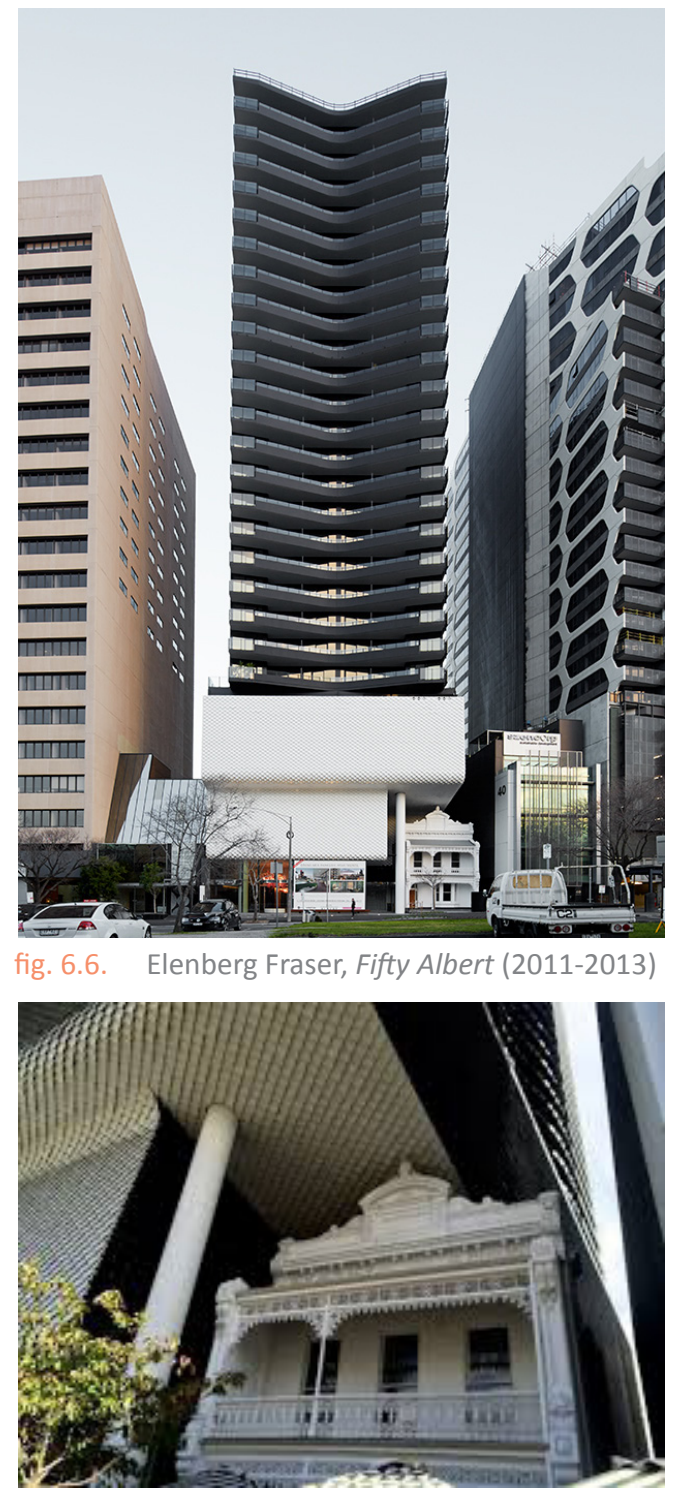

fig. 6.5. Elenberg Fraser, Fifty Albert (2011-2013) 
Fifty Albert

Elenberg Fraser

Melbourne, Australia

\section{1m, 282 apartments with Café}

The project shares a similar strategy of indifference to the heritage building as explored in the $\mathrm{Q}$ on Taranaki yet its delicate response to the street edge sets it apart. Situated in an inner city district, the tower presents an intriguing conversation between a 19th Century townhouse and intense densification surrounding. The form extends above in a narrow form, piercing the skyline and dwarfing the cottage to a miniscule blimp. However, from pedestrian eye level at the street this is hardly apparent. A feathered porcelain façade caps the base of the tower of the fifth floor, wrapping across generous setbacks and into the building to soften the transition to the human scale. As you approach the ground floor café and reception lobby, focus is away from the tower and directed to the house and its relation to the overhang above. The project supports the dialect with the macro scale; the high-rise character of the $\mathrm{CBD}$, as well as the approachable inviting pedestrian for the café. The two programs are stacked with a delicate transition between. 


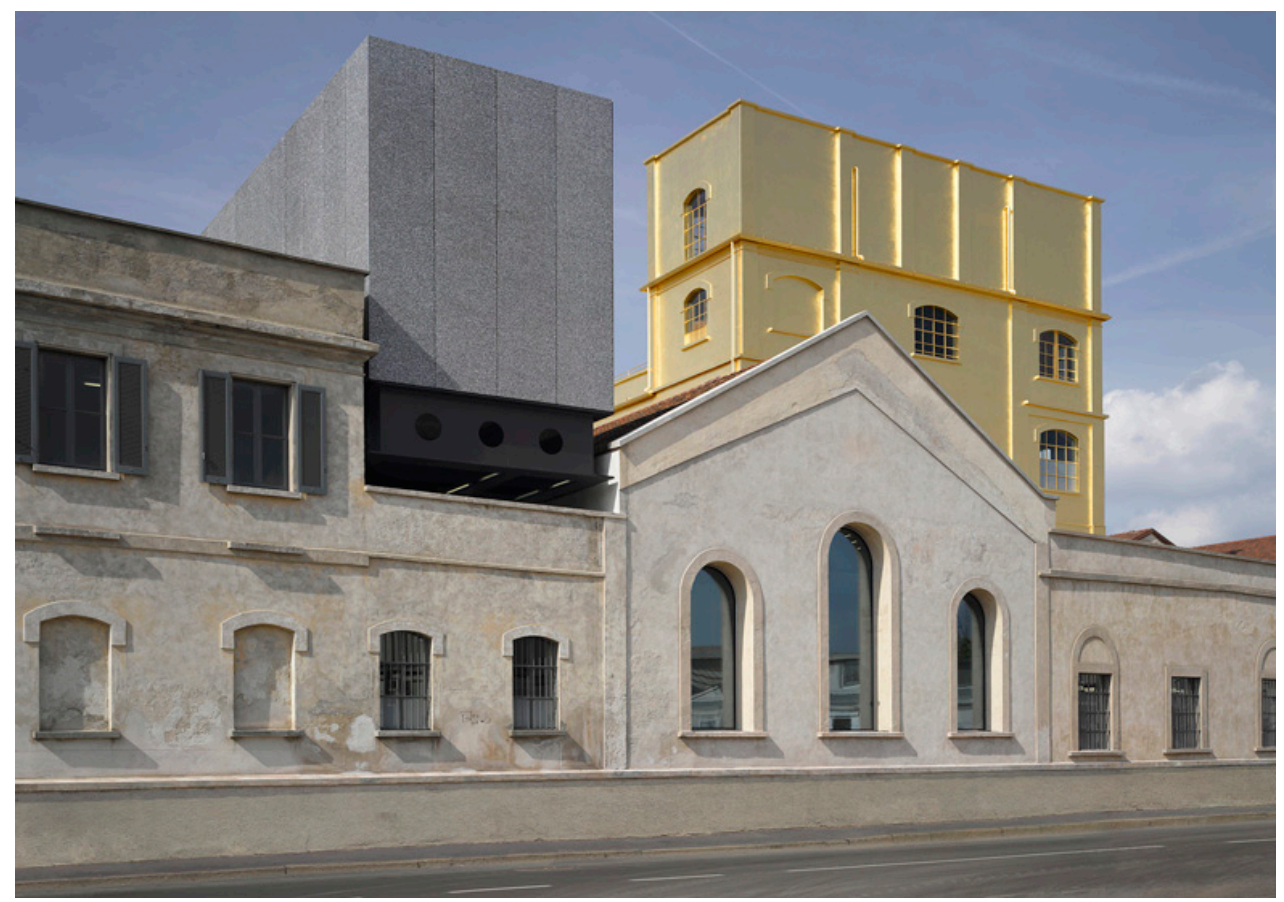

fig. 6.7. OMA, Fondazione Prada (2015). Elevation showing the articulation of the separate volumes.

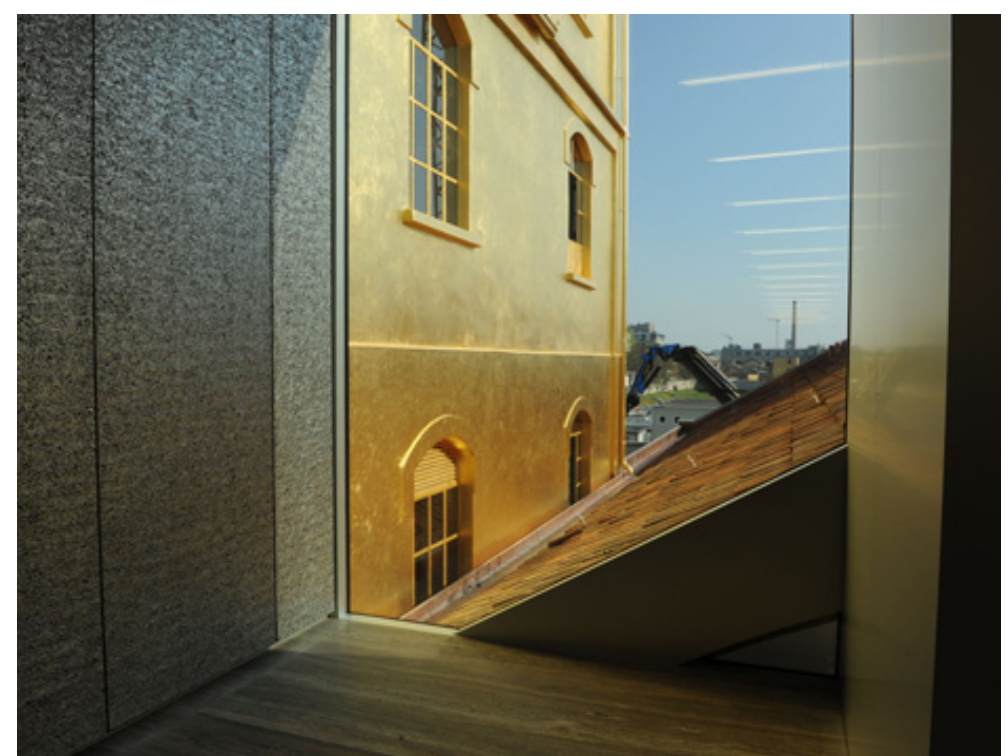

fig. 6.8. OMA, Fondazione Prada (2015). Interior perspective frames a point of convergence between the volumes. 
$\underline{\text { Fondazione Prada }}$

Rem Koolhaas, OMA

Milan, Italy 2015

The converted distillery softens its large volume by fragmenting the site into a collection of buildings surrounding a courtyard. The $19000 \mathrm{~m} 2$ campus consists of 7 existing buildings with 3 new interventions; a museum, a cinema and a ten-story gallery 'torre'. Rem Koolhaas describes a dialogue between the old and new conditions; "[they] confront each other in a state of permanent interaction offering an ensemble of fragments that will not congeal into a single image, or allow any part to dominate the others." ${ }^{28}$ The intermediary spaces of such a strategy present opportunities for intimacy within a large volume - opportunities for the domestic. Shifts in scale would support a gradual transition to the low to mid-rise character of Frederick Street and lighten the street edge.

"New, old, horizontal, vertical, wide, narrow, white, black, open, enclosed -- all these contrasts establish the range of oppositions that define the new Fondazione. By introducing so many spatial variables, the complexity of the architecture will promote an unstable, open programming, where art and architecture will benefit from each other's challenges." - Rem Koolhaas ${ }^{29}$

28. (OMA)

29. (ibid) 


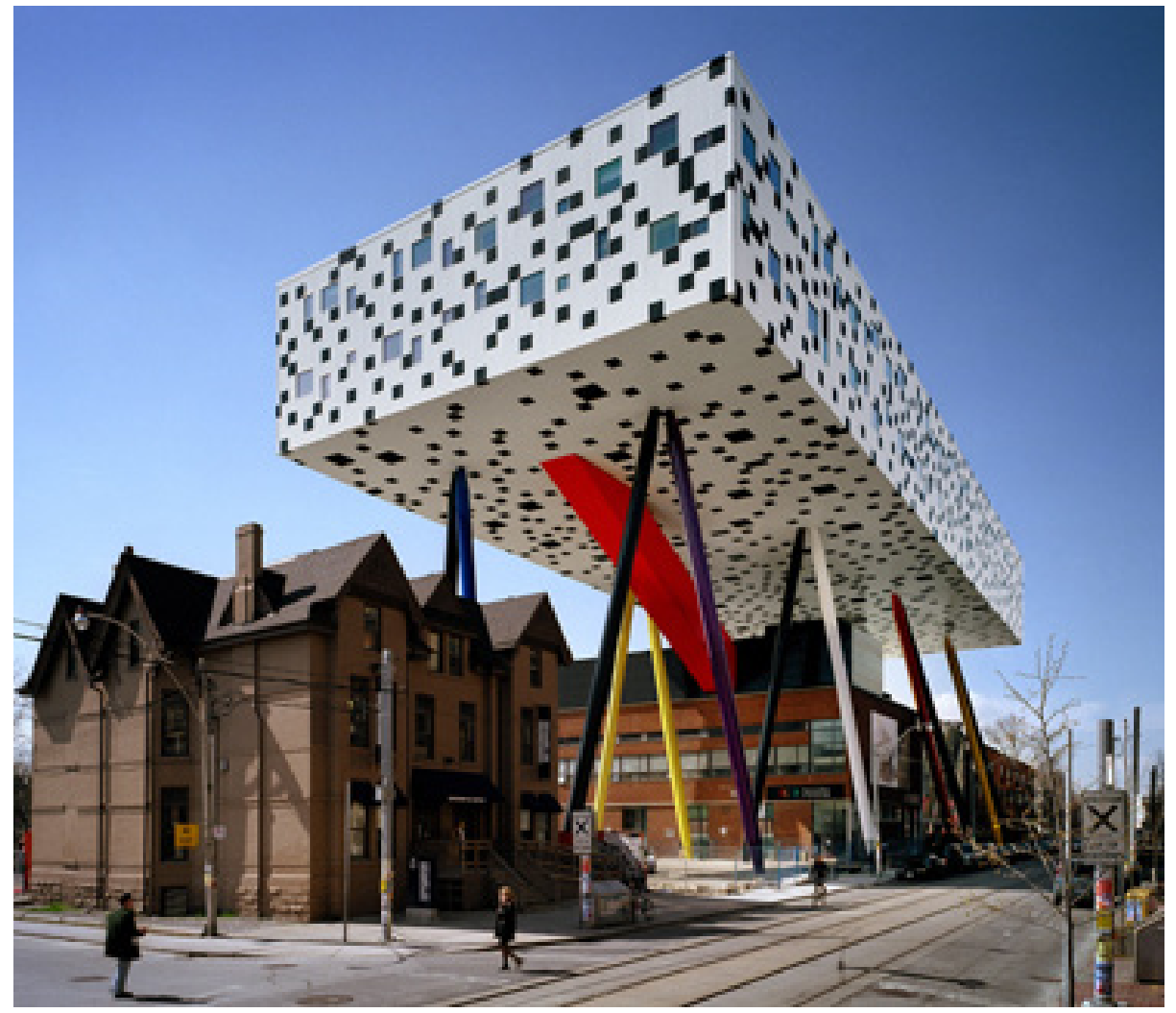

fig. 6.9. Alsop, Sharp Centre for Design (2004)

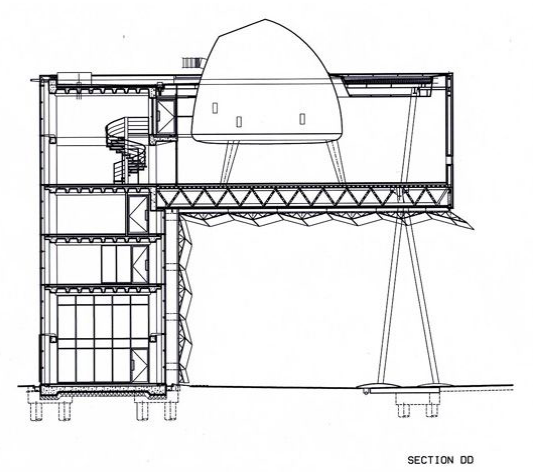

fig. 6.10. Alsop, Peckham Library (2000)

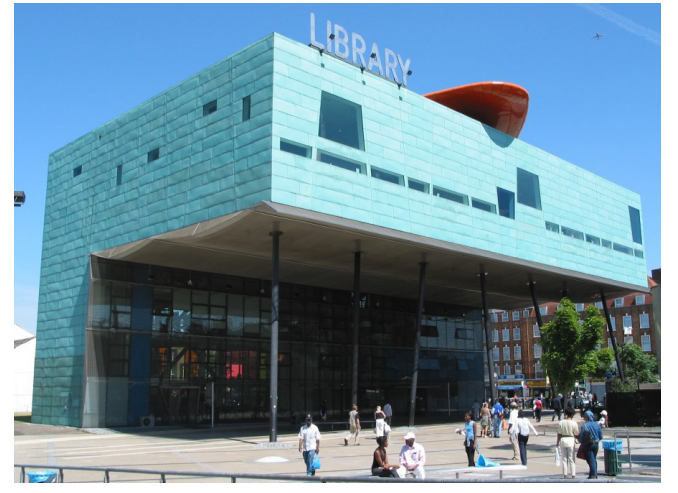

fig. 6.11. Alsop, Peckham Library (2000) 
\begin{tabular}{l|l} 
Sharp Centre for Design & $\begin{array}{l}\text { Will Alsop } \\
\text { Peckham Library }\end{array}$ \\
Toronto, Canada 2004 & London, England 2000
\end{tabular}

Will Alsops buildings are often likened to street creatures; insects walking the city. The structure is a body, hoist atop stick-like legs and freeing the underbelly to be inhabited by the city. The oppressive weight of such cantilevers are offset in both these projects by concealing the interior configuration. The structure is a foreign mass without defined floors or reference of scale. A technique of indifference, this preserves a visual distinction in the Sharp Design Centre from the existing buildings.

"To enter their protected plazas is to walk into the shadow of two apparently massive and multi-legged beasts" 

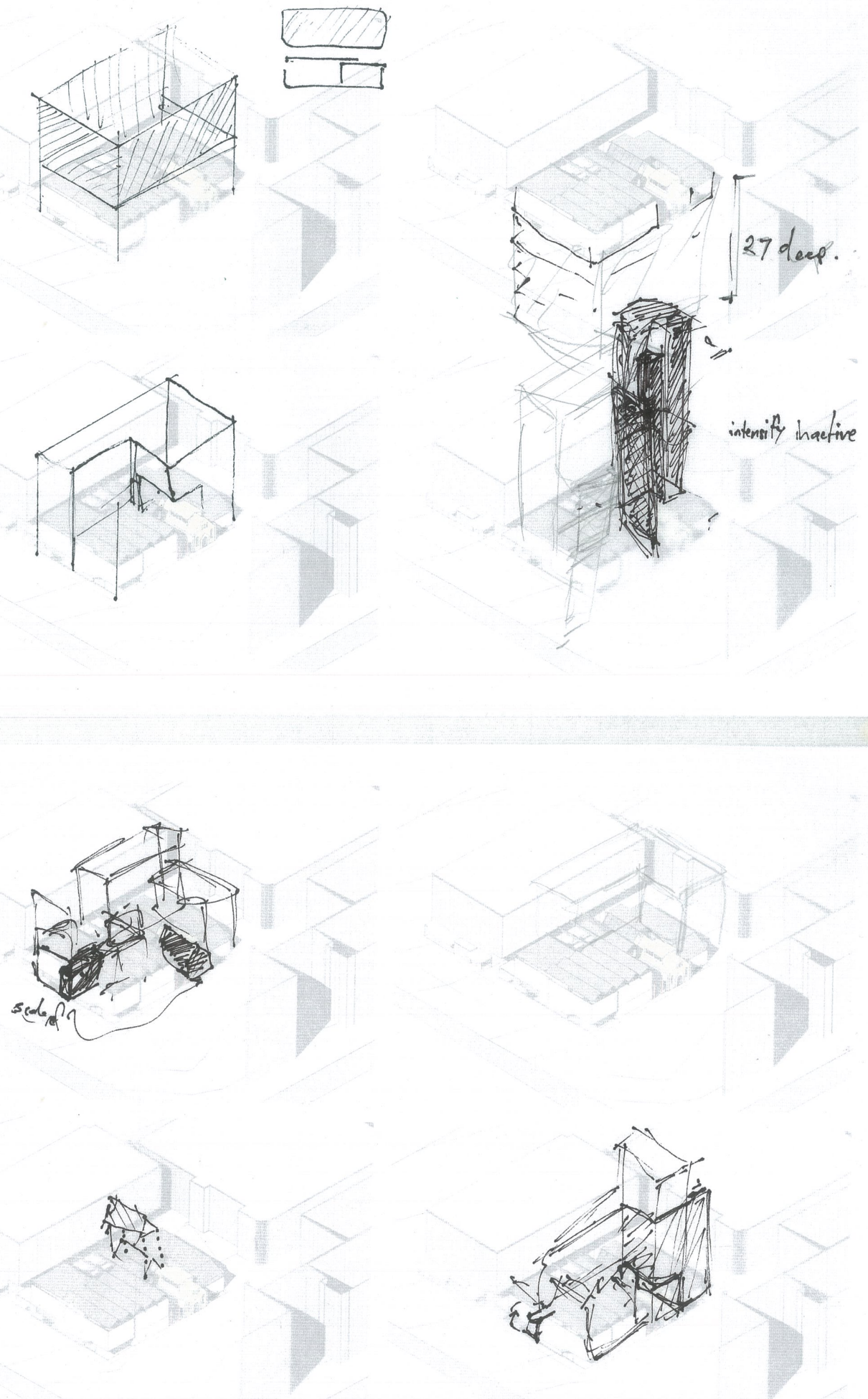

remene mission 


\section{Strategy}

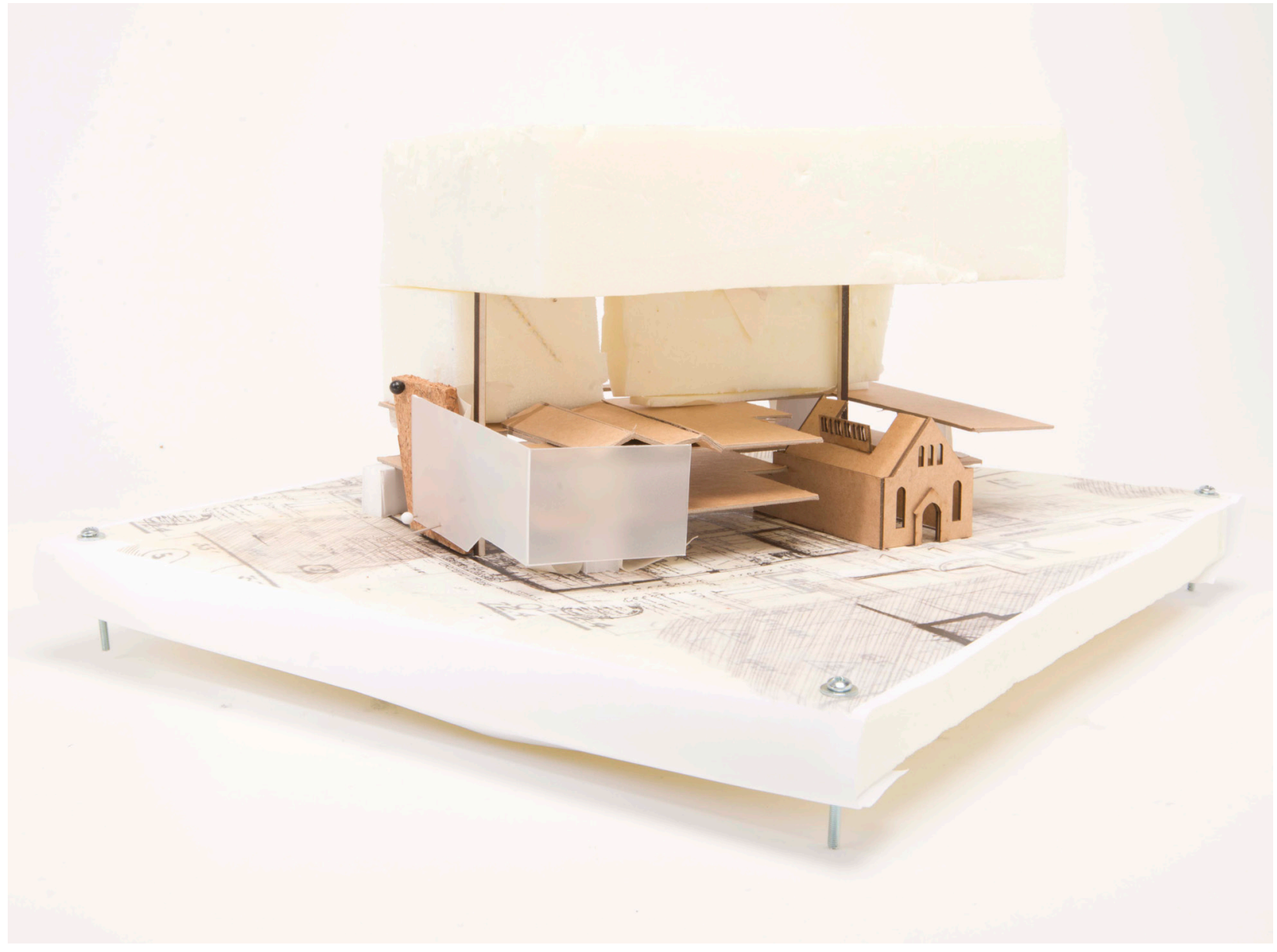

fig. 6.13. Maquette model of Design Phase 3

The approach derived from serial iteration maintains a separation from the Chinese Mission Hall and the south east facing skylights whilst intensifying the northern elevation above the maximum 27 metres. The composition expresses this dialogue between the art school and the Mission Hall with a significant void space - a fittingly vacant volume. The following design explorations articulate how the sketch model was fleshed out to consider the requirements of the multiple programs, and the conscious editing and integration of the art school. 


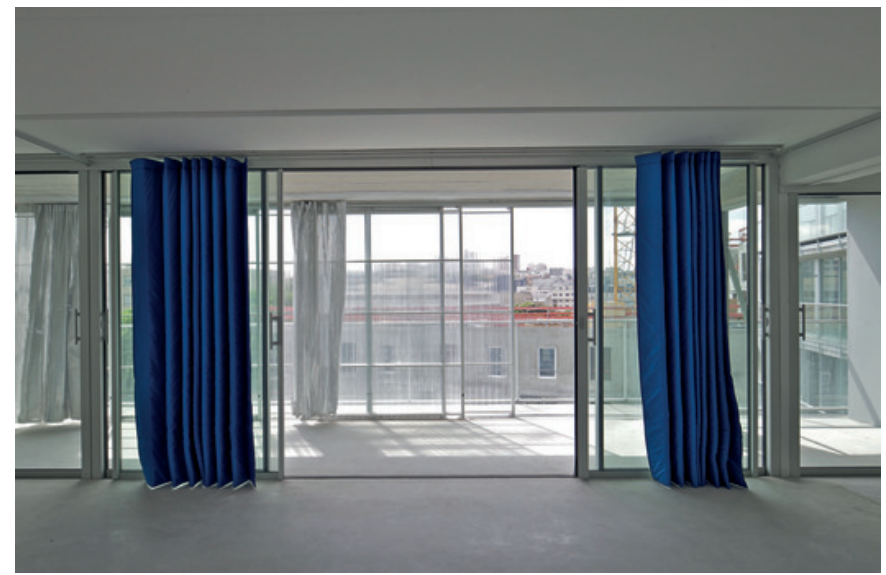

fig. 6.14. Lacaton and Vassal Ourcq Jaures Student \& Social Housing (2013) Interior view of a vacant Social Housing unit

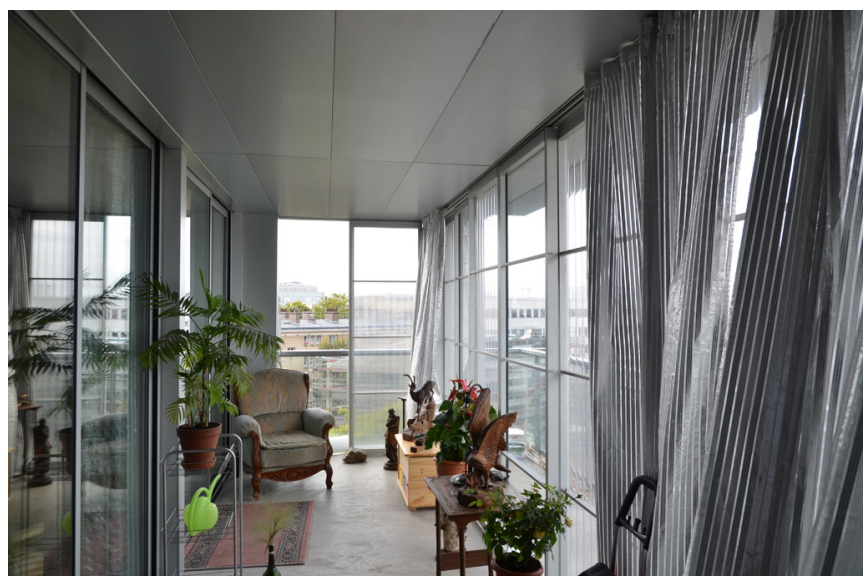

fig. 6.15. Lacaton and Vassal Ourcq Jaures Student \& Social Housing (2013) Interior view of an occupied Social Housing unit 


\section{Design approach for the Artist Colony}

The accumulation of programs provides a rich opportunity for the narratives to intertwine as they ascend the building. Questions emerge such as; what happens if the public is invited and encouraged to occupy the higher levels? What tensions are created between the resident, the student and the tourist? The Artist Colony seeks to invite the public to the top of the building and filter social spaces through. By activating the building and inviting this dialogue the opportunities are presented to express the thresholds between the arising tensions.

The Artist Colony will explore techniques to encourage informal gatherings and project spaces for the artist studios with adjoining spill over areas from the units. The notion of a shell is explored for the units whereby the unit provides the bare necessities and the occupants inhabit how they wish. A contingent architecture that allows the potential of such diverse uses as domestic living, art practicing, exhibition. The units work with specifics to provide a place to cook, a place to eat, a place to sleep, a place to bathe.

The work of Lacaton and Vassal Architects returns as a key reference for performative assemblages within the domestic setting ${ }^{26}$. They embrace the social realities of buildings over time by using standardised construction systems and materials; to be transformed by the occupant. fig. 6.14-fig. 6.15 "Their focus is on the vacancy of space itself and the events it can accomodate" ${ }^{27}$.

26. (Manolopoulou 144-146)

27. (ibid 146) 


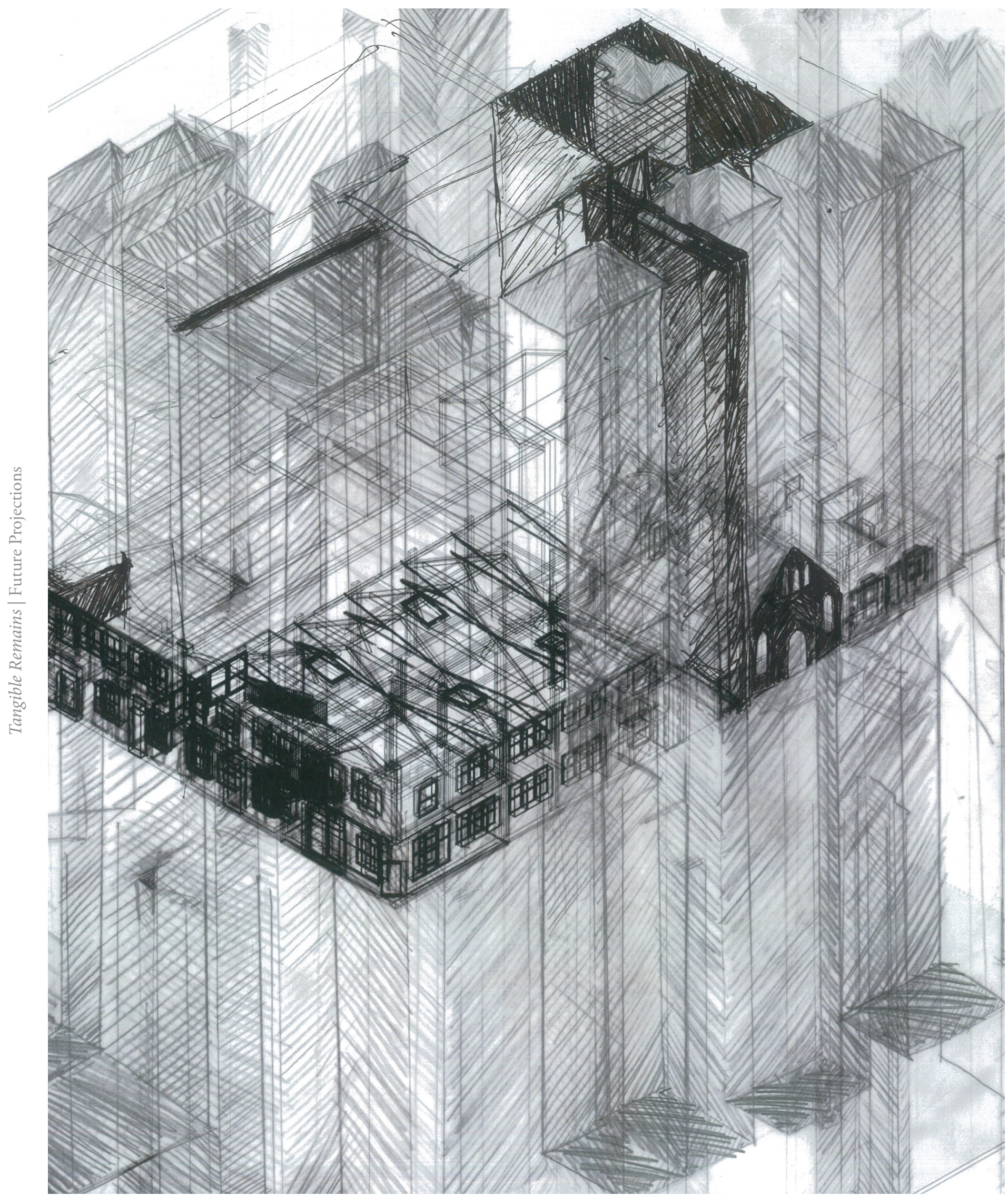

fig. 6.16. Spatial study of the 'Field of Intensities' extrudes the building footprints from the Thomas Ward Map to the $27 \mathrm{~m}$ height limit. 


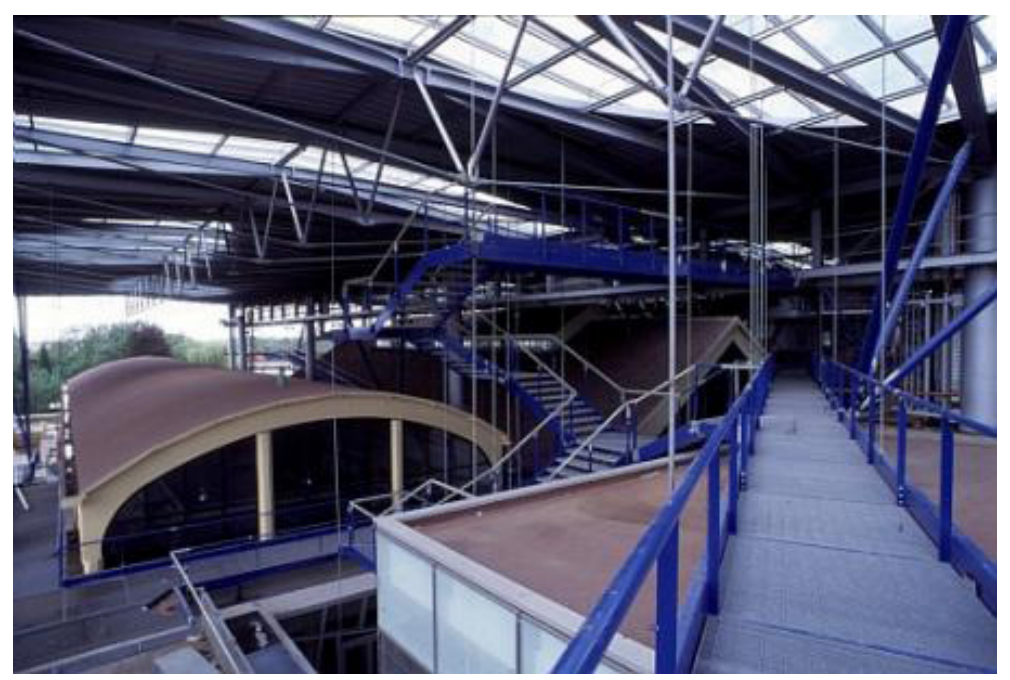

fig. 6.17. Tschumi Le Fresnoy Art Centre (1991-1997)

\section{Circulation}

Strategies for vertical and horizontal circulation are tested to explore various issues and opportunities: such as structure, activation of the void, integration of private and public movement. The ground floor was initially explored before progressing to the roof level.

- $\quad$ Tschumi's Le Fresnoy project presents a strategy for activating an in-between space by weaving access routes across and between a lower roof scape and through slender structural supports. This approach has the potential to activate a vacant zone and echo notions of temporality. Design tests found that the site's proportions are too shallow for such an approach without compromising the internal and external light qualities and the articulation of the overhang from the street. The attention to preserving this void was continued in the iterative testing of a services shaft ${ }^{\text {tig. 6.18 }}$. The positioning and volume was considered with reference to the ground floor as well as the amenity to the apartments. 

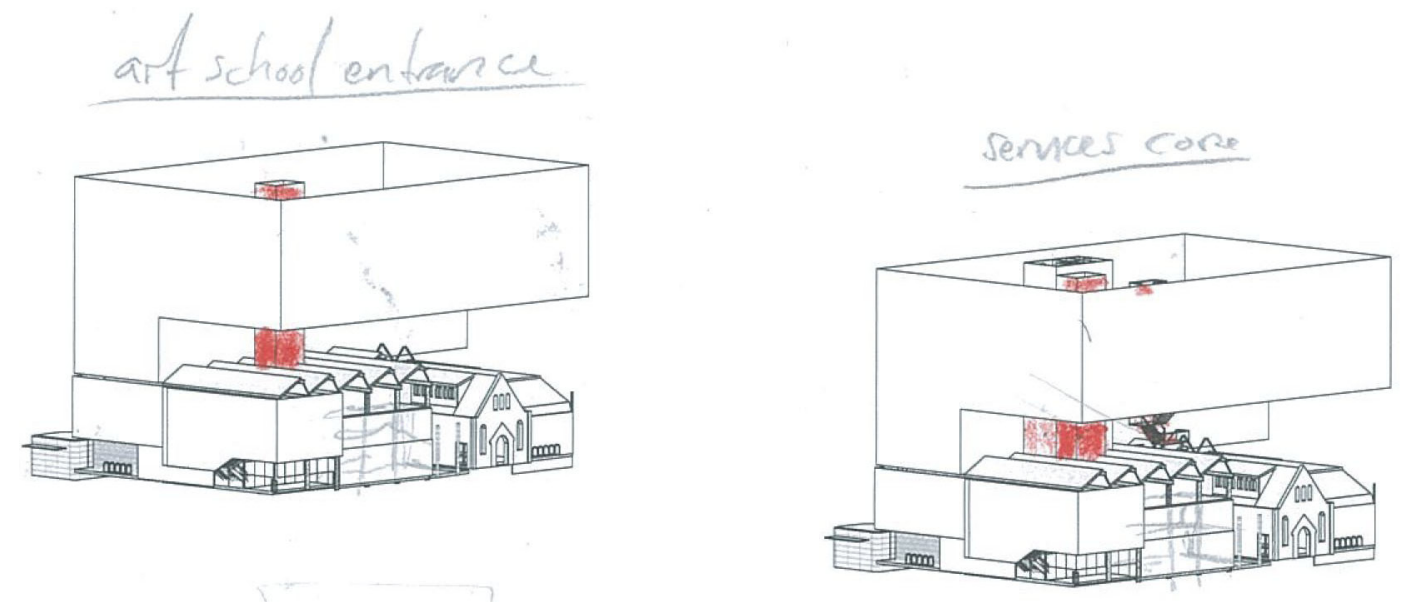

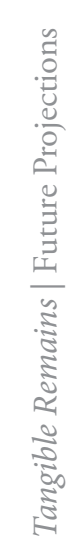
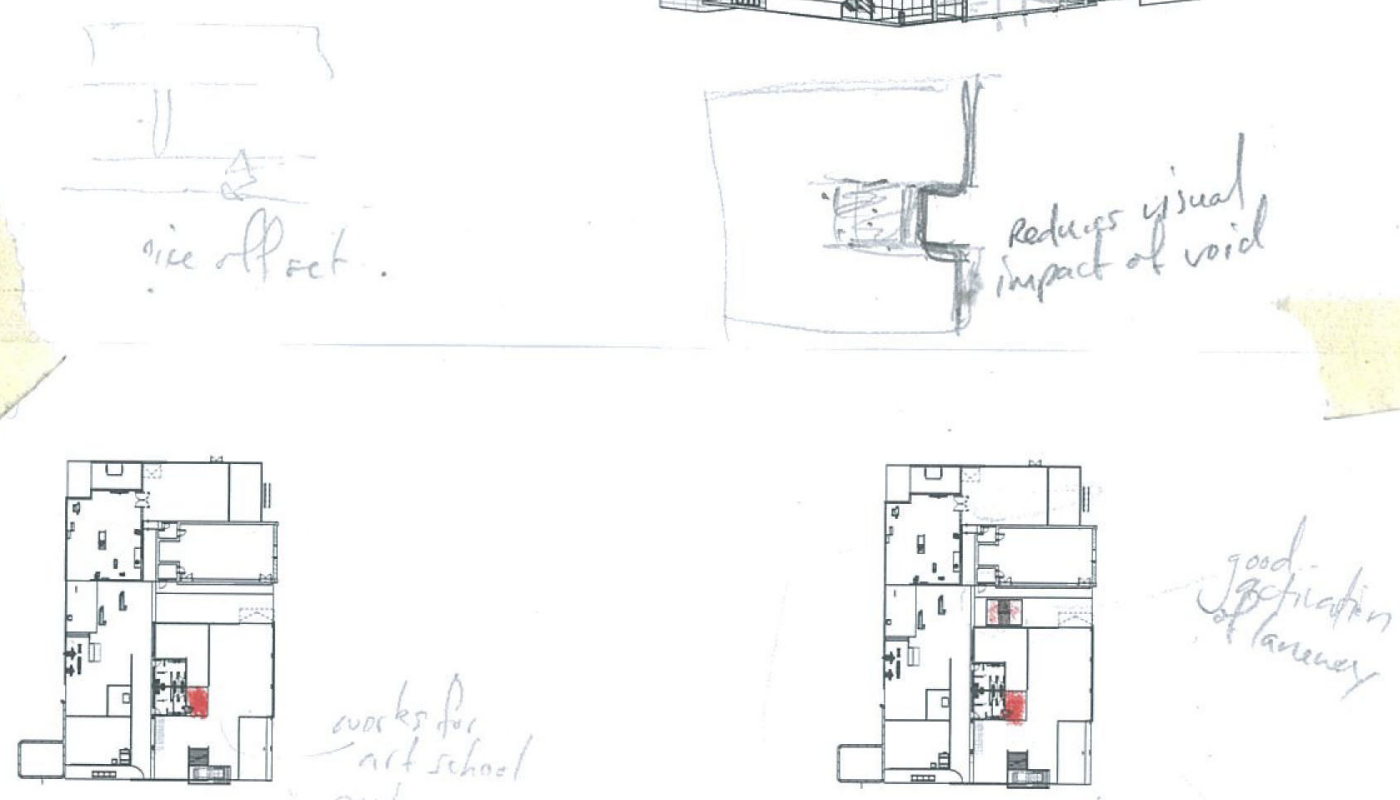

fig. 6.18. Thumbnail iterations exploring the visual impact and functionality of the new circulation 


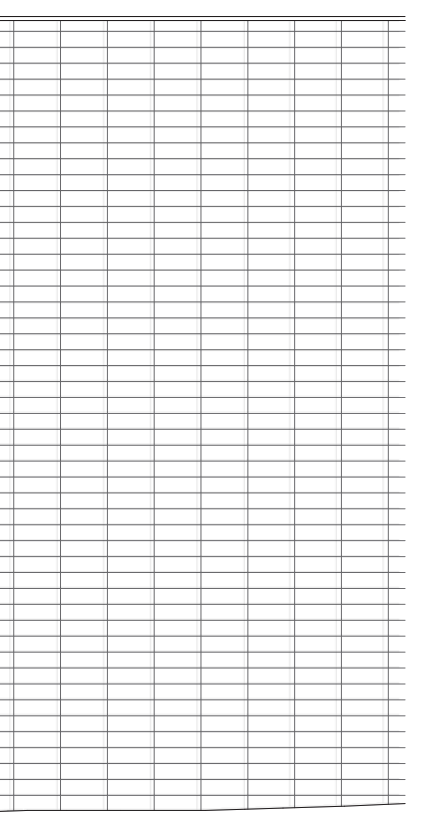




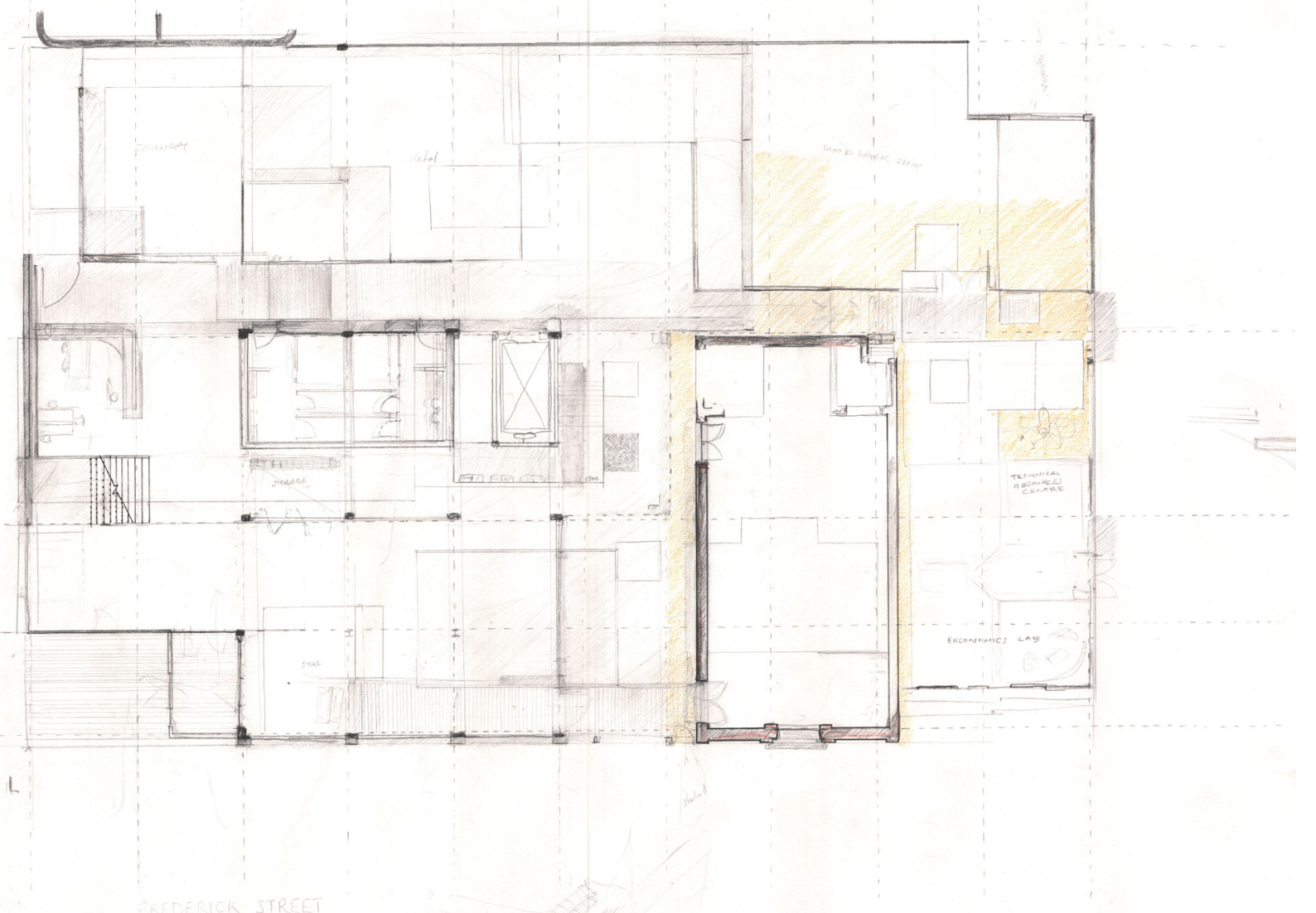

fig. 6.20. Hand drawn Ground Floor plan builds on top of the 'Field of Intensities'. Lines become sharper and more intense as decisions were made in the working drawing 


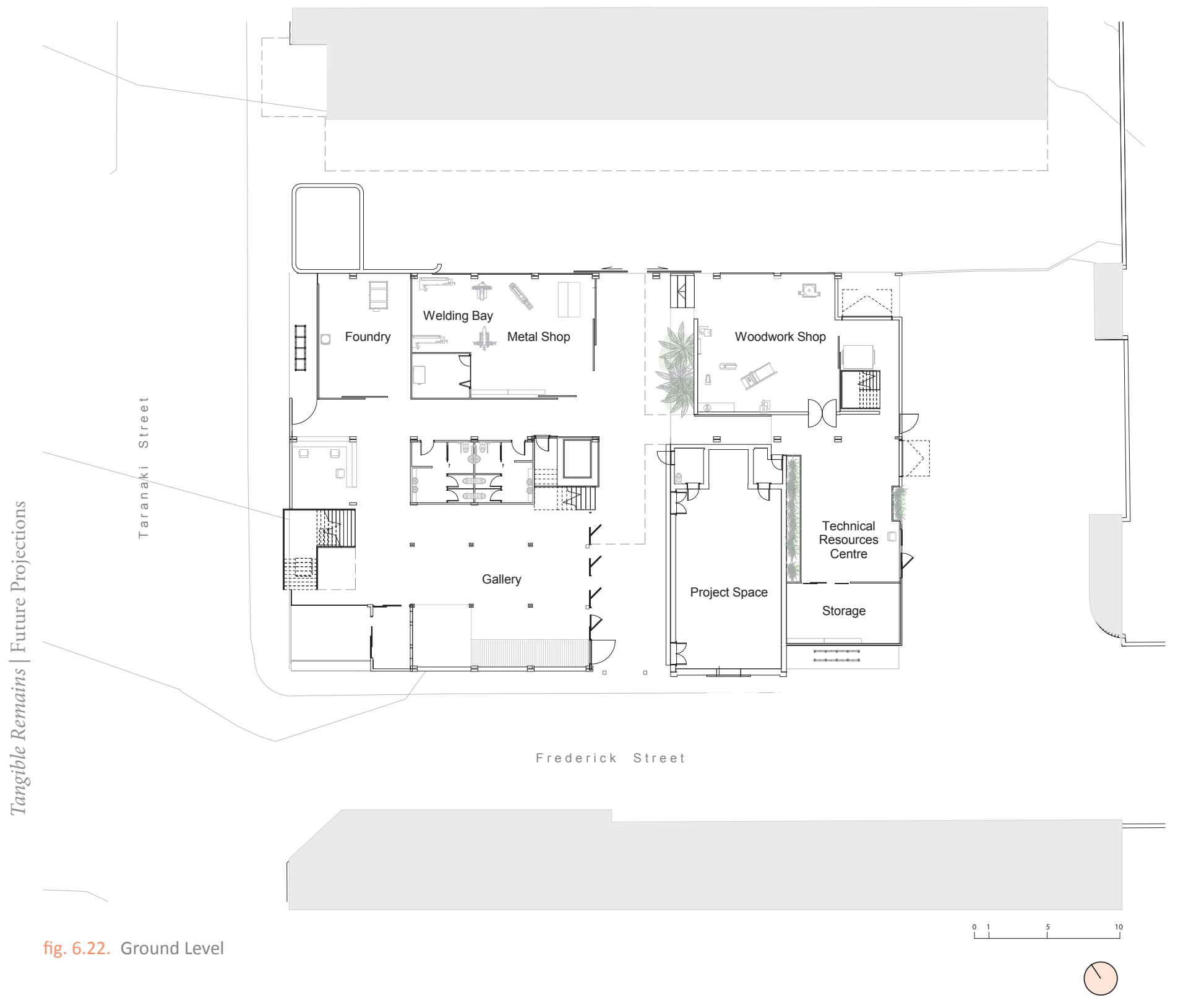




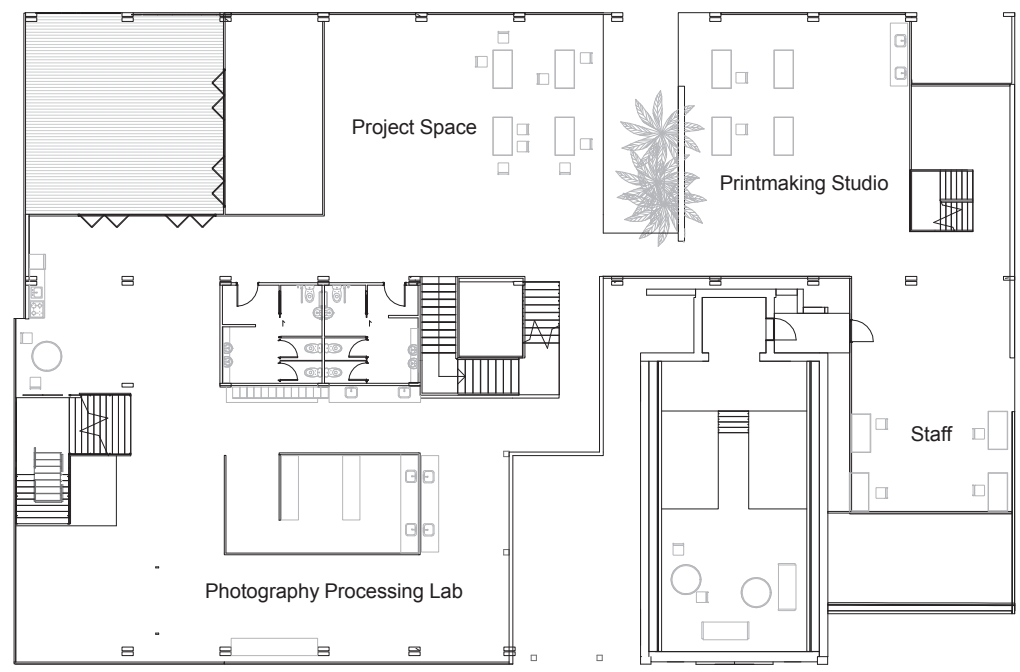

fig. 6.23. Level One

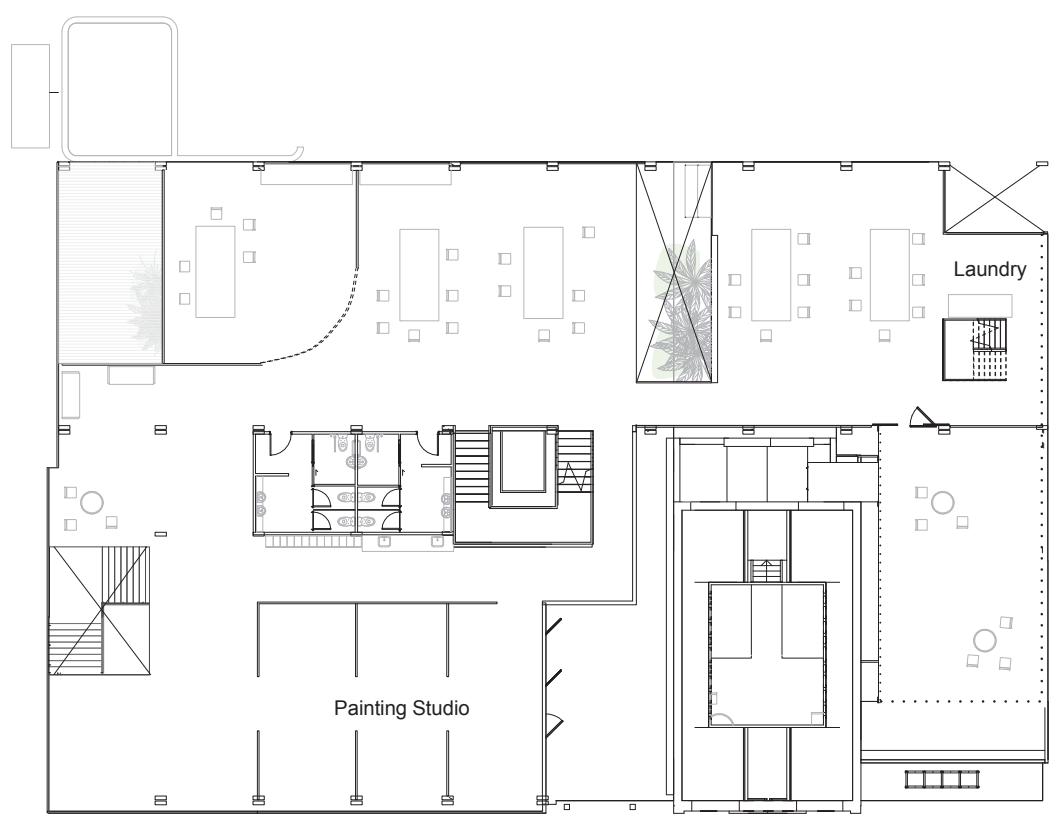

fig. 6.24. Level Two

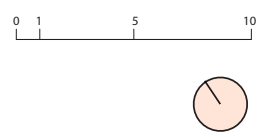




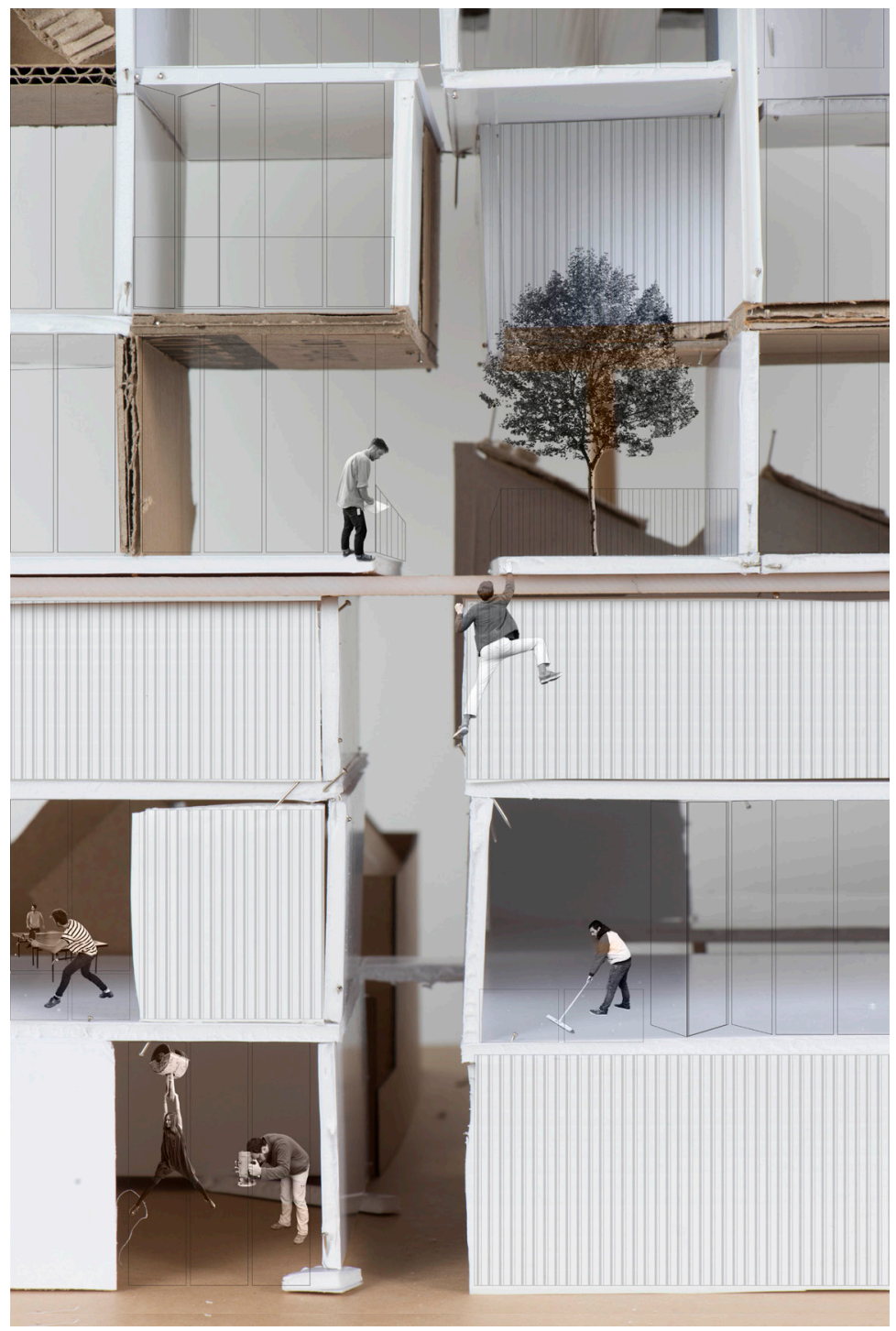

fig. 6.25. Rear view of Laneway

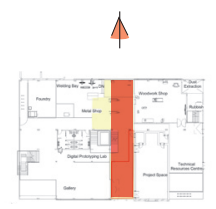




\section{laneway}

Laneway

intensified

The laneway developed in the second design phase presented an opportunity to be extended and amplified in the third design phase. An intense moment is created as the laneway extends into workshop and upward to punctures through the new mass of the units, drawing fragments of light down the split.

The split (laneway) became a key common area for resident, academic and public throughout the building. 

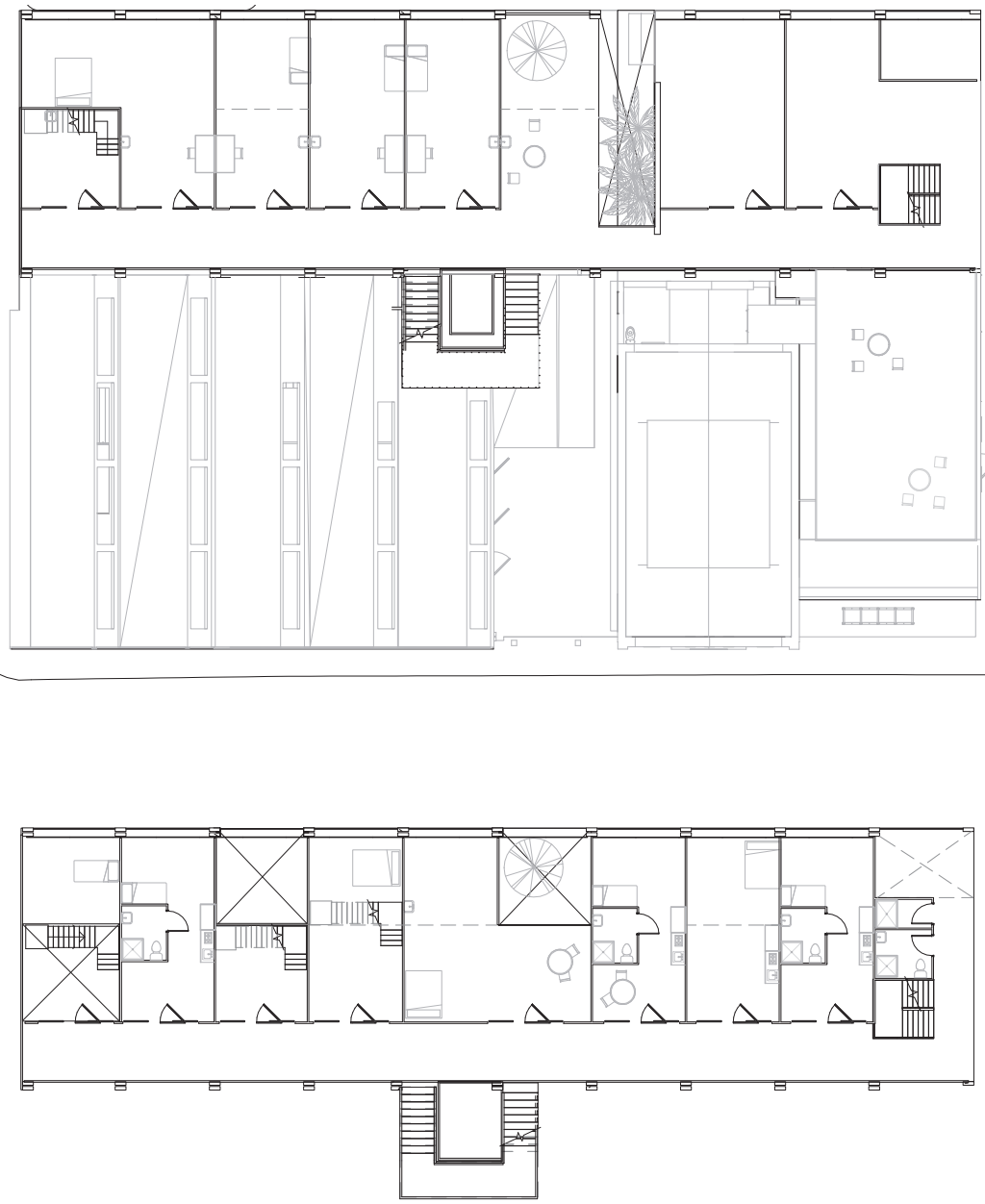

fig. 6.28. Level Three

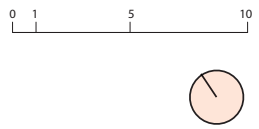

fig. 6.29. Level Four 

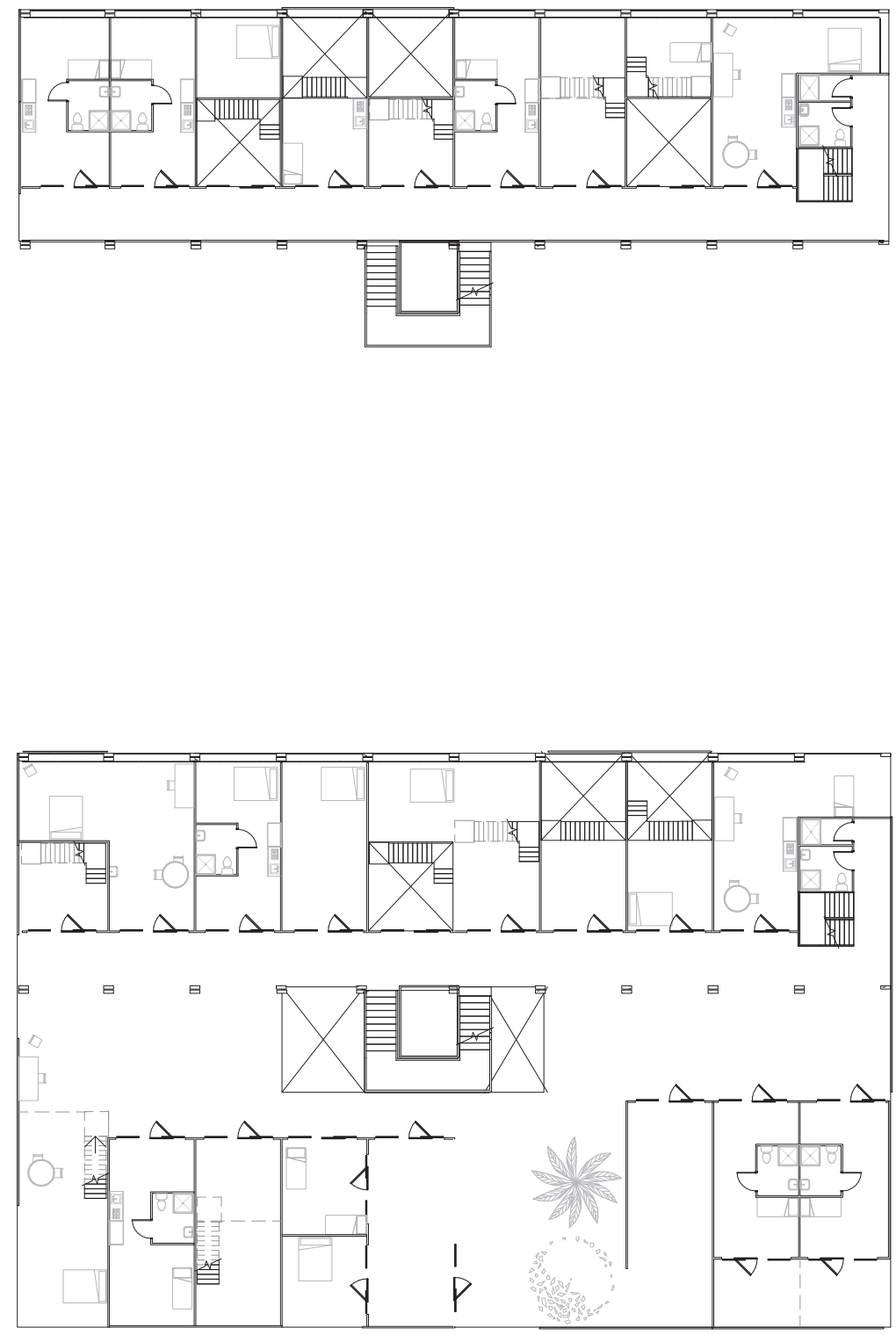

fig. 6.30. Level Five

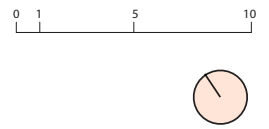

fig. 6.31. Level Six 

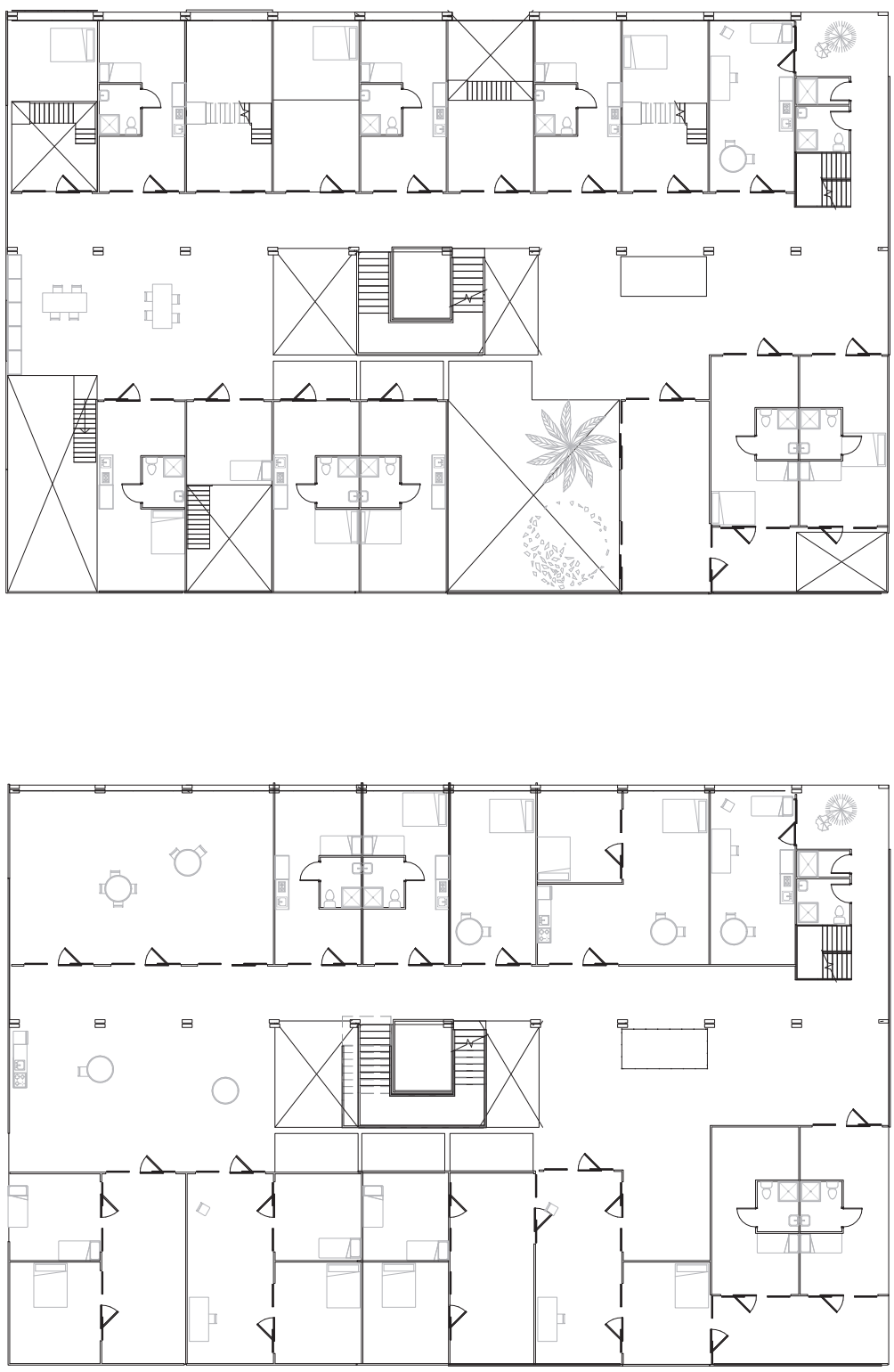

fig. 6.32. Level Seven

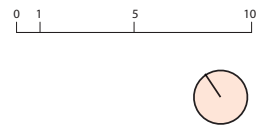

fig. 6.33. Level Eight 

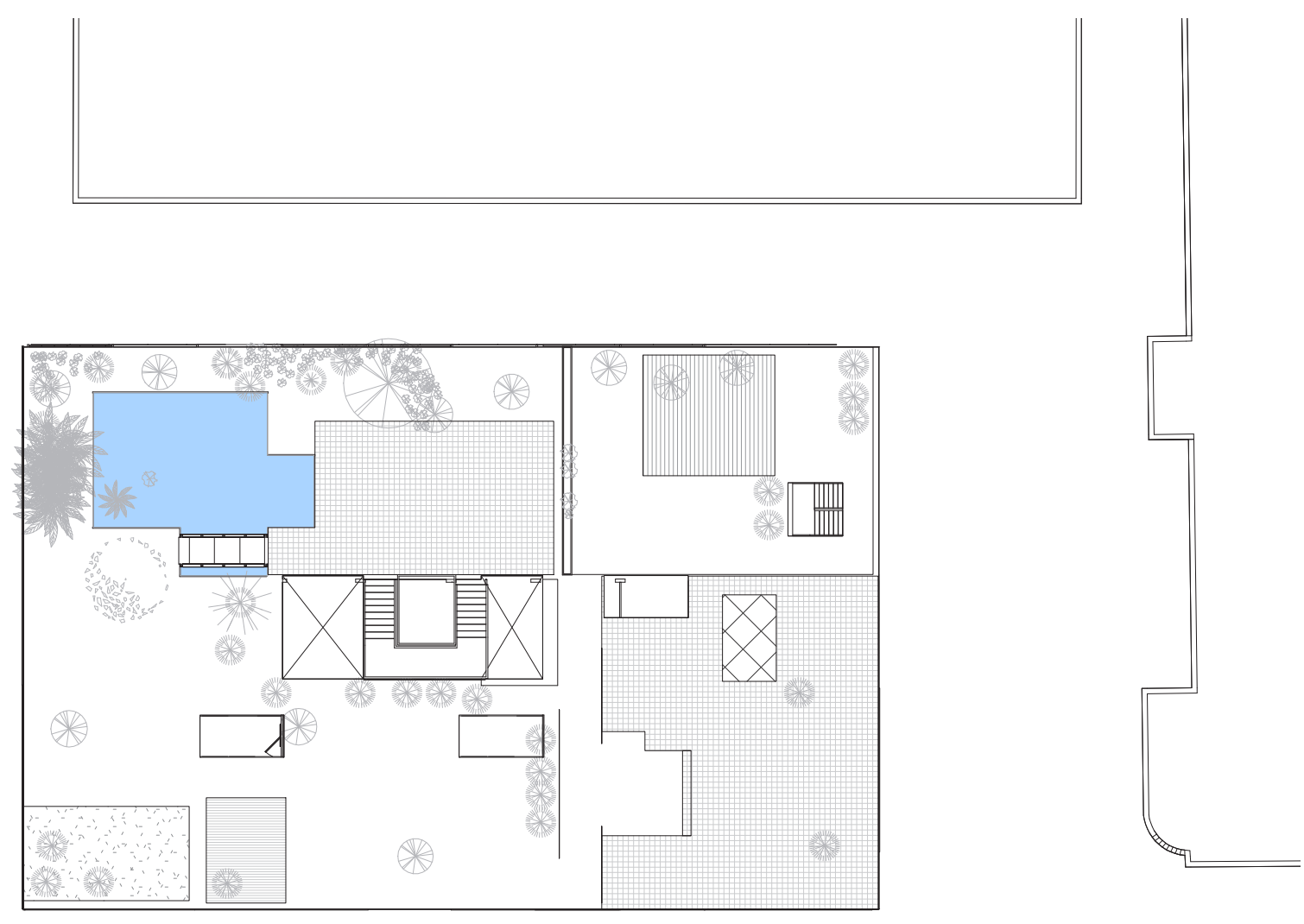

fig. 6.34. Level Nine

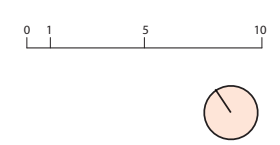




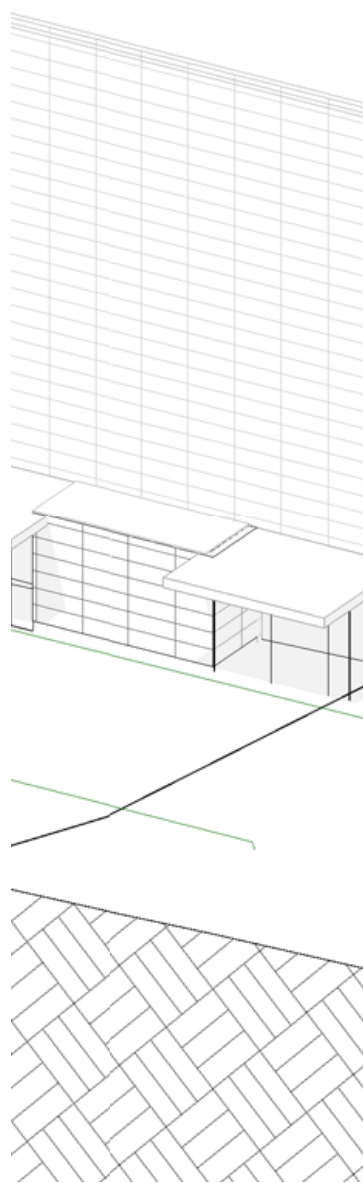




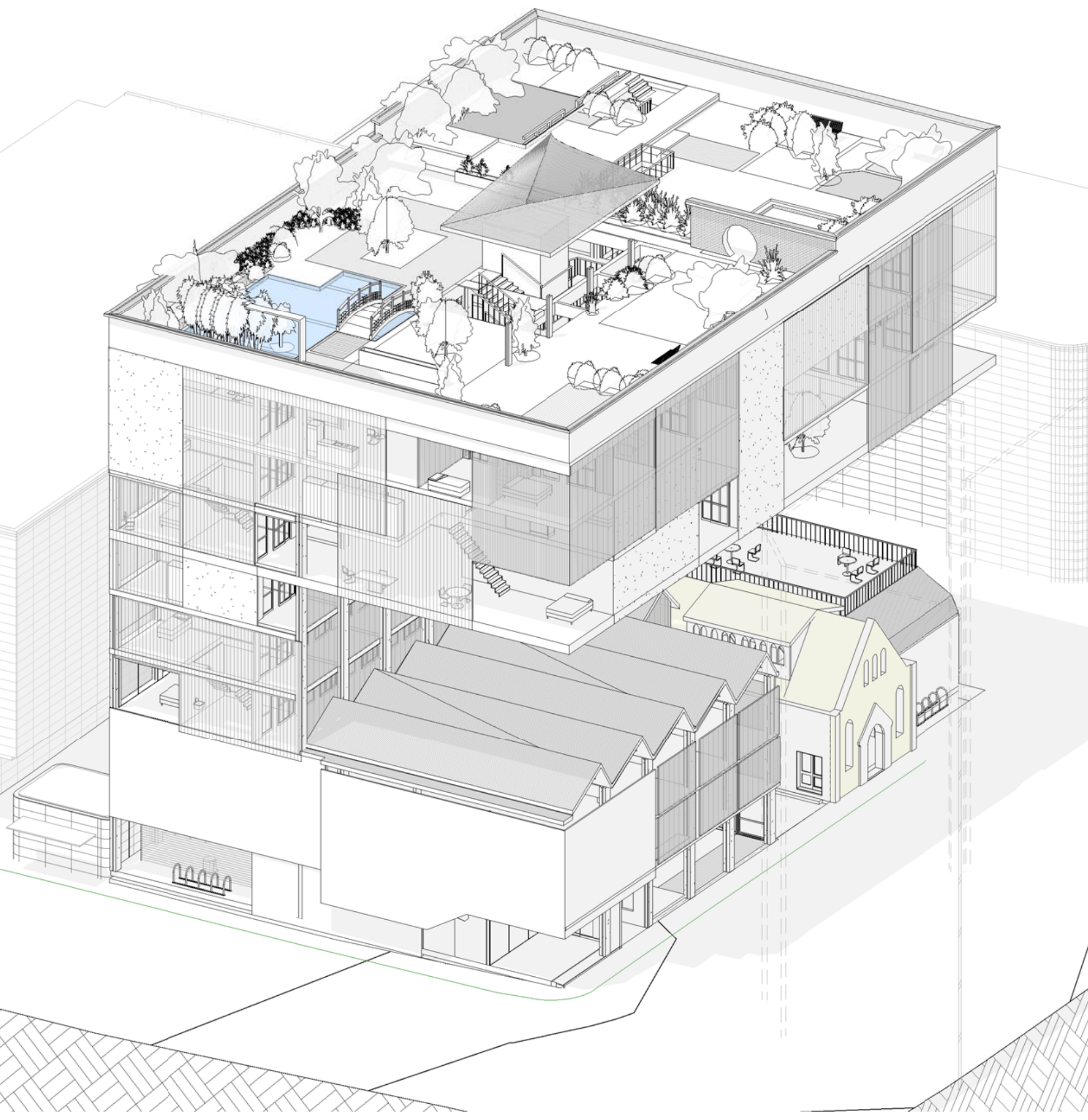




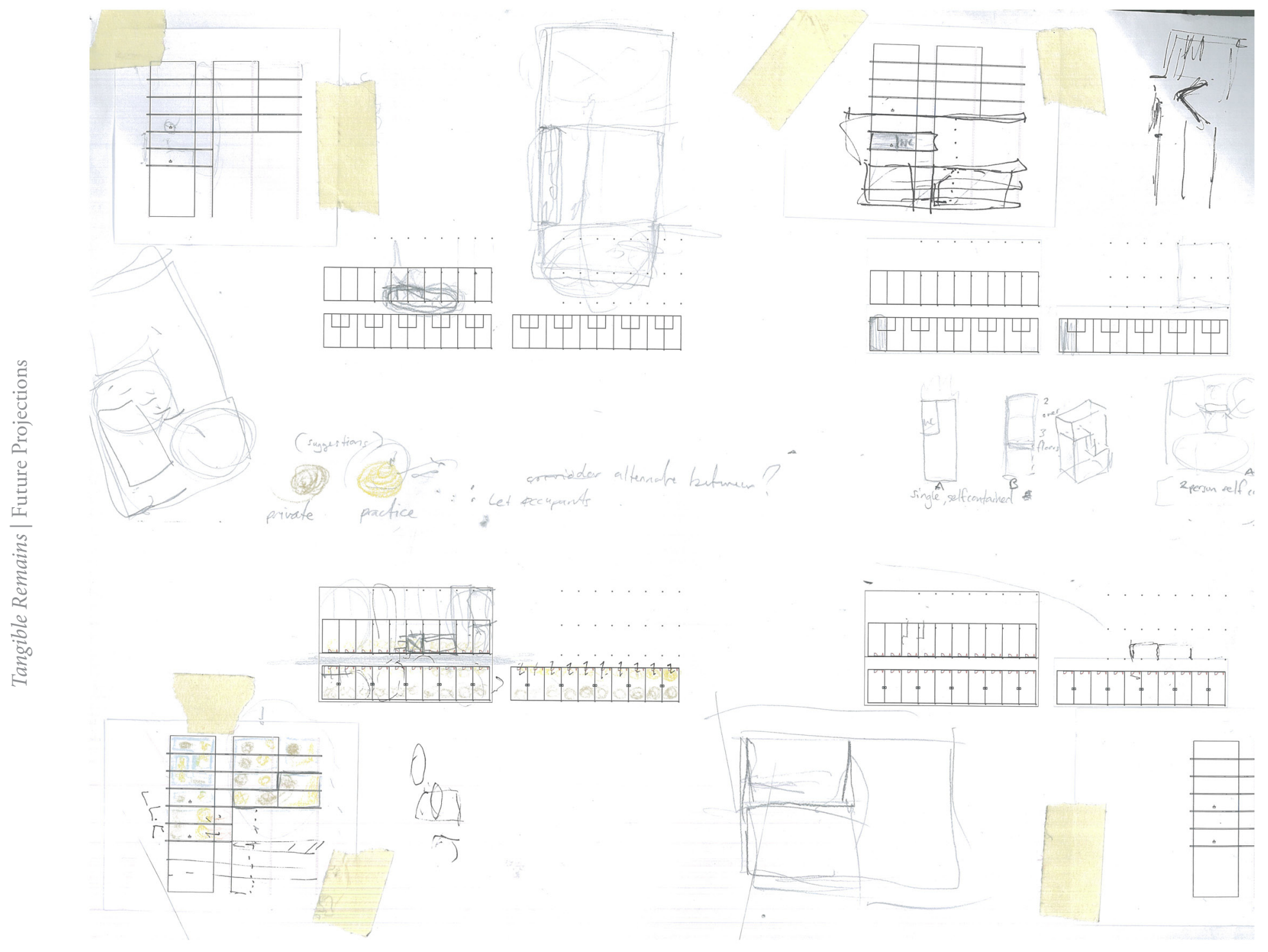

fig. 6.38. Unit iterations in the development of the street (corridor); how the units could maintain privacy yet extend out into the street for exhibition, art practice or communal living 


\section{[spine as}

street ]

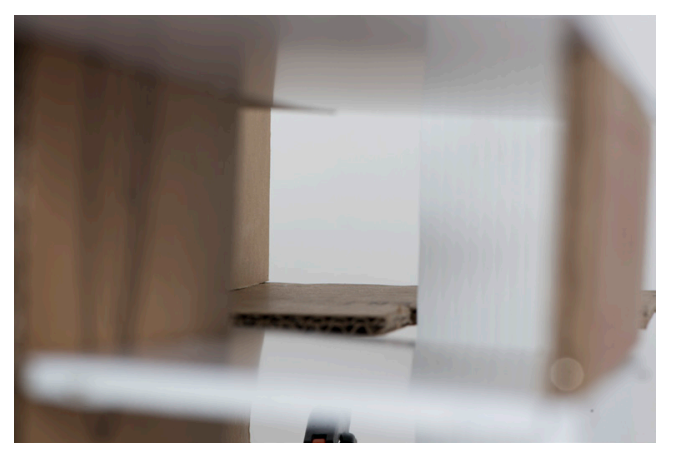

fig. 6.39. Relationship between units 


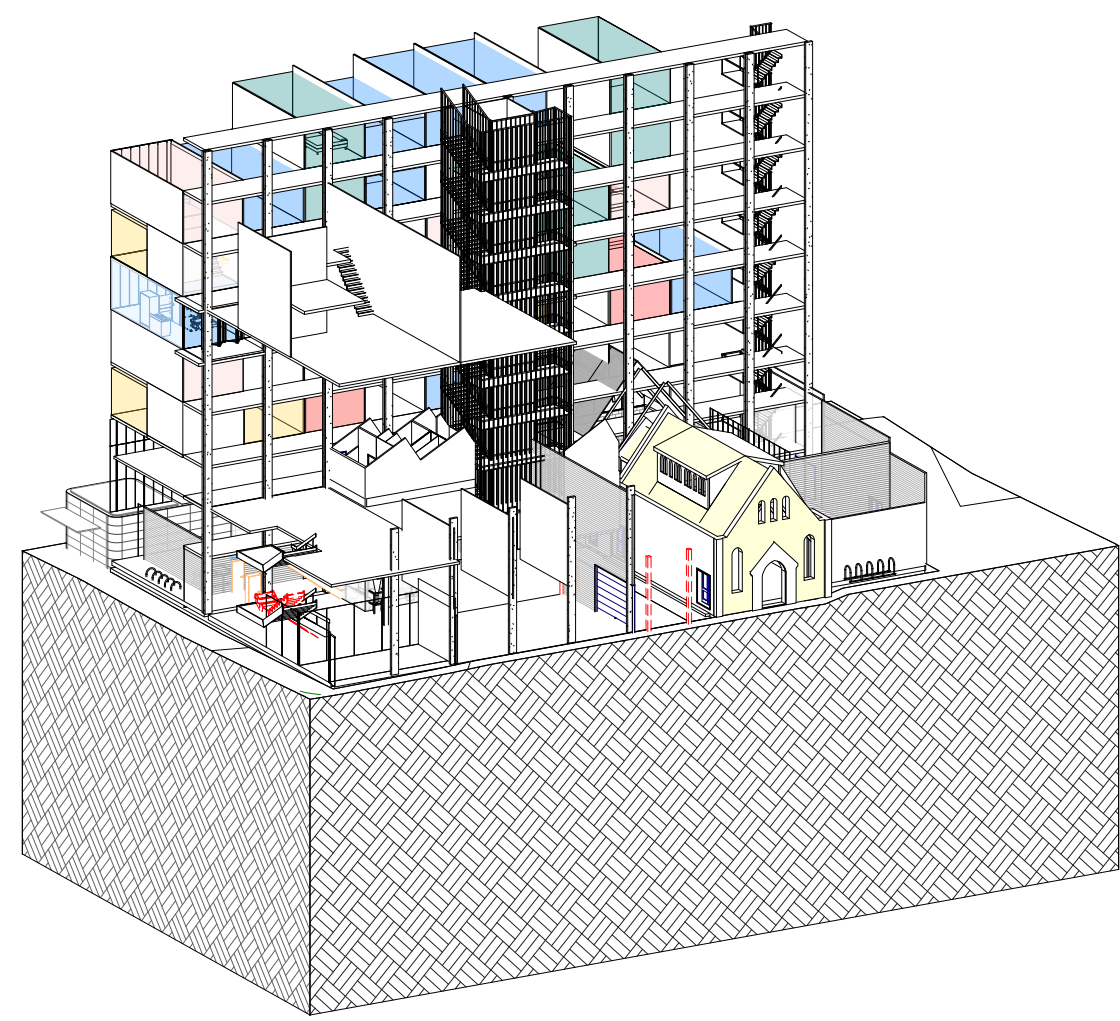

fig. 6.40. Units fed into the digital model 


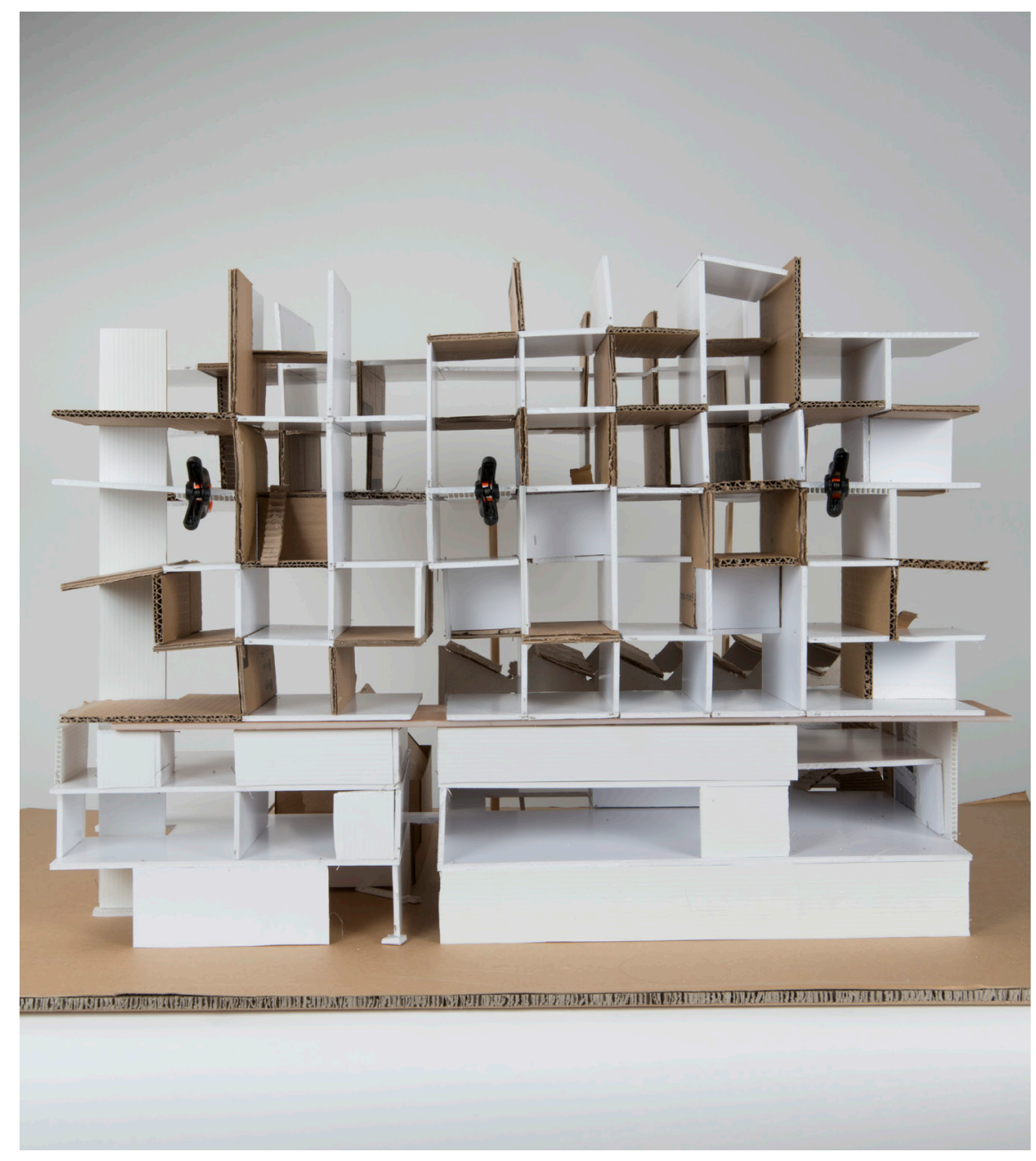

fig. 6.41. North Elevation of 1:50 Model 


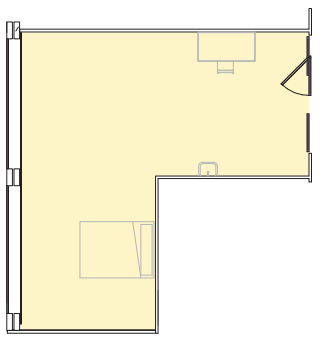

$48 \mathrm{~m} 2$
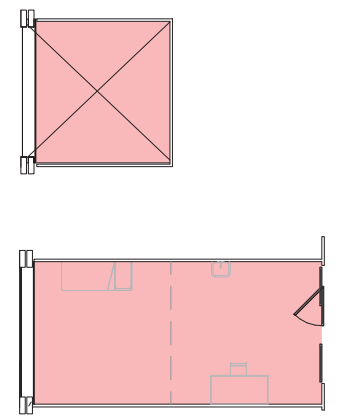

$48 \mathrm{~m} 2$

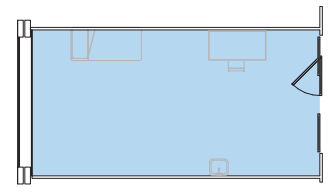

$33.6 \mathrm{~m} 2$
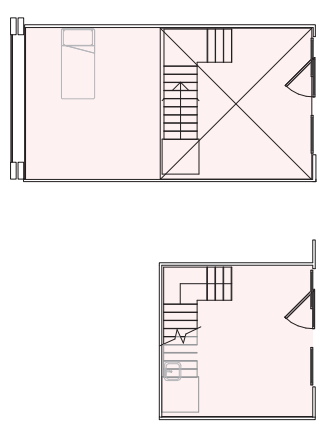

$48 \mathrm{~m} 2$
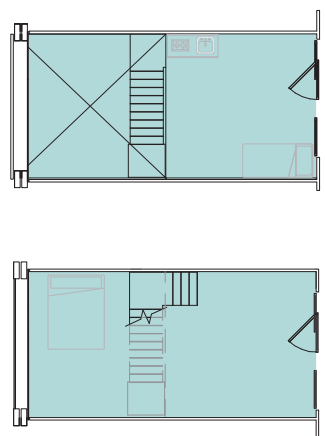

$67.2 \mathrm{~m} 2$

fig. 6.43. Unit variations for the north-east elevation provide options for single artists in residency or additional studio space for the school. Units situate in the overhang of Levels $6-8$ can be agglomerated for families or share houses; or opened for larger events. Many units share services and project areas to activate the internal 'streets'. 


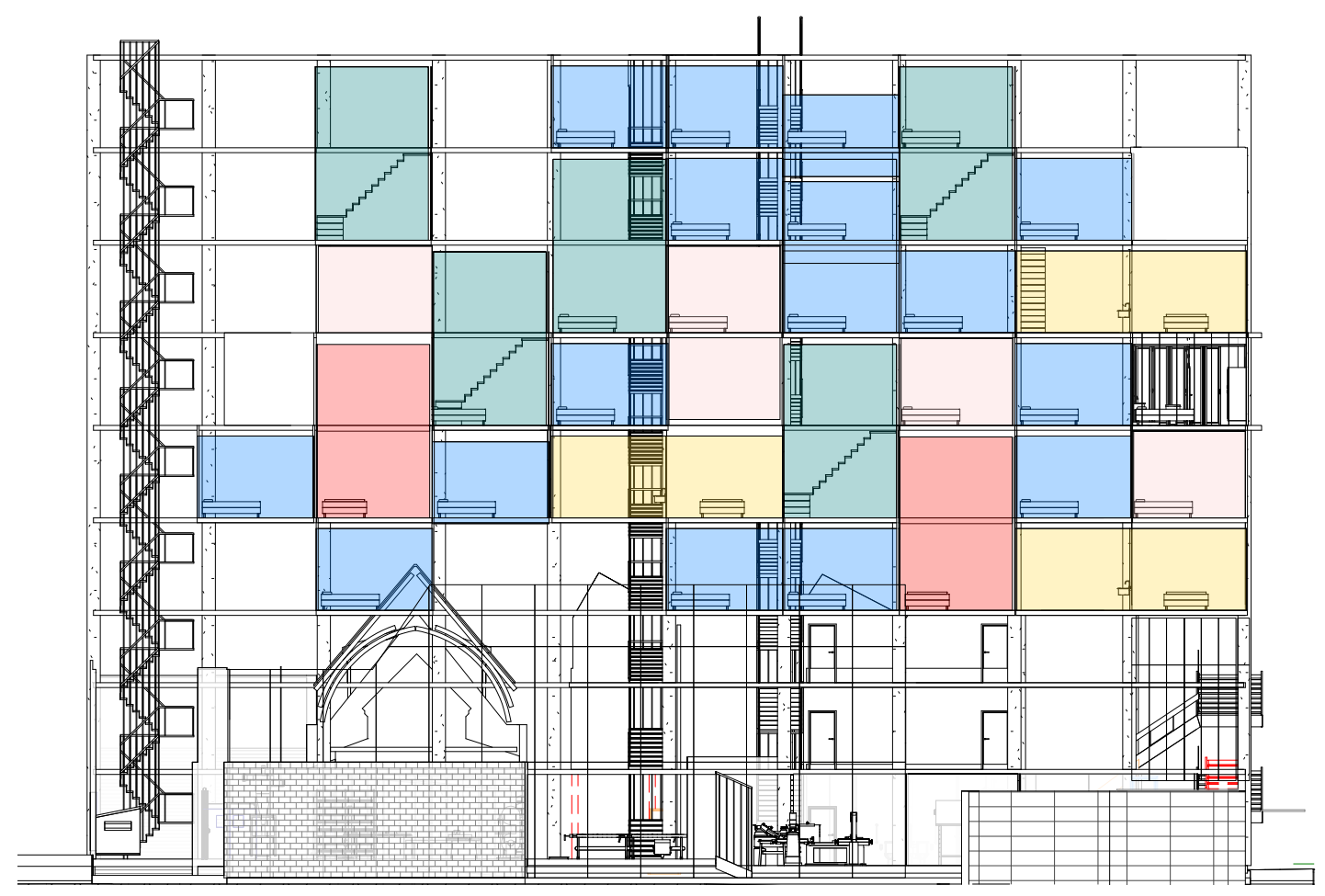

fig. 6.44. North-east elevation articulating the units 


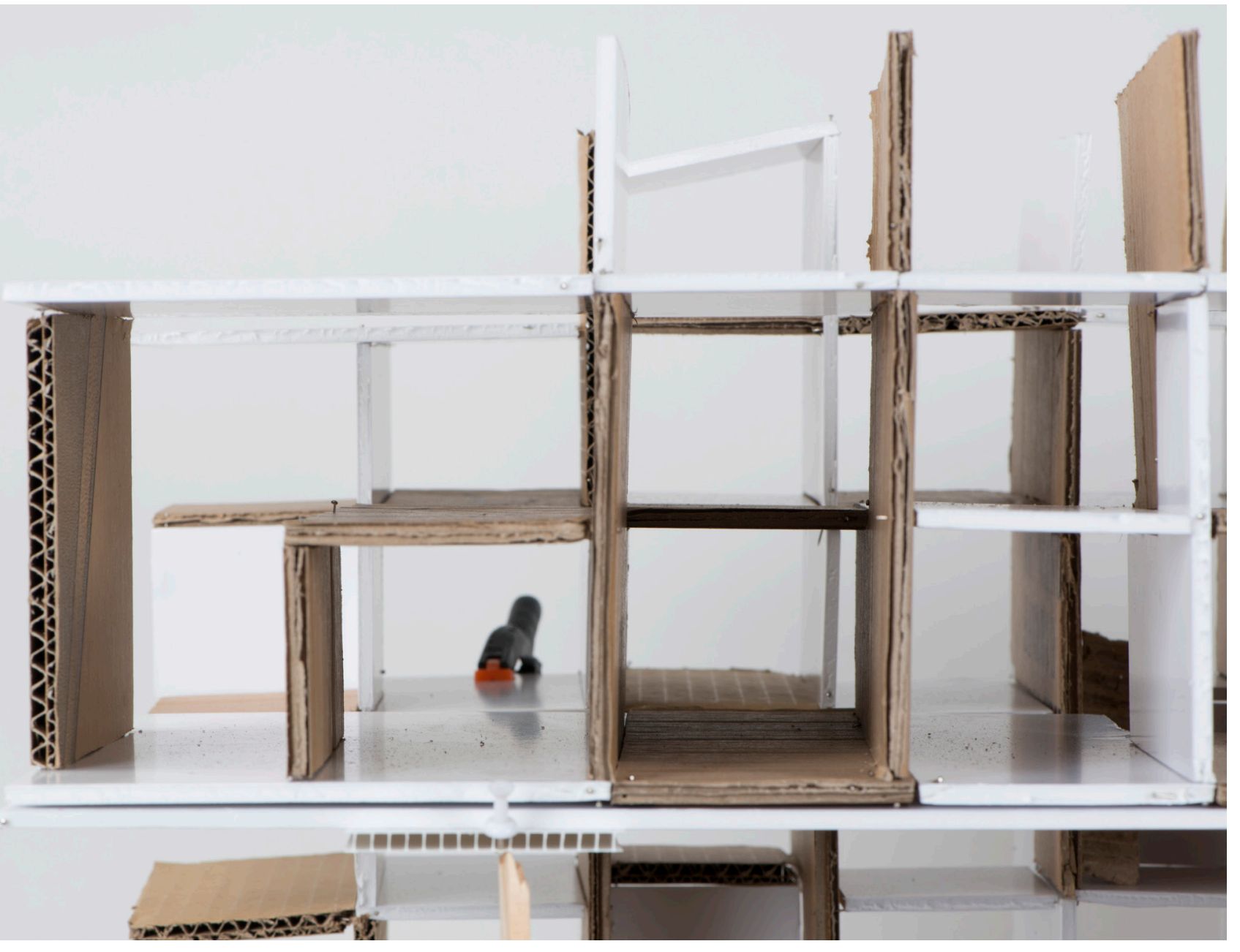



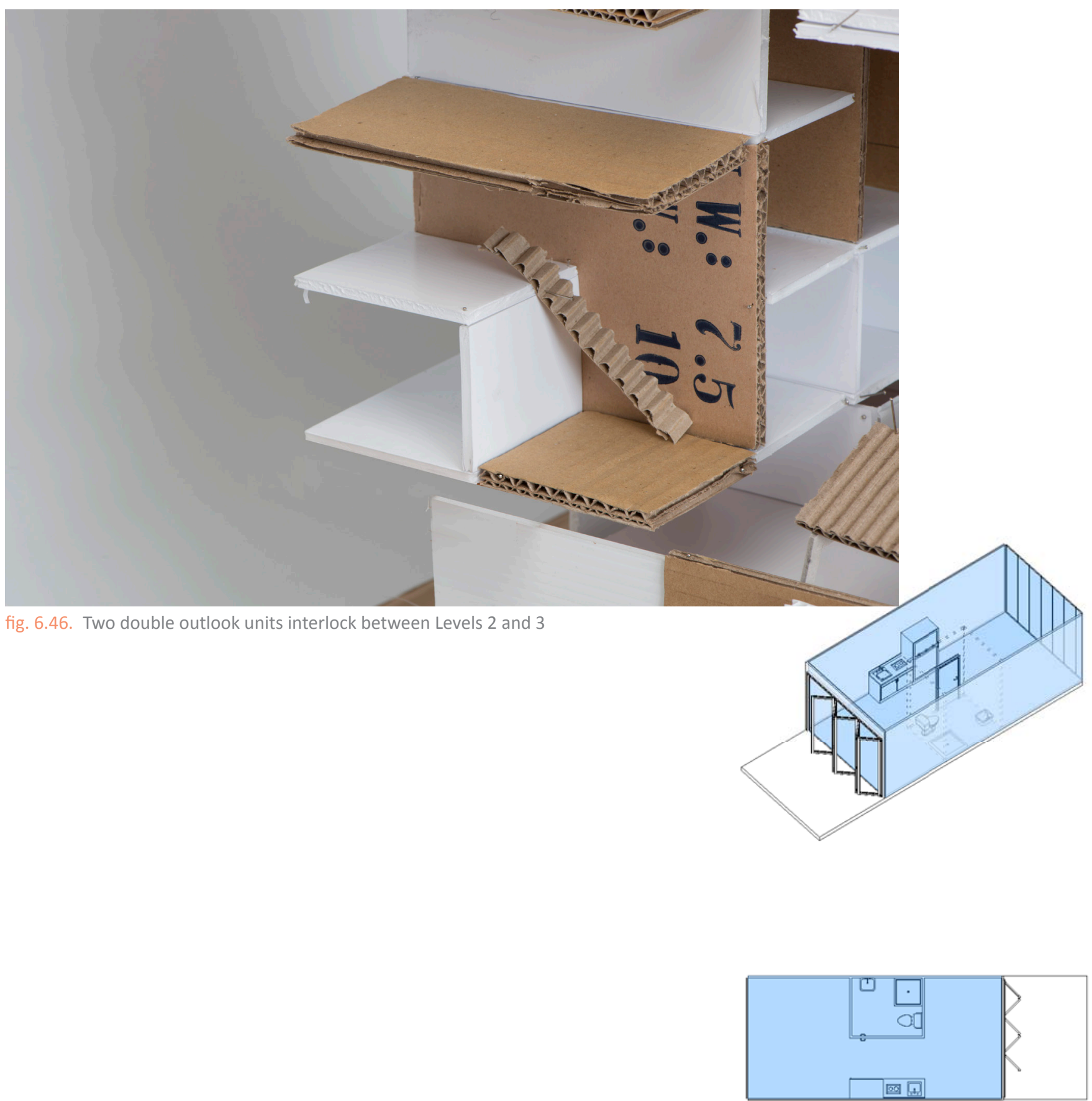

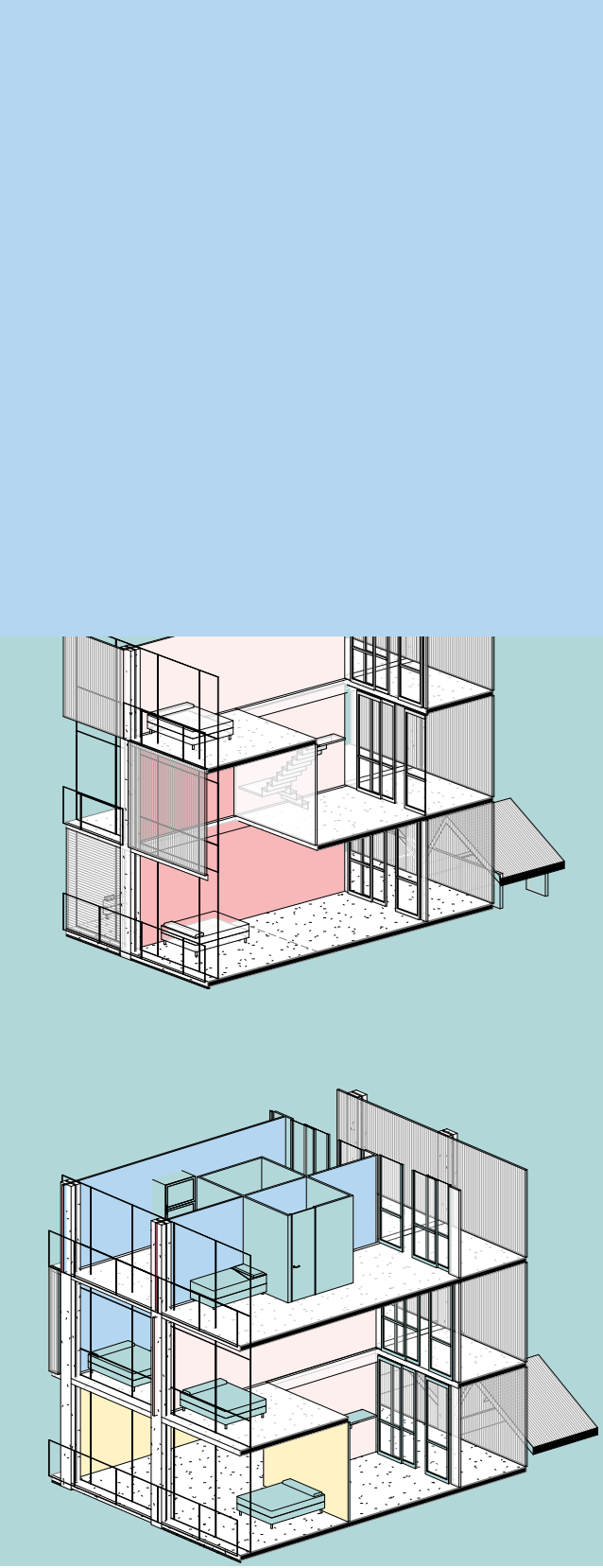

fig. 6.47. Configuration of units between Levels 3 and 5 


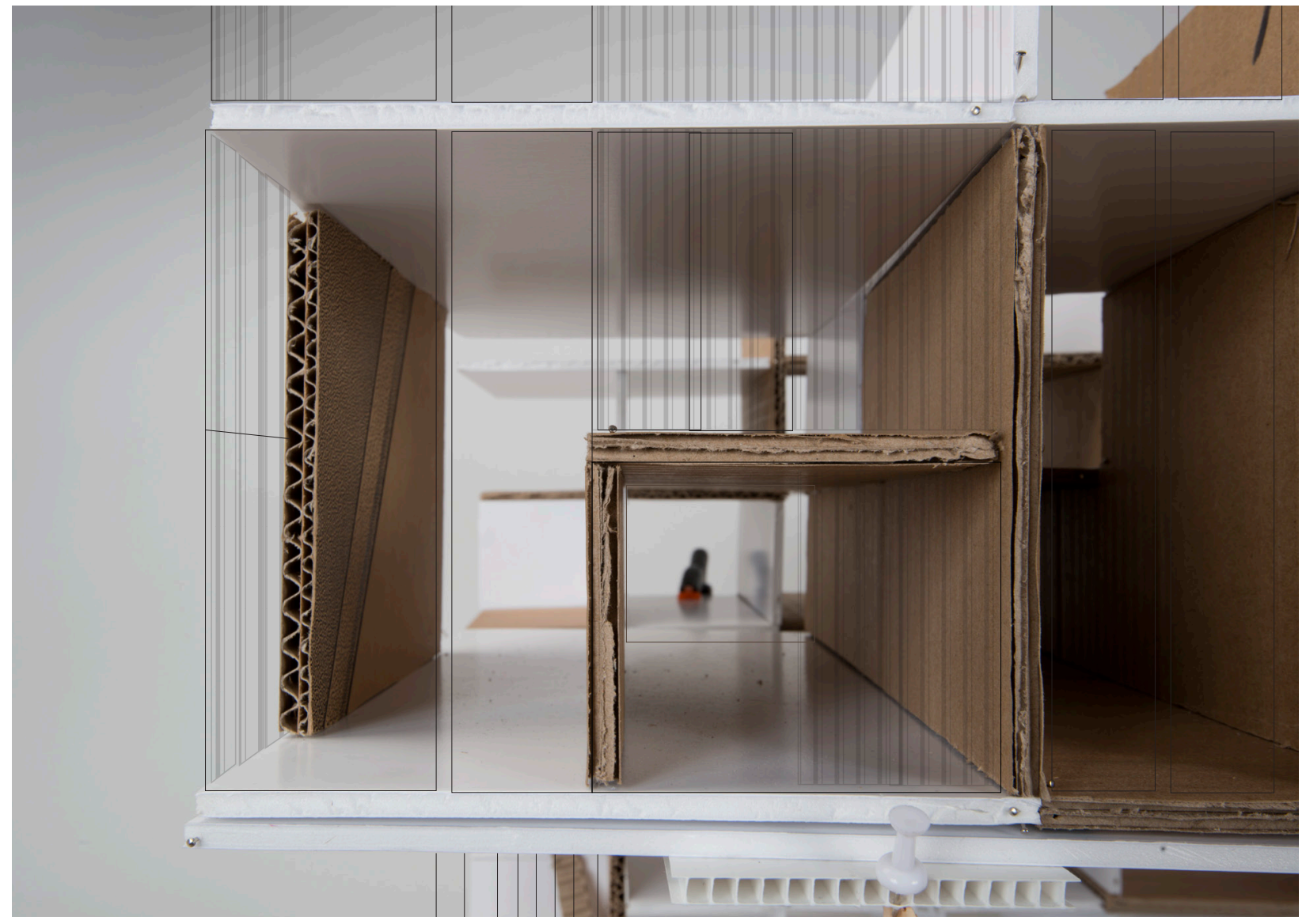

fig. 6.48. Solid walls are set back from the corner of the overhang. Double height spaces provide room for larger projects and create a singular moment when standing of the edge. 


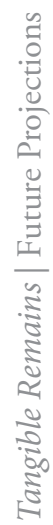
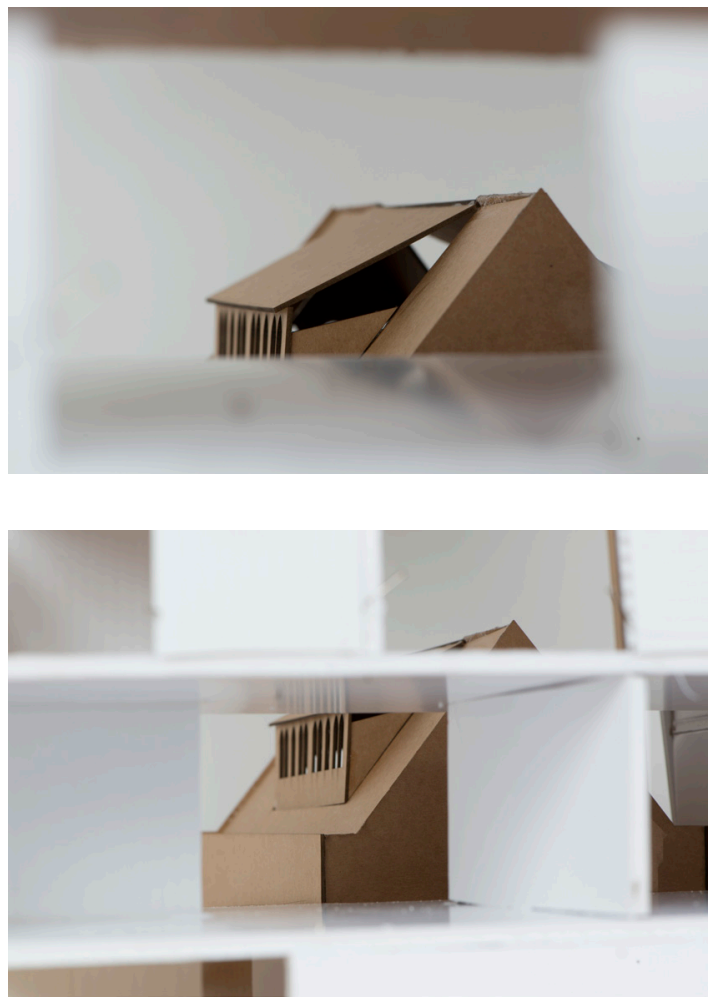


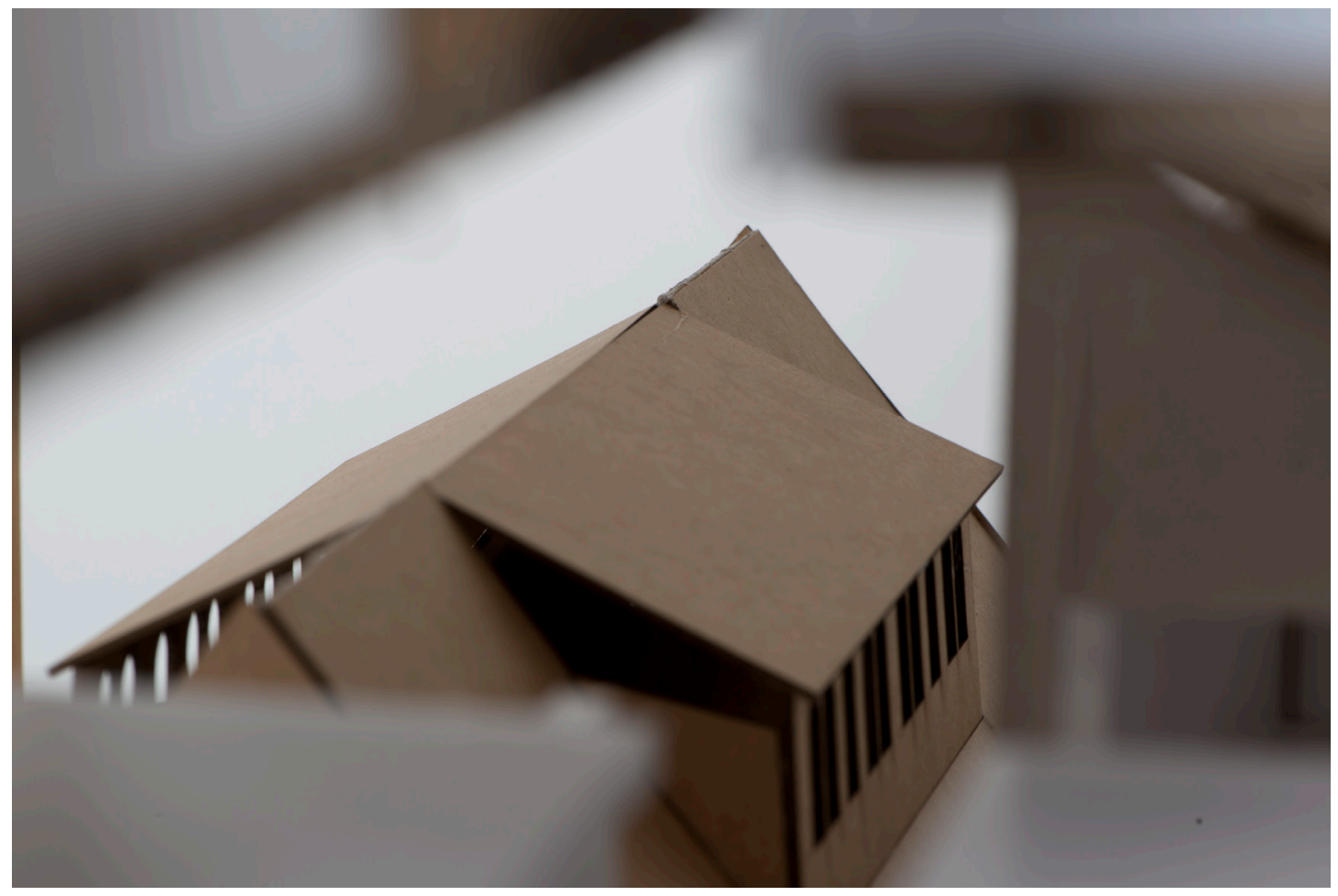

fig. 6.49. A journey of discovery. Glimpses of the Chinese Mission Hall are threaded through the building, gradually revealing new perspectives.

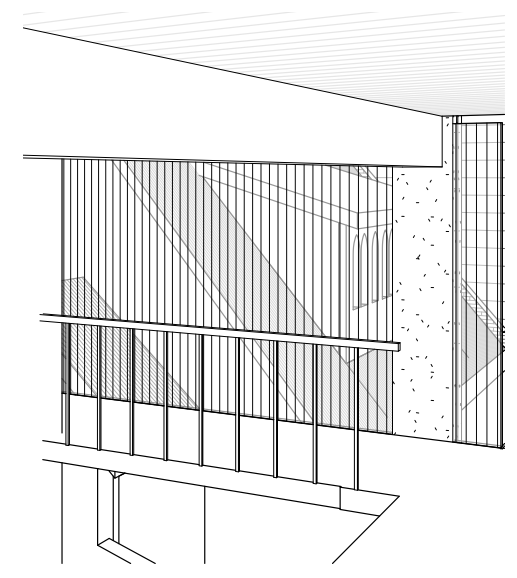




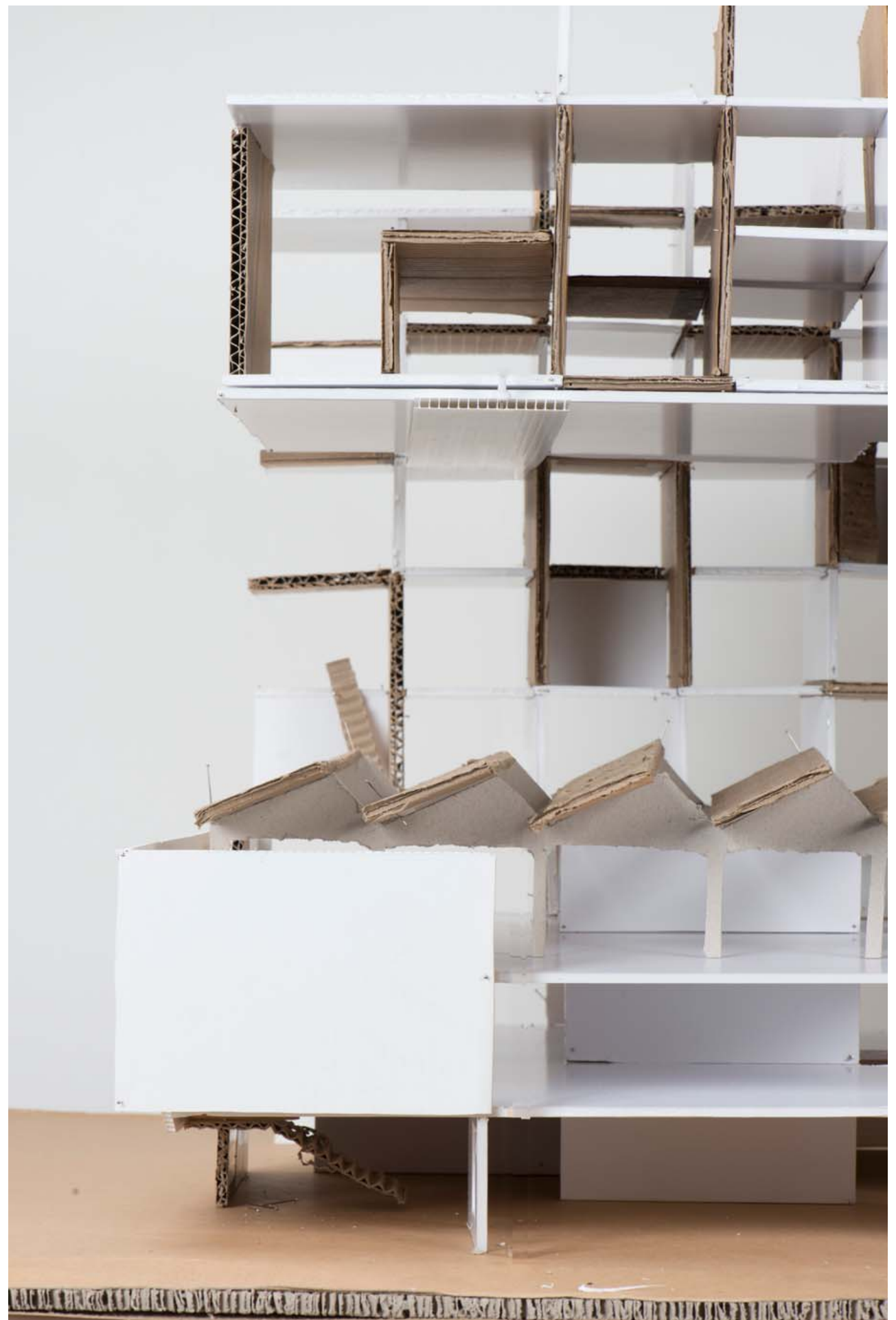

fig. 6.50. Frederick Street Elevation 


\section{Activation of void}

Extending the units above the roof of the Art School gave expression to the assemblage by articulating the relationship between the roof feature of the Art School, the Chinese Mission Hall and the Units (and garden) above. The visual weight of the overhang conveys the indifference of $\mathrm{Q}$ on Taranaki yet with similar issues of intimidation and a casting of shadows. The following the studies thus explored was of activating the underbelly of the overhang and lighten it's visual impact from the street.
i Inhabiting the roofscape
ii Material of the Underbelly
iii View into the street above
iv Driven Light Voids 


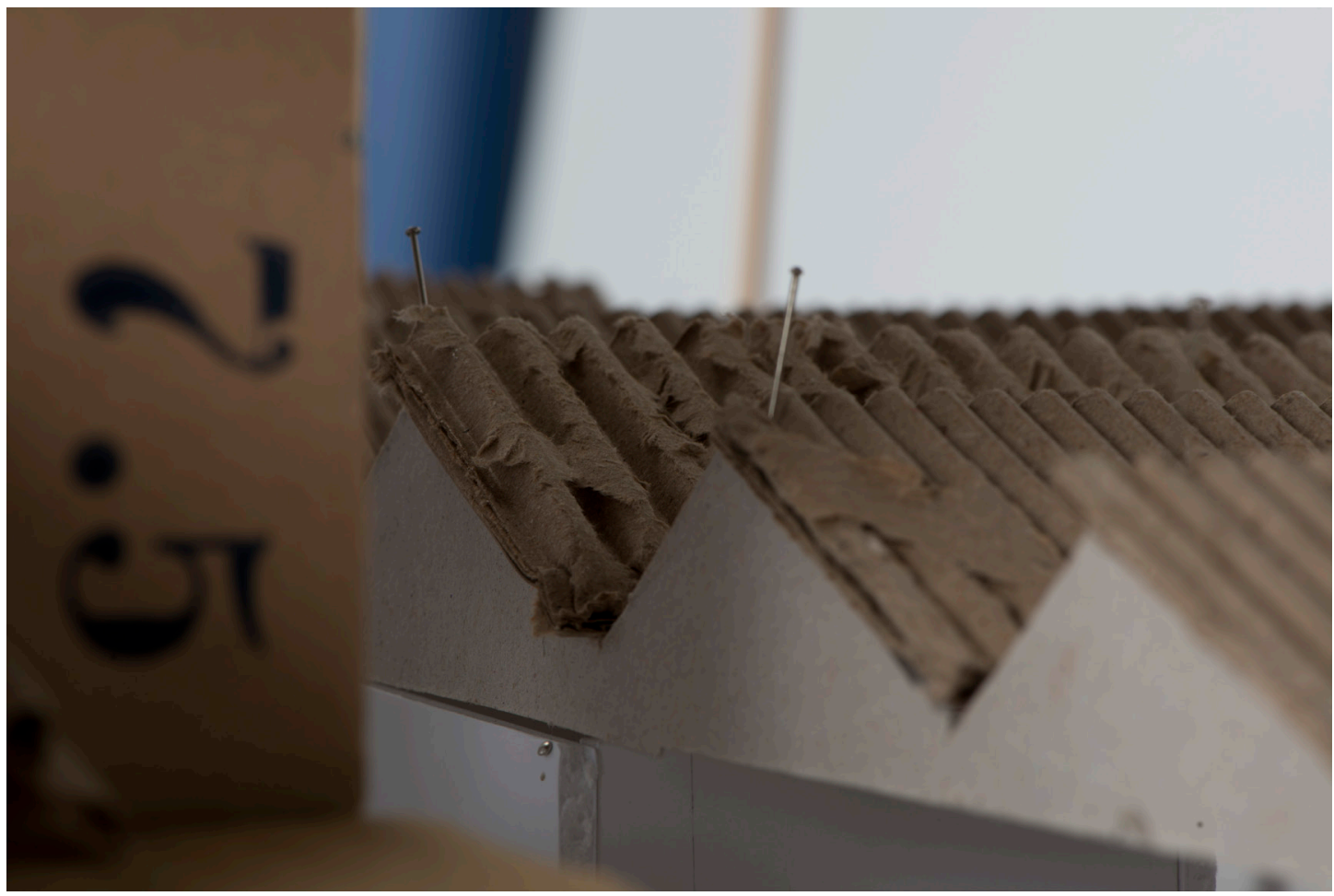

fig. 6.52. Level Three connects with the saw-tooth roofscape

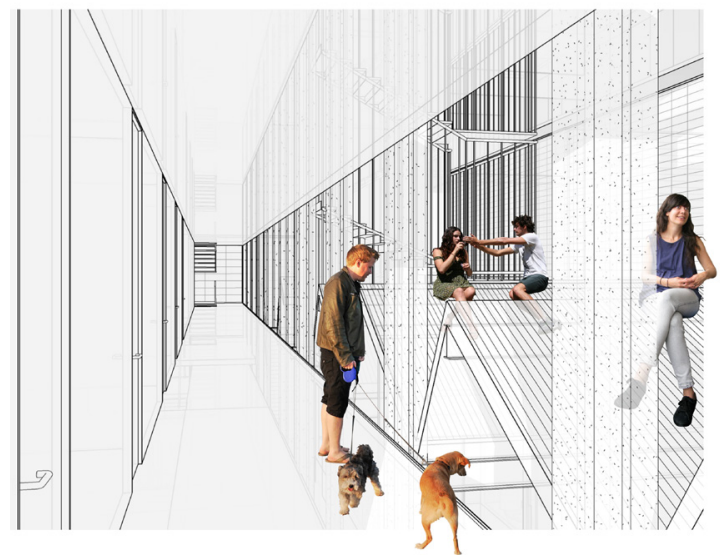




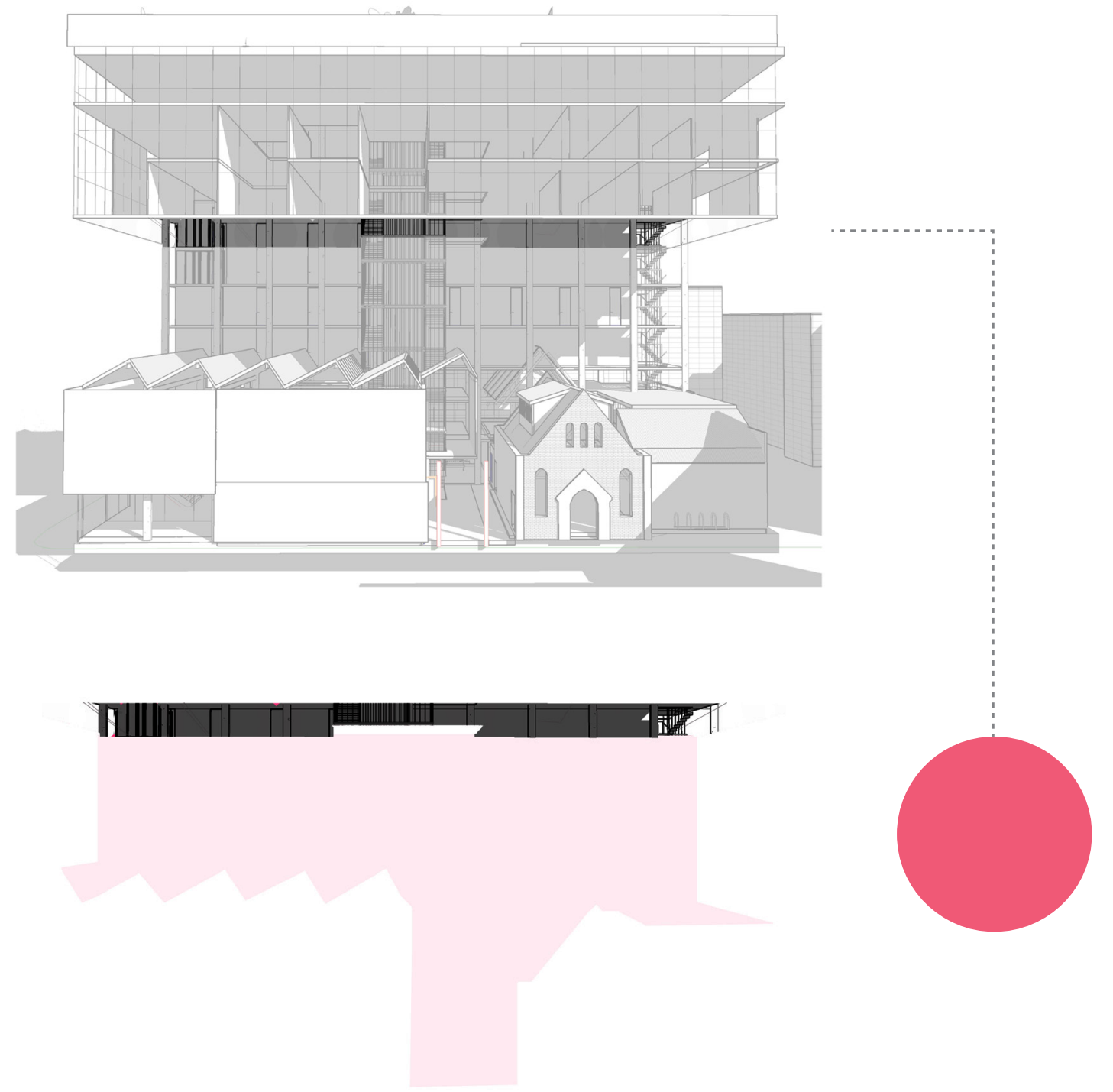

fig. 6.53. The polycarbonate facade with subtle pink tones wraps around the underside of the overhang to create a seamless continuity in the form. The 'underbelly' thus reflects light down into the street and lower roofscape, flooding the zone in the pink hue. 


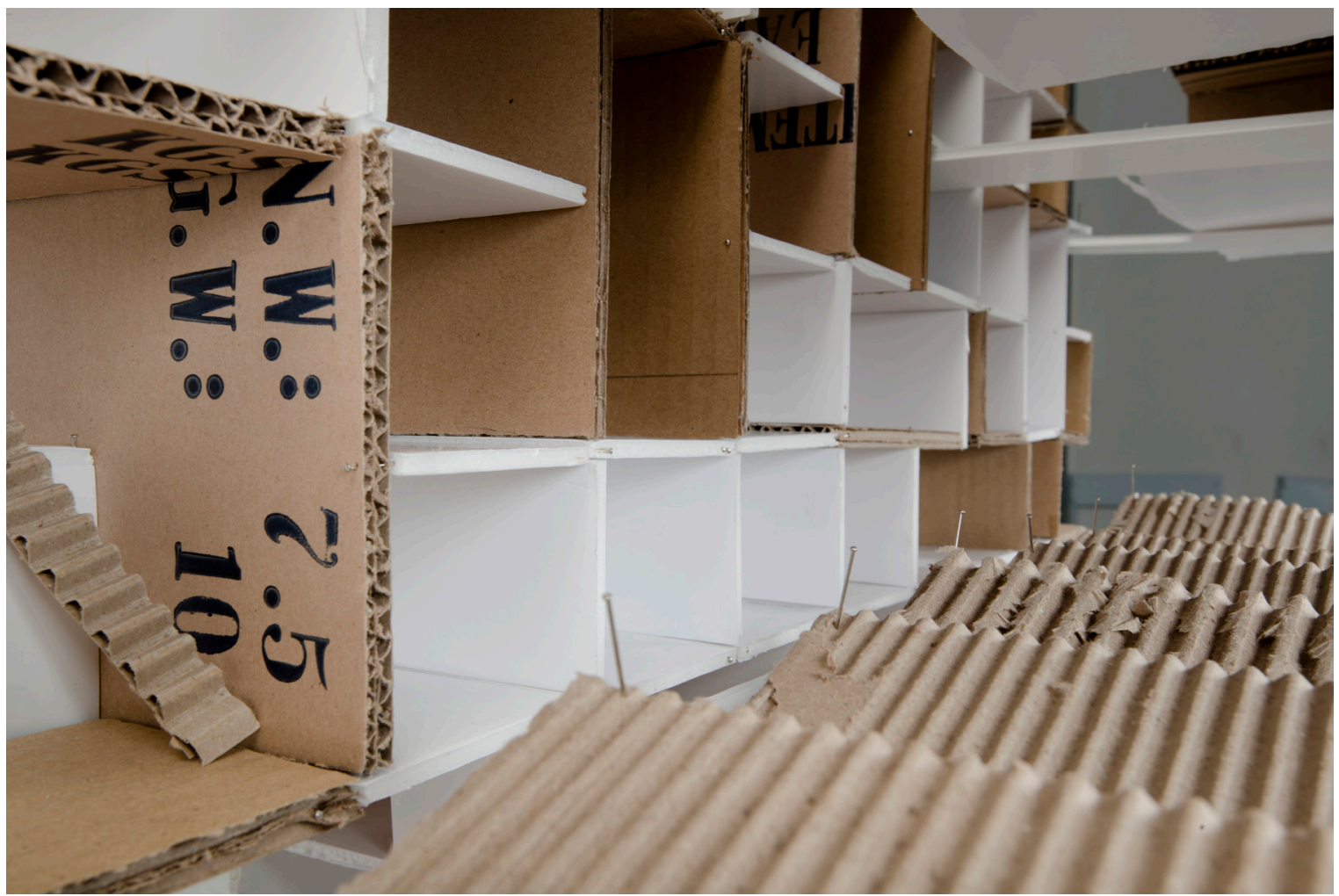

fig. 6.54. The facade facing the void is activated by the occupants themselves. Movement, events and daily activities in the spine are visible from the stree. Illuminated through polycarbonate panels during the night. 


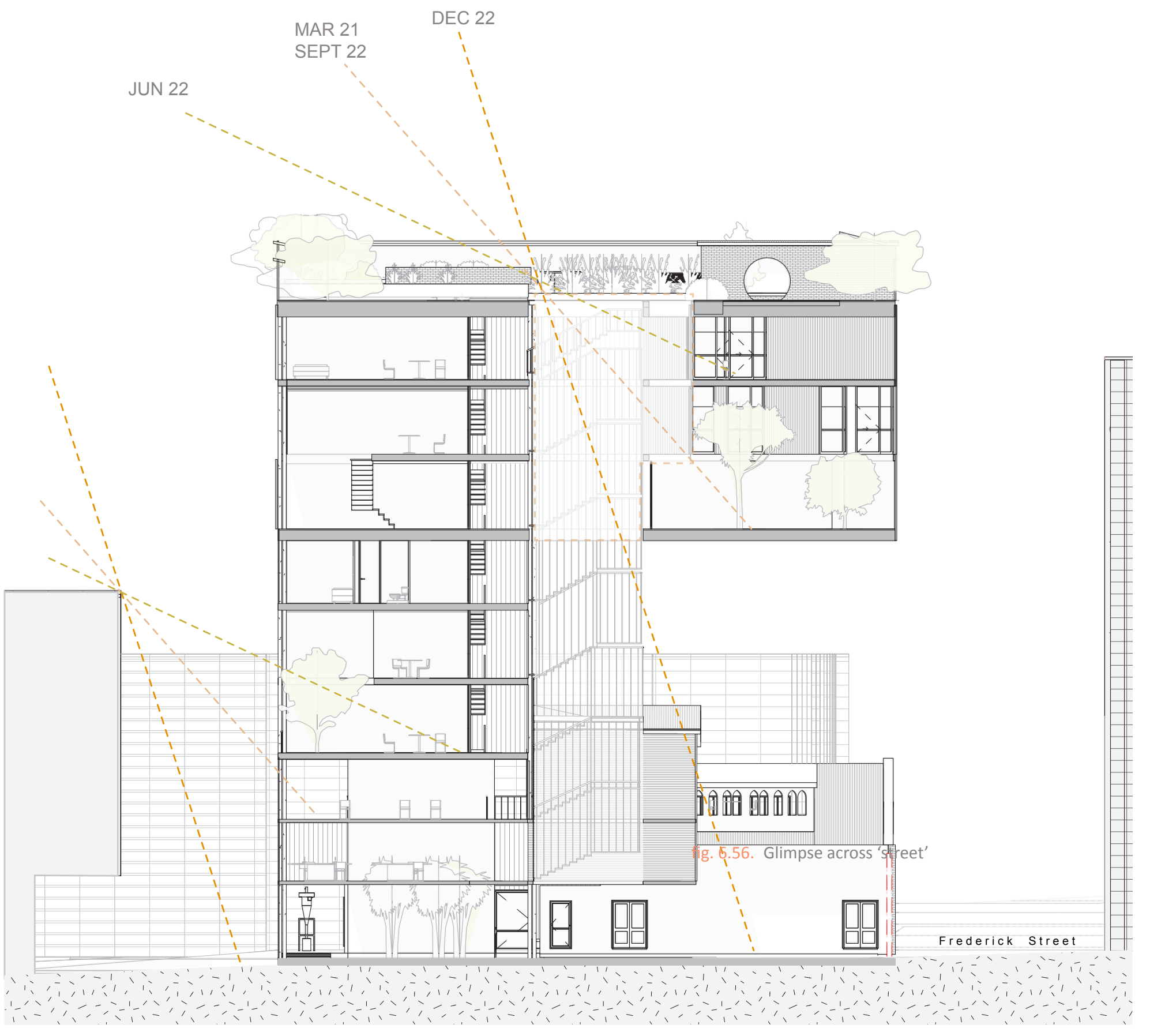

fig. 6.55. Study of driven light voids with angles of sunlight at noon at various times of the year which correlate with the exhibition or graduation times for the school. The study activates various common spaces thoughout the year. Singular moments occur when the light casts down the central stairway or ignites the windows of the Chinese Mission Hall 
We shall not cease from exploration, and the end of all our exploring will be to arrive where we started and know the place for the first time.

T. S. Eliot 


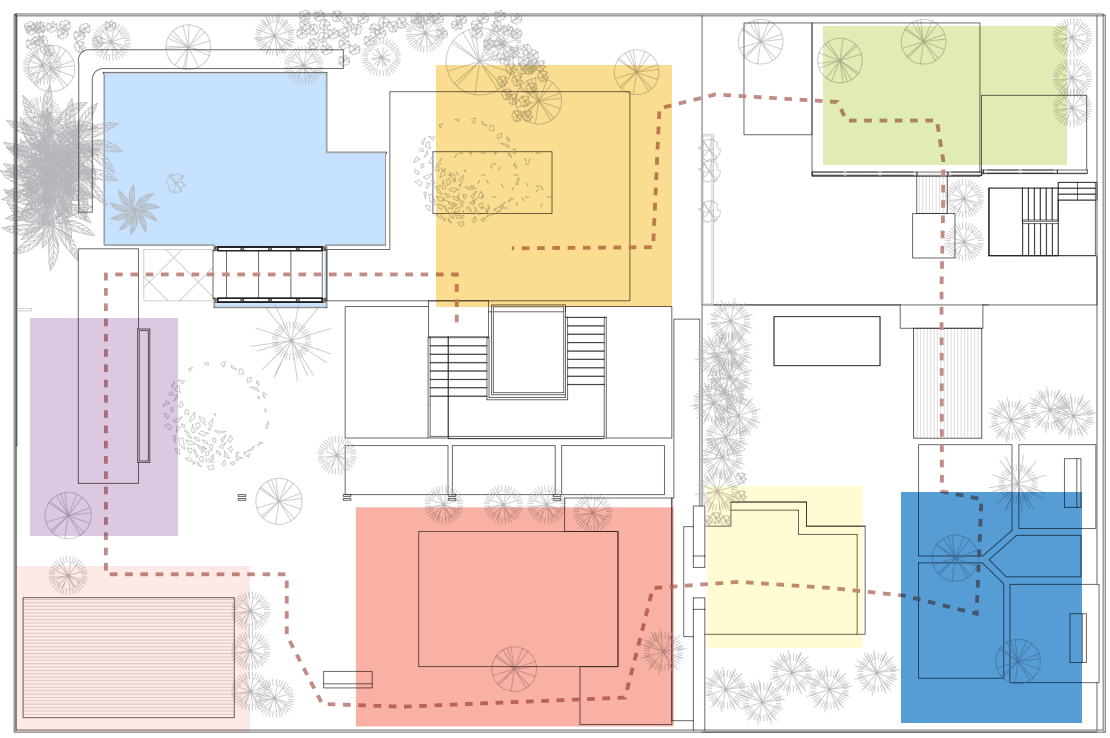

fig. 6.57. Chinese Garden

Chinese Garden of Transcendence 


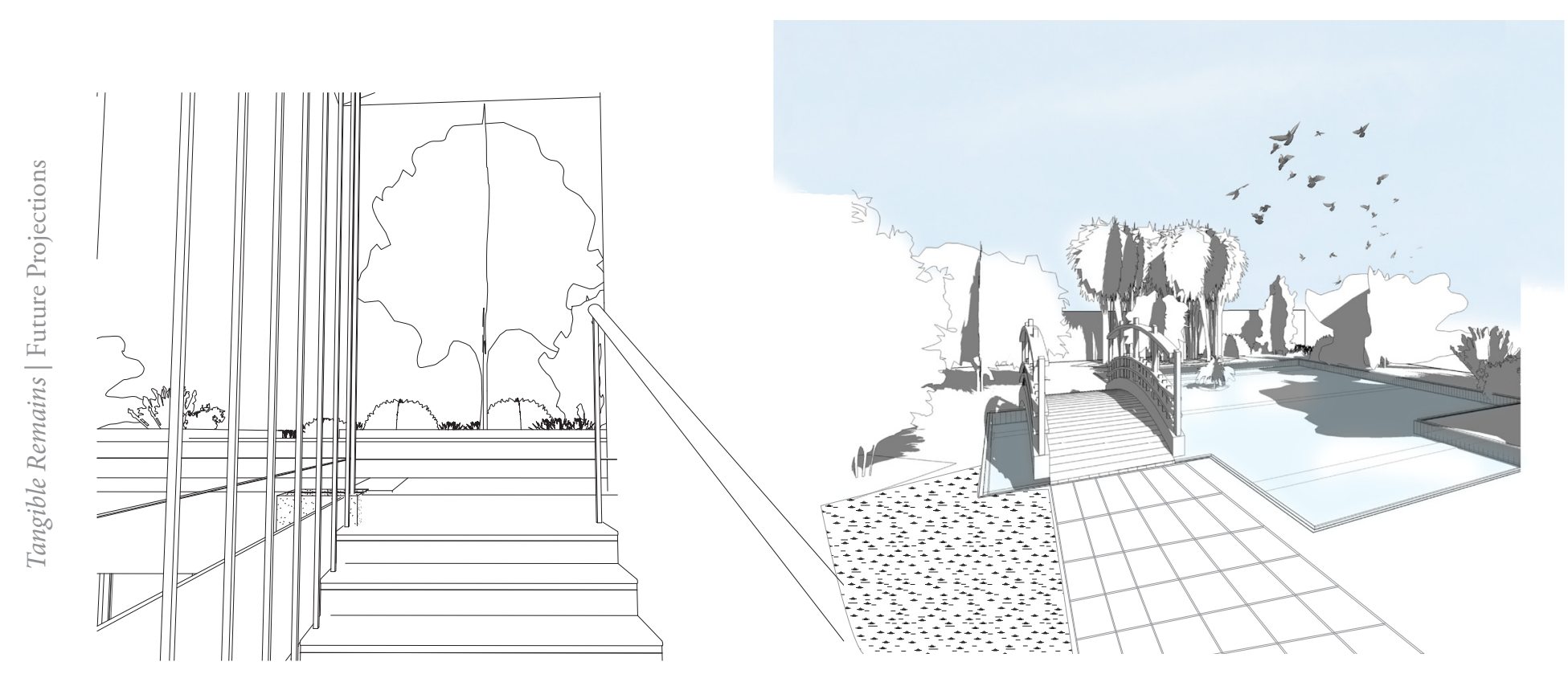




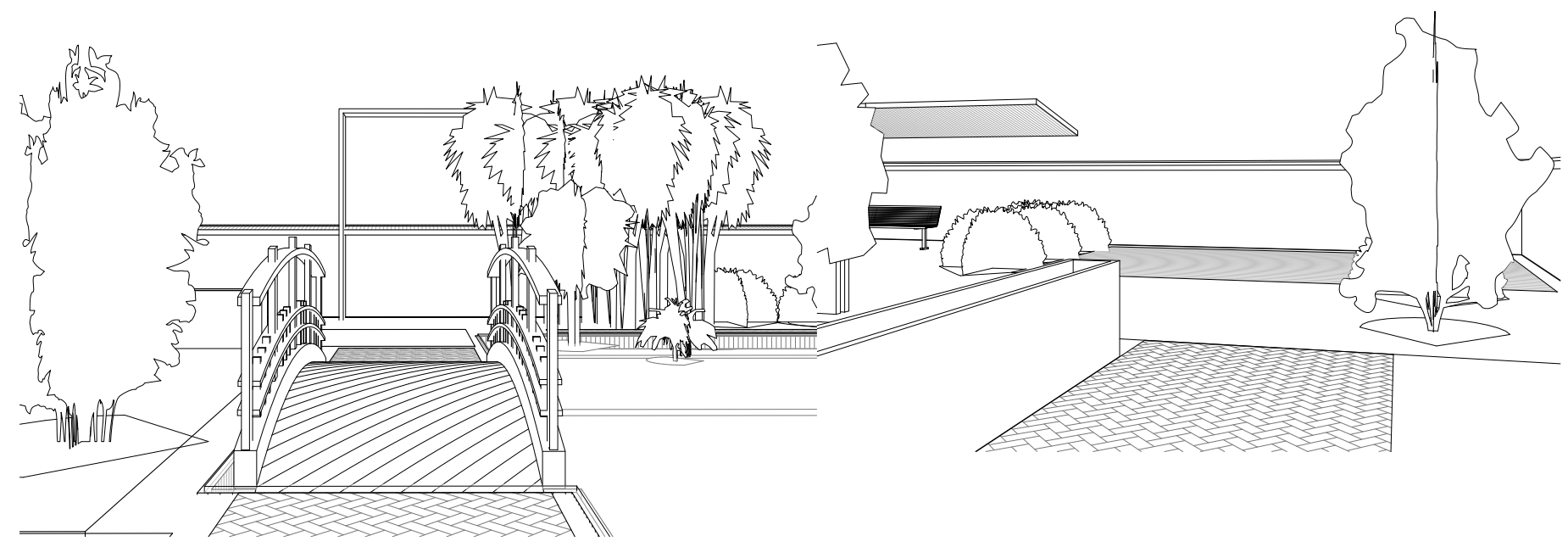




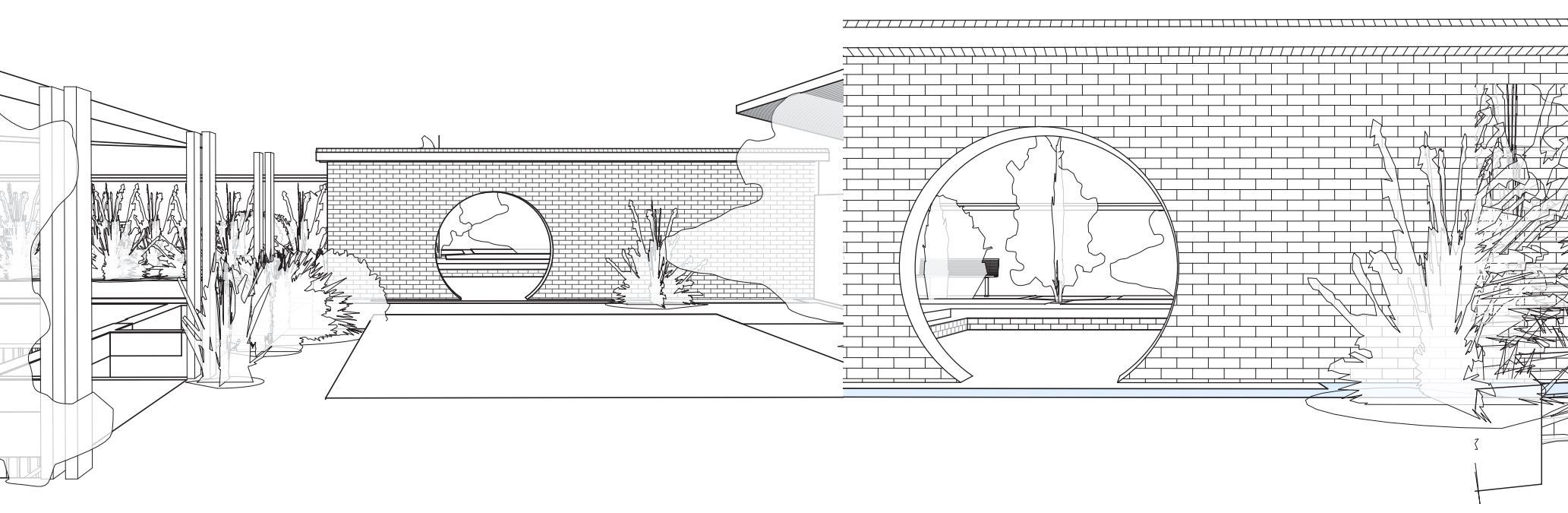




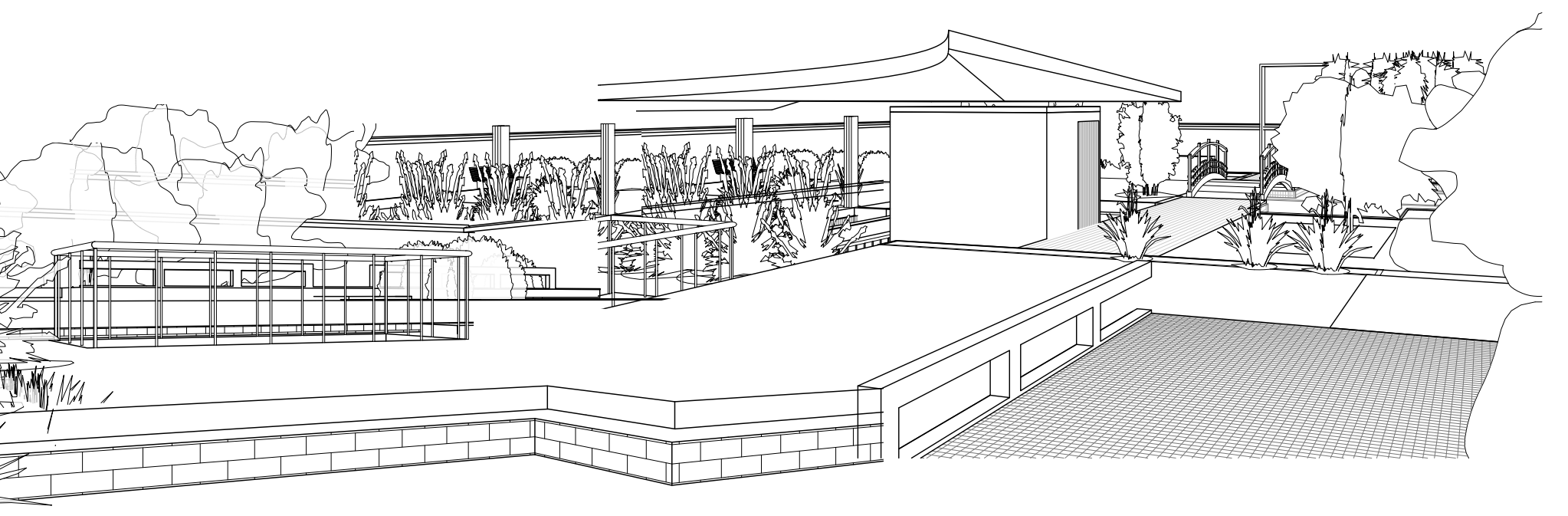




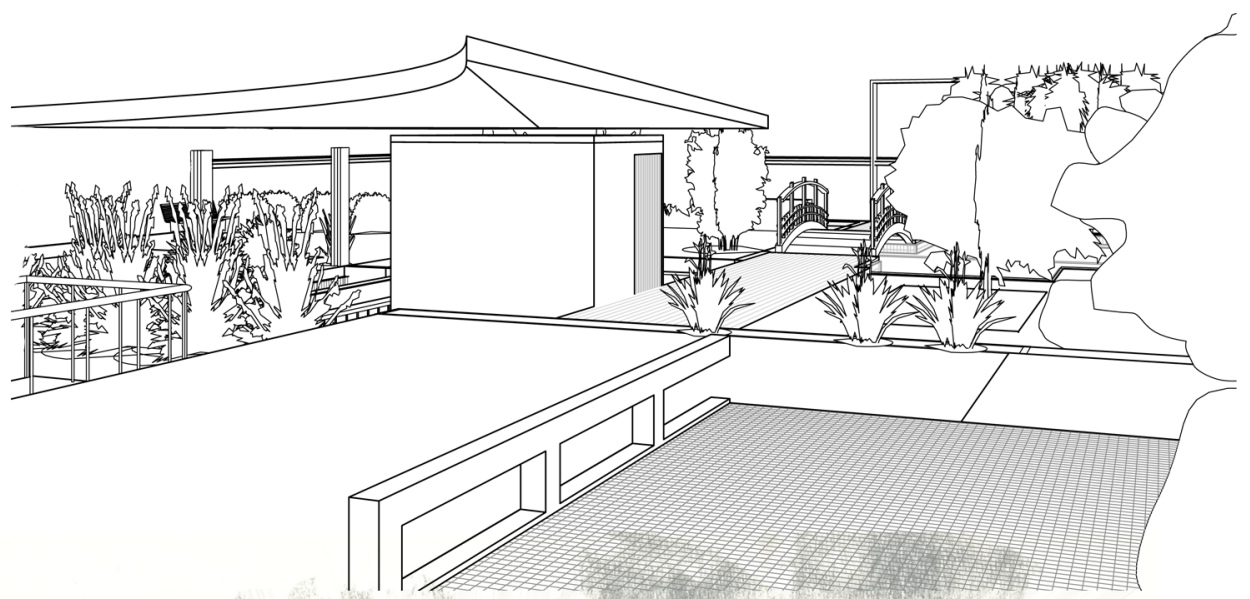

fig. 6.59. View from the mountain, overlooks the Chinese Garden of Transcendence and the Greater Wellington Region 


\section{Conclusions}

Design Phase Three involved a critical editing of the Art School as well as a grafting of the earlier Chinese Garden; it discovered elements and singular qualities to be expressed in the Artist Colony.

From the summit of the Artist Colony, the moutain, a singular moment of revelation occurs when you connect with the broader city and the town belt fig. 6.58. Traces are expressed of the structure below, the Chinese Garden of Immanence and the field of intensities. The moon gate creates a portal to another space of the garden, directly above the wall of the Chinese Mission Hall. The garden is a continuation of the Artist Colony. The ascent through the school and dwellings to the top level builds the anticipation to the garden and feeds together the various narratives within the building. Trees are discovered throughout the lower levels. Voids free the movement of sound, air, light between the levels; gradually revealing views of the garden or scenes beyond. 


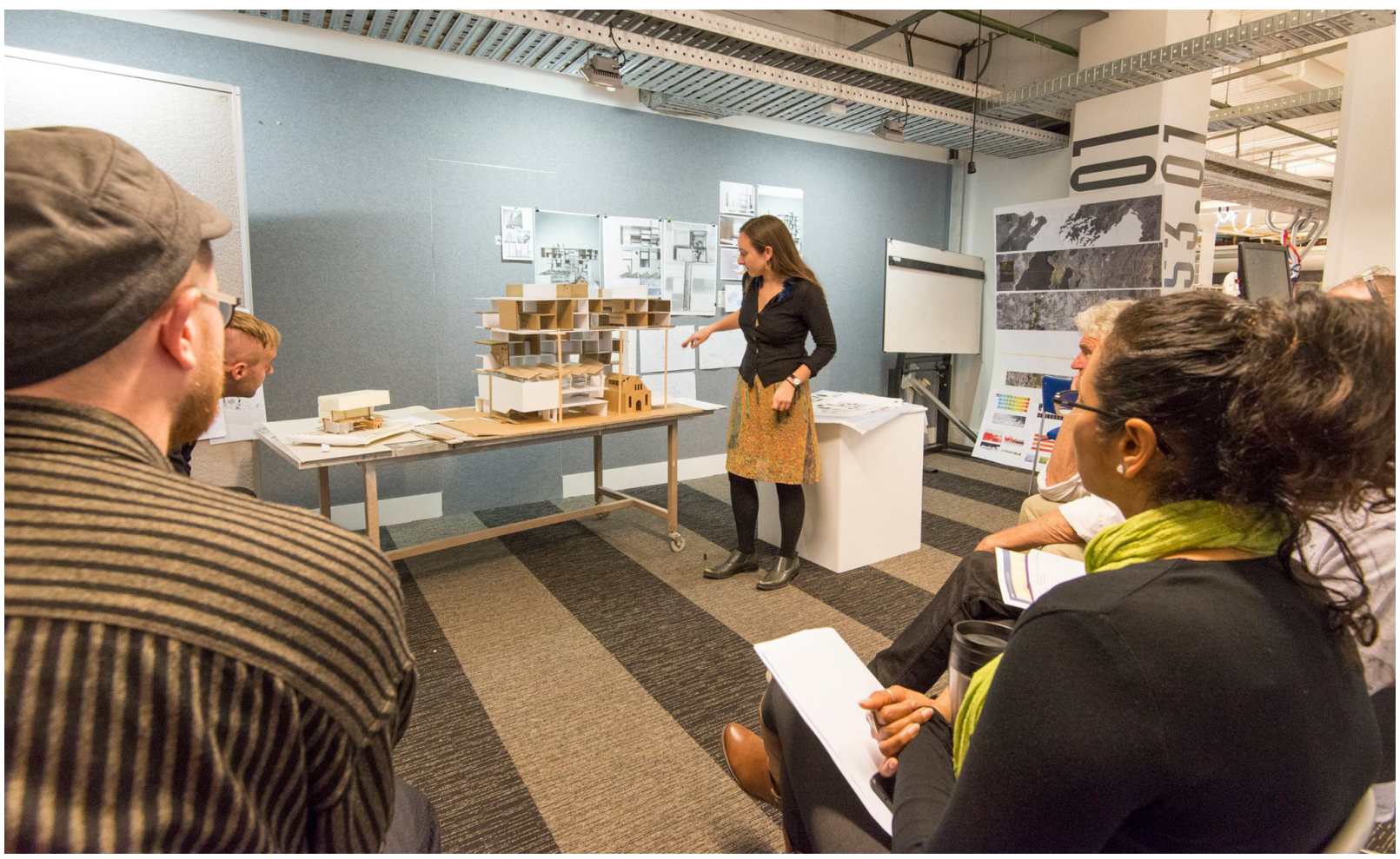

fig. 7.1. Final presentation to Nat Chesire, Michael Spooner, Shenuka de Sylva and Richard Leplastier 


\section{Seven | Conclusion}

\section{No man is an island, entire of itself - John Donne}

Too often subjects are considered irrespective of their preceding history, and their affective charge. As architects we typically deal with single sites; yet with contemporary development, sites are combined and scale shifts occur. This pressure for planning and intensification often sees the erasure of traces of history. I argue we must endeavour to nurture the patterns of the past. Not only do we have a responsibility to our physical neighbours but to the memory of what was. Everything is seen in relation to its neighbours and has a responsibility to them.

Over the course of the thesis a set of orders were established from a recognisably subjective interpretation of the site and incrementally extended as institutional problematics were introduced; complete with spatial requirements of programs, and detail such as health and safety regulations. The final design thus is a formally articulated assemblage of various components and dialectics: new/existing; private/public; visitor/resident. This notion was extended with methodological dialectics: pragmatic/abstract; precise/expressive. The discrepancies and thresholds between resulted in peculiar moments, singular moments throughout the building. 
Tangible Remains called for a contingent architecture, bridging past, present and future contexts. The urban Wellington site was thus recognised without origin or final state but in a continuous process of becoming; the existing building a tangible remain with tangible reminders of its stories.

The milieu of erasures and enduring traces were drawn to the surface and manifested across three design phases: 1 Chinese Garden, present condition; 2 Art School, past reflection; 3 Artist Colony; future projection. Initially intended as three discrete projects, the thesis structure evolved to accumulate over time, resulting in an additive composition across the three phases of the design.

An initial theoretical excavation of the site and its known histories crafted a set of tendencies and orders for the site. Design experiments began with superimposition and collage. Program was introduced as a device to incrementally build the complexity of the design. The existing building was made whole once more through its interrelationships with its wider contexts; it's layering into a larger urban condition informed by its history.

The value of conscious shifts in process and scale were a key part of the methodological finding. The design processes became layers that were recycled within the projects history and development over time. They opened the design process up to frequent reflection. Opportunities and weaknesses were identified facilitating the introduction of further constraints and intensity. Shifts between rapid and attentive iterations explored the significance of impulse.

Embodied in a place case study, Tangible Remains operates as a model for the city. It provides an exemplar of a methodology for activating dialogue in the built environment and an example of the potential increased environmental sensitivity and depth that is possible through the resulting design exemplar. This design method results in a rich, sensitive continuity of history where buildings such as the Chinese Mission Hall are more than an anachronism; they become the precise seeds of a future that integrates, respects and learns from its past. 


\section{Bibliography.}

Angélil, Marc, and Mark Lee. "Informe: Strategies of the Formless." Inchoate: An Experiment in Architectural Education. Zurich: Swiss Federal Institute of Technology, 2003. 536-53. Print.

Cadwell, Mike. "Swimming in the Querini Stampalia Foundation." Strange Details. Cambridge: MIT Press, 2007. 3-46. Print.

Campbell, Duncan. "Transplanted Gardens: Aspects of the Design of the Garden of Beneficence, Wellington, New Zealand." Studies in the History of Gardens \& Designed Landscapes 31.2 (2011): 160-66. Print.

Deleuze, Giles. The Fold: Leibniz and the Baroque. Trans. Conley, Tom. Minneapolis: University of Minnesota Press, 1993. Print.

---. The Logic of Sense. Trans. Lester, Mark and Charles Stivale. London: Athlone, 1990. Print.

Dickens, David. "Boom Has Thrown up a Few Dogs; What Makes a Good Building." Dominion Post 11 April 2007: A; 8. Print.

Donne, John. "Meditation XVII." Devotions upon emergent occasions (1624): 344-45. Print.

Fung, Stanislaus. "Mutality and the Cultures of Landscape Architecture." Recovering Landscape : Essays in Contemporary Landscape Architecture. Ed. Corner, James. New York: Princeton Architectural Press, 1999. 140-51. Print.

Genosko, G. Felix Guattari: An Aberrant Introduction. Bloomsbury Academic, 2002. Print.

id. "Te Aro ; Residential Development." Population Forecasts. June 2013. Web. 30 July 2015.

Nathalie Janson, "Lacaton \& Vassal Architects: Sustainable space makers." Nantes School of Architecture, University Building in France. Zürich: Holcim Foundation for Sustainable Construction, 2011, 22-69; 26. Print. 
Royal Australian Institute of Architects. "The Mint." Francis-Jones Morehen Thorp (FJMT). 2005. Web. 30 March 2016.

Kaji-O'Grady, Sandra. "Architectural Serialism." Architectural Theory Review 3.2 (1998): 17-31. Print

Kothari, Rachna. "Elemental Experience; Pei's Suzhou Museum Revisited." Uncube Magazine (2014). Web. 2015/06/02.

Kulper, Perry. "Drawing Architecture / a Conversation with Perry Kulper." What About It, Part 2 (2012): 86-93. Print.

Manolopoulou, Y. Architectures of Chance. Ashgate Publishing Company, 2013. Print.

McCarthy, Christine. "Re: District Plan Changes 53 Proposed Heritage Listings." Arch Centre (2007). Print.

MenzShed, City. "City Menzshed." City MenzShed - Facebook. Web.

OMA. "Fondazione Prada." OMA. 2015. Web. 15 August 2015.

Ostwald, Michael J. "Binding Issues and Critical Strengthening." Moments of Resistance. Sydney: Archadia Press, 2002. 23-40. Print.

Oxford. "Haecceity". Oxford Dictionaries. Oxford University Press. Print.

Patterson, Colin. "Wellington Neighbours Fear 'Shoebox Slum'." The Dominion Post 10 September 2007. Print.

Schultz, Anne-Catrin. Carlo Scarpa: Layers. Edition Axel Menges, 2007. Print.

Shrapnell, John. "Constitution." 2011. Web. 20 April 2015.

---. "Letters to the Editor." New Zealand Listener 30 July 2011: 8-10. Print.

Southcombe, Mark, and Andrew Charleson. [Re] Cuba: Renegotiating Seismic Resilience in Cuba Street Wellington. Wellington, New Zealand: Wellington City Council 2014. Print.

Spirn, Anne Whiston. "Toward a Unified Vision: Architecture in the Landscape." Landscape Architecture 80.8 (1990): 36-41. Print.

Stagoll, Cliff. "Event." The Deleuze Dictionary. Edinburgh: Edinburgh University Press, 2005. 89-91. Print.

Taleb, Nassim Nicholas. The Black Swan: Second Edition: The Impact of the Highly Improbable Fragility". London: Penguin, 2010. Print.

Tompkins, Haworth. "Dyson Building." Haworth Tompkins. 3 April 2016. Web. 
Tschumi, Bernard. Architecture and Disjunction. Massachusetts: MIT Press, 1996. Print.

Tuomey, John. Interview by Cooke, Rachel. "Inside the Homes of Our Star Architects." The Guardian. 23 November 2012. Web. 10 March 2016.

Valentine, Jessica Parker. Interview by Dikeou, Devon. "Interview: J. Parker Valentine." Zing Magazine. August 2011. Web. 20 June 2015

von Buttlar, A., and Staatliche Museen Berlin. Neues Museum Berlin: Architectural Guide. Dt. Kunstverl, 2010. Print.

Wainwright, Oliver. "Spain's Concrete Castle: A Case of Accidental Genius?” The Guardian. 10 March 2016 2016. Web. 15 March 2016.

WellUrban. "Wrong Building, Wrong Place." WellUrban. Web.

Whitehead, Alfred North. Process and Reality: An Essay in Cosmology. Cambridge Cambridge University Press, 1929. Print.

Young, E.B. "Whitehead, Alfred North." The Deleuze and Guattari Dictionary. Eds. Young, E.B., J. Watson and G. Genosko: Bloomsbury Academic, 2013. Print. 


\section{List of figures}

$>$ figures not atributed are author's own

fig. 16. Perry Kulper, David's Island Strategic Plots. 1996. http://archinect. com/news/article/54767042/drawing-architecture-conversationwith-perry-kulper

fig. 1.1. Jessica Parker Valentine Untitled, 2010.http://www.zingmagazine. com/drupal/node/1648

fig. 2.1. (a) Chevening Apartments <http://www.studiopacific.co.nz/ projects/2011/chevening-apartments/>

(h) Croxley Mills Apartments <http://www.custance.co.nz/sites/ default/files/project-images/Croxley\%20Mills\%2003.jpg> <http:// www.custance.co.nz/sites/default/files/project-images/Croxley\%20 Mills\%2001_1.jpg>

fig. 2.2. Fondazione Querini Stampalia https://s-media-cache-ak0.pinimg. com/736x/c1/95/bb/c195bb9950f67f4956b10310e8a12558.jpg

fig. 2.3. Museo Civico di Castelvecchio https://s-media-cache-ak0.pinimg. com/736x/de/27/e5/de27e574684dcb63043951978c44573c.jpg

fig. 2.4. Neues Museum Central Stairway restored http://www.theguardian. com/artanddesign/2009/mar/16/neues-museum-berlin

fig. 2.5. Neues Museum Central Stairway 1943 http://www.davidchipperfield. co.uk/project/neues_museum

fig. 2.6. Neues Museum Central Stairway http://www.architectsjournal. co.uk/news/first-look-chipperfields-neues-museum/1994351. fullarticle

fig. 2.8. The Mint diagram http://www.archdaily.com/59430/the-mintfjmt/5009035e28ba0d27a70012a3-the-mint-fjmt-exploded-axo

fig. 2.10. (all images clockwise) Kolumba Museum <http://www.architectureanddesign.com.au/features/productin-focus/bricks ><http://www.archdaily.com/72192/kolumbamusuem-peter-zumthor/1-custom ><http://www.wikiwand.com/ de/Kolumba_\%28Museum\%29>

fig. 2.12. (all images) QV Pod $H$ http://www.kerstinthompson.com/index. php?id=4

fig. 2.8. The Mint diagram http://www.archdaily.com/59430/the-mintfjmt/5009035e28ba0d27a70012a3-the-mint-fjmt-exploded-axo 


\section{fig. 3.35 Timeline}

a Terry, Edward Lionel. Terry, Edward Lionel, 1867-1952 :This man is mad ; Mammon Rex. [ca 1930]. 1900-1910. Graphite and coloured pencil on card $87 \times 60 \mathrm{~mm}$, on sheet $120 \times 90 \mathrm{~mm}$. Turnball Library

b Watercolour of Chinese Mission Hall by architect Frederick de Clere. http://mp.natlib.govt.nz/image/?imageld=images36379\&profile=access

c "Wellington Shanties." Auckland Star 1903/04/01/ 1903: 2. Web. 10 March 2015

d http://paperspast.natlib.govt.nz/cgi-bin/paperspast?a=d\&cl=search $\& d=E P 19221127 \cdot 2 \cdot 76.2 \& z$ to $=1$

e Chung Kung Tong Chinese Freemasons procession, https://natlib. govt.nz/records/22792532

$f \quad$ Chinese boys in Wellington with semaphore flags that spell 'China' http://natlib.govt.nz/records/22751251?search[path]=photos\&sear ch[text]=flags+chinese

g https://nzresearch.org.nz/records/23045641?search\%5Bi\%5D\%5Bc ategory\%5D=Images\&search\%5Bi\%5D\%5Bsubject\%5D=Sunday+sch ools\&search $\% 5$ Bpath $\% 5$ D=places

h Collage of photographs used in "The case against slums", http:// natlib.govt.nz/records/22768205

i Slums http://paperspast.natlib.govt.nz/cgi-bin/paperspast?a=d\&cl= search\&d=AG19121120.2.47\&zto $=1$

j Building construction site, BNZ, Corner of Vivian and Taranaki Streets, http://natlib.govt.nz/records/23254135?search[path]=pho tos\&search[text]=taranaki+street+vivian+street

k Cherished Murdoch Factory Sign, http://wellurban.blogspot.com. au/2007 0101 archive.html

I Evidence of Tunnels on Haining Street, Wellington http://natlib.govt. $\mathrm{nz} /$ records/30665601?search[path]=photos\&search[text]=haining+ street

m Mission Hall Creative logo https://plus.google. com/116810233738266443933

$\mathrm{n} \quad$ Andrew Ross Photograph of Mission Hall http://wellington.scoop. co.nz/?p=33821

o Q on Taranaki Elevation http://wellurban.blogspot.com.au/2007/01/ wrong-building-wrong-place.html

p 2009 Fredstock Poster http://www.orchestraofspheres.com/ node/73

q Murdoch Factory interior http://collections.tepapa.govt.nz/ object/966061

$r \quad$ Murdoch Factory laneway http://collections.tepapa.govt.nz/ object/966058

s 2010 Fredstock Poster http://www.adamartgallery.org.nz/calendar/ august-october-2010/

t 2011 Fredstock Poster http://snakebeings.co.nz/events/

u Farewell Party at Freds. http://www.newswire.co.nz/2012/03/fredshome-for-art-and-music-closes-its-doors/

fig. 4.2. The arts are closely tied in Chinese tradition. As the garden, painting uses dynamic composition of foreground and selective views. The priority lies in capturing the essence of the landscape as opposed to a detailed recording. 
fig. 4.3. Plan diagram of Garden of Harmonious Interest, Beijing. https://s-media-cache-ak0.pinimg.com/736x/d4/db/04/ d4db04a29765b225d6cbc340c4dda16b.jpg

fig. 4.4. Master of Nets Garden, Suzhou (1140) https://www.flickr.com/ photos/rita-h/9442785127/in/album-72157634946298614/

fig. 4.5. Suzhou Museum Garden http://images.travelpod.com/tw_slides/ ta00/9b2/1cc/3-suzhou-museum-suzhou.jpg

fig. 5.4. Views between studio spaces http://www.haworthtompkins.com/ built/proj35/index.html

fig. 5.1. Painting Studio, Sackler Building http://www.haworthtompkins. com/built/proj35/index.html

fig. 5.2. The Sackler Building Elevation http://www.haworthtompkins.com/ built/proj35/index.html

fig. 5.3. Driven void allows sound and light to move between the levels www.archdaily.com/483381/seona-reid-building-steven-holl-archit ects/5318d5d2c07a80688c000144-seona-reid-building-steven-hollarchitects-basement-floor-plan>

fig. 5.4. Basement Plan www.archdaily.com/483381/seona-reid-buildingsteven-holl-architects/5318d5d2c07a80688c000144-seona-reidbuilding-steven-holl-architects-basement-floor-

fig. 5.5. New intervention with existing http://www.archdaily.com/483381/ seona-reid-building-steven-holl-architects/5317fd88c07a80688c00 00af-seona-reid-building-steven-holl-architects-photo

fig. 5.6. A stairway intersects a driven void http://www.archdaily. com/483381/seona-reid-building-steven-holl-architects $/ 5317 \mathrm{fdc}$ 9c07a80688c0000b0-seona-reid-building-steven-holl-architectsphoto

fig. 5.7. The Pit http://architecturenow.co.nz/articles/massey-universityscollege-of-creative-arts/\#img=5

fig. 5.8. Te Ara Hihiko Plans adjusted http://www.archdaily.com/423453/teara-hihiko-athfield-architects

fig. 5.11. Nantes School of Architecture, http://images.adsttc.com/media/ images/5018/d4dc/28ba/0d5d/5d00/0b9f/large_jpg/stringio. jpg?1414251696

fig. 5.12. Nantes School of Architecture, http://images.adsttc.com/media/ images/5018/d4dc/28ba/0d5d/5d00/0b9f/large_jpg/stringio. jpg?1414251698

fig. 5.13. Nantes School of Architecture. http://images.adsttc.com/media/ images/5018/d491/28ba/0d5d/5d00/0b8b/large_jpg/stringio. jpg?1414251645 
fig. 5.14. Nantes School of Architecture. https://s-media-cache-ak0.pinimg. com/736x/d4/db/04/d4db04a29765b225d6cbc340c4dda16b.jpg

fig. 5.17. GSA poster campaign.https://pbs.twimg.com/media/CCx_eRxW8AA tHHg.jpg

fig. 5.18. Movable polycarbonate panels on the Nantes Architecture School https://s-media-cache-ak0.pinimg.com/736x/73/72/9c/73729c2a2 63455e381a14891fe88343b.jpg

fig. 6.2. Mackarin Apartments https://www.reddit.com/r/Wellington/ comments/42qnfd/135_taranaki_st_apartments_feedback_please/

fig. 6.5. Elenberg Fraser, Fifty Albert,http://elenbergfraser.com/wp-content/ uploads/2011/06/EF_FIFTY-ALBERT_091-293×421.jpg

fig. 6.6. Elenberg Fraser, Fifty Albert, https://studentbreakfastaustralia.files. wordpress.com/2015/05/img_2321.jpg

fig. 6.7. OMA, Fondazione Prada (2015). http://oma.eu/projects/fondazioneprada

fig. 6.8. OMA, Fondazione Prada (2015). http://oma.eu/projects/fondazioneprada

fig. 6.9. Alsop, Sharp Centre for Design (2004) < http://www.arcspace.com/ CropUp/-/media/10271/1ocad.jpg>

fig. 6.10. Alsop, Peckham Library (2000) http://www.kme.com/assets/ uploads/images/tecu/prj/peckham10.jpg

fig. 6.11. Alsop, Peckham Library (2000) http://www.kme.com/assets/ uploads/images/tecu/prj/peckham7.jpg

fig. 6.14. Lacaton and Vassal Ourcq Jaures Student \& Social Housing, Interior view of a vacant Social Housing unit http://www.archdaily. com/476650/ourcq-jaures-student-and-social-housing-lacatonand-vassal/52fc53a5e8e44e5482000091-ourcq-jaures-student-andsocial-housing-lacaton-and-vassal-photo

fig. 6.15. Lacaton and Vassal Ourcq Jaures Student \& Social Housing, Interior view of an occupied Social Housing unit http://www.metalocus. es/content/en/system/files/file-images/ml_03_FDA\%20TBP\%20 JH06_5976_1024.jpg

fig. 6.17. Tschumi Le Fresnoy Art Centre <https://sites.google.com/site/ paolafratalocchi/_/rsrc/1239307486173/le-fresnoy-di-bernardtschumi/143207.jpg?height $=336 \&$ width $=484>$ 